
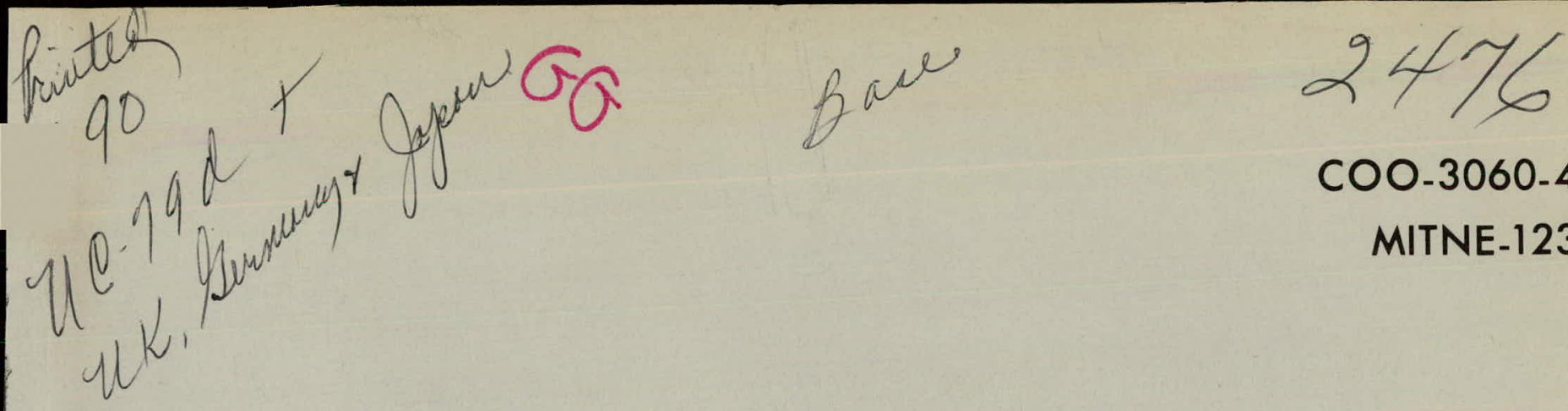

COO-3060-4

MITNE-123

\title{
THE ECONOMICS OF FUEL DEPLETION IN FAST BREEDER REACTOR BLANKETS
}

\section{RECEIVED BY TIC JAII $5 \quad 1973$}

by

S.T. Brewer, E.A. Mason and M.J. Driscoll

November, 1972

Department of Nuclear Engineering Massachusetts Institute of Technology

Cambridge, Massachusetts 02139

AEC Research and Development Report $\forall \in-34$ Physies

Contract AT(11-1)-3060

U.S. Atomic Energy Commission 


\section{DISCLAIMER}

This report was prepared as an account of work sponsored by an agency of the United States Government. Neither the United States Government nor any agency Thereof, nor any of their employees, makes any warranty, express or implied, or assumes any legal liability or responsibility for the accuracy, completeness, or usefulness of any information, apparatus, product, or process disclosed, or represents that its use would not infringe privately owned rights. Reference herein to any specific commercial product, process, or service by trade name, trademark, manufacturer, or otherwise does not necessarily constitute or imply its endorsement, recommendation, or favoring by the United States Government or any agency thereof. The views and opinions of authors expressed herein do not necessarily state or reflect those of the United States Government or any agency thereof. 


\section{DISCLAIMER}

Portions of this document may be illegible in electronic image products. Images are produced from the best available original document. 


\title{
MASSACHUSETTS INSTITUTE OF TECHNOLOGY DEPARTMENT OF NUCLEAR ENGINEERING
}

\author{
Cambridge, Massachusetts
}

THE ECONOMICS OF FUEL DERLETION IN FAST BREEDER REACTOR BLANKETS

\section{by}

S.T. Brewer, E.A. Mason and M.J. Driscoll

November, 1972

coo-3060-4

MITNE-123

AEC Research and Development Report $v e-34$ Physics-e Contract AT (11-1)-3060

\section{U.S. Atomic Energy Commission}

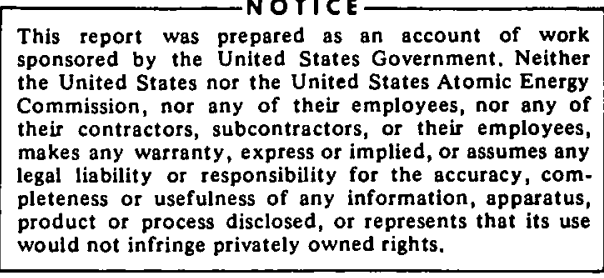

1 


$$
\begin{gathered}
\text { DISTRIBUTION } \\
\text { CO0-3060-4 MITNE- } 123 \\
\text { AEC Research and Development Contract } \\
\text { AT }(11-1)-3060 \\
\text { UC-34 Physics }
\end{gathered}
$$

U.S. Atomic Energy Commission, Headquarters

Division of Reactor Development and Technology Reactor Physics Branch

(3 copies)

U.S. Atomic Energy Commission

Cambridge, Office

(2. copies)

Dr. Paul Greebler, Manager

Nuclear Energy Division

Breeder Reactor Department

General Electric Company

310 DeGuigne Drive

Sunnyvale, California. 94086

( 1 copy)

Dr. Harry Morewitz, Manager

LMFBR Physics and Safety Projects

Atomice. International

P.O. Box 309

Canoga Park, California 91305

( 1 copy )

Mr. Malcolm Dyos, Manager

Nuclear Development; LMFBR Project

Westinghouse Electric Corporation

Advanced Reactors Division

Waitz Mill Site

P.O. Box 1.58

Madison, Pennsylvania 15663

( 1 copy )

Dr. Robert Avery; Director

Reactor Physics Division

Argonne National Laboratory

9700 South Cass Avenue

Argonne, Illinois 60539

( 1 copy)

Dr. Charles A. Preskitt, Jr.

Mgr., Atomic and Nuclear Department

Gulf Radiation Technology

P.0. Box 608

San Diego, California 92112

( 1 copy) 


\section{ABBSTRACT}

A fast breeder reactor fuel depletion-economics nodel was developed and applied to a number of 1000 MWe LMFBR case studies, involving radial blanket-racial reflector design, radial blanket fuel managenent, and sensitivity of energy costs to changes in the economic enviroment.

Choice of fuel cost accounting philosophy, e.g. Whether or not to tax plutonium revenue, was found to have significant effect on absolute values of energy costs, without, however, distorting design rankings, comparative results, anci irradiation tirue optimization.

A single multigroup physics conputation, to obtain the flux shape and local spectra for depletion calculations, was found to be sufficient for prelininary design and sensitivity studies. The major source of error in blanket ciepletion results was found to be the assumption of a... fixed flux shape over an irradiation cycle; spectrum hardening in the radial blanket witil irradiation is of minor importance.

The simple depletion-economics model was applied to several 1000 MWe LMFBR case studies. Advantages of a moderating reflector were founu to increase as blanket thickness was reduced. For a $45 \mathrm{~cm}$ radial blanket, a beryllium metal reflector offered little inprovement, in blanket fuel economics, over sodium; for a 15 on blanket, berylliuni increased net blanket revenue by about $60 \%$. An improvement of about $30 \%$ in net blaniket revenue resulteü when each radial blanket annular region was assumea to be exposea to its own local optimum irradiation time. Optiinum radial blaidket irradiation time and tire net bianket revenue (mills/Nivie) at this optimum were found to be approximately linear in the wint fuel cycle costs, i.e. fabrication and reprocessing costs $(\$ / \mathrm{kg} i \mathrm{il})$ and fissile lilarket value $(\$ / \mathrm{kg})$. 


\section{ACKNOWLEDGEMENTS}

The work described in this report has been performed primarily by the prinoipal authol, 3.T. Brewer, who has submitted substantially the same report in partial fulfillment of the requirements for the Ph.D degree at MIT.

Financial support from the U.S. Atomic Energy Commission under contracts $\operatorname{AT}(30-1)-4105$ and $\operatorname{AT}(11-1)-3060$. Is gratefully acknowledged.

Computer calculations were performed at the MIT Information Processing Center.

Dr. W.W. Little and Mr. R.W. Hardie of Battelle Northwest graciously provided the computer program 2DB and cross section data used as a starting point in this work.

Thls report was ably typed by Mrs. Rosemarie Wilkes and Mrs. Linda Ilsley. Their patience and consclentiousness in completing this task are appreciated.

Several MIT faculty members provided encouragement and counsel: the late Professor and USAEC Commissioner Theos J. Thompson, and Professors Norman C. Rasmussen, Manson Benedict, and Thomas Olson. 
TABLE OF CONTENTS

Abstract

Page

Acknowledgments

Täble of Contents

3

List of Figures

4

List rof Tables

13

Chapter 1. Introduction and 'Sunmary

1.1. Introduction

1.2. Outline of the Report

1.3 Qualitative Discussion of FBR Blanket Design

1.4 Surmary

.31

1.4.1 Objectives

1.4.2 The Depletion-Ëconomics Node1

1.4.2.1 Cost Analysis Model

1.4.2.2 Physics-Depletion Mlodel

1.4.3 1000 MNe LMFBR Case Studies

1.4.3.1 Radial Blanket Thickness and

1.4.3.2 Advantage of Local Fuel Management

1.4.3.3 Sensitivity of LAFBR Fuel Energy Costs to the Econonic Environment

1.4.4 Reactor Size and Blanket Fuel Economics

1.5 Conclusions and Recommendations

Chapter 2. Fuel Cost Analysis Method

2.1 Introduction

2.1.1 Objectives of the Chapter 58

2.1.2 Background: Utility Corpany Economics 58 
2.1.3 Scope of the Cost Analysis Hode1 $\cdots$

2.1.4 Outline of the Chapter 61

2.2 Derivation of a General Expression for the Leve1- 62 ized Cost of Electricity (Cash Flow Method)

2.3 Application to FBR Fuel Costs 69

2.3.1 Separation of Costs 69

2.3.2 Application to FBR Fuel Costs 70

2.3.2.1 Method A 74

2.3.2.2 Direct and Carrying Charge Contributions 79

2.3.2.3 Method B 80

2.3.2.4 Direct Dollar Costs Per Lot 82

2.4 Simplifications for Batch and Scatter Fuel 83

Managenent Schemes; Local Fuel Economic Perfornance

2.4.1 Batch Fuel Management 83

2.4.2 Scatter Fue1 Management 34

2.4.3 Local Fuel Economic Performance 87.

2.5 Cormarison of Fuel Cost Accounting Methods 90

2.5.1 Effect of Tax Assumptions in the Cash 90 Flow Method

2.5.2 Relationship of the Cash Flow Method to 96

Two Other Accounting Methods

2.5.2.1 Cash Flow Method (CFM) 95

2.5.2.2 Simple Interest Method (SIM) . 96

2.5.2.3 Compound Interest Method (CMD) 101

2.5.2.4 Summary 102

2.6 Sample Calculation: Behavior of Blanket Fuel Costs 102 with Irradiation Time

2.7 Summary 108

Chapter 3. Physics-Depletion Model · 113

3.1 Introduction 113 
3.2 Description of Time Step Depletion (TSD) Calculations . 115

3.3 Scmi-Analytic Depletion Metiod (SAD) 120

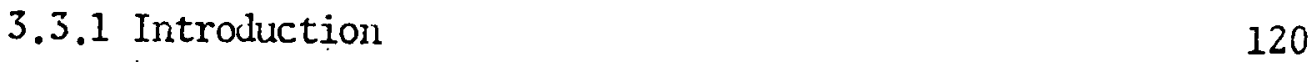

3.3.2 Analytic Solution of Depletion Equations 121

3.3 .3 Sumary 124

3.4 Effects of the Assumptions of Constant Local Flux 125 and Spectrum

3.4.1 Description $\quad 125$

3.4.2 Results (witin Time as the Independent Variable) 130

3.4.3 Results (witi Burnup as the Independent Variable) 139

3.5. Criticality and Reactivity 149

3.5.1 SAM

3.5.2 1G-TSD

149

3.6 Comparison of Conputer Tine Requirements for 26G-TSD, 153 1G-TSD and SA:1

3.7 Effect of Heterogeneity on Blanket Deplction Results 155

3.8 Surinary 163

Chapter 4. Integrated Depletion-Economics Hodel, Selection 164 of Reference LMFBR, Reference LMFBR Fuel Economics

4.1. Introduction 164

4.2 Integrated Depletion-Economics Model ' 164

4.3 Reference LMFBR Configuration $\quad 170$

4.4 Reference LIFBR Economics 171

$\begin{array}{lll}4.5 \text { Sumnary } & 189\end{array}$

Chapter 5. 1000 MNe LAFBR Case Studies · 192

5.1 Introduction 192

5.2 Effects of Radial Blanket Thickness and Radial Reflector 194 Material on Core and Axial Blanket Fuel Depletion Economics

5.3 Radial Blanket Thickness and Radial Reflector Material 
5.4 Radial Blanket Fuel l.anagement Scismes : 207

5.5 Sensitivity of Fuel Energy Costs to the Economic 200 Enviromnent

5.5.1 Irstroduction 209

5.5.2 Core and Axial Blanket . 213

5.5 .3 kaciial Blanket ' 223 5.5.4 Fissile Market Price and tise Ecomomic
Potential of LMFBR B̈lankets

Chapter 6. Conclusions and Recomnendations 237

6.1 Conclusions $\quad 237$

6.2 Recommendations 241

Appendix A. Nomenclature 248

Appenäix B. keactor Size and Blaraket Fuel Economics 253

B.1. Introduction 253

B.2 Equations 255

B.3 Sample Calculation 281

$\ddot{\text { B. }} 4$ Results 231 
Appendix C. SPP1A, A Depletion-Economics Program for Fast 292 Breeder Reactors

C.1 Description of Program 292

C.2 Input Instructions 293

C.3 Sample Problen. 293

C.4 Fortran Listing $\quad 304$

Appendix D. References 


\section{LIST OF FIGURES}

Fig. No.

Page

1.1 Effect of Radial Blanket Thickness and Radial

41 Reflector ilaterial on Radial Blanket Fuel Economics

1.2 Sensitivity of Optimum Radial Blanket Fuel Energy

50 Cost to Unit Fabricatiun Cust

1.3 Sensitivity of Optimun Radial Blanket Fuel Energy

51 Cost to Unit Reprocessing Cost

1.4 Sensitivity of Optimum Radial Blanket Fuel Energy Cost to Fissile Plutonium Price

1.5 Effect of Fissile Pu Price on Total Reactor Fuel Energy Cost

1.6 Reactor Fuel Energy Costs with and without a Breeding Blanket

2.1 Scope of the FBR Fuel Cost Analysis Mode1

2.2 Utility Company Cash Flow Accounting

2.3 Tining of Cash Flows Associated with a Fuel Lot

2.4 Effect of Post-Irradiation Tax Assumption on Levelizeu Core Fuel Energy Cost

2.5 Effect of Post-Irradiation Tax Assumption on

Levelized Axial Blanket Fuel Energy Cost

2.6 Effect of Post-Irradiation Tax Assumption on

Levelized Radial Blanket Fuel Energy Cost

2.7 Construction of Value-Tine P1ots From Fuel Lot Casin Flows

2.8 Value-Time Plots for a Core Fuel Batch

98

2.9 Value-Tine Plots for a Radial Blanket Fuel Batch

2.10 Comparison of Carrying Charge Factors for Capitalized Transactions Computed by CFM, CIM, Ani SIM!

2.11 Components of Radial Blanket Levelized Costs as Functions of Irradiation Tine .

2.12 Coilponents of Radial Blanket Fuel Levelized Annual Costs and Energy Costs as Functions of 
Fig. No.

Page

3.1 H-Group Tine Step Depletion Calculation .:

3.2 Procedure for Methods Comparisons: 26G-TSD vs. $1 G-T S D$ vs. SAl'

3.3 Reference LFBR Configuration (Reactor \#1)

3.4 Comparison of Radial Blanket Depletion Results for

3.5 Comparison of Radial Blanket Depletion Results for Reactor \#2 (Be-Radial Reflector)

3.6 Procedure for Comparing SNM Results using Clean

3.7 Conparison of SAM Radial Blanket Results using

Clean and Irradiated Fuel Neutronic Data

3.8 Depletion Results for Outer-Most Radial Blanket

3.9 Depletio:: Results for Entire Radial Blanket: Tine vs. Burnup as the Independent Variable

3.10 Burnup-Fissile Concentration Characteristics for Inner-lost and Outer-Most Radial Blanket Regions

3.11 Comparison of Burnup-Fissile Concentration Characteristics of Core, Axial Blanket, and Radial Blanket

3.12 Illustration of Depletion Iteration to Select Initial Core Enrichnent

3.13 Illustration of the Effect of Core Initial Enrichnent on Material Inventory Cost

3.14 26-Group U238 Absorption Crnss Sections for Core and Blanket as Generated by the 1DX Program from the Russian Set

3.15 Spectrum-Weiglited One-Group U233 Absorption Cross Sections as Functions of Radial Position

3.16 Effect of Heterogeneity Correction on Radial Blanket Depletion Results

4.1 Integrated Depletion-Economics Mode1

4.2 Reference LMFBR Configuration (Reactor \#1)

4.3 Reference LIFBR Core Fuel Energy Cost as a Function of Exposure 
Fig. No.

Page

4.4

Reference LIFBR $\Lambda x i a l$ Blanket Fuel Energy Cost

183 as a Function of Exposure

4.5 Reference LMFBR Radial Blanket Fuel Cost as a Function of Exposure

4.6 Local Neutronics of the Reference LMFBR Radial Blanket

4.7 Fuel Economic Performance of Annular Regions in the Reference LIFBR Radial Blanket

4.8 Fuel Economic Performance as a Function of Radial

Position in the Reference IMFBR Radial Blanket

5.1 Effect of Radial Blanket Thickness and Radial

Reflector viaterial on Radial Blanket Fuel Economics:

5.2 Effect of Economic Environment on Optimun Radial Blanket Thickness

5.3

Local U238 Capture Reactions Rates $\left(\sigma^{28} \phi\right)$ for

Various Radial Blanket Thicknesses and Radial

Reflector Materials

5.4 Local Neutronics in the Radial Blanket

5.5 Effect of Unit Fabrication Cost on Core Fue1 Linergy Cost

5.6 Effect of Unit Reprocessing Cost on Core Fue1 Energy Cost

5.7 Effect of Fissile Plutonium Price on Core Fuel Energy Cost

5.8 Lffect of Discount Rate on Core Fuel Energy Cost

5.9 Effect of Unit Fabrication Cost on Axial Blanket Fuel Energy Cost.

5.10 Effect of. Unit Reprocessing Cost on Axial Blanket Fuel Energy Cost

5.11 Effect of Fissile Plutonium Price on Axial Blanket Fuel Energy Cost

5.12 Effect of Discount Rate on Axial Blanket Fuel Energy Cost

5.13 Effect of Unit Fabrication Cost on Radial Blanket 


\begin{tabular}{|c|c|c|}
\hline Fig. No. & & $\underline{\text { Page }}$ \\
\hline 5.14 & $\begin{array}{l}\text { Effect of Unit Reprocessing Cost on Radial Blanket } \\
\text { Fuel Energy Cost }\end{array}$ & 226 \\
\hline 5.15 & $\begin{array}{l}\text { Effect of Fissile Plutoniun Price on Radial Blanket } \\
\text { Fuel Energy Cost }\end{array}$ & 227 \\
\hline 5.16 & $\begin{array}{l}\text { Effect of Discount Rate on Radial Blanket Fuel } \\
\text { Energy Cost }\end{array}$ & 228 \\
\hline 5.17 & $\begin{array}{l}\text { Sensitivity of Optimun Radial Blanket Fuel Energy } \\
\text { Cost to Unit Fabrication Cost }\end{array}$ & 230 \\
\hline 5.18 & $\begin{array}{l}\text { Sensitivity of Optimun Radial Blanket Fuel Energy Cost } \\
\text { to Unit Reprocessing Cost }\end{array}$ & 231 \\
\hline 5.19 & $\begin{array}{l}\text { Sensitivity of Optimum Radial Blanket Fuel Energy } \\
\text { Cost to Fissile Plutonium Price }\end{array}$ & 232 \\
\hline 5.20 & $\begin{array}{l}\text { Effect of Fissile Pu Price on Total Reactor Fuel } \\
\text { Energy Cost }\end{array}$ & 235 \\
\hline ì.1 & Critical Core Enrichment as a Function of Core Volume & 283 \\
\hline B.2 & Breeding Ratios as Functions of Core Volune & 283 \\
\hline 3.3 & $\begin{array}{l}\text { Effect of Blanket Burnup (Poiver Fraction) Assumption } \\
\text { Ui Reactor Fucl Energy Costs }\end{array}$ & 285 \\
\hline B.4 & $\begin{array}{l}\text { Effect of Blanket Burnup (Power Fraction) Assumption } \\
\text { on Blanket Fuel Energy Costs }\end{array}$ & 285 \\
\hline B. 5 & $\begin{array}{l}\text { Reactor Fuel Energy Costs with and witinout a Breeding } \\
\text { Blaniet }\end{array}$ & 286 \\
\hline B. 6 & $\begin{array}{l}\text { Core Fuel Energy Costs for Reactors with and without } \\
\text { Breeding Blankets }\end{array}$ & 289 \\
\hline B. 7 & $\begin{array}{l}\text { Fuel Energy Cost Components for Reactors with and } \\
\text { without Breeding Blankets }\end{array}$ & 289 \\
\hline C.1 & SPPIA Sanple Problem Input Deck & 298 \\
\hline C. 2 & SPPIA Sample Problem Printed Output (Partial) & 301 \\
\hline
\end{tabular}


Table No.

Effect of Radial Reflector on Radial Blanket Breeding, 25 Russian Experimental Results Effect of Radial Reflector on Radial Blanket Breeding, German Study

1.3 Shielding Performance of Reflectors, German Studies

Effect of Radial Reflector on Blanket Revenue, Gemnan Studies

1.5 Effect of Radial Blanket Thickness and Radial Reflector Material on Radial Blanket Fuel Econonics

1.6 Radial Blanket Econonic Environment

1.7 Ranges of Economic Environment Parameters

Sensitivity Coefficients, $\left(A,{ }_{q}\right)_{0}$, for Reference LMFBR Core, Axial Blanket, and Radial Blanket

2.1 Tax Treatment of Fuel Transactions

2.2 Effect of Assuming a Single Tax Depreciation Credit

2.3 Surmary of Expressions for Carrying Charge Factors, $\mathrm{F}_{\mathrm{m}}^{\mathrm{q}}$, by Cash Flow lethod

2.4 Effect of the Approximation

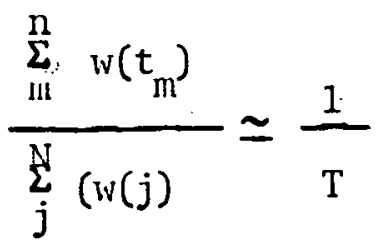

2.5 Surmary of Expressions for Carrying Charge Factor $\left(\mathrm{F}_{\mathrm{m}}^{\mathrm{q}}\right)$ by CFII, CIM and SI:I

2.6 Sumunary of FBR Fuel Cost Analysis Equations (Cash Flow Method)

3.1 Depletion Calculational Methods to Determine Effects of Constant Flux, Constant Spectrum Assumptions

3.2 Couparison of Core Depletion Results for Reactor \#1 (Reference Reactor)

3.3 Comparison of Core Depletion Results for Reactor \#2 (Be-Radial Reflector) 
Table No.

Page

3.4 Comparison of Axial Blanket Depletion Results for Reactor \#1 (Reference LMFBR)

3.5 Comparison of Axial Blanket Depletion Results for

135 Reactor \#2 (Be-Radial Reflector)

3.6 Cormparison of $\mathrm{SAlI}_{0}, \mathrm{SAM}_{4}$, and 26G-TSD Radial Blanket

3.7 Comparison of lultiplication Constant Values from 26G-TSD and 1G-TSD Calculations

3.8 Comparison of Computer Time Requirements for 26G-TSD, IG-TSD, and SAli

3.9 U238 Capture Data Illustrating Radial Blanket lieter.

4.1 Survey of LFBR Designs

172

4.2 Reference Economic Environnent

178

4.3 Reference Fuel Cycle Tining

180

4.4 Reference Plant Power Parameters

181

4.5 Effect of Core Enrichment Zoning on Blanket Fuel

$5.1 \quad$ Case Definitions

5.2 Effects of Radial Configuration Changes on Core and Axial Blanket Fuel Costs

5.3 Effect of Radial Blanket Thiclness and Radial Reflector - Waterial on Radial Blanket Fuel Economics

5.4 Reference and More Favorable Economic Environments

5.5 Thole Blanket vs. Regional Fuel lanagement Schemes

208

5.6 Radial Blanket Fuel lanagement Schernes

5.7 Ranges of Economic Environment Parameters

5.8 Core and Axial Blanket Sensitivity Coefficients, $\left(A_{\mathrm{q}, \mathrm{s}}\right)_{\mathrm{o}}$ 
15

Table :No.

B.1 Summary of Working Equations

B.2 Assumptions

B.3 Region Compositions and One-Group Data

B.4 Economics Data

S.b Plant Power-Related Parameters and Batch Fuel Timing

B.6 Sample Calculations

B.7 Advantages and Disadvantages of Substituting Sodium Reflector for Breeding Blanket

C.1 SPP1A Input

C.2 Interpretation of SPP1A Printed Output $\frac{\text { Page }}{256}$

259

260

261

262

282

288

294

302 


\section{CHAPTER 1}

\section{INTRODUCTION AND SUMMARY}

\subsection{INTRODUCTION}

A Fast Breeder Reactor blanket performs several functions: fertileto-fissile converter, reflector, shield. In addition, it produces some power, thereby relieving, slightly, the power burden on the core. Of these functions, the fissile breeding objective is considered paramount. For current 1000 Mve designs, a fast reactor without blankets is not a breeder; although most of the conversion is accomplished in the core (internal breeding ratio $\sim 0.8$ ), a fertile blanket is required to achieve overa11 breeding ratios above unity.

An AEC sponsored program is underway at MIT using the Fast Reactor Blanket Test Facility (BTF) to investigate blanket neutronics for the L:FBR effort (60, 61). To guide the selection of blanket nock-up experiments, comparative studies have been made of the fuel economics of several LIFBR blanket-reflector configurations.

Objectives of the work reported here were twofold: (1) to develop a simple depletion-economics calculational tool for survey evaluations of LiFBR blanket configurations; and (2) to perform several comparative studies around a 1000 MVe reference LFFR configuration. The 1000 MVe case studies involve choice of radial reflector material (Be-metal vs. sodium), radial blanket thickness, advantages of local fuel management in the radial blanket, and the sensitivity of LMFBR fuel energy costs to clanges in the economic environment. 


\subsection{OUTLINE OF THE REPORT}

Calculational methods for FBR fuel depletion econonics are developed in Chapters 2 and 3. Chapter 2 deals with the accounting details involved in detemining energy costs by reactor region (core, axial blanket, radial blanket). The depletion method is developed in Chapter 3.

In Chapter 4 , the energy cost and depletion methods are combined to form a computational tool for evaluating the fuel economic performance in units of mills/KWle or $\$ / \mathrm{kg} \mathrm{HM} /$ year - of regions under either batch or scatter fuel management schemes. (Appendix C describes a computer program, SPPIA, developed to perform the depletion-economics computations.) A reference LMFB configuration is selected, and the integrated depletioneconomics model is applied to this reactor, in a reference economic environment.

In Chapter 5, the fuel depletion-economics model is applied to a series of case studies in which the radial blanket thickness, radial reflector material, fuel management scheme, and economic environment are varied around the reference.

Chapter 6 sumarizes major conclusions of the study and lists several recommendations for future efforts.

Appendix B describes a preliminary scoping study examining the economic viability of FBR blankets as reactor unit size increases.

\subsection{QUALITATIVE DISCUSSION OF FBR BLANKET DESIGN CONSIDERATIONS AND LITERATURE SURVEY}

The major economic objective ${ }^{1}$ of FBR blanket design is to maximize the

1 Another objective frequently adopted is the maximization of blanket breeding ratio. This objective, which is usually not consistent with the net revenue (or minimum power cost) objective, is macro-economic in nature, and is keyed to national fuel resource conservation considerations. 
net blanket fissile revenue, that is, to maximize the fissile credit less fabrication, reprocessing, and carrying charges. At the same time thermalhydraulic engineering design seeks to minimize the effects of the blanket power swing over a refueling cycle interval and to minimize the power gradient across the blanket. Other engineering considerations are the shielding role of the blanket, and possible material constraints on blanket exposure.

The blanket designer has several design variables and options to work with in meeting these objectives while satisfying the constraints. Some of the major variables and options are discussed qualitatively below. Studies which have addressed these considerations are referenced. Blanket Thickness

Selection of blanket thickness involves a tradeoff between the fissile plutonium production rate and fuel cycle costs - fabrication, reprocessing, and associated carrying charges. An incremental increase in blanket thickness imposes additional fabrication and reprocessing costs while providing some additional fissile production. The incremental increase in fissile production decreases with blanket thickness because of flux attenuation. An incremental increase in thickness beyond some point is unprofitable - the added fissile revenue is not sufficient to offset the added fabrication and reprocessing costs.

The"optimum" thickness depends on the econonic environment - fissile value $\left(\$ / \mathrm{kg} P \mathrm{u}_{\mathrm{f}}\right)$, fabrication cost $(\$ / \mathrm{kg} \mathrm{HM})$ and reprocessing cost $(\$ / \mathrm{kgHM})$. Thick blankets are indicated when fissile value is high and/or fabrication and reprocessing costs are low, Thicker blankets may also be in order when leakage flux to the blanket is increased due to changes in core design.

The Westinghouse LMFBR Follow-On Studies (73), Task I, have shown that the optimum radial blanket thickness is not sharp, that is, the 
blanket profit is a weak function of blanket thickness. This conclusion is borne out in the present study. The Westinghouse optimum thickness is between 25 and $30 \mathrm{~cm}$, again consistent with the present study. Blanket Irradiation Tinie

Below some irradiation time, $\mathrm{T}_{1}$, the bred fissile inventory in the blanket is not sufficient. to offset the blankel fabrication, reprocessing, and carrying charges. At $\mathrm{T}_{1}$, the "breakeven point", the revenue from bred fissile is just equal to fabrication, reprocessing, and carrying charges. Beyond $T_{1}$, the blanket produces a net profit. As irradiation time, $T$, is further increased, Pu239 is produced at a decreasing rate, because of the burnup of both fertile U238 and fissile Pu239, and the fissile credit averaged over irradiation time, $\mathrm{T}$, decreases. Also, as irradiation time $\mathrm{T}$ increases, carrying charges increase, and direct fabrication and reprocessing charges decrease. Taken together, these opposing effects resu1t in an optimum irradiation time, Topt, at which the net revenue in $\$ / \mathrm{kg} \mathrm{HM} /$ year (or in mills/KWHe) is a maximum.

Local optimum irradiation time decreases, and local net revenue at the optimum increases, with increased local flux. Thus regions near the blanket-core interface reach their optima sooner and produce more revenue than regions deeper in the blanket. For pancaked cores, the axial blanket optimum irradiation time is less than that of the radial blanket. Thinner blankets enjoy shorter optimum irradiation times.

Several studies have assessed optimum blanket irradiation times for particular designs $(\underline{1}, \underline{4}, \underline{12}, \underline{70})$. Typical local optima range from about two to about eight years across the radial blanket.

Engineering considerations such as burnup, power swing, corrosion, and irradiation danage of cladding may tend to limit feasible irradiation time. 
Blanket Fuel Management Scheme

Axial blanket fuel management is constrained to that of the core since axial blanket fuel assemblies are merely extensions of core assemblies in present LMFBR designs. The core-axial blanket fuel management scheme adopted in the 1000 MVe LAFBR Follow-on Studies (69, 70,71, 72,73) can be described as a region-scatter scheme. In this scheme, the core-axial blanket is divided into annular regions. At each refueling event, fractions $g_{1}, g_{2}, \ldots$ of regions $1,2, \ldots$ are discharged and replaced with fresh fuel. Fuel sees only one position in the reactor. The discharge fractions $g_{1}, g_{2}, \ldots$ decrease with distance from the core centerline, implying that irradiation times increase with distance from the core centerline. This procedure enhances flux flattening and discharge burnup uniformity.

Radial blanket fuel management is independent of that of the coreaxial blanket, with the restriction, of course, that blanket refueling dates coincide with those of the core-axial blanket, to minimize reactor shutdowns for refueling. With the exception of Westinghouse (73) the scheme selected in the 1000 MNe Follow-on Studies is region-scatter. Again, irradiation time increases and discharge fraction decreases with distance of the region from the core-blanket interface, thus implementing flux flattening across the blanket. Batch management is the special case of scatter management in which the discharge fractions are set equal to unity, i.e. at each refueling event for a given region, $100 \%$ of the fuel is discharged and replaced with fresh fuel.

Other schemes proposed for the radial blanket are out-in, in-out, and fuel assenbly rotation. The Westinghouse Follow-on design (73) specifies in-out. In this scheme, fresh fuel is loaded in the innermost blanket 
region, and is moved outwand in subsequent refuelings, remaining in each annular region for one or more cycles. Fuel is discharged,finally, from the outermost region. Advantages (10) of the in-out management are power flattening, reduction of local power swing, and burnup uniformity. An earlier study (4) argued qualitatively that in-out management would be uneconomic due to the prolonged holdup of bred fissile. This was not demonstrated quantitatively.

In the out-in scheme, fresh fuel is loaded in the outermost region, moved inward, and discharged from the innermost region. The scheme has the advantage of achieving uniform burnup, and would tend to reduce the power swing over an irradiation cycle. However, out-in would tend to aggravate the power tilt across the blanket. Out-in management was compared (4) to fixed element management (batch or scatter) and was found to have only a few percent profit advantage.

A recent study (17), has investigated the optimum out-in throughput for a 1000 MWe LMFBR radial blanket. The study determined the effect of throughput on 10-year fuel cycle costs. Halving of the radial blanket out-in throughwut increased fuel cycle costs (from optinnal) by less than $5 \%$. Increasing the throughput by a factor of about 1.5 increased the 10 year fuel cycle cost by about $1 \%$.

The optirmm throughput analysis reported in this (17) study was used as an illustration of a computational method for selecting optimal FBR fuel nnanagement strategies in a changing economic environment. The method permits changing fuel management during plant life (in response to changes in the economic environment) in order to minimize fuel costs during the remainder of plant life. In the radial blanket illustration cited, remaining plant life is 10 years. 
Fuel element rotation has been studied by Westinghouse $(10)$. Rotation may be considered a sub-fuel nnagement scheme in that it may be used in conjunction with the other schemes. During a refueling, fuel assemblies are simply rotated in place, thus moving fuel with high fissile content deeper into the blanket. Advantages of rotation are powerflattening and reduction of local power swing over an irradiation cycle. Westinghouse has show that the naximum (with tine) rod peaking factor for a radial blanket rod adjacent to the core can be reduced by about $20 \%$ by rotation. The reduction in power peaking across the blanket was not reported. Also, the effect of rotation on breeding economics was not reported. Inner Radial Moderator

Insertion of a layer of moderating material between core and blanket would offer the advantage of softening the leakage flux entering the blanket, improving the fertile capture rate per incident neutron. On the other hand, the incident flux (entering the blanket) would be diminished due to absorption and reflection by the moderating layer. Thus the net effect of inner radial moderator configuration on blanket breeding is not qualitatively clear. Furthermore, one might expect the moderating layer to return more neutrons to the core and to degrade the returning spectrum. The net effect (on critical mass and internal breeding ratio) of the improved reflection plus degraded core spectrum is also not intuitively evident.

Perks and Lord (5) have perforned survey calculations on the inner radial moderator concept, using a variety of moderating materials and thicknesses. Candidate materials were graphite ( $82 \%$ graphite), graphitesteel (41\% graphite, $51 \%$ stainless stee1) and sodium (100\% sodium). The inner radial moderator configuration consistently resulted in a small reduction in critical mass, an increase in internal breeding ratio, a 
reduction in blanket breeding ratio, and a net reduction in total breeding ratio. Their (5) cost results show that the core fissile inventory reduction does not offset the breeding revenue reduction; thus, the inner radial moderator concept does not appear economically attractive. Moderated Blankets

Replacing some blanket fuel with moderator material would tend to soften the blanket spectrum, enhancing the conversion rate per unit of fue1. Opposing this effect is the lessened gross breeding occasioned by the diminished fuel content. Some candidate moderating materials are graphite, $\mathrm{ZrH}_{2}$, and $\mathrm{BeO}$.

Two studies $(\underline{4}, \underline{12})$ have investigated the breeding economics of moderated blankets. Hasnain (4) considered graphite in an LMFBR radial blanket, while layer (12) considered graphite, $\mathrm{ZrH}_{2}$, and $\mathrm{BeO}$ in a steamcooled fast reactor (SCFR) radial blanket. In all cases, the inclusion of moderating materials (at the expense of fuel volume) ged to a reduction in breeding ratio. Core parameters ( $k_{\text {eff }}$, critical mass) were only slightly affected. Botin studies concluded that moderated blankets offered no significant economic advantages.

Nnother study (17) has shown that seeding a typical LimBR radial blanket with carbon leads to a slight irprovenent in the breeding performance of the inner radial blanket: about $10 \%$ increase in inner radial blanket fissile concentration. The outer radial blanket was found to be practically unaffected. Radial Reflector

Functions of the radial reflector are: (1) to enhance radial blanket performance by flattening blanket flux, and, possibly, by softening the return spectruin; and (2) to provide a neutron sinield for structural materials outside the reactor. Two major design decisions are choice of radial reflector composition and choice of radial reflector thickness. 
In the Westinghouse LMFBR Follow-On work (73), $\mathrm{Fe}, \mathrm{C}, \mathrm{Ni}$, and Na (reference case) reflectors were compared for a 10.5 inch thick radial blanket. Maximum improvement (over the Na reflected case) in radial blanket fuel economic performance was only $0.008 \mathrm{mills} / \mathrm{kWH}$ (the 12 inch graphite reflector). A 3 inch Fe reflector provided minimum improvement (0.002 mills/KWHe). A 3 inch $\mathrm{Ni}$ reflector resulted in $0.007 \mathrm{mills} / \mathrm{KWHe}$ savings. Choice of radial reflector material and thickness was found to have little effect on power ratios across the blanket. Nickel provided a significant improvement in flux attenuation and was selected as the preferred reflector material.

Using the BR-1 reactor, Russian experimenters (6) have studied the effect of reflector composition on radial blanket breeding. Be, C, Ni, $\mathrm{Fe}, \mathrm{Cu}, 1 \mathrm{Kh} 18 \mathrm{NgT}$ steel, water, and extended blanket material were compared. The thicknesses of these reflectors were chosen such that any further increase in thickness resulted in negligible increase in blanket U238 ( $n, \gamma)$ captures. "Reflector efficiency" was defined as

$$
B_{i}=A_{i} / A_{x B}
$$

where

$$
\begin{aligned}
& A_{i}= \text { additional U238 }(n, \gamma) \text { captures resulting from } \\
& \text { addition of reflector of material } i \text {. } \\
& A_{X B} \text { additional U238 }(n, \gamma) \text { captures resulting from } \\
& \text { extending the blanket. }
\end{aligned}
$$

The base radial blanket thïckness was not given, nor could it be inferred. Two types of blankets - uranium carbide and metallic uranium - were used.

Table 1.1 sumnarizes the results. The reflector efficiency for the extended blanket case was unity, by definition. All other efficiencies were less than unity, indicating that an extended blanket is preferable if fabrication and reprocessing costs are ignored. The results show that 
TABLE 1.1

EFFECT OF RADIAL REFLECTOR ON RADIAL BLANKET BREEDING, RUS3IAN EXPERTEEVIAL NESUL'T'S (6)

\begin{tabular}{|c|c|c|c|}
\hline \multirow[b]{2}{*}{$\begin{array}{l}\text { Reflector } \\
\text { Material }\end{array}$} & \multirow[b]{2}{*}{$\begin{array}{c}\text { Reflector } \\
\text { Thickmess } \\
\text { (cm) }\end{array}$} & \multicolumn{2}{|c|}{$\mathrm{Bi}$} \\
\hline & & $\begin{array}{l}\text { Uranium } \\
\text { Carbide } \\
\text { Blanket }\end{array}$ & $\begin{array}{l}\text { Metallic } \\
\text { Uranium } \\
\text { Blanket }\end{array}$ \\
\hline $\mathrm{Be}$ & 140 & 0.54 & 0.86 \\
\hline $\mathrm{C}$ & 600 & 0.50 & - \\
\hline $\mathrm{Ni}$ & 192 & 0.47 & 0.51 \\
\hline$\Gamma \mathrm{c}$ & 184 & 0.42 & 0.28 \\
\hline Steel & 160 & 0.33 & 0.40 \\
\hline $\mathrm{Cu}$ & 184 & 0.24 & 0.41 \\
\hline Water & 144 & 0.23 & 0.49 \\
\hline $\mathrm{UC}$ & & 1.00 & - \\
\hline U-net. & & - & 1.00 \\
\hline
\end{tabular}

moderating reflectors (Be, water) are significantly more effective for lietallic blankets than for carbide blankets, owing to the harder spectrum in netallic blankets and the potential for improved U238 $(n, \gamma)$ capture. For both carbide and metallic blankets, Be is the preferred reflector. 
The study included no analysis of the fissile revenue-fuel cycle cost tradeoff in extending the blanket. Thus froril their results, Table 1.1, it is not possible to reach a firm economic judgement vis-avis replacenent of blanket material with reflector.

In an analytic study at IIT (61) it was found that for an 18 inch blanket, no inprovenent in blanket breeding was accomplished by increasing the reflector $(\mathrm{Fe})$ thickness beyond 18 incines. Sinilarly, no improvenent was noted in extending an unreflected 18 inch blanket by more than an adlitional 18 inches, i.e. beyond a total unreflected thickness of 30 inclies. Thus an 18 inch iron reflector and a 36 incl radial blanket are effectively infinite.

A German study (12) has evaluated radial reflector materials for stean cooled FBRs. Candidate materials were steam, water, $\mathrm{ZrH}_{2}, \mathrm{BeO}$, graphite, steel, $\mathrm{UO}_{2}$ (extended blanket), and $\mathrm{U}$ metal. The radial blanket in all cases, was $35 \mathrm{~cm}$ thick, and composed of $56 \mathrm{v} / \mathrm{o} \mathrm{UO}_{2}$ and $18 \mathrm{v} / \mathrm{o}$ structural material. Reflectors, in all cases, were $80 \mathrm{v} / 0$ reflector material, $10 \mathrm{v} / 0$ steel, and $10 \mathrm{v} / 0$ coolant.

The reflector materials were first ranked by their effect on "breeding rate" (undefined). Optimum reflector thickness was selected such that further increase in thickness increased the breeding rate by less than $1 \%$. Table 1.2 surmarizes the results of the breeding rate ranking.

The molerating reflectors are $\mathrm{ZrH}_{2}, \mathrm{BeO}$, and graphite. of these, $\mathrm{ZrH}_{2}$, has the strongest noderating effect, but it is also the strongest absorber and thus the weakest net reflector. It has the least beneficial effect on blanket breeding. The less-thermalizing and less-absorbing BeO and graphite return more neutrons, albeit at higher energies, and result in higher blanket breeding. 
TABLE 1.2

EFFECT OF RADIAL REFLECTOR ON RADIAL BLANKET BREEDING, GERMAN STUDY (12)

Reflector

Material

$\mathrm{BeO}$

graphite

steel

$\mathrm{UO}_{2}$

U-metal

$\mathrm{ZrH}_{2}$
Optimum
Reflector
Thickness

$(\mathrm{cm})$

$12-16$

$12-16$

$6-8$

$6-8$

$6-8$

4
$B^{1}$

0.023

0.021

0.015

0.013

0.013

0.011

1) $B=$ radial breeding ratc - radial breeding rate with no reflector 
The shielding effectiveness of the materials was also considered. In these studies, reflector thickness was held constant at $8 \mathrm{~cm}$. Flux values (in arbitrary units) at the outer edge of the reflectors are shown in Table 1.3. If the objective is to minimize high energy flux, $\mathrm{ZrH}_{2}$ would be the preferred reflector. The other moderating reflectors, BeO and graphite, are somewhat poorer attenuators.

The breeding rate and shielding effectiveness surveys described above were based on "snapshot" multigroup physics computations. In a further study, the same author $(\underline{12})$ evaluated the blanket revenues, with the various reflectors, at optimm irradiation times. Fabrication costs of the blanket were ignored entirely. Also portions of the blanket which would not yield a net profit (after reprocessing) were not counted. That is, these unprofitable regions did not burden the blanket with any cost whatever; they were simply not considered to be reprocessed. Table 1.4 summarizes the percent revenue improvements (over the case with no reflector) resulting from the addition of the various reflectors. The oversimplified economic assumptions apparently account for the inconsistency in reflector rankings between Tables 1.2 and 1.4 . Metallic vs. Oxide Blankets

The economics of metallic and oxide blankets have been compared by Kaickman (1). Core design was held fixed. Optimum thickness for the metallic blanket $(\sim 20 \mathrm{~cm})$ was about one half that of the oxide blanket $(\sim 40 \mathrm{~cm})$. For these thicknesses, the two blankets had approximately the same breeding ratio, uranium content, and flux attenuation characteristics. Burnup limitations were assumed to be $5000 \mathrm{MWD} / \mathrm{M}$ for the metallic blanket and 25,000 M $/ \mathrm{MT}$ for the oxide blanket. The study showed that the low burnup limitation severely disadvantages the metallic blanket - its regional optimun irradiation times cannot be achieved. The oxide blanket's ir- 
TABLE 1.3

SHIELDING PERFORMANCE OF REFLECTORS,

GERMAN SIUDIES (12)

Flux at Outer-Edge of an $8 \mathrm{~cm}$ Reflector

Reflector

Waterial

$\mathrm{BeO}$

graphite

steel

$\mathrm{UO}_{2}$

U-metal

$\mathrm{ZrH}_{2}$
Total Flux

$0-10.5 \mathrm{Mev}$

(arbitrary units)

1.63

2.68

2.77

2.41

2.00

1.09
49.66

53.30

39.14

33.28

25.46

33.24 
TABLE 1.4

EFFECT OF RADIAL REFLECTOR ON BLANKET REVENUE, GERMAN STUDIES (12)

Reflector

ivaterial

$\mathrm{BeO}$

graphite

steel

$\mathrm{UO}_{2}$

U-inetal

$\mathrm{ZrH}_{2}$
Blanket Revenue Improvcmenf
with respect to reference

$11.6 \%$

12.9

6.8

4.0

3.2

9.8

1) Reference $=$ no reflector 
radiation time was not so-limited. Even without the burmup limitations, the oxide blanket was found to be economically preferable.

\subsection{SUMPARY}

\subsubsection{Objectives}

The objectives of this work were twofold:

(1) to develop a simple depletion-economics calculational tool for survey evaluations of LMFBR blanket configurations; and

(2) to perform several comparative studies around a 1000 Mie reference LMFBR configuration.

The 1000 whe case studies (2), to which model (1) was applied, dealt witi (a) effect of choice of radial reflector material (Be-metal vs. Na) and radial blanket thickness on radial blanket fuel economics, (b) the advantage of operating each radial blanket region on its own local optinum irradiation schedule, and (c) the sensitivity of LMFBR fuel energy costs to the econonic environment.

A preliminary study examined the economic viability of FBR blankets as reactor size is increased. The reactor size-blanket economics study used only the economics equations developed in task (1) above. Depletion information was obtained from simple, one energy group, spherical geometry breeding ratio expressions. Three cases were compared over a range of core sizes: (a) a spherical core surrounded by a breeding blanket, with no fissile burnup in the blanket; (b) a spherical core surrounded by a sodium reflector (no blanket); and (c) a spherical core surrounded by a breeding blanket, with blanket burmup (power) accounted for.

\subsubsection{The Depletion-Economics Model (Chapters 2,3)}

The depletion-economics model has two parts: (a) the cost analysis 
model which yields the fuel conponents of energy cost, given unit fabrication and reprocessing costs ( $\$ / \mathrm{kgHND}$, plutonium inarket values $\left(\$ / \mathrm{kgPu} \mathrm{f}_{\mathrm{f}}\right)$, money costs (discount and tax rates), and the nuclide balance data; and (b) the physics-depletion model, which yields the nuclide balance data load and discharge masses of fertile and fissile materials - used in the cost analysis model. The depletion economics model is progranmed in tine computer code SPPIA, described in Appendix C. Given local physics data (local flux and flux-averaged cross sections) from a single multigroup pilysics computation, and given the economic parameters, the code yields fuel costs locally (or for an annular region) in $\$ / \mathrm{kgHN} /$ year, and energy costs by major region (core, axial blanket, radial blanket) in liills/kitle.

\subsubsection{Cost Analysis ilodel}

Despite attempts to standardize nuclear fuel cost accounting methodology $(21,22,23,24)$, a casual review of nethods actually used in design evaluations and tradeoff studies reveals substantial inconsistencies. Furthermore, FBR blankets impose several unique accounting problems: blanket fuel appreciates with irradiation, raising certain tax questions; and the long irradiation times in the radial blanket make the treatment of blanket carrying charges important. For these reasons, a cash flow method (CFM) was adopted in the present work.

A general CFil expression for the levelized cost of electricity (mills/KWHe) was derived and applied to FBR fuel costs. When applied to a region (core, axial blanket, or radial blanket) or subregion under fixedelement (batch or scatter) management, the equations reduce to forms giving local fuel economic performance, e.g. in an annular zone, or at a "point", in mills/KWHe or \$/kgHilyear: 


$$
\begin{aligned}
& \overline{\mathrm{e}}=\frac{1000}{\mathrm{E}} \mathrm{M}_{\mathrm{FM}}^{0}\left[\frac{\mathrm{C}_{\mathrm{fiss}} \epsilon_{0}^{\mathrm{Fi}}(\mathrm{T})}{\mathrm{T}} \quad \begin{array}{l}
\text { material } \\
\text { purchase }
\end{array}\right. \\
& \mathrm{C}_{\mathrm{fab}} \mathrm{F}^{\mathrm{faj}}(\mathrm{T}) \\
& +T \\
& \mathrm{~T} \\
& +\frac{C_{\text {repr }} \text { Frepr }^{\text {T }} \text { T) }}{T} \\
& C_{\text {fiss }} \in(T) F^{m c}(T) \quad \text { material } \\
& \text { fabrication } \\
& \text { reprocessing } \\
& \text { credit }
\end{aligned}
$$

where $\bar{e}$ is the local levelized fuel component of the energy cost (mills/ KWtie), $E$ is the electrical energy produced by the reactor in one year (iswhe/yr), $T$ is tine local irradiation tirie $\left(y^{\prime}.\right), C_{\text {fab }}$ and $C_{\text {repr }}$ are the unit faurication and reprocessing costs ( $\dot{\psi} / \mathrm{kghin}), \mathrm{C}_{\text {fiss }}$ is the fissile plutoniun price $(\$ / \mathrm{kg}), \epsilon_{0}$ is the initial enriciment, $\epsilon(\mathrm{T})$ is the disciarge einriciment ( $\mathrm{kg}$ fissile discharged per $\mathrm{kg}$ of heavy netal loaded), $F \mathcal{G}(T)$ is thie carrying charge factor for cost component $q$, and $M_{\text {in. }}^{0}$ is the mass of heavy metal loaded. The term in brackets [ ] may be regarded as a figure of merit representing local fuel economic performance, having units of dollars per year per local kilogram of heavy metal loaded. The carrying charge factors, $\mathrm{F}^{\mathrm{q}}(\mathrm{T})$, are given by

$$
\begin{aligned}
F q(T) & =\frac{1}{1-\tau}\left[\frac{1}{(1+x)^{\mathrm{Tq}}}-\tau\right] \\
& =\frac{1}{(1+x)^{\mathrm{Tq}}} \quad \begin{array}{l}
\text { for capitalized } \\
\text { costs or revenues }
\end{array} \\
& \begin{array}{l}
\text { for non-capitalized } \\
\text { costs or revenues } \\
\text { (expensed cost or } \\
\text { taxed revenue) }(1-2)
\end{array}
\end{aligned}
$$


where

$$
x=(1-\tau) r_{b} f_{b}+r_{s} f_{s}=\text { "discount rate" }
$$

and where $\tau$ is the income tax rate, $f_{b}$ and $f_{s}$ are the debt and equity, fractions, $r_{b}$ and $r_{s}$ are the debt and equity rates of return, and $T^{q}$ is the time between the cash flow transaction $q$ and the irradiation midpoint.

The "front end" components, fabrication and material purchase, are nomally capitalized. The "backend" components, reprocessing and material credit, may be capitalized or not, according to tax interpretation. If they are not capitalized, then revenue from the sale of plutonium is taxed as ordinary income, along with electricity revenue, and reprocessing charges are treated as tax deductible expenses in the year in which they occur. The two methods, capitalizing and not capitalizing backend transactions, were compared and were found to have a significant effect on absolute values of energy costs. However, choice of method does not distort conparative or incremental results, e.g. design rankings, optimum blanket irradiation time, sensitivity studies. In the case studies to which the depletion-economics model was applied, material credit was consistently taxed and reprocessing charges were consistently expensed.

The CFM treatment of carrying charges is embodied in Equations $(1-2)$ above. Two approximate methods, here labeled "Simple Interest Method" (SIM) and "Compound Interest Method" (CIM), were identified in the literature:

$$
F^{q}=1+y_{q} T^{q}
$$

and

$$
F^{q}=\left(1+y_{q}\right)^{T^{q}}
$$


where

$$
\begin{aligned}
y_{\mathrm{q}}=x / 1-\tau & \text { for capitalized costs or revenues } \\
=x & \begin{array}{l}
\text { for non-capitalized costs or } \\
\text { revenues (expensed costs or } \\
\text { taxed revenues) }
\end{array}
\end{aligned}
$$

The CFM expressions were shown, through series expansinns, to reduco to SIM and CIM for small $\mathrm{T}^{\mathrm{q}_{\mathrm{q}}}$. SIM underpredicts, while CIM overpredicts, the carrying charge factor. Because radial blanket irradiation times are typically long, the CFN method was selected for use in the case studies of this report.

\subsubsection{Physics-Depletion Mode1}

The function of the physics-depletion model is to furnish discharge fuel composition, $\in(T)$, to the cost analysis model for use in computing material credit.

In the method developed for this work, the "Semi-Analytic Method" (SAM), local physics data (fluxes and spectrum-weighted cross sections) from a single multigroup calculation are used in the analytic solutions of the reaction rate equations to obtain discharge fissile content:

$$
\begin{aligned}
& \epsilon=\frac{M_{49}+M_{41}}{M_{H M}^{0}} \\
& M_{49}=N_{49} V \frac{\tilde{M}_{49}}{N_{a v}}, M_{41}=N_{41} V \frac{\tilde{M}_{41}}{N_{a v}} \\
& N_{49}=N_{28}^{0} A \exp \left(-\sigma_{a}^{28} \theta\right)\left[1-\exp \left(-\left(\frac{\left.\left.\left.\sigma_{a}^{49}-\sigma_{a}^{28}\right) \theta\right)\right]}{N^{28}}\right.\right.\right.
\end{aligned}
$$




$$
\begin{aligned}
& N_{41}=N_{28}^{0} A B_{1} C_{1} \exp \left(-\frac{\sigma^{28} \theta}{a}\right)-N_{28}^{0} A_{2} C_{2} \exp \left(-\sigma_{a}^{49} \theta\right) \\
& +N_{49}^{0} B_{2} C_{2} \exp \left(-\sigma_{a}^{49} \theta\right)+\beta_{1} C_{3} \exp \left(-\sigma_{a}^{40} \theta\right)+\beta_{2} \exp \left(-\sigma_{a}^{41} \theta\right) \\
& A=\sigma_{c}^{28} /\left(\sigma_{a}^{49}-\sigma_{a}^{28}\right) \\
& B_{1}=\sigma_{c}^{49} /\left(\sigma_{a}^{40}-\sigma_{a}^{28}\right) \quad \quad B_{2}=\sigma_{c}^{49} /\left(\sigma_{a}^{40}-\sigma_{a}^{49}\right) \\
& C_{i}=\sigma_{a}^{40} /\left(\sigma_{a}^{41}-\sigma_{a}^{28}\right) \quad C_{2}=\sigma_{c}^{40} /\left(\sigma_{a}^{41}-\sigma_{a}^{49}\right) \quad C_{3}=\underset{c}{\sigma^{40}} /\left(\sigma_{a}^{41}-\sigma_{a}^{40}\right) \\
& \beta_{1}=N_{40}^{0}-\left(N_{28}^{0} A B_{1}-N_{28}^{0} A_{2}+N_{49}^{0} B_{2}\right) \\
& \beta_{2}=N_{41}^{0}-\left(N_{28}^{0} A B_{1} C_{1}-N_{28}^{0} A B_{2} C_{2}+N_{49}^{0} B_{2} C_{2}+\beta_{1} C_{3}\right) \\
& \theta=\int^{T} \phi\left(T^{\prime}\right) d T^{\prime}=10 c a 1 \text { flux time } \\
& \mathrm{M}_{49}, \mathrm{M}_{41}=\text { discharge masses of Pu239, Pu241 respectively } \\
& \mathrm{N}_{49}, \mathrm{~N}_{41}=\underset{\text { discharge atom density of Pu239, Pu241 }}{\text { respectively }} \\
& \tilde{M}_{49}, \tilde{M}_{41}=\text { atomic masses of Pu239, Pu241 respectively } \\
& \mathrm{N}_{\mathrm{av}}=\text { Avogadro's Number } \\
& \mathrm{V}=\text { volume of the zone }
\end{aligned}
$$

Local flux and local spectrum-weighted cross sections are taken from a single multigroup physics computation, and are assumed constant over a fueling cycle.

Several effects complicate the physics-depletion characteristics of FBR blankets: (1) spectrum softening with distance from the core-blanket interface; (2) spectrum hardening with irradiation time, due to the 
relatively large buildup of fissile plutonium in the blanket; (3) flux shift, i.e. increase in blanket flux with irradiation tine, due to buildup of fissile plutonium in the blanket; and (4) heterogeneity effects occasioned by the soft blanket spectrum, and aggravated, in the case of radial blankets, by larger pin diameters.

Effect (1) requires that cross sections be input to the depletion calculation with sufficient spatial detail, i.e. a separate cross section set, properly flux weighted, for each of many blanket regions. Since the accurate spatial description of blanket physics is a prime concern in the Blanket Test Facility work, no atteript was made to determine potential savings in computational effort through reduced spatial detail. Instead, attention was concentrated on effects (2) and (3).

Effects (2) and (3) suggest that static physics calculations be performed sufficiently often, during a depletion calculation, to correct the local fluxes and cross sections. Since most of the computational effort is absorbed by the multigroup calculations, computer expense can be significantly reduced by minimizing their frequency, that is by maximizing the irradiation time intervals over which flux shape and local spectra are assumed constant. For this reason, studies were performed to assess the effects of item (2), spectrum hardening, and item (3) flux shift, on depletion calculation results. Qualitatively, the two effects operate in opposite directions, spectrum hardening tending to decrease blanket discharge fissile inventory, flux shift tending to increase blanket discharge fissile inventory.

Three parallel depletion calculations were performed for a reference 1000 MNe LMFBR:

(a) a 26 energy group time step depletion calculation (26G-TSD), which accounted for both spectrum changes and flux shift; 
(b) a 1 energy group tine step depletion calculation (1G-TSD), which accounted only for flux shift; and

(c) a "seni-analytic method" (SAM) calculation, which accounts for neither spectrum change nor flux shift with irradiation. The two approxinate methods, (b) and (c), used local spectrum-weighted cross sections from the initial (time zero) method (a) solution. In addition, method (c) used local fluxes from the initial method (a) solution. The computer' program 2DB (26) was used for calculations (a) and (b). Method (a) used the Bondarenko 26 group cross section set (48), heterogeneitycorrected by the program 1DX (27).

The calculations assumed batch management of both core (plus axial blanket) and radial blanket. Core and axial blanket fuel was assumed replaced after two years irradiation, corresponding to an average burnup of 100,000 MND/MT. Radial blanket fuel was assumed irradiated to four years. The use of batch management in these calculations imposes a severe test of the constant flux, constant spectrum assumptions. For the same irradiation time, the variations of composition, flux shape, and spectra over a cycle interval are greater for batch management than for scatter management.

Principal findings of the methods study described above are listed below.

(1) For the core, the discharge fissile inventories from the three calculations were practically in exact agreement (errors less than $0.1 \%)$.

(2) For the axial blanket, 1G-TSD overpredicted discharge fissile inventory by less than $4 \%$, while SAM underpredicted by less than $4 \%$. 1. Compared to the $26 \mathrm{G}-\mathrm{TSD}$ calculation. 
(3) For the radial blanket, 1G-TSD overpredicted discharge fissile inventory by about $10 \%$, due to its soft cross sections. SAM

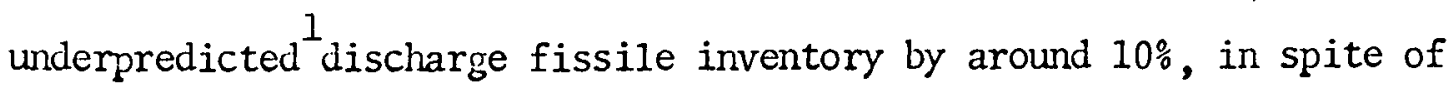
its soft cross sections, because of its low flux values.

(4) Of the two effects exanined in this exercise, spectrum hardening and flux shift, the latter was found to be dominant.

The SAM calculation, performed by the program SPPIA, resulted in computer time savings (over the 26G-TSD, performed by 2DB) of on the order of $90 \%$, while the 1G-TSD (2DB) 1 do to about $60 \%$ time savings. In addition to depletion results, the SPPIA computation obtained fuel costs by region, as functions of irradiation tine.

The effect of heterogeneity corrections (i.e. U238 resonance, spatial self-shielding) on radial blanket depletion results was examined. Heterogeneity influences blanket fissile production in two opposing ways: (a) the lower effective U238 microscopic capture cross section, ${ }_{c}{ }_{c}^{28}$, depresses the conversion rate, tending to decrease bred fissile inventory; (b) viewing blanket neutronics as an attenuation process, the lower $\sigma_{c}^{28}$ results in higher blanket fluxes, tending to increase the conversion rate and bred fissile inventory. Of these two opposing effects, (a) dominates and heterogeneity leads to a net adverse effect on blanket breeding.

Two multigroup physics computations were performed using, respectively, 26 group infinitely dilute cross sections and 26 group heterogeneity corrected cross sections in the blanket. Local fluxes and one group cross sections from these two computations were then input to SAM to obtain depletion results with and without heterogeneity corrections. Comparison of the two SAM results showed that blanket heterogeneity reduced fissile discharge inventory by about $10 \%$ for irradiation times of interest (2-7 years). A similar study (30) showed that heterogeneity corrections for a l.Compared to the 26G-TSD calculation. 
typical LMFBR axial blanket diminished calculated axial blanket Pu239 discharge mass by as much as $3 \%$.

\subsubsection{MNe LMFBR Case Studies (Chapter 5)}

The depletion-economics model established above was applied to case studies involving radial blanket thickness, choice of radial reflector material, radial blanket fuel management, and the sensitivity of LIFBR fuel energy costs to the economic environment.

\subsubsection{Radial Blanket Thickness and Radial Reflector Material}

Combinations of three radial blanket thicknesses $(15,30,45 \mathrm{~cm})$ and two radial reflector materials (sodium, beryllium metal) were evaluated. The total radial dimension (blanket plus reflector) was held fixed at 95 on, since even the thinnest (50 on) reflector is effectively infinite (6, 61). The core and axial blanket configuration was also held fixed. Core volume was 4908 liters, core height-to-diameter ratio was 0.4 and the axial blanket was $40 \mathrm{~cm}$ thick. Core and axial blanket fuel economics were found to be insensitive to radial blanket/reflector design changes. A solid beryllium metal reflector (no coolant, no structural material) was selected as a limiting case, i.e. as the reflector apt to provide maximum improvement in radial blanket fuel economics.

Figure 1.1 and Table 1.5 sumnarize the results of the blanket thickness-reflector material survey. "Reference" and "more favorable" economic enviroments, for radial blankets, are defined in Table 1.6. Principal findings are listed below.

1. The relative advantage of the moderating reflector, Bemetal, increases as the reflector is moved nearer the high flux zones of the blanket, that is, as the blanket thickness decreases. For a thick 


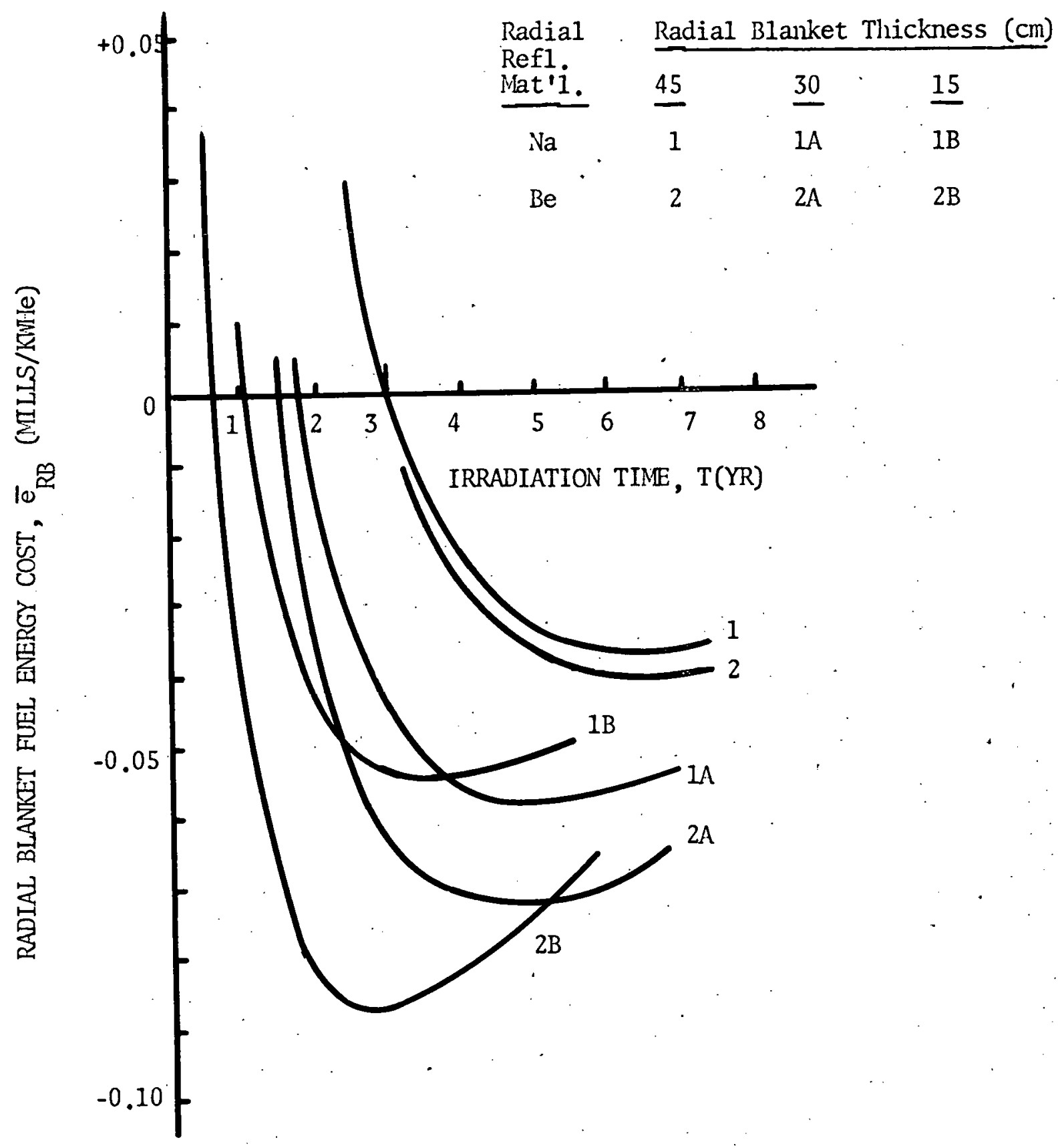

FIG. 1.1 EFFECT OF RADIAL BLANKET THICKNESS AND RADIAL REFLECTOR MATERIAL ON RADIAL BLANKET FUEL ECONOMICS 
TABLE 1.5 EFFECT OF RADIAL BLANKET THICKNESS AND RADIAL

REFLECTOR MATERIAL ON FADIAL BLANKET FUEL ECONOMIICS

\begin{tabular}{|c|c|c|c|c|c|c|c|c|c|}
\hline \multirow[b]{2}{*}{$\begin{array}{l}\text { Configur- } \\
\text { ation \# }\end{array}$} & \multirow[b]{2}{*}{$\begin{array}{l}\text { Radial } \\
\text { Blanket } \\
\text { Thickness } \\
\quad \text { (cin) }\end{array}$} & \multirow[b]{2}{*}{$\begin{array}{l}\text { Radial } \\
\text { Reflector } \\
\text { Material }\end{array}$} & \multirow[b]{2}{*}{$\begin{array}{l}\mathrm{M}_{49} / \mathrm{T} \\
\text { e } \mathrm{T}=2 \mathrm{yr} . \\
(\mathrm{kg} / \mathrm{yr})\end{array}$} & \multicolumn{3}{|c|}{ Reference Economic Environment } & \multicolumn{3}{|c|}{$\begin{array}{l}\text { More Favorable } \\
\text { Economic Environment }\end{array}$} \\
\hline & & & & $\begin{array}{l}\text { Topt } \\
\text { (yr) }\end{array}$ & $\begin{array}{l}\overline{\mathrm{e}}_{\mathrm{RB}} \\
\text { eTopt } \\
\text { (mills/KWHe) }\end{array}$ & $\begin{array}{l}\mathrm{M}_{49} \\
\text { @Topt }(\mathrm{kg})\end{array}$ & $\begin{array}{l}\text { Topt } \\
\text { (yr) }\end{array}$ & $\begin{array}{l}\bar{e}_{\mathrm{RB}} \\
\text { @Topt } \\
\text { (mills/ } \\
\text { KWHe) }\end{array}$ & $\begin{array}{l}\mathrm{M}_{49} \\
\text { eTopt (kg) }\end{array}$ \\
\hline 1 & 45 & $\mathrm{Na}$ & 158 & $6-1 / 2$ & -0.037 & 825 & $3-1 / 2$ & -0.237 & 512 \\
\hline 2 & 45 & Be-metal & 160 & $6-1 / 2$ & -0.040 & 845 & $3-1 / 2$ & -0.243 & 521 \\
\hline $1 \mathrm{~A}$ & 30 & $\mathrm{Na}$ & 141 & $4-3 / 4$ & -0.058 & 596 & $2-1 / 2$ & -0.242 & 342 \\
\hline $2 \mathrm{~A}$ & 30 & Be-metal & 157 & $4-1 / 2$ & -0.072 & 610 & $2-1 / 2$ & -0.279 & 380 \\
\hline $1 B$ & 15 & $\mathrm{Na}$ & 97 & $3-1 / 2$ & -0.055 & 304 & 2 & -0.188 & 194 \\
\hline $2 \mathrm{~B}$ & 15 . & Be-metal & 130 & $2-3 / 4$ & -0.087 & 308 & $1-1 / 2$ & -0.276 & 205 \\
\hline
\end{tabular}


TABLE 1.6

RADIAL BLANNET ECONOIIC ENVIRON:ENT

Reference

69

31

Reprocessing, $\$ / \mathrm{kglM}$

Fissile ilarket Value, $\$ / \mathrm{kg} \quad 10,000$

Discount Rate, ?
More Favorable

40

31

20,000

8 
(45 an) blanket, the effect of radial reflector material choice is only slight.

2. For either reflector, reducing the blanket thickness always reduces the bred plutonium inventory of the blanket, that is, the plutonium forfeited in the region eliminated is greater than the additional plutonium bred in the remaining region as a result of improvement of its breeding performance $\left(\overline{\left.\sigma_{c}^{23} \emptyset\right)}\right.$.

3. Optimum irradiation time decreases as the radial blanket thickness decreases and as the econonic environnent improves. The effect of the choice of radial reflector material on optimun irradiation time is more pronounced the thimer the blanket.

4. Radial blanket thickness optimization is weak, that is, net blanket revenue does not display a sharp peak as radial blanket thickness is reduced froin 3 rows to 2 rows to 1 row (15 $\mathrm{cm}$ per row). Thick blankets are indicated when fabricaliun and reprocessing costs decrease and/or fissile market value increases.

\subsubsection{Advantage of Local Fuel Management}

Fuel management schemes addressed in this study are characterized as "fixed fuel" schemes, i.e. fuel sees only one position in the reactor. During a refueling event a fraction, $g$, of a region's fuel is discharged and replaced with fresh fuel ("scatter" management). If all of the region's fuel $(g=1.0)$ is replaced, the region is said to be "batch" managed.

The entire radial blanket may be batch or scatter managed, in which case all fuel experiences the same irradiation time. Alternatively, the blauket may be divided into annular regions (rows), with each irradiated to its own local optimum irradiation time, again in a batch or scatter 
management scheme. The advantage of operating each radial blanket annular region on its own local optimum irradiation schedule was estimated for the reference LMFBR configuration (45 $\mathrm{cm}$ blanket, Na radial reflector). Net radial blanket revenue in mills/KWHe was found to be about $30 \%$ higher when local managenent was assuned. The local optimum irradiation time ranged from 2.5 years (at the core blanket interface) to about 12 years (at the blanket-reflector interface), while the optimum irradiation time for the blanket as a whole was 6.5 years.

Another advantage of local fuel management, not quantified in the present studies, is the power flattening effect.

1.4.3.3 Sensitivity of LMFBR Fuel Energy Costs to the Economic Environment

Costs generated throughout the fuel cycle are ultimately transferred to the utility company and borne, along with the utility company's carrying charges, hy the electricity consumer vid the fuel component of the levelized cost (price) of electricity in mills/KWHe. Economic environment is defined here as the unit costs for fabrication ${ }^{1}$ and reprocessing $(\$ / \mathrm{kgHN})$, the fissile Pu market value ( $\$ / \mathrm{kgPu}$ fissile) and the utility company discount rate $\left(\begin{array}{l}(0) \\ 0\end{array}\right)$. The sensitivity of reference LIFBR fuel energy costs (mills/KWHe) to components of the economic environment was examined by varying each parameter around the reference values given in parentheses in Table 1.7. Sensitivity of region "s" fuel cost $\left(\bar{e}_{s}\right)$ to cost component " $q$ ", about reference environment " 0 ", is represented by the "sensitivity coefficient", $\left(A_{q, s_{0}}\right)_{0}$ defined by

$$
\left(A_{q, s}\right)_{0}=\left(c_{q, s} / \bar{e}_{s}\right)_{0}\left(\partial \bar{e}_{s} / \partial c_{q, s}\right)
$$

1. Carrying charges of the fuel cycle industries are included in their unit costs $(\$ / \mathrm{kgl} \mathbb{N})$. Carrying charge components of energy costs refer to utility company carrying charges. 


\section{TABLE 1.7}

RANGES OF ECONOMIC ENVIRONMENT PARAMETERS

Unit Processing Costs [\$/kgrM]

$\begin{array}{lr}\text { Fabrication } \\ \text { Core } \\ \text { Axial Blanket } \\ \text { Radial Blanket } \\ \text { Reprocessing } \\ \quad \text { Core. } \\ \quad 20-(314)-330 \\ \text { Axial Blanket } & 20-(80)-314 \\ \text { Radial Blanket } & \\ & 15-(31)-60 \\ & 15-(31)-60 \\ & 15-(31)-60\end{array}$

Nuclide Narket Values $(\$ / \mathrm{kg})$

Fertile $\left(\mathrm{C}_{28}, \mathrm{C}_{40}\right)$ 0

Fissile $\left(\mathrm{C}_{49}, \mathrm{C}_{41}\right)$ $5000-(10,000)-25,000$

Utility Company Financial Parameters

Income Tax Rate $(\tau)$

Discount Rate $(x)$

$0.06-(0.08)-0.10$

( ) indicates reference value 
Table 1.8 sumarizes the sensitivity coefficients for the reference core, axial blanket, and radial blanket. Fabrication and reprocessing components include their respective carrying charges. The rlaterial component is the net direct fissile material cost (fissile naterial purchase less fissile material credit) plus the material carrying charges (inventory). For all three regions, the energy costs for fuel are seen to be most sensitive to unit fissile value and least sensitive to unit reprocessing cost.

For the core and axial blanket, irradiation time is set by the burnup limit of the core. Thus, for these regions, Equation (1-1) reduces to simple linear relations of the unit costs:

$$
\bar{e}_{s}=a_{f a b, s} C_{f a b, s}+a_{\text {repr,s }} C_{\text {repr }, s}+a_{\text {mat }, s} C_{\text {fiss }}
$$

where

$$
a_{q, S}=\frac{1000}{E T} M_{H M}^{0} g(T)=\text { constant. }
$$

Hience, for these regions, sensitivity coefficients simply represent the fractions of the regional cost, $\overline{\mathrm{e}}_{\mathrm{s}}$, contributed by the respective components:

$$
\left(A_{q, s}\right)_{0}=\left(\frac{\bar{e}_{q, s}}{\bar{e}_{s}}\right)_{0}
$$

where

$$
\bar{e}_{q, s}=a_{q, s} c_{q, s}
$$

The radial blanket energy cost of interest is the fuel cost at the optimum irradiation time, $\left(\overline{\mathrm{e}}_{\mathrm{RB}}\right)_{\text {Topt }}$. Since the optimum irradiation time is an implicit function of the economic environment parameters, the Equation (1-1) for the radial blanket does not reduce exactly to a simple linear form. However, sensitivity results from the SPPIA program, 
TABLE 1.8

SENSITIVITY COEFFICIENTS, $\left(A_{q, s_{0}}\right)_{\circ}^{*}$, FOR REFERENCE LIFBR CORE, AXIAL BLANKET, AND RADIAL BLANKET

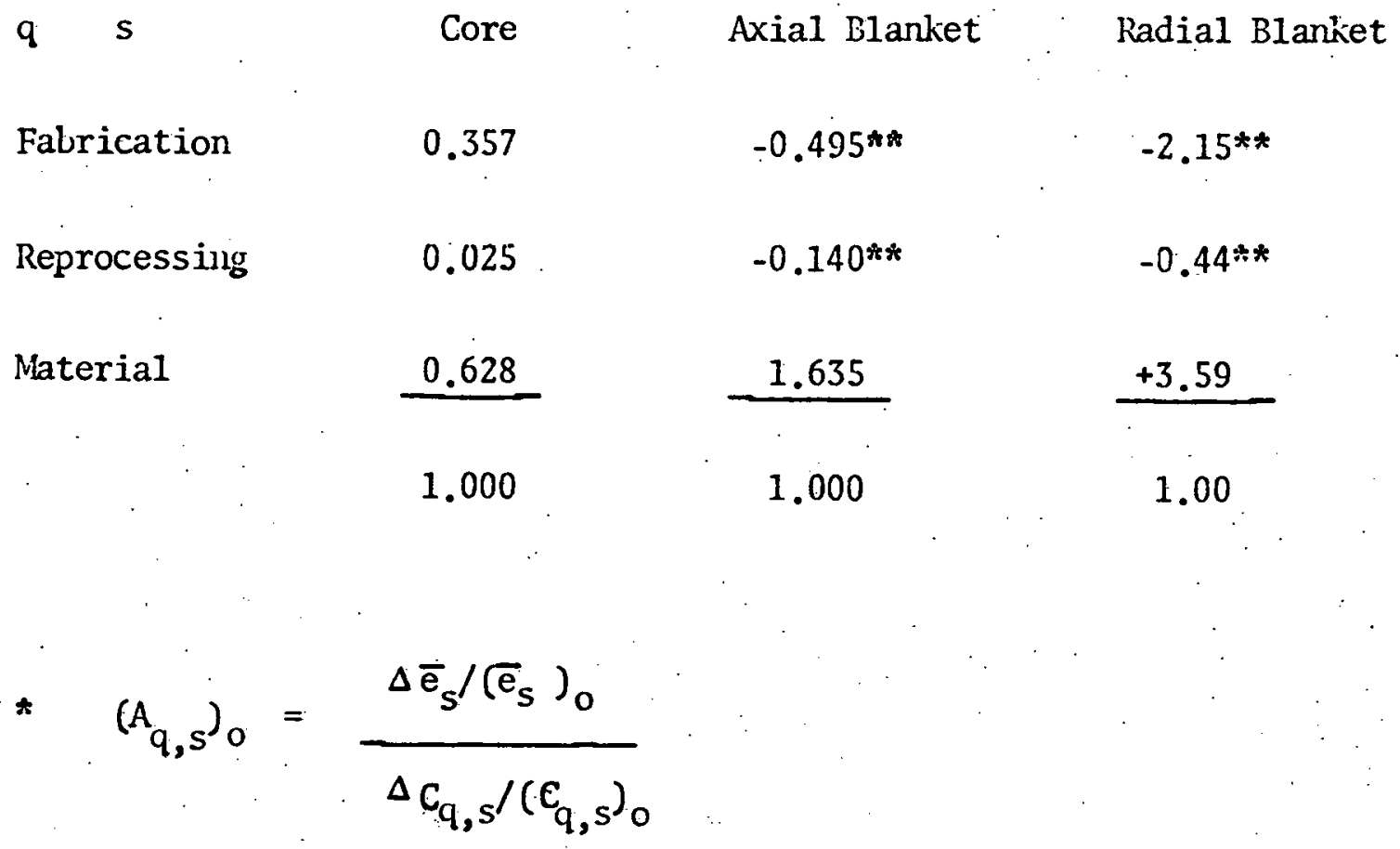
** These terns are negative because the $\left(\overline{\mathrm{e}}_{\mathrm{s}}\right)_{0}$ for the blankets
are negative. 
Figures $1.2,1.3$ and 1.4 , showed that $\left(\bar{e}_{\mathrm{RB}}\right)_{\text {Topt }}$ is practically linear in $C_{\mathrm{ab}}, \mathrm{C}_{\text {repr }}$, and $\mathrm{C}_{\mathrm{fiss}}$ over the expected ranges of these parameters. Thus, Equations (1-15) and (1-16) are applicable to the radial blanket near reference economic conditions.

Figures 1.2, 1.3, and 1.4 also show that Topt is approximately linear in $C_{\text {fab }}, C_{\text {repr }}$, and $C_{\text {fiss }}$, and that Topt decreases with improvement in the radial blanket's economic environment.

Figure 1.5 shows the regional (core, axial blanket, and radial blanket) and total fuel costs as functions of fissile plutonium value. Several features are noted:

(a) Due to the core fissile inventory component, the total reactor fuel energy cost, $\bar{e}_{\text {reactor }}$, increases with $C_{\text {fiss }}$ despite the fact that the reactor produces more fissile plutonium than it consumes.

(b) The axial blanket is more profitable than the radial blanket, because the axial blanket sees more neutrons in this particular, but typical, design $(\mathrm{H} / \mathrm{D}=0.4)$.

(c) The axial blanket breakeven point occurs at about $3.9 \$ / \mathrm{gm}$.

(d) The radial blanket breakeven point occurs at about $7.25 \$$ gm.

(e) As fissile price increases, the blankets become more viable, substantially offsetting the higher core inventory costs.

It is unlikely that the disparity between axial blanket profit and radial blanket profit would be dininished significantly by reasonable changes in the thickness or composition of either blanket. The axial blanket advantage is largely inherent: the axial blanket enjoys a higher flux, and higher fissile generation rate per unit of heavy metal loaded, and a short optimum irradiation time close to that set by the core burnup limit, ( 2 years). Hence axial blanket fissile credit is not threatened by overwhelriing processing and naterial carrying charges. 


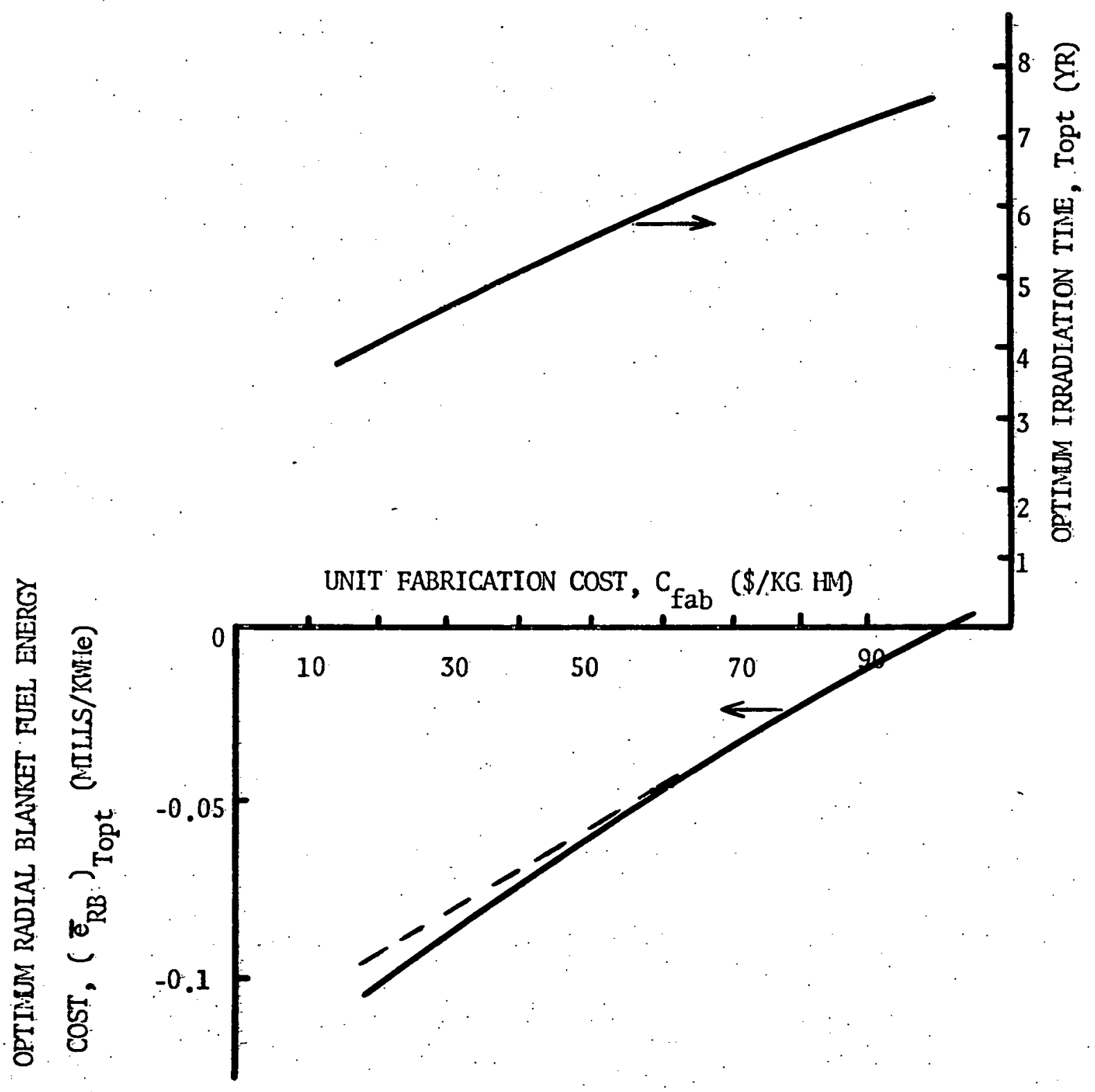

FIG. 1.2 SENSITIVITY OF OPTIMUM RADIAL BLANKET FUEL ENERGY COST TO UNIT FABRICATION COST 


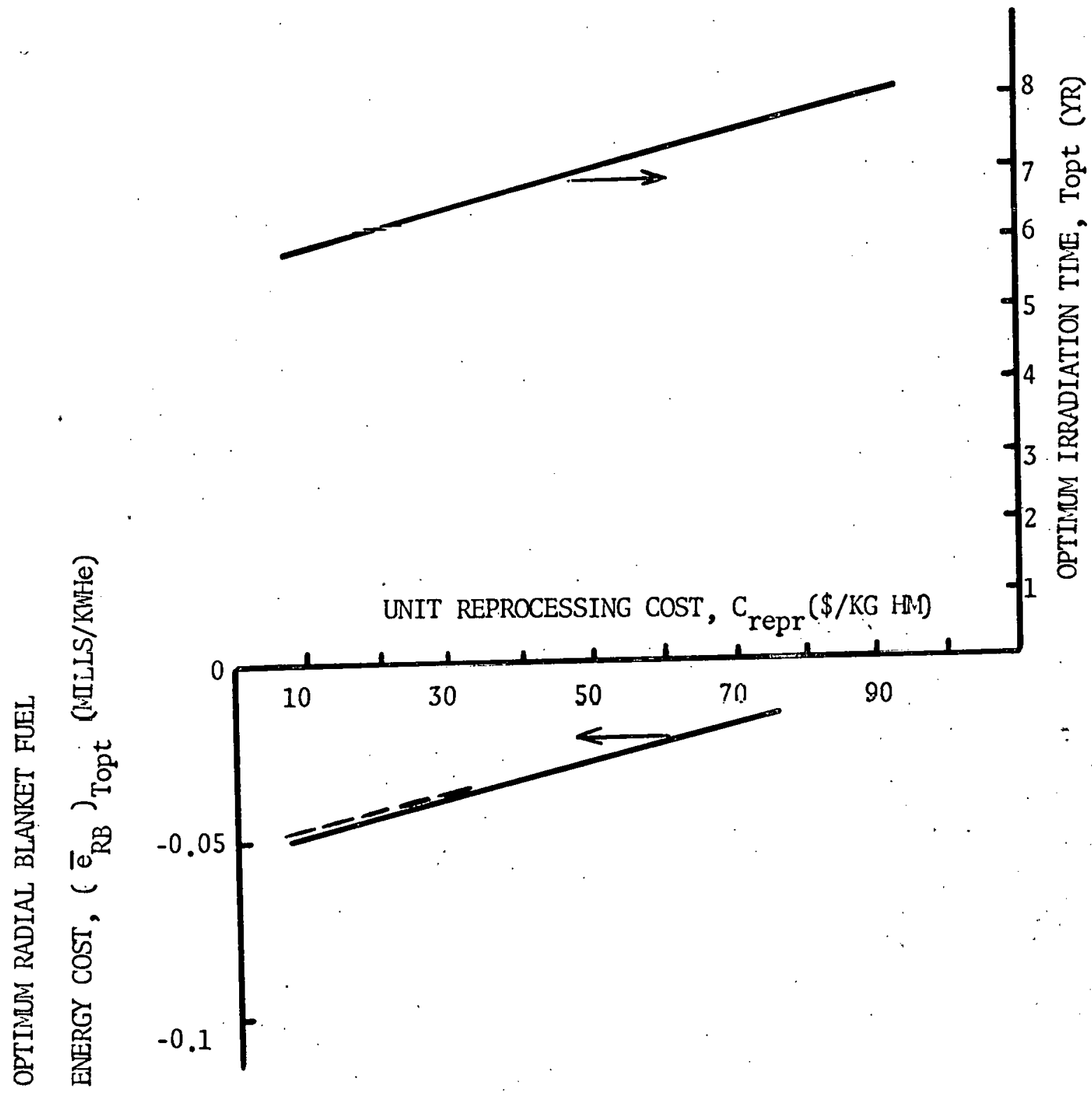

FIG. 1.3 SENSITIVITY OF OPTIMM RADIAL BLANKET FUEL ENERGY COST TO UNIT REPROCESSING COST 


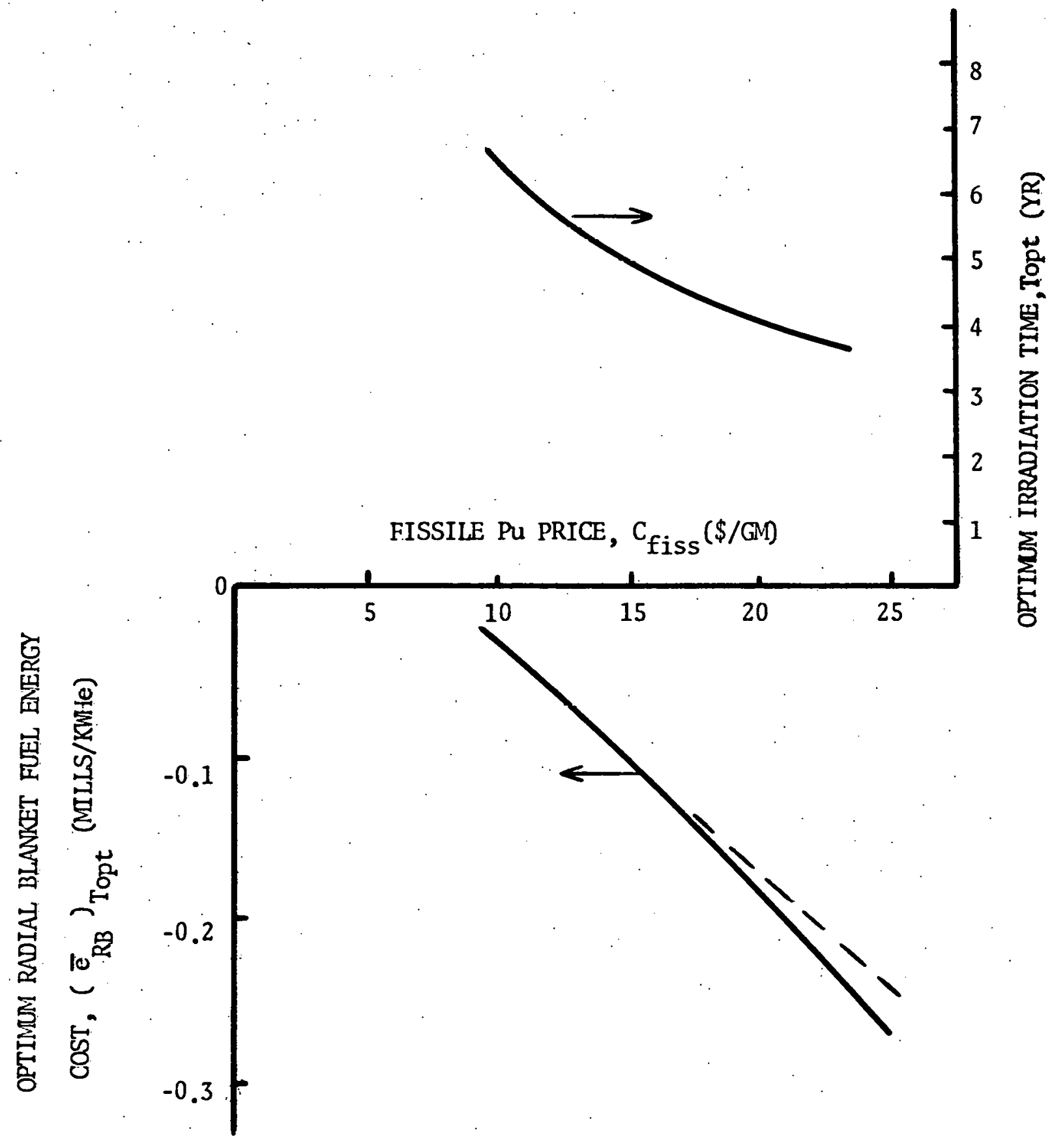

FIG. 1.4 SENSITIVITY OF OPTIRMM RADIAL BLANKET FUEL ENERGY COST TO FISSILL PLUTONIUM PRICE 


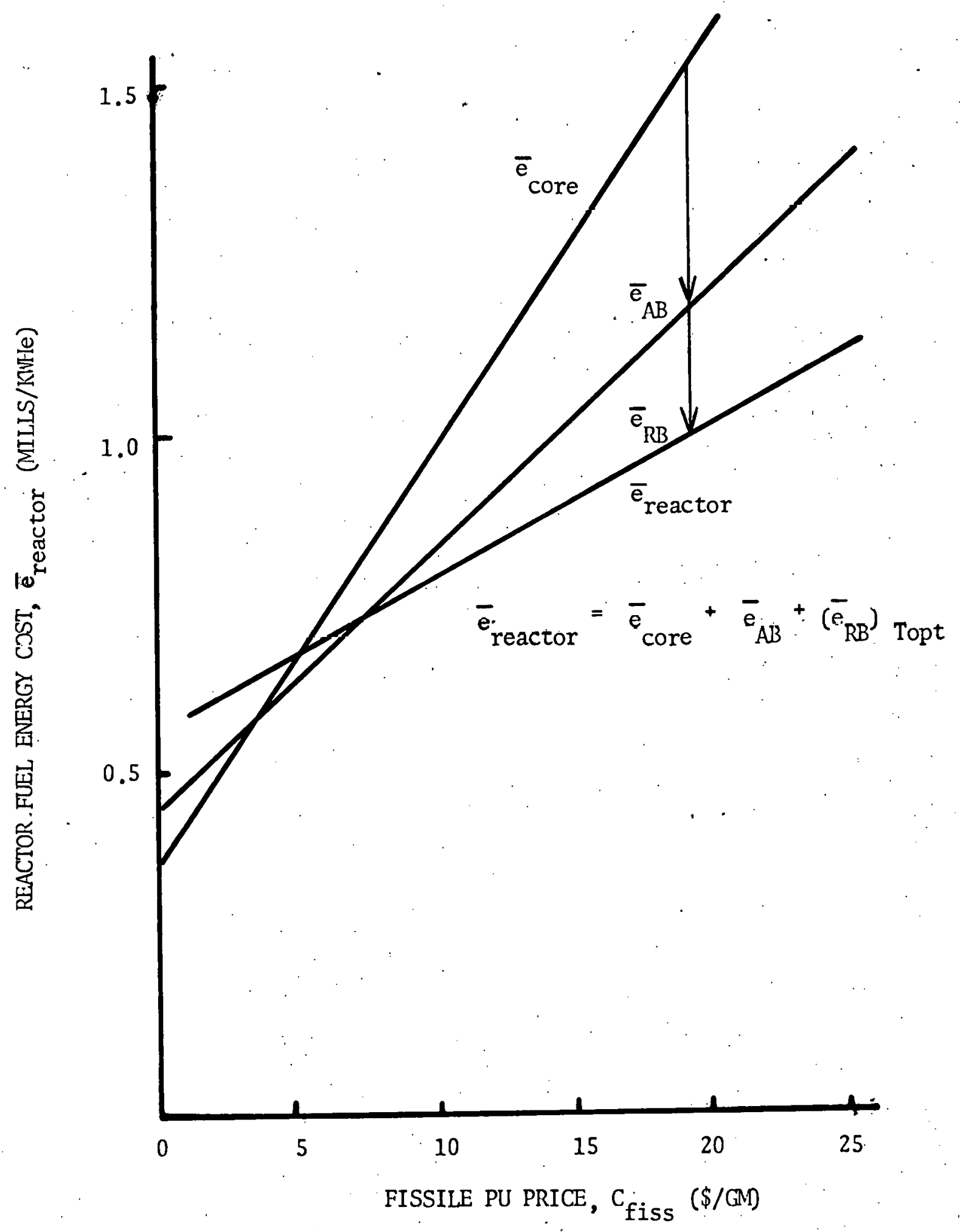

FIG. 1.5 EFFECT OF FISSILE PU PRICE ON TOTAL REACTOR FUEL ENERGY COST 


\subsubsection{Reactor Size and Blanket Fuel Economics}

A semiquantitative scoping study was performed to examine the effect of reactor unit rating on the economic viability of blankets. As core size increases (holding core shape fixed), core fuel economics improve due to the decreased critical enrichment and increased internal breeding ratio. At the same time, core surface-to-volume ratio and external breeding ratio diminish, and blanket fuel economics degenerate.

All of the major assumptions in this preliminary study penalized the blanket. A spherical core was assuned throughout the range of core size, that is, core geometry spoiling to maintain negative sodium void coefficients was not accounted for. A one-zone core was assumed, whereas a graded enrichment scheme would have enhanced blanket economics. The increased control requirements, and associated costs, involved in increasing the internal breeding ratio much above unity, ivere ignored.

Figure 1.0 shows that in spite of these (and other) penalties, the blanket concept is economically preferable to a non-breeding reflector (Na) for reactor ratings well over $1000 \mathrm{Mve}$. Beyond the "indifference point", the advantage of the "no-blanket" configuration is only very slight. Thus, it is likely that blanketswill remain an important part of LMFBR design for the foreseeable future.

\subsection{CONCLUSIONS AND RECONENDATIONS}

The most significant findings and recommendations are summarized in the following paragraphs.

Choice of fuel cost accounting method has a significant effect on absolute values of energy costs (mills/KWHe), but does not distort comparative and increnental results, design rankings, optimization of fuel residence times, etc. Choice of taxing method can, however, affect the 


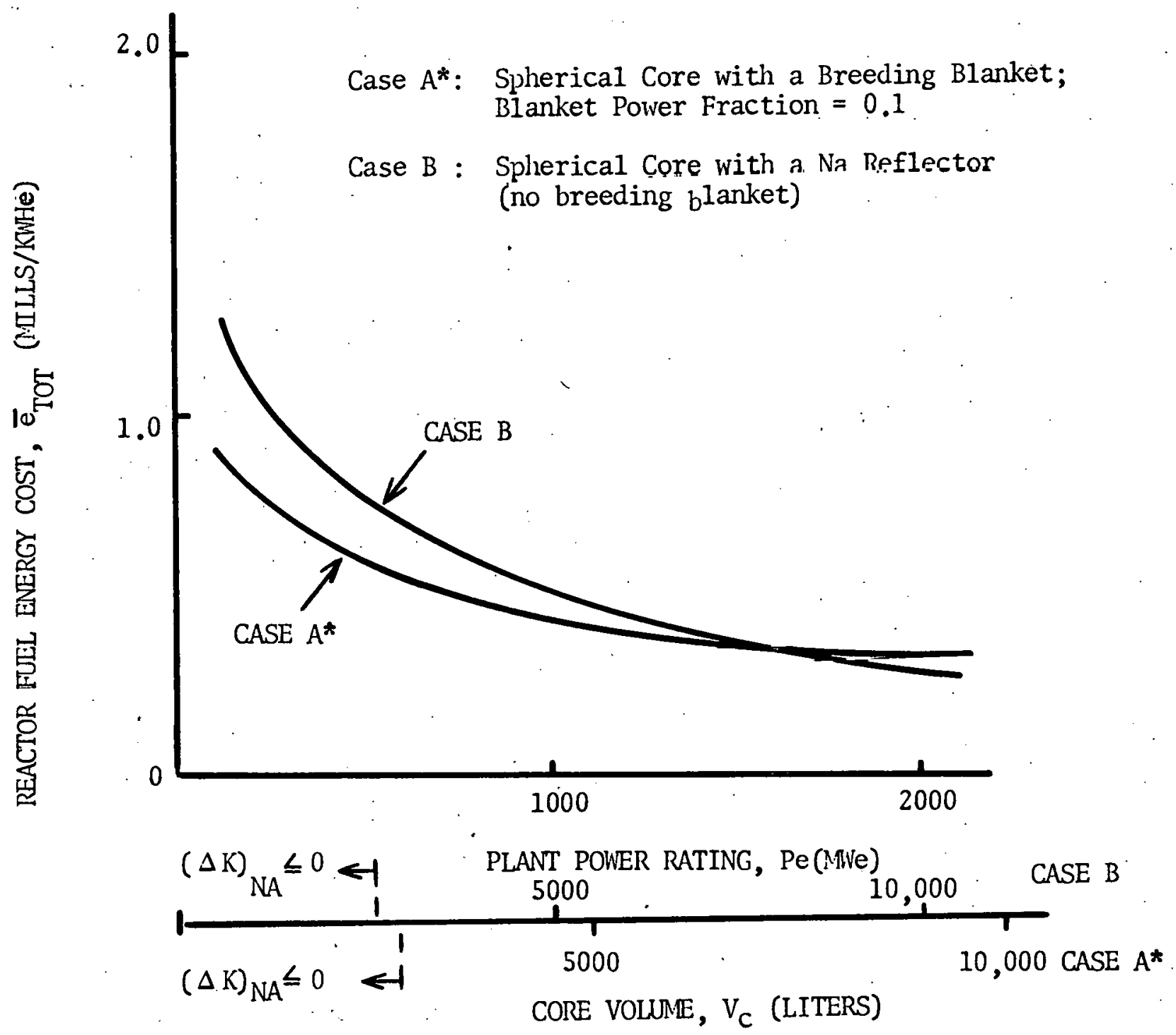

FIG. 1.6 REACTOR FUEL ENERGY COSTS WITH AND WITHOUT A BREEDING BLANKET 
optimized thickness of blankets.

A single multigroup physics computation, to obtain the flux shape and local spectra for depletion calculations, is sufficient for evaluating blanket/reflector design changes and for scoping and sensitivity studies. The major source of error in depletion results is the assumption of constant local flux over an irradiation cycle.

Choice of radial reflector material is important for radial blankcts of one or two rows of subassemblies $(15-30 \mathrm{~cm})$. The relative advantage of a moderating reflector increases as the reflector is moved nearer the high flux zones of the blanket, that is, as the blanket thickness decreases from three $(45 \mathrm{~cm})$ rows to two $(30 \mathrm{~cm})$ tows to one $(15 \mathrm{~cm})$ row of subassemblies.

Radial blanket thickness optimization is weak, i.e. net blanket revenue does not display a sharp peak as radial blanket thickness is reduced from three rows to two rows to one row. Significant improvement ( $\sim 30 \%$ increase in net blanket revenue) results from irradiating each radial blanket region to its own, local optimun irradiation time.

Both the optimum radial blanket irradiation time and the corresponding radial blanket net revenue are approximately linear functions of the unit costs in dollars per kilogram for fabrication, reprocessing, and fissile material. For increased fissile costs, both blankets (axial and radial) become more inportant in offsetting the increased core fissile inventory costs.

Based on a simple examination of reactor size versus blanket fuel economics, blankets are expected to remain an important part of LMFER design for the foreseeable future. 
Fast breeder reactor blanket design and fuel management has not received attention, in the open literature, commensurate with its inportance. Design and fuel management study results tend to be highly specialized and fragmentary, making normalizations and comparisons difficult. A comparative evaluation of scatter, batch, out-in, and in-out equilibrium radial blanket fucl llallagement schemes, for a fixed reactor configuration, is recoimended.

The flexibility of radial blanket fuel management, after the reactor is in operation, presents the opportunity of optimizing reload strategies in accordance with the current and projected economic environments. Further effort in this area is recommended.

Interactions between engineering design and fuel management parameters should be examined with the aim of better understanding and characterizing the blanket. Radial blanket fuel management directly influences the degree of power flattening across the blanket, the power swing over an irradiation cycle, and the core-blanket power split. The associated economic trade offs are not well understood. In particular, an analysis of the benefits and penalties of blanket fissile seeding is recomended. In brief, the most important recommendation is that, whatever aspects of blanket fuel management are subjected to further scrutiny, this be done on a more global basis, at the minimum taking into consideration the strong interaction of management schemes and the flow orificing pattern adopted.

Since unit sizes are project ed to increase to 2000 MWe and beyond after the year 2000, a more thorough parametric study of bianket performance versus reactor rating is recommended. 


\section{CHAPIER 2}

FUEL COST ANALYSIS METHOD

\subsection{INTRODUCTION}

\subsubsection{Objectives of the Chapter}

The purpose of this chapter is to establish a fuel cost analysis method, for fast breeder reactors, capable of

(a) ranking major technological alternatives, e.g. choice of blanket and reflector materials,

(b) optimizing certain design and fuel management variables, e.g. optimum blanket thickness, optimm blanket irradiation time(s), and

(c) determining the sensitivity of fuel cost to changes in the economic environment, e.g. changes in unit fabrication and reprocessing costs, sale value of fissile nuclides, and cost of money parameters.

A secondary purpose of the chapter is to compare alternative fuel cost accounting methods. While alternative methods frequently yield significantly different absolute values of power costs in mills/KWHe, choice of accounting method should not distort the ranking of design alternatives, the values of optimized parameters nor the results of the sensitivity studies.

\subsubsection{Background: Utility Company Economics}

In non-regulated industries, the objective function used in measuring performance is profit (to be maximized), i.e. the stockholders' return on investment. By contrast, the objective function in utility company economics is usually the cost of electricity to the customer (to be minimized), or price, since a ceiling is imposed on investors' rate of return by regulatory 
agencies. Hence, in utility economic analyses, investors' rate of return is treated as an expense to the customer, is fixed in the calculations, and the cost (price) of electricity to the customer must be such that the company's revenue from the sale of electricity balances all of its costs in generating and delivering that electricity, including payment of investors' principal and return, taxes, and direct expenses.

For purposes of selecting generating plant type, design studies, etc., the electricity generated by a given plant is normally burdened with the costs associated with that plant alone. For purposes of preparing financial statements and setting electricity rates, however, the costs of different plants are, of course, mixed.

Generation costs are normally divided into three categories: plant capitalization, fuel, and operating and maintenance costs. Only LMFBR fuel costs are considered in this report. Costs generated throughout the nuclear fuel cycle are ultimately transferred to the utility company, burdened to the production of electricity, and borne by the customer, along with the company's costs of capital associated with the fuel, in the form of a levelized price (cost) of electricity (mills/KWHe).

\subsubsection{Scope of the Cost Analysis Model}

Figure 2.1 illustrates the scope of the cost analysis model established for the present work. The model has the features and restrictions listed below.

1. The model is restricted to fuel costs. It excludes the other major cost categories;plant capitalization, and operating and maintenance.

2. The model treats costs associated with an individual plant or class of plant, i.e. LMFBR, in a given economic environment. Other concerns such as the mix of plant types (capacity planning),co.upling effects, 


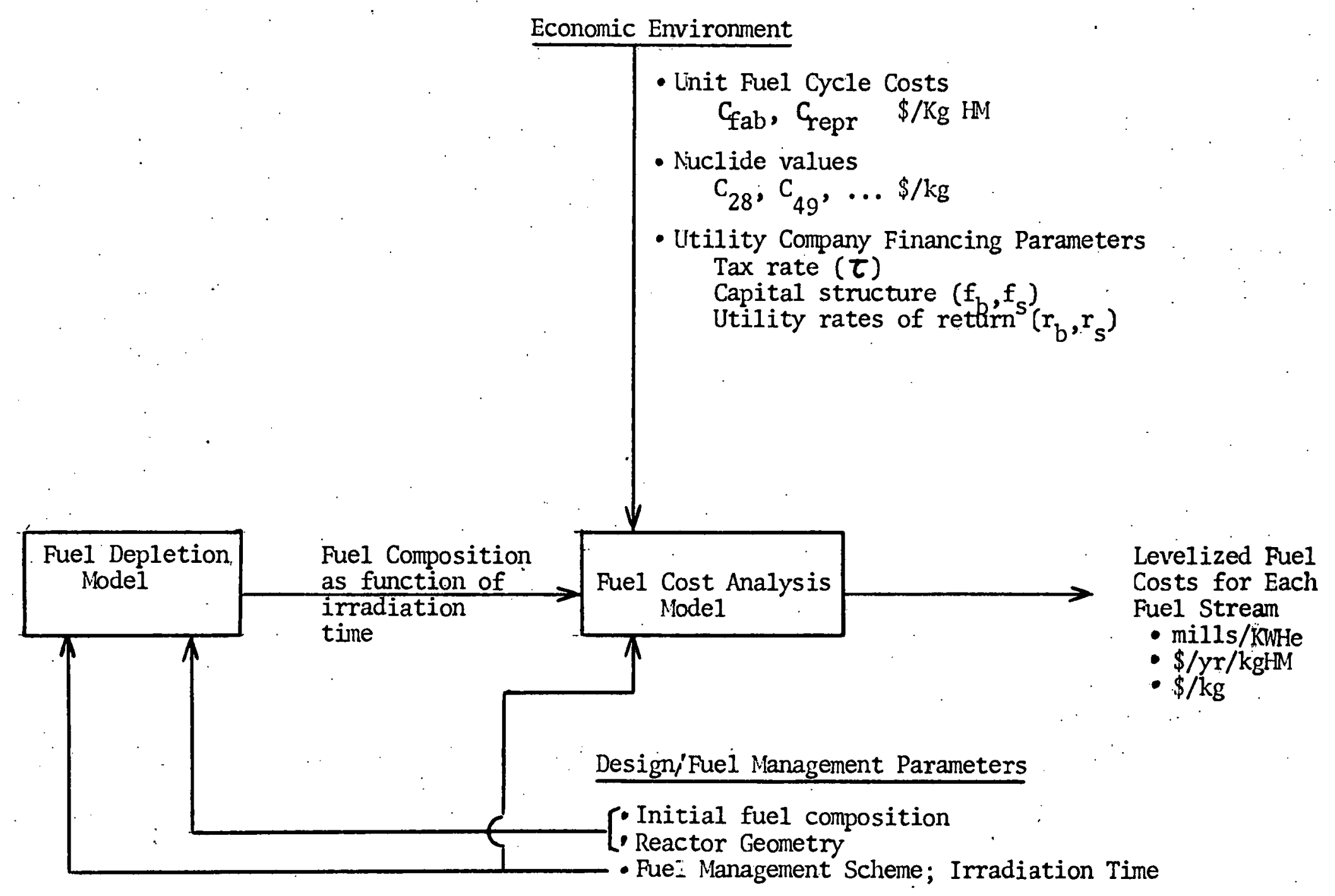

FIG. 2.1 SCOPE OF THE FBR FUEL COS 
generating schedules (dispatching) are not treated.

3. The "economic environment" is set, in parametric fashion, outside the cost analysis, and is assumed to be constant throughout plant life. The "economic environment" is defined here as the market value of fuel materials, prices of fuel cycle processing services, and the utility company's cost of money parameters. Such macroeconomic concerns as supplydemand effects in the market place (value of fissile isotopes), allocation of national resources, and effects of total processing industry throughput on processing prices, are not treated by the model.

4. As shown in Figure 2.1 , the cost analysis model requires irradiation-depletion data from a fuel depletion model. (Fuel depletion models for LMFBR's are discussed in Chapter 3.) Output of the cost analysis model includes the following:

* fuel component of electricity costs, in mills per kilowatt hour (electric), by major region, i.e. core, axial blanket, radial blanket; and

* local annual fuel costs, in units of dollars per year per kilogram of heavy metal loaded, by major region, subregion (an annulus of fue1), or at a point.

\subsubsection{Outline of the Chapter}

A general expression for the levelized cost of electricity is derived in Section 2.2. This formulation, labeled here as the "cash flow method" (CFM), is applicable to all categories of costs: plant capitalization, fuel, and operating and maintenance costs. The derivation presented in Section 2.2 follows that of Vondy (19), with the following exception: an option is included for taxing revenue from sources other than the sale of electricity. 
The CFM expression is applied to fast breeder reactor fuel costs in Section 2.4. Two methods for the tax treatment of post-irradiation transactions are derived.

In Section 2.4, the CFM expressions are specialized for fixed-fuel management schemes, in which fuel assumblies "see" only one irradiation position. A figure of merit representing local fuel economic performance (\$/year/local $\mathrm{kg}$ heavy metal) is derived.

In Section 2.5, several fuel cost accounting methods are compared. The effect of post-irradiation tax assumptions is shown. The cash flow method (CFM) is related to and numerically compared with two other methods: the sinple-interest method (SIM) and the compound interest method (CIM) .

A sample CFM calculation is present in Section 2.6. Major features of the blanket fuel cost vs. irradiation time characteristic are shown, i.e. the breakeven point and the optimum irradiation time.

\subsection{DERIVATION OF A GENERAL EXPRESSION FOR THE LEVELIZED COST OF ELECTRI - CITY (CASH FLOW METHOD)}

A general expression for the levelized cost of electricity, $\bar{e}(\operatorname{mills} / \mathrm{KWHe})$ applicable to plant capitalization costs, fuel costs and operating and maintenance costs - is derived in this section. The general expression is applied to FBR fuel costs in Section 2.3.

An electric utility company interacts financially with

* customers (electricity revenue, $\overline{\mathrm{e}} \mathrm{E}_{j}$ );

* capital equipment suppliers (capitalized costs, $z_{j}$ );

* fuel suppliers, fabricators, reprocessors (capitalized costs $z_{j}$, expensed costs, $o_{j}$ )

* federal, state and local governments (income $\operatorname{tax}, \mathrm{T}_{\mathrm{j}}$, property $\left.\operatorname{tax}, \pi_{j}\right)$ 
* investors, including stockholders (owners) and bondholders $\left(Y_{j}\right)$

* and others.

Nomenclature is given in Appendix A.

Figure 2.2 illustrates the detailed accounting treatment of utility company cash flows in year $j$.

Book value (liability to investors) at the end of year $j$ is the book value, $Y_{j}$, in effect during year $j$ plus any new capitalization which occured during year $j$. Residual revenue for year $j$ (revenue after taxes, current expenses, and return to investors have been subtracted), $R_{j}$, is applied against end-of-year book value to obtain the book value in effect for the following year, $j+1$, i.e.

$$
Y_{j+1}=Y_{j}-R_{j}+Z_{j}
$$

Residual revenue, $R_{j}$, is a function of the levelized price (cost) of electricity, $\bar{e}$. Application of the boundary conditions

$$
Y_{1}=Z_{0}
$$

and

$$
\mathrm{Y}_{\mathrm{N}+1}=0
$$

to equation (2-1) yields an expression for $\bar{e}$, as is shown below.

Residual revenue, $R_{j}$, is given by

$$
\begin{aligned}
R_{j} & =\text { (taxable revenue }+ \text { non-taxable revenue) } \\
& - \text { (current expenses) } \\
& - \text { (investors return) } \\
& -(\text { income tax) } \\
& =\text { eE }_{j}+V_{j}+v_{j}^{\prime} \\
& -0_{j}-\left(r_{b} f_{b} Y_{j}+r_{s} f_{s} Y_{j}\right)-T_{j}
\end{aligned}
$$




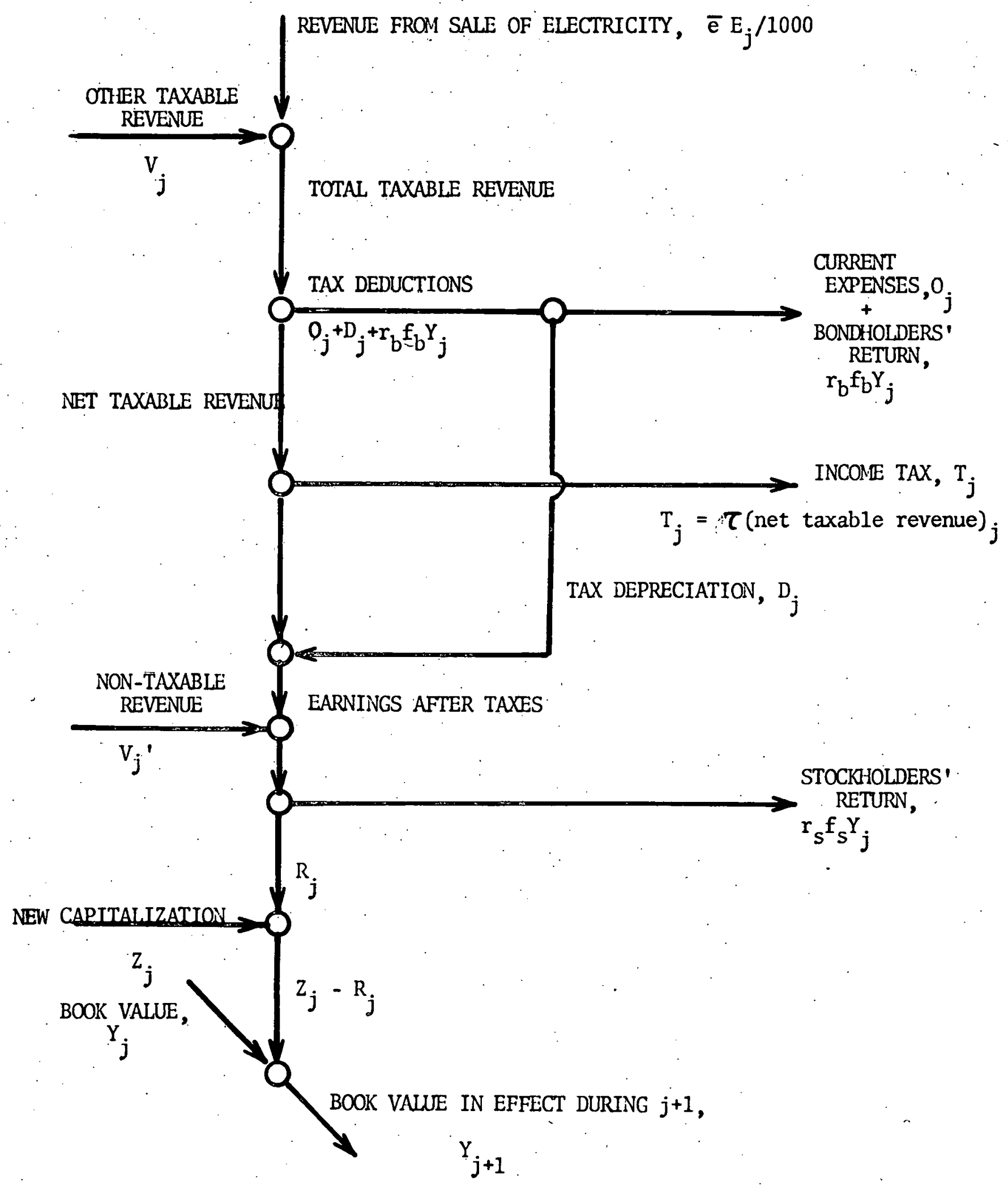

FIG. 2.2 UTILITY CO:PANY CASH FLON ACCOUNTING 
65

Income tax, $T_{j}$, is computed by applying an income tax rate $(T)$ to the net taxable revenues, i.e.

$$
\begin{aligned}
\mathrm{T}_{j} & =\tau[\text { net taxable revenues, } \mathrm{j}] \\
& =\tau\left[(\text { taxable revenue })_{j}-(\text { tax deductions })_{j}\right]
\end{aligned}
$$

Taxable revenue is given by

$$
(\text { taxable revenue })_{j}=\frac{\overline{\mathbf{A}} \mathrm{E}_{j}}{1000}+v_{j}
$$

The second term $v_{j}$ (taxable revenue from sources other than the sale of electricity) is included for flexibility and generality.

Allowed tax deductions are:

current (non-capitalized) costs, $\mathrm{O}_{\mathbf{j}}$;

return on debt capital (bonds), $\Upsilon_{b} f_{b} Y_{j}$; and

depreciation of capitalized costs, $D_{j}$ :

$$
\text { (tax deductable expenses) }_{j}=0_{j}+r_{b} f_{b} Y_{j}+D_{j} \text {. }
$$

Thus income tax for year $j$ is given by

$$
T_{j}=\tau\left[\frac{\bar{e} E_{j}}{1000}+v_{j}-o_{j}-r_{b} f_{b} Y_{j}-D_{j}\right]
$$

Substituting Equation $(2-8)$ into Equation $(2-4)$ for $T_{j}$, one obtains

$$
\begin{aligned}
R_{j} & =\frac{\bar{e} E_{j}}{1000}+v_{j}+v_{j}^{\prime}-O_{j}-r_{b} f_{b} Y_{j}-r_{s} f_{s} Y_{j} \\
& -\tau\left[\frac{\bar{e} E_{j}}{1000}+v_{j}-O_{j}-r_{b} f_{b} Y_{j}-D_{j}\right] \\
& =(1-\tau)\left[\frac{\bar{e} E_{j}}{1000}+V_{j}-0_{j}\right]+\tau D_{j} \\
& -\left[(1-\tau) r_{b} f_{b}+r_{s} f_{s}\right] Y_{j}+V_{j}^{\prime}
\end{aligned}
$$


The residual revenue $R_{j}$ is available to pay back the bondholders' and stockholders' principal, as shown in (2-1), and may be thought of as a book depreciation payment. Substituting Equation (2-9) into Equation (2-1) for $R_{j}$,

$$
\begin{aligned}
Y_{j+1} & =Y_{j}+z_{j}-(1-\bar{t})\left[\frac{\bar{e} E_{j}}{1000}+v_{j}-O_{j}\right] \\
& +\tau D_{j}+V_{j}^{\prime}-\left[(1-\tau) r_{b} f_{b}+r_{s} f_{s}\right] Y_{j}
\end{aligned}
$$

Defining

$$
A_{j}=z_{j}-(1-\tau)\left[\frac{\bar{e} E_{j}}{1000}+V_{j}-O_{j}\right]-\tau D_{j}+V_{j}^{\prime}
$$

and collecting terms on $Y_{j}$, one obtains

$$
Y_{j+1}=\left[1+(1-\tau) r_{b} f_{b}+r_{s} f_{s}\right] Y_{j}+A_{j}
$$

Defining

$$
x \equiv \quad(1-\tau) r_{b} f_{b}+r_{s} f_{s},
$$

Equation (2-12) becomes

$$
Y_{j+1}=(1+x) Y_{j}+A_{j}
$$

The quantity $x$ defined in Equation (2-13) will presently be identified as the appropriate discount rate for present value calculations.

The recursive relation $(2-14)$, together with the boundary conditions $(2-2),(2-3)$ and the definition of $A_{j}$, Equation $(2-11)$, leads to a closed form expression for levelized price of electricity, E. Equation (2-14) is applied repeatedly, as follows, subject to the boundary conditions:

$$
Y_{1}=Z_{0}=A_{0}
$$




$$
\begin{aligned}
& Y_{2}=(1+x) Y_{1}+A_{1}=(1+x) A_{0}+\dot{A}_{1} \\
& \dot{Y}_{3}=\quad(1+x)^{2} A_{0}+(1+x) A_{1}+A_{2} \\
& Y_{i}=\sum_{j=0}^{i-1}(1+x)^{i-1-j} A_{j} \\
& Y_{N+1}=\sum_{j=0}^{N}(1+x)^{N-j} A_{j}=0 \\
& =(1+x)^{N} \quad \sum_{j=0}^{N}(1+x)^{-j} A_{j}=0
\end{aligned}
$$

Substituting Equation (2-11) for $A_{j}$ into Equation $(2-15)$, and solving for $\overline{\mathbf{e}}$,

$$
\bar{e}=1000 \frac{\sum_{j=0}^{N}(1+x)^{-j}\left[\frac{Z_{j}}{\Gamma-\tau}-\frac{V_{j}}{\Gamma-\tau}-\frac{\tau}{I-\tau} D_{j}-V_{j}+0_{j}\right]}{\sum_{j=0}^{N}(1+x)^{-j} E_{j}} .
$$

The factor $(1+x)^{-j}$ is seen to be the "discount factor", or "present value factor",

$$
w(j)=(1+x)^{-j}
$$

and $x$, defined by

$$
x=(1-\tau) r_{b} f_{b}+r_{s} f_{s}
$$

is identified as the "discount rate". 
The derivation above assumes that the capital structure $\left(f_{b}, f_{s}\right)$ and rates of return $\left(r_{b}, r_{s}\right)$ are fixed.

The cash flow approach used in deriving Equation (2-16) has many advantages. First; Equation $(2-16)$ is exact; that is, it avoids the tax iteration of methods which treat income taxes as costs to be present-valued separately. In the cash flow method derived above, allowance for income taxes is implicit in the coefficients of the present values $(1 / 1-\tau, \tau / 1-\tau$, 1) and in the discount rate.

Another advantage is that vagaries in the interpretation of the discount rate are circumvented. The discount rate is defined within the cash flow derivation above. It may be calculated once the tax rate $(\tau)$, capital structure $\left(f_{b}, \dot{f}_{s}\right)$, and debt and equity rates of return $\left(r_{b}, r_{s}\right)$ are set.

Further, the cash flow method (CFM) is flexible. A broad range of financial conventions may be accommodated within the CFM structure. Whether to "capitalize" ( $\left(\mathrm{V}, \mathrm{V}^{\prime}\right)$ or "expense" $(0, \mathrm{~V})$ a given transaction is the user's decision, subject to IRS and state regulations. Equation (2-16) specifies how these transactions are treated. Different classes of transactions must be treated in different ways, when taxes are present, and the CFM specifies how.

Finally, in other methods (20) two depreciation schedules sometimes appear (depreciation for tax purposes, and depreciation for computing investors' return), leading to confusion. In the CFM described above, depreciation enters the calculation only in the tax computation. The depreciation of investors principal is set by the assumption that residual revenue $R_{j}$ is applied toward paying back this principal. This restriction imposes a standard convention, of sorts, but permits alternative designs to be evaluated on a standard basis, free of accounting artifices. 


\subsection{APPLICATION TO FBR FUEL COSTS}

A general expression for the levelized cost of electricity, Equation (2-16), was developed in Section 2.3. In the present section, that formulation is specialized to treat FBR fuel costs.

\subsubsection{Separation of Costs}

For convenience and flexibility, one wishes the costs to be as separ. able and additive as possible. They are made additive, in this report, by burdening the total reactor energy with each cost item individually, as opposed to charging the energy released by a single fuel stream with costs associated with that stream.

The reactor fuel costs are separated, or classified, as follows:

(a) by fuel stream. A fuel stream is a distinct sequence of fuel lots which sees one (batch or scatter management) or more (e.g. in-out, out-in management, etc.) positions in the reactor. A fuel stream can normally be identified with a major region (core, axial blanket, or radial blanket), and may be characterized by features such as pin diameter, initial isotope composition, etc.

(b) by component, for each stream. Each fuel lot of each stream incurs certain "component" costs as it proceeds through the fuel cycle, i.e. material purchase, fabrication, reprocessing, and material credit.

(c) as direct costs or carrying charges: Each component of each stream includes direct and carrying charge subcomponents. Thus there are eight (8) cost items per fuel stream.

If $S$ is the number of fuel streams, there are SX8 separate cost items in mills/KWHe which may be added directly to obtain total reactor fuel cost. These cost items may be regrouped as desired to assist technological economic insight, to make results comparable with other studies, etc. 
For example, direct material purchase and direct material credit may be combined to form "burnup" cost. Their carrying charges may be combined to form "inventory" cost.

\subsubsection{Application to FBR Ruel Costs}

The cost expressions associated with an arbitrary fuel stream are developed below. Total reactor fuel cost may be found by summing the costs of the individual streams, provided the denominator of Equation (2-16), discounted total plant electricity, is retained in each of the stream equations. For the moment, attention is focused on the numerator:

For an arbitrary fuel stream, the numerator of Equation (2-16) may be expressed as a sum over the fuel lots $(m)$ rather than over years $(j)$ :

$$
\begin{aligned}
& \text { (numerator) }=\sum_{j=0}^{N} w(j) \quad\left[\begin{array}{lll}
z_{j} & -\frac{V_{j}}{1-\tau} & 1-\tau
\end{array}-\frac{\tau}{1-\tau} D_{j}-v_{j}-0_{j}\right] \\
& =\sum_{m=1}^{n}\left\{\frac{m}{1-\tau} w\left(t_{m}^{2}\right)-\frac{v_{m}^{\prime}}{1-\tau} w\left(t_{m, k}^{v^{\prime}}\right)\right. \\
& -\frac{\tau}{1-\tau} \sum_{k}\left(D_{m}\right)_{k} w\left(t_{m, k}^{D}\right) \\
& -v_{m} w\left(t_{m}^{V}\right)+{ }^{\circ} o_{m} w\left(t_{m}^{0}\right)
\end{aligned}
$$

where the t's are the times, in years, from beginning of plant life to the indicated transactions. 
For each fuel lot $\mathrm{m}$, four direct cash flows are identified, as shown in Figure 2.3:

$$
\begin{aligned}
& \text { material purchase, } \underset{m}{\mathrm{mp}} ; \\
& \text { fabrication cost, } \mathbf{z}_{\mathrm{m}}^{\mathrm{fab}} ; \\
& \text { reprocessing cost, } \underset{\mathrm{m}}{\mathrm{repr}} ; \text { and } \\
& \text { material credit, } \mathbf{- z}_{\mathrm{m}}^{\mathrm{mc}}
\end{aligned}
$$

Each of these transactions is to be assigned to one of the classes of transactions appearing in Equation (2-16) and Equation $(2-18)$.

These classes of transactions and two methods of assigning the lot's costs to them are summarized in Table 2.1. In both methods, the preirradiation transactions (material purchase and fabrication) are capitalized. Method A treats post-irradiation transactions as non-capitalized; that is, revenue from the sale of valuable isotopes is taxed as ordinary income, along with revenue from the sale of electricity, and reprocessing cost is written off as a tax deductable expense in the year that it occurs. Nethod B capitalizes the post-irradiation transactions.

Method B is strictly applicable, or at least conceptually correct, in cases of depreciating fuel, such as thermal reactor fuel, which experiences no not fissile gain during irradiation. For depreciating fuel,

$$
D=\left(z_{m}^{f a b}+z_{m}^{m p}\right)-\left(z_{m}^{m c}-z_{m}^{r e p r}\right)>0
$$

and the interpretation of the tax depreciation credit, $\tau \mathrm{D} /(1-\tau)$, is clear and correct. On the other hand, if fuel appreciates, as in a fast. breeder reactor blanket,

$$
D<0,
$$




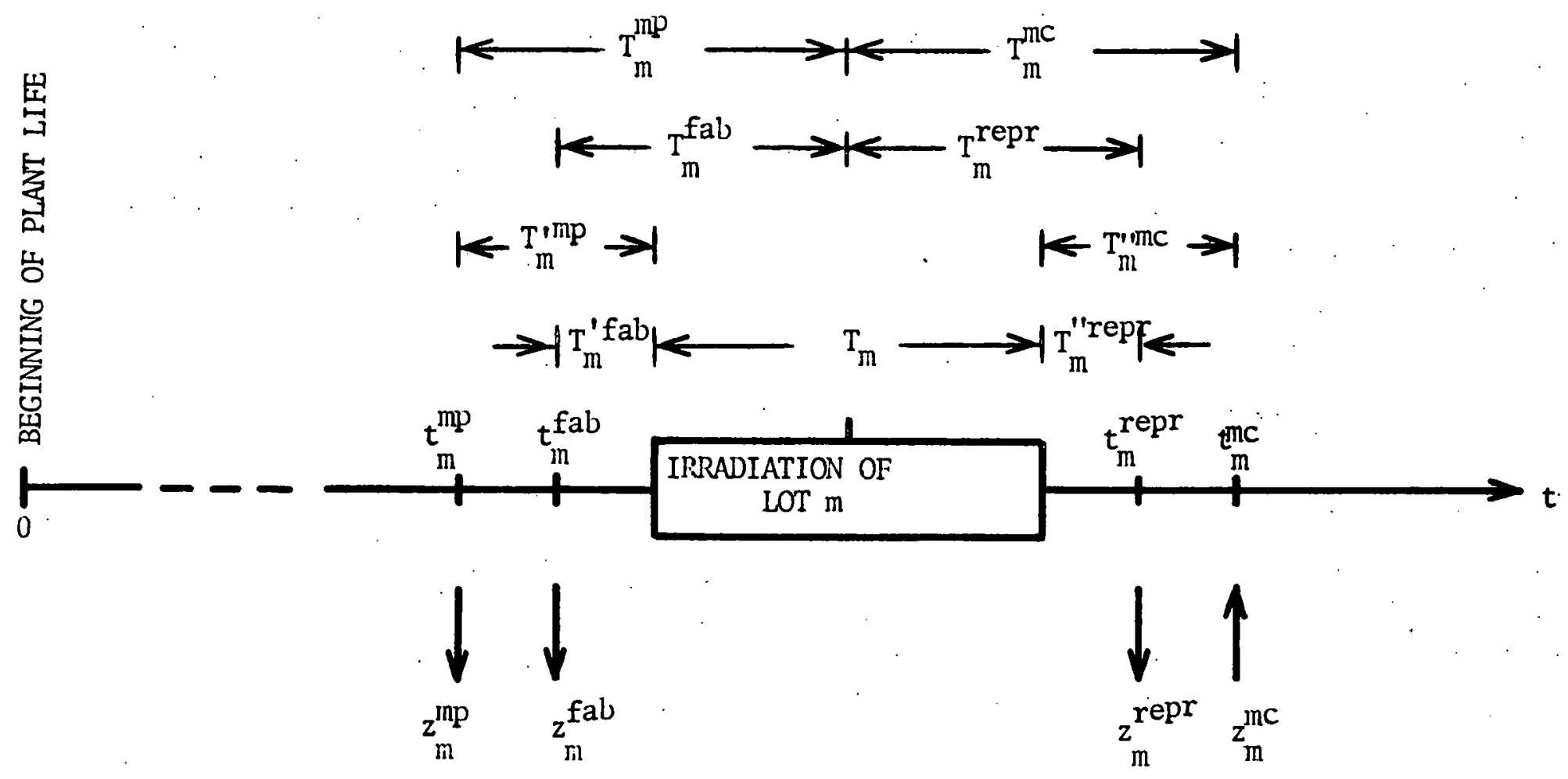

FIG. 2.3 TIMING OF CASH FLOWS ASSOCIATED WITH A FUEL LOT 
TABLE 2.1 TAX TREAT ENT OF FUEL TRANSACTIONS

Trans -

action

Type

Description

$\operatorname{Tax}$

Factur

ifethod

3ethod

A

B

Z

capitalized cost

$1 / 1-\tau$

material

purchase;

fabrication

material pur -

chase; fabrication; re-

processing

0

expensed cost

1

reprocessing

$v^{\prime}$

capitalized (non-tax- $1 / 1-\tau$ able) revenue from sources other than sale of electricity

material credit

V

non-capitalized (taxable) revenue

1 from sources other than sale of electricity

i
depreciation for
$\tau / 1-\tau$ tious; for each Z-
type cost, there nust appear a de- preciation term

material

purchase and

material

credit fabrication
(material purchase and fabrication) - (material credit -re- processing)


and the tax depreciation credit reverses sign. This would imply a "tax appreciation debit", an entity not recognized in accounting nor allowed by taxing authorities. There is no symmetry with regard to tax depreciation: appreciation is not the opposite, or mirror image, of depreciation, for tax purposes.

Tax regulations require that ordinary income - that from the sale of the firm's ordinary product - be taxed at the corporate rate, $\tau$, at the time that the income is realized (product exchanged for cash). Other regulations and rates cover extraordinary income, capital gains, losses, etc. The "ordinary" product of electric utility companies is electricity. It is conceivable that fissile material could become another ordinary product for utilities operating breeders, and that this new income will be taxed in the same manner as that from the sale of electricity.

How or whether this income is to be taxed, and the details of the fuel account structure, are beyond the scope of this report, and must await resolution by tax and regulatory agencies, or by common usage. Methods $A$ and B are compared in Section 2.5. Choice of method has a significant effect on absolute values of levelized fuel cost, particularly in the radial blanket, but does not distort the economic ranking of design alternatives, nor does it significantly affect optimized parameters such as exposure. Method A was selected and used consistently in the case studies of Chapter 5.

\subsubsection{Method A}

Under Method A, Equation (2-18) becomes 


$$
\begin{aligned}
\text { (numerator) } & =\sum_{m}^{n}\left\{\frac{z_{m}^{m p}}{1-\tau} w\left(t_{m}^{m p}\right)+\frac{z_{m}^{f a b}}{1-\tau} w\left(t_{m}^{f a b}\right)\right. \\
& +z_{m}^{r e p r} w\left(t_{m}^{r e p r}\right)-z_{m}^{m c} w\left(t_{m}^{m c}\right) \\
& \left.-\frac{\tau}{1-\tau}\left(z_{m}^{m p}+z_{m}^{f a b}\right) \sum_{k}^{K} g_{k} w\left(t_{m}^{k}\right)\right\},
\end{aligned}
$$

where the inner summation is taken over the tax depreciation credits, $k$, for lot $\mathrm{m}$, and the $\mathrm{g}_{\mathrm{k}}$ are fractional coefficients determined by the tax depreciation schedule used.

Capitalized costs associated with the fuel lot $\mathrm{m}$ are amortized (depreciated for tax purposes) over the time the lot is in productive use, i.e. the time it spends in the reactor. Except for tax purposes, the depreciation schedule is immaterial: only the initial and discharge values of the fuel are relevant. Tax depreciation need not be consistent with the actual change of fuel value during irradiation since the IRS permits certain fictitious tax depreciation schedules. For consistency, simplicity, and because actual fuel value changes are practically linear, straight line depreciation of fuel is frequently used in utility accounting( $\underline{80}$.

With straight line tax depreciation, the tax depreciation term for lot $\mathrm{m}$ becomes

$$
\begin{aligned}
& \frac{\tau}{1-\tau}\left(z_{m}^{m p}+z_{m}^{f a b}\right) \sum_{k}^{K} g_{k} w\left(t_{m}^{k}\right) \\
& =\frac{\tau}{1-\tau} \frac{\left(z \text { mp }+z_{m}^{f a b}\right)}{K} \sum_{K}^{K} w\left(t_{m}^{k}\right) \\
& =\frac{\tau}{1-\tau} \frac{\left(z_{m}^{\dot{m} p}+z_{m}^{f a b}\right)}{K} w\left(t_{m}\right) \sum_{k}^{K} w\left(T_{m}^{k}\right) \text {, }
\end{aligned}
$$


where

$$
\begin{aligned}
& t_{\mathrm{m}} \equiv \begin{array}{l}
\text { time from beginning of plant life to midpoint of } \\
\text { irradiation of lot } \mathrm{m},
\end{array} \\
& \mathrm{T}_{\mathrm{m}}^{\mathrm{k}} \equiv \mathrm{t}_{\mathrm{m}}^{\mathrm{k}}-\mathrm{t}_{\mathrm{m}} \\
& \mathrm{t}_{\mathrm{m}}^{\mathrm{k}} \equiv \text { time of depreciation credit } \mathrm{k} .
\end{aligned}
$$

Little accuracy is lost if only one tax depreciation credit is assumed and it occurs at the irradiation midpoint. Table 2.2 illustrates the effect of this assumption for an irradiation time of five years. With this assumption, Equation (2-21) becomes

$$
\begin{aligned}
\text { (numerator) } & =\sum_{m}^{n}\left\{\frac{z_{m}^{m p}}{z_{1-\tau}^{m}} w\left(t_{m}^{m p}\right)+\frac{z_{m}^{f a b}}{1-\tau} w\left(t_{m}^{f a b}\right)\right. \\
& +z_{m}^{r e p r} w\left(t_{m}^{r e p r}\right)-z_{m}^{m c} w\left(t_{m}^{m c}\right) \\
& -\frac{\tau}{1-\tau}\left(z_{m}^{m p}+z_{m}^{f a b}\right) w\left(t_{m}\right) \mid
\end{aligned}
$$

Grouping the terms by component (mp, fab, repr, mc) and recalling Equation (2-16), the contribution of the fuel stream (e) to the total reactor fuel cost is given by

$$
\begin{aligned}
& \bar{e}=\bar{e}_{m p}+\bar{e}_{f a b}+\bar{e}_{r e p r}+\bar{e}_{m c} \\
& \bar{e}_{m q}=1000 \frac{\sum_{m}^{n} z_{m}^{m p}\left[\begin{array}{l}
w\left(t_{m}^{m p}\right) \\
\frac{1-\tau}{m}-\frac{\tau}{1-\tau} w\left(t_{m}\right)
\end{array}\right]}{\sum_{j}^{N} w(j) E_{j}}
\end{aligned}
$$


TABLE 2.2 EFFECT OF ASSUMING A SINGLE TAX DEPRECIATION CREDIT

$$
\begin{aligned}
& K=5 \\
& \text { "exact" } \\
& \mathrm{K}=1 \\
& \text { "approx." } \\
& \text { k } \quad \mathrm{T}_{\mathrm{m}}^{\mathrm{k}} \quad \mathrm{w}\left(\mathrm{T}_{\mathrm{m}}^{\mathrm{k}}\right) \\
& k \quad T_{m}^{k}(y r) \quad w\left(T_{m}^{k}\right) \\
& 1 \quad-2 \quad 1.1664 \\
& \begin{array}{lll}
2 & -1 & 1.08000
\end{array} \\
& \begin{array}{lll}
3 & 0 & 1.00000
\end{array} \\
& 10 \\
& 1.00000 \\
& 4+1 \quad 0.92593 \\
& \begin{array}{lll}
5 & +2 & 0.85754
\end{array} \\
& \frac{1}{K} \sum_{k}^{K} w\left(T_{m}^{k}\right)= \\
& 1.00594 \\
& 1.00000
\end{aligned}
$$




$$
\bar{e}_{f a b}=\frac{\sum_{m}^{n} f a b\left[\frac{w\left(t_{m}^{f a b}\right)}{1-\tau}-\frac{\tau}{1-\tau} w\left(t_{m}\right)\right.}{\sum_{j}^{N} w(j) E_{j}}
$$

$$
\bar{e}_{r e p r}=1000 \frac{\sum_{m}^{n} z_{m}^{r e p r} w\left(t_{m}^{r e p r}\right)}{\sum_{j}^{N} w(j) E_{j}}
$$

$$
\bar{e}_{m c}=-1000 \frac{\sum_{m}^{n} z_{m}^{m c} w\left(t_{m}^{m c}\right)}{\sum_{j}^{N} w(j) E_{j}}
$$

Defining

$$
\begin{aligned}
& T_{m}^{\mathrm{mq}} \equiv t_{m}-t_{m}^{m q}=T_{m}^{\prime m p}+1 / 2 T_{m} \\
& T_{m}^{f a b} t_{m}-t_{m}^{f a b}=T_{m}^{\prime f a b}+1 / 2 T_{m} \\
& T_{m}^{r e p r} \equiv t_{m}-t_{m}^{r e p r}=-\left(T_{m}^{\prime \prime r e p r}+1 / 2 T_{m}\right) \\
& T_{m}^{m c} \equiv t_{m}-t_{m}^{m c} \equiv-\left(T_{m}^{\prime \prime m c}+1 / 2 T_{m}\right),
\end{aligned}
$$

observing that

$$
w(a) w(b)=w(a+b),
$$

one obtains, for the fuel stream in question, 


$$
\bar{e}_{m p}=1000 \frac{\sum_{m}^{n} w\left(t_{m}\right) z_{m}^{m p}\left[\frac{w\left(-T_{m}^{m p}\right)}{1-\tau}-\frac{\tau}{1-\tau}\right]}{\sum_{j}^{n} w(j) E_{j}}
$$

$$
\bar{e}_{f a b}=1000 \frac{\sum_{m}^{n} w\left(t_{m}\right) z_{1 n}^{f a b}\left[\frac{w\left(-T_{m}^{f a b}\right)}{1-\tau}-\frac{\tau}{1-\tau}\right]}{\substack{\Sigma \\ j}_{j}^{N} w(j) E_{j}}
$$$$
\overline{\mathrm{e}}_{\mathrm{repr}}=1000 \frac{\sum_{m}^{n} w\left(t_{m}\right) z_{m}^{\text {repr }}:\left[w\left(-\mathrm{T}_{\mathrm{m}}^{\mathrm{repr}}\right)\right]}{\sum_{j}^{N} w(j) E_{j}}
$$

$$
\bar{e}_{m c}=-1000 \frac{\sum_{m}^{n} w\left(t_{m}\right) z_{m}^{m c}\left[w\left(-T_{m}^{m c}\right)\right]}{\sum_{j}^{N} w(j) E_{j}}
$$

\subsubsection{Direct and Carrying Charge Contributions}

Each fuel stream component can further be separated into direct and carrying charge subcomponents. For component $q(\mathrm{mp}, \mathrm{fab}$, repr, or $\mathrm{mc})$, of lot $\mathrm{m}$, the direct dollar cost is $z_{\mathrm{m}}^{\mathrm{q}}$. Let $\left(\mathrm{z}_{\mathrm{m}}^{\mathrm{q}}\right)^{\text {** }}$ be the carrying charge component. Then the total dollar cost, $\left(\mathrm{z}_{\mathrm{m}}^{\mathrm{q}}\right)^{*}$, is given by 


$$
\begin{aligned}
\left(z_{m}^{q}\right)^{*} & \equiv(\text { direct })_{m}^{q}+(\text { Ca.Chg. })_{m}^{q} \\
& =z_{m}^{q}+\left(z_{m}^{q}\right)^{* *} \\
& =z_{m}^{q}+f_{m}^{q} z_{m}^{q} \\
& =z_{m}^{q} \quad F_{m}^{q}
\end{aligned}
$$

where

$$
F_{m}^{q} \equiv 1+f_{m}^{q}
$$

The carrying charge factors $\left(\mathrm{F}_{\mathrm{m}}^{\mathrm{q}}\right)$ are readily identified as the bracketed [ ] terms in Equation (2-27), and are summarized in Table 2.3. Levelized cost of electricity associated with the fuel stream's component $q$ is therefore

$$
\begin{aligned}
\bar{e}_{q} & =(t) 1000 \frac{\sum_{m}^{n} w\left(t_{m}\right) z_{m}^{q} F_{m}^{q}}{\sum_{j}^{N} w(j) E_{j}} \\
& =1000 \frac{\sum_{m}^{N} w\left(t_{m}\right) z_{m}^{q}}{\sum_{j}^{N} w(j) E_{j}}+1000 \frac{m}{\sum_{j}^{n} w\left(t_{m}\right) z_{m}^{q} f_{m}^{q}} \\
& =\bar{e}_{q, \text { direct }}^{N}+\bar{e}_{q, \text { CaChg }}^{N} w(j) E_{j}
\end{aligned}
$$

\subsubsection{Method B}

In Method B, the reprocessing and material credit transactions are capitalized. Only the reprocessing and material credit carrying charge factors differ between Methods A and B. 
TABLE 2.3 SUMMARY OF EXPRESSIONS FOR CARRYING CHARGE FACTORS; $\mathrm{F}_{\mathrm{m}}^{\mathrm{q}}$; BY CASH FLOW METHOD

Component

$\mathrm{q}$

material purchase

fabrication

reprocessing

material credit

\section{Method}

A

$$
\frac{1}{1-\tau}\left[w\left(-T_{m}^{m p}\right)-\tau\right]
$$

$\frac{1}{1-\tau}\left[\mathrm{w}\left(-\mathrm{T}_{\mathrm{m}}^{\mathrm{fab}}\right)-\tau\right]$

$\mathrm{w}\left(-\mathrm{T}_{\mathrm{m}}^{\mathrm{repr}}\right)$

$\mathrm{w}\left(-\mathrm{T}_{\mathrm{m}}^{\mathrm{mc}}\right)$
Method

B

$\frac{1}{1-\tau}\left[w\left(-T_{m}^{m p}\right)-\tau\right]$

$\frac{1}{1-\tau}\left[w\left(-T_{m}^{f a b}\right]-\tau\right]$

$\frac{1}{1-\tau}\left[w\left(-T_{m}^{r e p r}\right)-\tau\right]$

$\frac{1}{1-\tau}\left[\mathrm{w}\left(-\mathrm{T}_{\mathrm{m}}^{\mathrm{mc}}\right)-\tau\right]$ 
Following a derivation parallel to Equation (2-21) through Equation (2-29), the Method B carrying charge factors shown in Table 2.3 are found. Equations $(2-29)$ are common to both methods.

\subsubsection{Direct Dollar Costs Per Lot}

A fuel lot's direct costs are given in terms of unit costs $(\$ / \mathrm{kg})$ as follows:

$$
\begin{aligned}
& z_{m}^{m p}=C_{28} M_{28}^{0}+C_{49} M_{49}^{0}+C_{40} M_{40}^{0}+C_{41} M_{4}+C_{42} M_{42}^{0} \\
& z_{m}^{f a b}=C_{f a b} M_{H M}^{0} \\
& z_{m}^{\text {repr }}=C_{r e p r}{ }^{M_{H M}^{0}} \\
& z_{m}^{m c}=C_{28} M_{28}(T)+C_{49}{ }_{49}^{M}(T)+C_{40} M_{40}(T)+C_{41} M_{41}(T)+C_{42} M_{42}(T)
\end{aligned}
$$

where

$$
M_{H M}^{0}=M_{28}^{0}+M_{49}^{0}+M_{40}^{0}+M_{41}^{0}+M_{42}^{0}
$$

The M's are masses of the isotopes U238, Pu239, Pu240, Pu241, Pu242 contained in the lot $\mathrm{m}$ in kilograms. Isotope values $\left(\mathrm{C}_{28}, \mathrm{C}_{49}, \ldots\right)$ have units of dollars per kilogram of the isotope in question. Processing unit costs $\left(\mathrm{C}_{\mathrm{fab}}, \mathrm{C}_{\text {repr }}\right)$ have units of dollars per kilogram of heavy metal $(\mathrm{U}, \mathrm{Pu})$ loaded, and depend, of course, on the region for which the lot is intended (core, axial blanket, radial blanket).

The unit costs $\left(\mathrm{C}_{\text {fab }}, \mathrm{C}_{\text {repr }}, \mathrm{C}_{28}, \mathrm{C}_{49}, \ldots.\right)$ together with the cost of money parameters $\left(\tau, f_{b}, r_{b}, f_{s}, r_{s}\right)$ are regarded in this report as forming the "economic environment", and are set parametrically, external to the present fuel costing model. Economic environment is varied in the sensitivity studies of Chapter 5 . 
2.4 SIMPLIFICATIONS FOR BATCH AND SCATTER FUEL MANAGEMENT SCHEMES; LOCAL FUEL ECONOMIC PERFORMANCE

\subsubsection{Batch Fuel Management}

"Batch" fuel management of a region (core, axial blanket or radial blanket) is defined here as a scheme in which the region's fuel is discharged and replaced as a whole, and the fuel associated with the region or fuel stream sees only one position in the reactor.

If plant load factor remains approximately constant throughout plant life, and if physics-depletion characteristics of the stream are insensitive to the fuel management $f$ the remainder of the reactor, then the fuel lots in the stream are identical: the load and discharge compositions of all lots are the same, the irradiation times for the lots are the same, and for the fuel stream in question, there are no beginning-of-plant-1ife and end-of-plant-life transients. For such a fuel stream, Equation (2-29) becomes

$$
\bar{e}_{q}=1000 \frac{z^{q} F \sum_{m}^{n} w\left(t_{m}\right)}{E \sum_{j}^{N} w(j)}
$$

where $\bar{e}_{q}$ is the levelized energy cost (mills/KWHir) for cost component $q$, $F^{q}$ is the carrying charge factor for component $q, E$ is the annual electricity produced in $\mathrm{KWH}, \mathrm{n}$ is the number of fuel lots in the fuel stream throughout plant life, $N$ is the number of years of plant life, and $z^{q}$ is the direct cost in dollars for component $q$ associated with a fuel lot, that is, associated with the total fuel volume of the batch-managed region.

The expression may be further simplified by noting that 


$$
\frac{\sum_{m}^{n} w\left(t_{m}\right)}{\sum_{j}^{N} w(j)} \simeq \frac{n}{N}=\frac{1}{T}
$$

where $T$ is the irradiation time of a fuel lot in years.

Equation $(2-32)$ is exact for $n=N(T=1$ year) $:$ Error in the approximation $(2-32)$ increases with decrease in $n$ (increase in $T$ ). Irradiation times of interest are about six years (radial blanket fuel) or less. Table 2.4 shows that the error, for a six year irradiation time and an $8 \%$ discount rate, is less than $1 \%$.

The factor $1 / \mathrm{T}$ may be thought of as the fuel throughut in lots per year, for the fuel stream in question.

Equation (2-31) becomes

$$
\bar{e}_{q}=\frac{1000}{E T} z^{q} F^{q}
$$

and the total cost associated with the stream is

$$
\overline{\mathrm{e}}=\frac{1000}{E T} \quad \begin{gathered}
\Sigma \\
\mathrm{q}
\end{gathered} \mathrm{z}^{\mathrm{q}} \mathrm{Fq}
$$

\subsubsection{Scatter Fuel Management}

"Scatter" fuel management of a region or subregion is a scheme in which a fraction $g$ of the region's fuel is discharged and replaced during a refueling event. As in batch management, the fuel sees only one position in the reactor.

Because a fraction $1-g$ of the initial load is incompletely irradiated, the region experiences a beginning of plant life fuel transient. Once in 


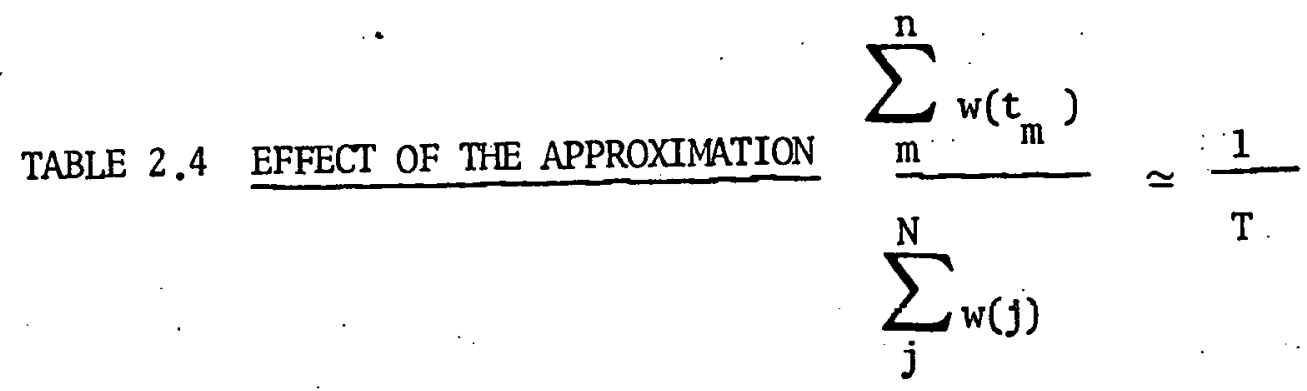

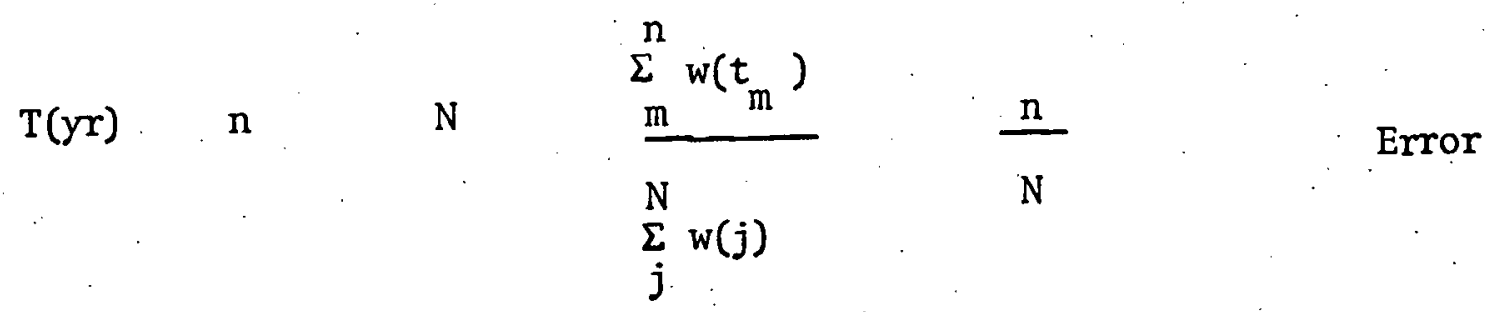

1

30

30

1.00000

1.00000

0

6

5

30

0.1653066

0.166666

less than 
equilibrium, the fuel lots' irradiation times and load and discharge compositions are identical, and assuming plant load factor remains constant, Equation (2-31) modified for equilibrium scatter fueling is:

$$
\left(\bar{e}_{q}\right)_{E Q}=\frac{1000 g^{q} F^{q} \sum_{m}^{n} w\left(t_{m}\right)}{E \sum_{j}^{N} w(j)}
$$

where the fuel. lot size is one-gth of the total fuel volume of the region.

The expression corresponding to Equation (2-32) for equilibrium scatter management is:

$$
\frac{\sum_{m}^{n} w\left(t_{m}\right)}{\sum_{j}^{N} w(j)} \simeq \frac{n}{N}=\frac{1}{g T}
$$

Thus,

$$
\left(\bar{e}_{q}\right)_{E Q}=\frac{1000}{E T} z q \cdot F^{q}
$$

and the total equilibrium fuel cost associated with the stream is

$$
\text { (₹) })_{E Q}=\frac{1000}{E T} \quad \sum_{q} z^{q} F^{q}
$$

Comparison of Equations $(2-33),(2-34),(2-33 A)$ and $(2-34 A)$ shows that the functional forms of the batch and equilibrium scatter cost equations are identical. Indeed, the processing costs - fabrication, reprocessing are numerically equal as well, for the same irradiation time. Only the material costs

$$
\begin{aligned}
& z^{m p}=C_{28} M_{28}^{0}+C_{49} M_{49}^{0}+\ldots \\
& z^{m c}=C_{28} M_{28}(T)+C_{49} M_{49}(T)+\ldots
\end{aligned}
$$


may differ, owing to the possibly-differing physics-depletion characteristics of the two management schemes.

For the same irradiation time $(T)$, the time averaged composition, e.g. fissile plutonium content, of a region managed by scatter refueling is qualitatively the same as if it were batch managed. In scatter management, however, the composition varies within a smaller range, since its cycle time is shorter - one gth that of the batch managed region.

\subsubsection{Local Fuel Economic Performance .}

It is useful to disply the fuel economic performance as a function of position in one of the major regions (core, axial blanket, radial blanket), under batch or scatter management. For example, one may wish to know the performance of the third row of fuel assemblies in the radial blanket, and how it compares to that of the second row, etc. For purposes of comparing these sulregions, a figure of merit independent of their volumes is desired.

From Equation (2-34), the fuel costs associated with a stream (region or subregion) is

$$
\begin{aligned}
E= & \bar{e}_{m p}+\bar{e}_{f a b}+\bar{e}_{r e p r}+\bar{e}_{m c} \\
= & \frac{1000}{E}\left[\frac{z^{m p_{F}^{m p}}(T)}{T}+\frac{z^{f a b_{F}^{f a b}(T)}}{T}\right. \\
& +\frac{z \operatorname{repr}_{F}^{r e p r}(T)}{T}-\frac{z^{m c}(T) F^{m c}(T)}{T}
\end{aligned}
$$

where the carrying charge factors and direct material credit have been expressed as functions of irradiation time, $\mathrm{T}$. 
Using Equations (2-30) to expres: the direct dollar costs in terms of unit costs, one obtains

$$
\begin{aligned}
\bar{e} & =\frac{1000}{E}\left[\frac{\left(C_{28} M_{28}^{0}+C_{49} M_{49}^{0}+\ldots\right) F^{m p}(T)}{T}\right. \\
& +\frac{C_{f a b} M_{H M}^{0} F^{f a b} \cdot(T)}{T} \\
& +\frac{C_{r e p r} M_{H M}^{0} F^{r e p r}(T)}{T} \\
& \left.+\frac{\left(C_{28}^{M}{ }_{28}(T)+C_{49}^{M}{ }_{49}(T)+\ldots .\right) F^{m c}(T)}{T}\right]
\end{aligned}
$$

The contribution of fertile material (U238, Pu240) to the value of fuel is insignificant. For core fuel

$$
\begin{aligned}
& C_{\text {fert }} M_{\text {fert }}^{0}<<C_{\text {fiss }} M_{\text {fiss }}^{0}, C_{\text {fab }} M_{H M}^{0}, C_{\text {repr }} M_{f M}^{0} \\
& C_{\text {fert }}{ }_{\text {fert }}(T)<<C_{\text {fiss }}{ }_{\text {fiss }}(T), C_{\text {fab }} M_{H M}^{0}, C_{\text {repr }} M_{H M}^{0}
\end{aligned}
$$

For blanket fuel,

$$
\begin{aligned}
& C_{\text {fert }} M_{\text {fert }}^{0}<<C_{\text {fiss }} M_{\text {fiss }}(T), C_{\text {fab }} M_{f M}^{0}, C_{\text {f }} M_{\text {HM }}^{0} \\
& C_{\text {fert }}{ }_{\text {fert }}{ }^{(T)}<\left\langle C_{\text {fiss }} M_{\text {fiss }}(T)\right.
\end{aligned}
$$

In either case, the assumption

$$
\text { a) } \mathrm{C}_{\text {fert }} \simeq 0
$$

has a negigible effect on results. In addition, the following assumption is made: 
b) $\mathrm{C}_{\text {fiss }}=\mathrm{C}_{49}=\mathrm{C}_{41}$

With assumptions a) and b), Equation (2-36) reduces to

$$
\begin{aligned}
\cdot \overline{\mathrm{e}} & =\frac{1000}{\mathrm{E}}\left[\frac{\mathrm{C}_{\text {Fiss }}\left(\mathrm{M}_{49}^{0}+\mathrm{M}_{41}^{0}\right) \mathrm{F}^{\mathrm{mp}}(\mathrm{T})}{\mathrm{T}}\right. \\
& +\frac{\mathrm{C}_{\mathrm{fab}} \mathrm{M}_{\mathrm{HM}}^{0} \mathrm{~F}^{\mathrm{fab}}(\mathrm{T})}{\mathrm{T}} \\
& \left.+\frac{\mathrm{C}_{\text {repr } \mathrm{M}_{\mathrm{HM}}^{0} \mathrm{~F}^{\mathrm{repr}}(\mathrm{T})}}{\mathrm{T}}\right] \\
& \left.-\frac{\mathrm{C}_{\text {fiss }}\left(\mathrm{M}_{49}(\mathrm{~T})+\mathrm{M}_{41}(\mathrm{~T})\right) \mathrm{F}^{\mathrm{mc}}(\mathrm{T})}{\mathrm{T}}\right]
\end{aligned}
$$

Multiplying and dividing by $\mathrm{M}_{\mathrm{HM}^{\prime}}^{0}$

$$
\begin{aligned}
\bar{e} & =\frac{1000}{E} \cdot M_{H M}^{0}\left[\frac{C_{\text {fiss }} \in_{0} F^{m p}(T)}{T}\right. \\
& +\frac{C_{\text {fab }} F^{f a b}(T)}{T} \\
& +\frac{C_{\text {repr }} F^{r e p r}(T)}{T}
\end{aligned}
$$

where

$$
\begin{aligned}
& \epsilon_{0}=\left(M_{49}^{0}+M_{41}^{0}\right) / M_{H M}^{0} \\
& \epsilon(T)=\left(M_{49}(T)+M_{41}(T)\right) M_{H M}^{0}
\end{aligned}
$$


The term in brackets may be regarded as a figure of merit representing local fuel performance, having units of dollars per year per local kilogram of heavy metal. Normalizing to kilograms of initial heavy metal in this manner removes the volume effect in comparing regions or subregions. Except through the discharge composition, $\epsilon(T)$, in the material credit term, the local performance is independent of reactor power level, or load factor.

\subsection{COMPARISON OF FUEL COST ACCOUNTING METHODS}

\subsubsection{Effect of Tax Assumptions in the Cash Flow Method}

In Section 2.3, two tax interpretations were applied to the treatment of post-irradiation transactions:

Method A: The post-irradiation transactions are not capitalized i.e. reprocessing cost is written off as a tax deductable expense in the year that it occurs, and material credit is taxed as ordinary income, along with the sale of electricity.

Method B: The post-irradiation transactions are capitalized. Choice of Method A or B affects only the carrying charges associated with reprocessing and material credit. All direct costs and the carrying charges on pre-irradiation costs remain the same.

For a tax rate of $50 \%$, the carrying charges on material credit and reprocessing under Method B are double those from Method A, i. e.

$$
\begin{aligned}
\frac{\left(\mathrm{e}^{\mathrm{repr}}\right)_{B}^{\star *}}{\left(\mathrm{e}^{\mathrm{repr}}\right)_{A}^{*-*}} & =\frac{\left(\mathrm{F}^{\mathrm{repr}}\right)_{B}-1}{\left(\mathrm{~F}^{\mathrm{repr}}\right)_{A}-1} \\
& =\frac{\frac{1}{1-\tau}\left[w\left(-\mathrm{T}^{\mathrm{repr}}\right)-\tau\right]-1}{W\left(-\mathrm{T}^{\mathrm{repr}}\right)-1}=2 ;
\end{aligned}
$$


and similarly,

$$
\frac{\left(\mathrm{e}^{\mathrm{mc}}\right)_{B}^{* *}}{\left(\mathrm{e}^{\mathrm{mc}}\right)_{A}^{* *}}=2
$$

Thus,

$$
\frac{\left(\bar{e}^{m c}\right)_{B}^{* *}+\left(\bar{e}^{-r e p r}\right)_{B}^{* *}}{\left(\bar{e}^{m c}\right)_{A}^{* *}+\left(\bar{e}^{\text {repr }}\right)_{A}^{* *}}=.2
$$

The carrying charges on reprocessing and material credit are but two of the eight subcomponents making up the total cost of the fuel lot. Also, the carrying charges on reprocessing and material credit are of opposite sign, tending to cancel.

The discrepancy between total costs of the 1ot, as calculated by Methods $A$ and $B$, increases with irradiation time as carrying charges in general become more important, and as the material credit (plutonium buildup) from blanket fuel further overshadows blanket reprocessing costs.

Figures $2.4,2.5$ and 2.6 compare the two methods as applied to core, axial blanket and radial blanket fuel costs, respectively, of the reference LMFBR (Chapter 4). Method $A$ is seen to result in lower total fuel costs in all three regions. The discrepancy in core fuel costs is about $10 \%$ at the design residence time of two years.. In the axial blanket, the discrepancy is about $20 \%$ at two years. For the radial blanket, the discrepancy is quite severe, although the two methods yield comparable optimum residence times - 6 years in Method B, 6.5 years in Method A.

2.5.2 Relationship of the Cash Flow Method to Two Other Accounting Methods

For cost component $q$, lot $\mathrm{m}$, the carrying charge in dollars, $\left(\mathrm{z}_{\mathrm{m}}^{\mathrm{q}}\right)^{* \star}$, and the total cost in dollars, $\left(\mathrm{z}_{\mathrm{m}}^{\mathrm{q}}\right)$ *, are given by 


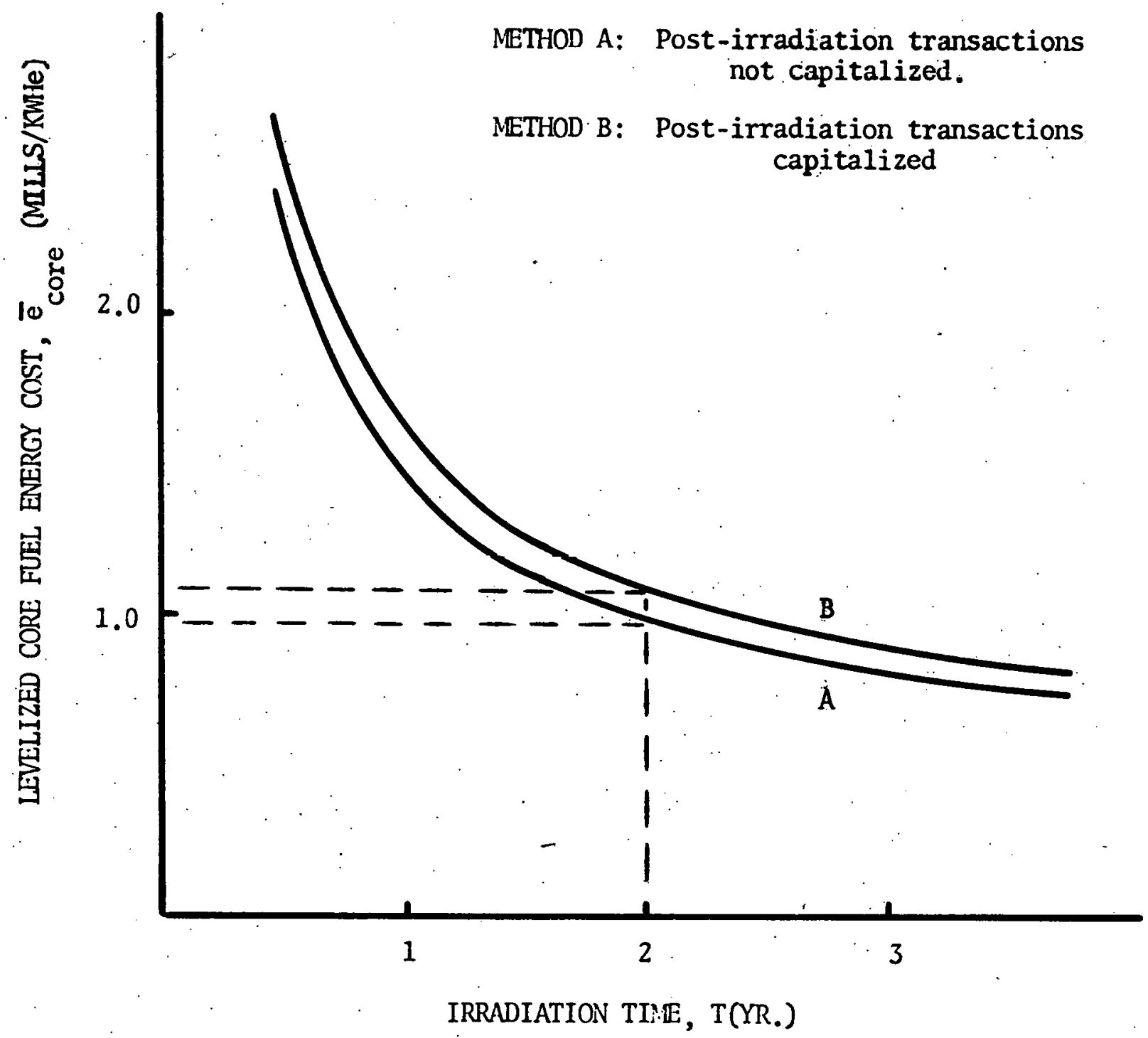

FIG. 2.4 EFFECT OF POST-IRRADIATION TAX ASSUMPTION ON LEVELIZED CORE FUEL ENERGY COST 


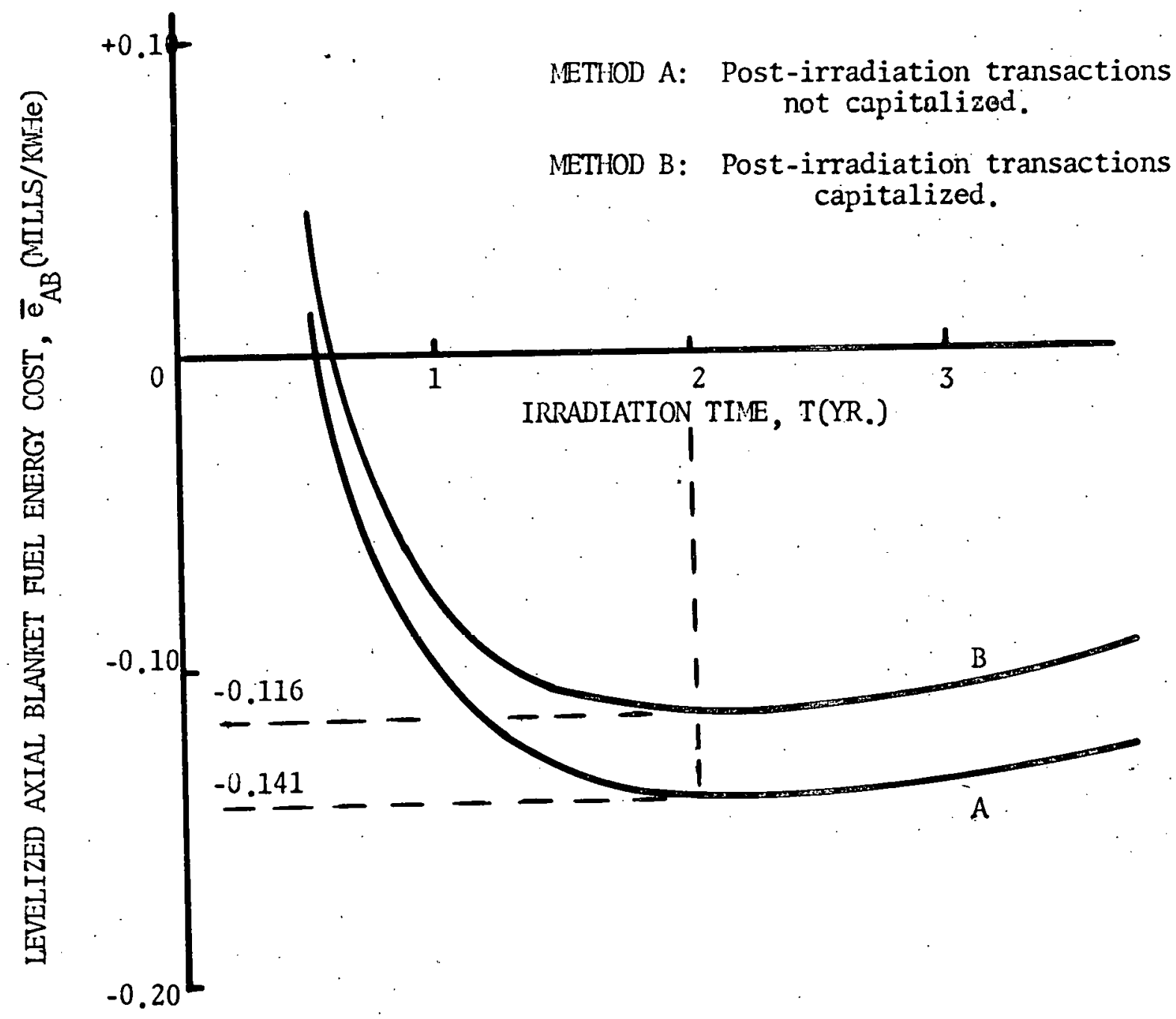

FIG. 2.5 EFFECT OF POST-IRRADIATION TAX ASSURPTION

ON LEVELIZED AXIAL BLANKET FUEL ENERGY COST. 


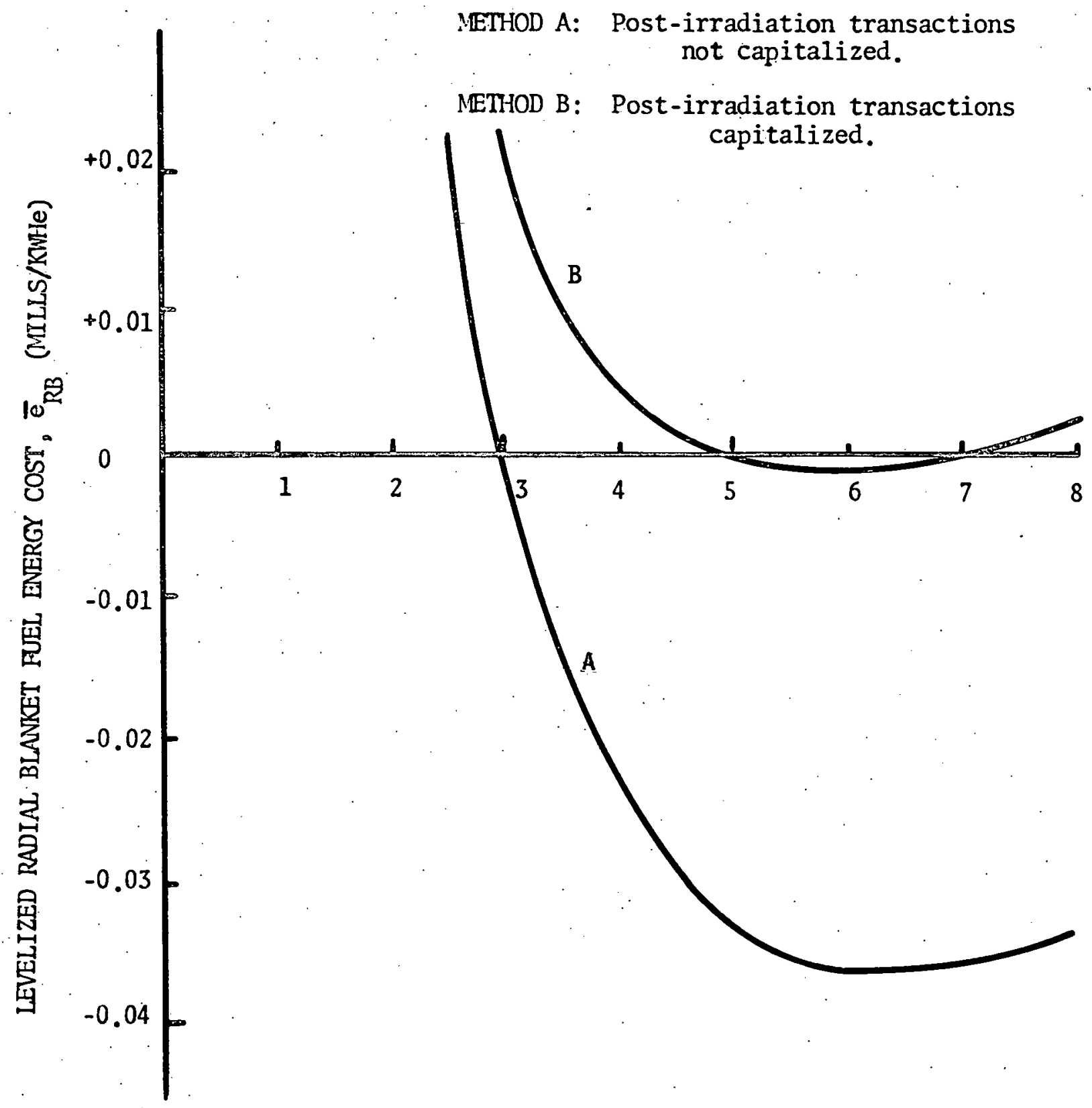

FIG. 2.6 EFFECT OF POST-IRRADIATION TAX ASSUMPTION ON LEVELIZED RADIAL BLANKET FUEL ENERGY COST 


$$
\underset{m}{(z q * *}=z_{m}^{q} \underset{m}{q}
$$

and

$$
\left(z_{m}^{q}\right) *=z_{m}^{q} F_{m}^{q}
$$

where

$$
F_{m}^{q} \equiv 1+f_{m}^{q}
$$

\subsubsection{Cash Flow Method (CFM)}

The cash flow method (CFM) of Sections 2.2 and 2.3 showed that for capitalized costs or capitalized revenues the carrying charge factor $F_{m}^{q}$ takes the form

$$
\left(\mathrm{F}_{\mathrm{m}}^{\mathrm{q}}\right)_{\mathrm{CFM}}=\frac{1}{1-\tau}\left[\mathrm{w}\left(-\mathrm{T}_{\mathrm{m}}^{\mathrm{q}}\right)-\tau\right] \cdot \quad \text { (capitalized) }
$$

while for expensed costs and taxed revenues the factor is

$$
\left(\mathrm{F}_{\mathrm{m}}^{\mathrm{q}}\right)_{\mathrm{CFM}}=\mathrm{w}\left(-\mathrm{T}_{\mathrm{m}}^{\mathrm{q}}\right) \quad \text { (expensed costs; taxed revenues) }
$$

where

$$
\begin{aligned}
& w\left(-T_{m}^{q}\right) \equiv \frac{1}{(1+x)-T_{m}^{q}}=(1+x) \overbrace{m}^{q} \equiv \text { discount factor } \\
& x \equiv(1-\tau) r_{b} f_{b}+r_{s} f_{s} \equiv \text { discount rate }
\end{aligned}
$$

Two other methods of treating nuclear fuel carrying charges are commonly. used:

(a) Simple Interest Method (SIM), (20, 22, 23)

(b) Compount Interest Method (CIM), (83)

The cash flow method (CFM) is related to these "approximate" methods below. x. 


\section{5.2.2 Simple Interest Method (SIM)}

The SIM associates carrying charges with areas under a fuel lot's value histogram. Figure 2.7 shows the general appearance of such histograms for (a) depreciating core fuel and (b) appreciating blanket fuel, and how they may be constructed from the cash flows. Figures 2.8 and 2.9 are value histograms for the reference reactor core and radial blanket, respectively, defined in Chapter 4. Pre-irradiation transactions (material purchase and fabrication are assumed to occur simultaneously, as are the post-irradiation transactions. (reprocessing and material credit).

In the SIM, the carrying charge and total dollar costs for component $\mathrm{q}$ of lot $\mathrm{m}$ are given by

and

$$
\left(z_{m}^{q}\right)_{S I M}^{* *}=\left(z_{m}^{q}\right) T_{m}^{q} y_{q}
$$

$$
\left(z_{m}^{q}\right)_{S I M}^{*}=(\underset{m}{q})^{q}\left(1+T_{m}^{q} y_{q}\right)
$$

respectively, where

$$
\begin{aligned}
T_{m}^{q} & =T_{m}^{\prime q}+1 / 2 T_{m} \quad \text { (pre-irradiation cash flows) } \\
& =-\left(T_{m}^{q}+1 / 2 T_{m}\right) \quad \text { (post-irradiation cash flows) } \\
y_{q} & \equiv \text { carrying charge rate applicable to component } q .
\end{aligned}
$$

Thus the carrying charge factors $\mathrm{F}_{\mathrm{m}}^{\mathrm{q}}$ for the SIM are given by

$$
\left(F_{m}^{q}\right)_{S I M}=1+T_{m}^{q} y_{q} .
$$

The factors $\left(\mathrm{F}_{\mathrm{m}}^{\mathrm{q}}\right)_{\mathrm{CFM}}$, given by Equations $(2-47)$ and $(2-48)$, reduce to $\left(\mathrm{F}_{\mathrm{m}}^{\mathrm{q}}\right)_{\mathrm{SIM}}$ for small $\mathrm{T}_{\mathrm{m}}^{\mathrm{q}} \mathrm{y}_{\mathrm{q}}$. Expanding the discount factor in Equation (2-47) in a binomial series, one finds, for capitalized costs or capitalized revenues, 


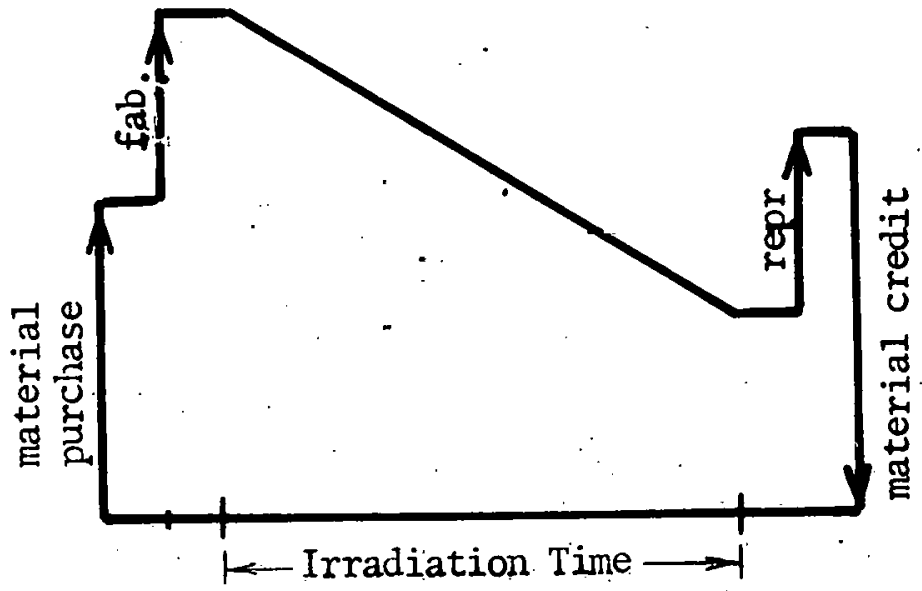

(a) FBR CORE FUEL

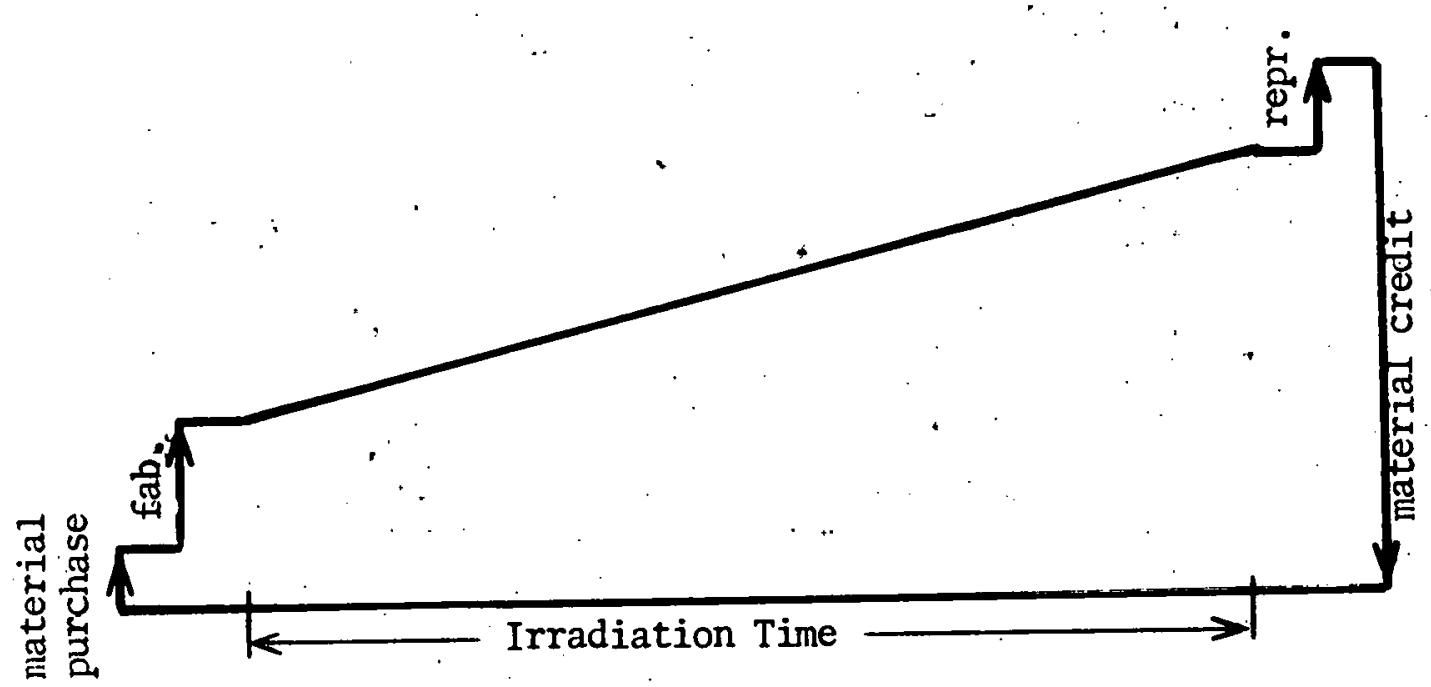

(b) FBR BLANKET FUEL

FIG. 2.7 CONSTRUCTION OF VALUE-TIME PLOTS FROM FUEL LOT CASH FLOWS 

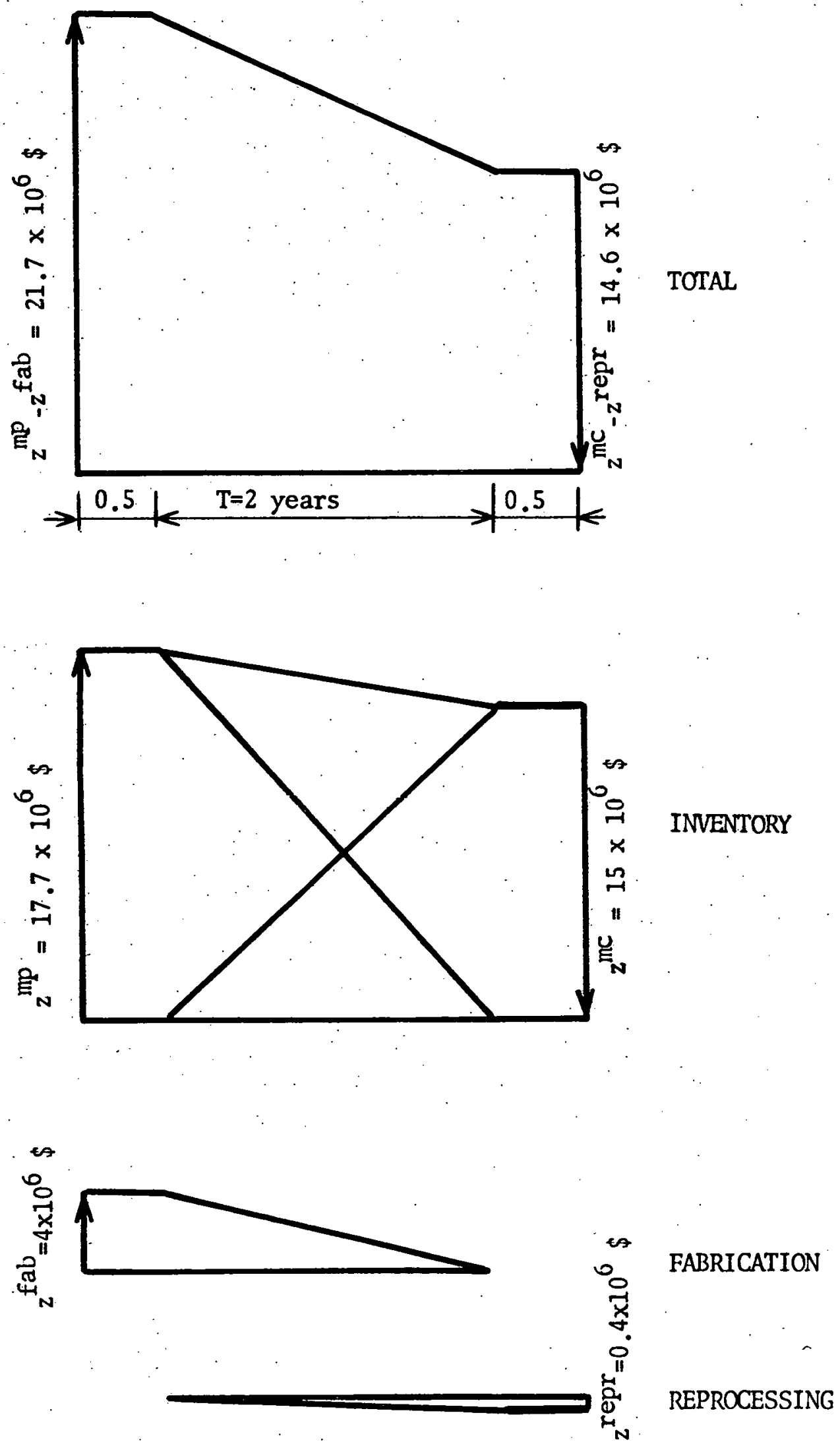

FIG, 2.8 VALUE-TIME PLOTS FOR A CORE FUEL BATCH 

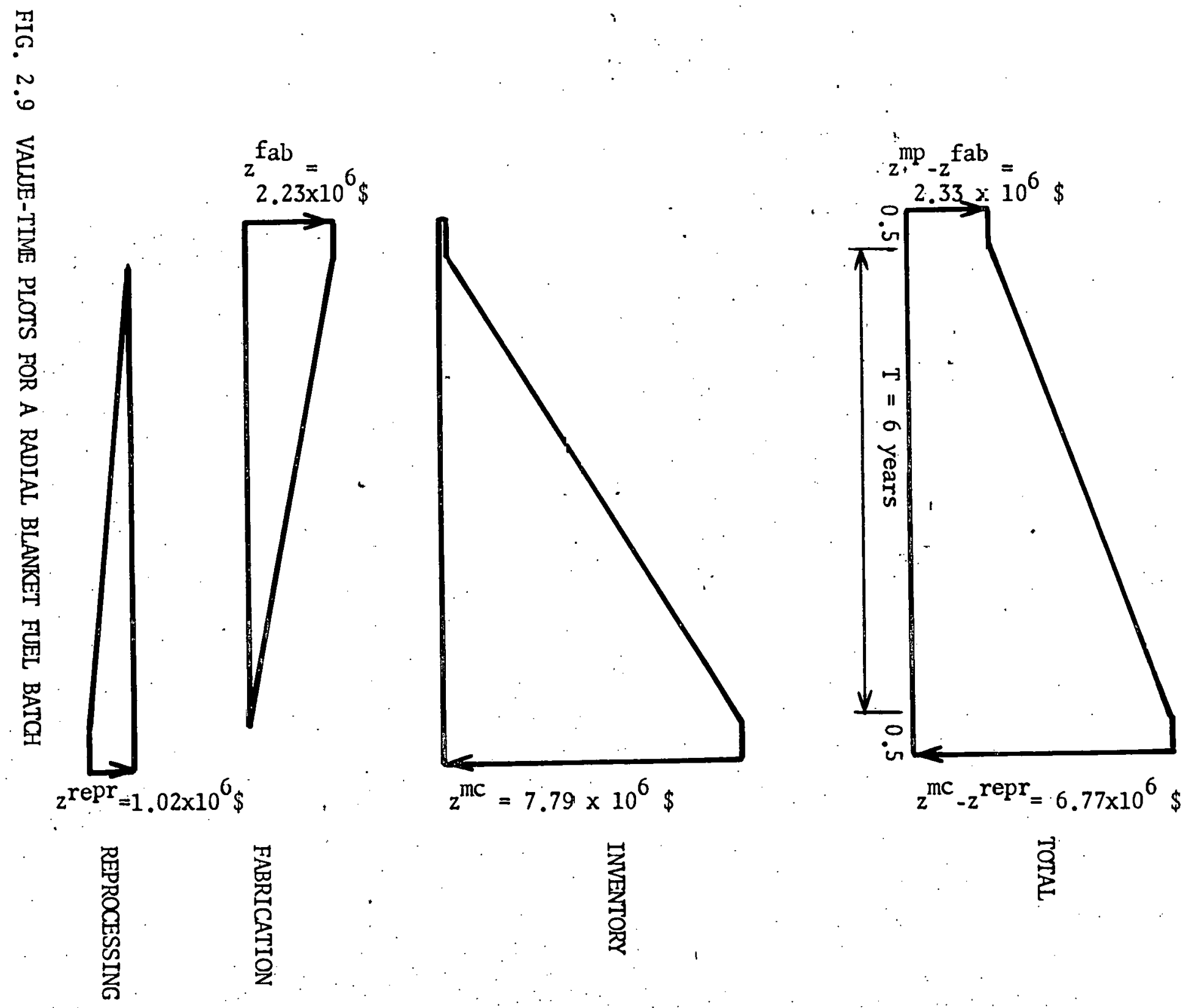


$$
\begin{aligned}
\left(F_{m}^{q}\right]_{C F M}= & \frac{1}{1-\tau}\left[W\left(-T_{m}^{q}\right)-\tau\right] \\
= & \frac{1}{1-\tau}\left[(1+x) T_{m}^{q}-\tau\right] \\
= & \frac{1}{1-\tau}\left[1-\tau+T_{m}^{q} x+\frac{T_{m}^{q}\left(T_{m}^{q}-1\right) x^{2}}{2 !}+\ldots\right] \\
& =1+T_{m}^{q} \frac{x}{1-\tau}+\frac{T_{m}^{q}\left(T_{m}^{q}-1\right)}{2 !} \frac{x^{2}}{1-\tau}+\ldots
\end{aligned}
$$

For small $\mathrm{T}_{\mathrm{m}}^{\mathrm{q}} \mathrm{x} / 1-\tau$ Equation $(2-55)$ reduces to the approximate form

$$
\left(\mathrm{F}_{\mathrm{m}}^{\mathrm{q}}\right)_{\mathrm{CFM}} \simeq 1+\mathrm{T}_{\mathrm{m}}^{\mathrm{q}} \frac{\mathrm{x}}{1-\tau} \equiv 1+\mathrm{T}_{\mathrm{m}}^{\mathrm{q}} \mathrm{y}_{\mathrm{q}}=\left(\mathrm{F}_{\mathrm{m}}^{\mathrm{q}}\right)_{\mathrm{SIM}}
$$

Thus for capitalized costs and capitalized revenues (not taxed), the correct carrying charge rate $y_{q}$ for the SIM is

$$
y_{q}=\frac{x}{1-\tau} \quad \text { (capitalized costs or }
$$

where the discount rate $(x)$ is given by $(2-50)$.

Similarly, for expensed costs and taxed revenues,

$$
\begin{aligned}
\left(F_{m}^{q}\right)_{C F M} & =w\left(-T_{m}^{q}\right)=(1+x)_{m}^{T_{m}^{q}} \\
& =1+T_{m}^{q} x+\frac{T_{m}^{q}\left(T_{m}^{q}-1\right) x^{2}}{2 !}
\end{aligned}
$$

For $\operatorname{small} \mathrm{T}_{\mathrm{m}}^{\mathrm{q}} \mathrm{x}$;

$$
\left(F_{m}^{q}\right)_{C F M} \simeq 1+T_{m}^{q} x=1+T_{m}^{q} y_{q}=\left(F_{m}^{q}\right)_{S I M}
$$

Thus for expensed costs and taxed revenues the correct carrying charge 
rate $y_{q}$ in the SIM is

$$
y_{q .}=x \quad \begin{array}{r}
\text { (expensed costs or } \\
\text { taxed revenues) }
\end{array}
$$

where, as before, the discount rate $(x)$ is given by Equation $(2-50)$.

\subsubsection{Compound Interest Method (CIM)}

The restriction on SIM Equations $(2-56)$ and $(2-57)$ that $T_{m}^{q} y_{q}$ be small suggests that SIM may be improved by continuing $(2-56)$ in a series of powers of $y_{q}$ :

$$
\begin{aligned}
\left(\mathrm{F}_{\mathrm{m}}^{\mathrm{q}}\right)_{\mathrm{CIM}} & =1+\mathrm{T}_{\mathrm{m}}^{\mathrm{q}} \mathrm{y}_{\mathrm{q}}+\frac{\mathrm{T}_{\mathrm{m}}^{\mathrm{q}}\left(\mathrm{T}_{\mathrm{m}}^{\mathrm{q}}-1\right)}{2 !} \mathrm{y}_{\mathrm{q}}^{2}+\cdots \\
& =\left(1+\mathrm{y}_{\mathrm{q}}\right)_{\mathrm{m}}^{\mathrm{T}}
\end{aligned}
$$

Thus for the cuilpound interest method (CIM),

$$
\left(z_{m}^{q}\right)_{C I M}^{* *}=\left(z_{m}^{q}\right)\left[\left(1+y_{q}\right)_{m}^{T_{m}^{q}}-1\right]
$$

and

$$
\left(z_{m}^{q}\right)^{*}=\left(z_{m}^{q}\right)\left(1+y_{q}\right)^{T}{ }_{m}^{q}
$$

where, again,

$$
\begin{aligned}
& y_{q}=\frac{x}{1-\tau} \quad \begin{array}{c}
\text { (capitalized costs or } \\
\text { capitalized revenues) }
\end{array} \\
& =x \quad \begin{array}{r}
\text { (expensed costs or } \\
\text { taxed revenues) }
\end{array}
\end{aligned}
$$

The $\left(\mathrm{F}_{\mathrm{m}}^{\mathrm{q}}\right)_{\text {SIM }}$ factors reduce, of course, to the $\left(\mathrm{F}_{\mathrm{m}}^{\mathrm{q}}\right)_{\mathrm{CIM}} \cdot$ Comparing Equations (2-61) and (2-60) with Equation (2-48), one observes that the $\left(\mathrm{F}_{\mathrm{m}}^{\mathrm{q}}\right)_{\mathrm{CIM}}$ and $\left(\mathrm{F}_{\mathrm{m}}^{\mathrm{q}}\right)_{\mathrm{CFM}}$ are identical for expensed costs and taxed revenues. 
However, the $\left(\mathrm{F}_{\mathrm{m}}^{\mathrm{q}}\right)_{\mathrm{CIM}}$ and $\left(\mathrm{F}_{\mathrm{m}}^{\mathrm{q}}\right)_{\mathrm{CFM}}$ are not identical for capitalized costs and capitalized revenues, as can be seen by comparing the expansions (2-61) and (2-55): their first order terms are identical, but a CIM term of order $k>1$ is in error by a factor of $(1-\tau)^{k-1}$. The CIM overpredicts the true (CFM) factor. $F_{m}^{q}$, for capitalized transactions.

\subsubsection{Summary}

Table 2.5 summarizes the distinction between the three methods of computing carrying charge factors, $\mathrm{F}_{\mathrm{m}}^{\mathrm{q}}$.

Figure 2.10 illustrates the discrepancies between the three methods of computing $\mathrm{F}_{\mathrm{m}}^{\mathrm{q}}$ for a capitalized transaction. A discount rate of $8 \%$ and a tax rate of $50 \%$ are assumed in Figure 2.10. The SIM underpredicts $F_{m}^{q}$, while CIM overpredicts $\mathrm{F}_{\mathrm{m}}^{\mathrm{q}}$. In both cases, errors are significant only for large $\mathrm{T}_{\mathrm{m}}^{q}$, or large $y_{q}$, or both. Since radial blanket fuel may be irradiated as long as ten years, the CFM derived in Sections 2.2 and 2.3 was selected.

\subsection{SAMPLE CALCULATION: BEHAVIOR OF BLANKET FUEL COSTS WITH IRRADIATION TIME}

Results using the fuel cost model derived in this Chapter exhibit features one would expect qualitatively. Figures 2.5 and 2.6 show the levelized fuel costs of the reference reactor's axial and radial blankets, respectively, as functions of irradiation time. Two major characteristics are noted.

(1) A "breakeven" exposure point exists, at which material credit just balances the material purchase, fabrication, and reprocessing costs:

$$
m_{.} c_{.}=m_{.} p_{.}+f_{a b}+\text { repr. }
$$

For blanket irradiation times below this point, fissile material produced 
TABLE 2.5 SUMMARY OF EXPRESSIONS FOR CARRYING CHLRGE FACTOR $\left(F_{m}^{q}\right)$ BY CFM, CIM AND SIM

Expression for Carrying Charge Factor, $F_{m}^{q}$

Transaction

Transaction
Type

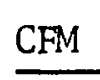

CIMI

$\underline{\text { SIM }}$

Capitalized

Costs (Z) and

Revenues ( $V^{\prime}$ ).

$\frac{i}{1-\tau}\left[(1+x)^{\mathrm{T}_{\mathrm{m}}^{\mathrm{q}}}-\tau\right]$

$\left(1+y_{q}\right)^{T} T_{m}^{q}$

$1+y_{q} T_{m}^{q}$

$y_{q}=\frac{x}{1-\tau}$

$y_{q}=\frac{x}{1-\tau}$

Non-Capitalized

Transactions:

Expensed Costs ( 0 )

$(1+x)^{T^{q}}$

$\left(1+y_{q}\right)^{T^{q}}$

$1+y_{q} T^{q}$

Taxed Revenues (V)
$y_{q}=x$
$y_{q}=x$

Discount Rate: $x=(1-\tau) r_{b} f_{b}+r_{s} f_{s}$
Discount Intervals:

$\mathrm{T}_{\mathrm{m}}^{\mathrm{q}} \equiv \mathrm{T}_{\mathrm{m}}^{\prime} \mathrm{q}+1 / 2 \mathrm{~T}_{\mathrm{m}}$ (pre-irradiation transactions)

$\equiv-\left(\mathrm{T}_{\mathrm{m}}^{\prime \prime \mathrm{q}}+1 / 2 \mathrm{~T}_{\mathrm{m}}\right) \quad$ (post irradiation transactions)

$$
\left(\mathrm{F}_{\mathrm{m}}^{\mathrm{q}}\right)_{\mathrm{SIM}}<\left(\mathrm{F}_{\mathrm{m}}^{\mathrm{q}}\right)_{\mathrm{CFM}}<\left(\mathrm{F}_{\mathrm{m}}^{\mathrm{q}}\right)_{\mathrm{CIM}}
$$

For $\mathrm{T}_{\mathrm{m}} \mathrm{q}_{\mathrm{q}}<<.1$,

$$
\begin{aligned}
& \left(\mathrm{F}_{\mathrm{m}}^{\mathrm{q}}\right)_{\mathrm{CHM}} \rightarrow\left(\mathrm{F}_{\mathrm{m}}^{\mathrm{q}}\right)_{\mathrm{SIM}} \\
& \left(\mathrm{F}_{\mathrm{m}}^{\mathrm{q}}\right)_{\mathrm{CIM}} \rightarrow\left(\mathrm{F}_{\mathrm{m}}^{\mathrm{q}}\right)_{\mathrm{SIM}}
\end{aligned}
$$




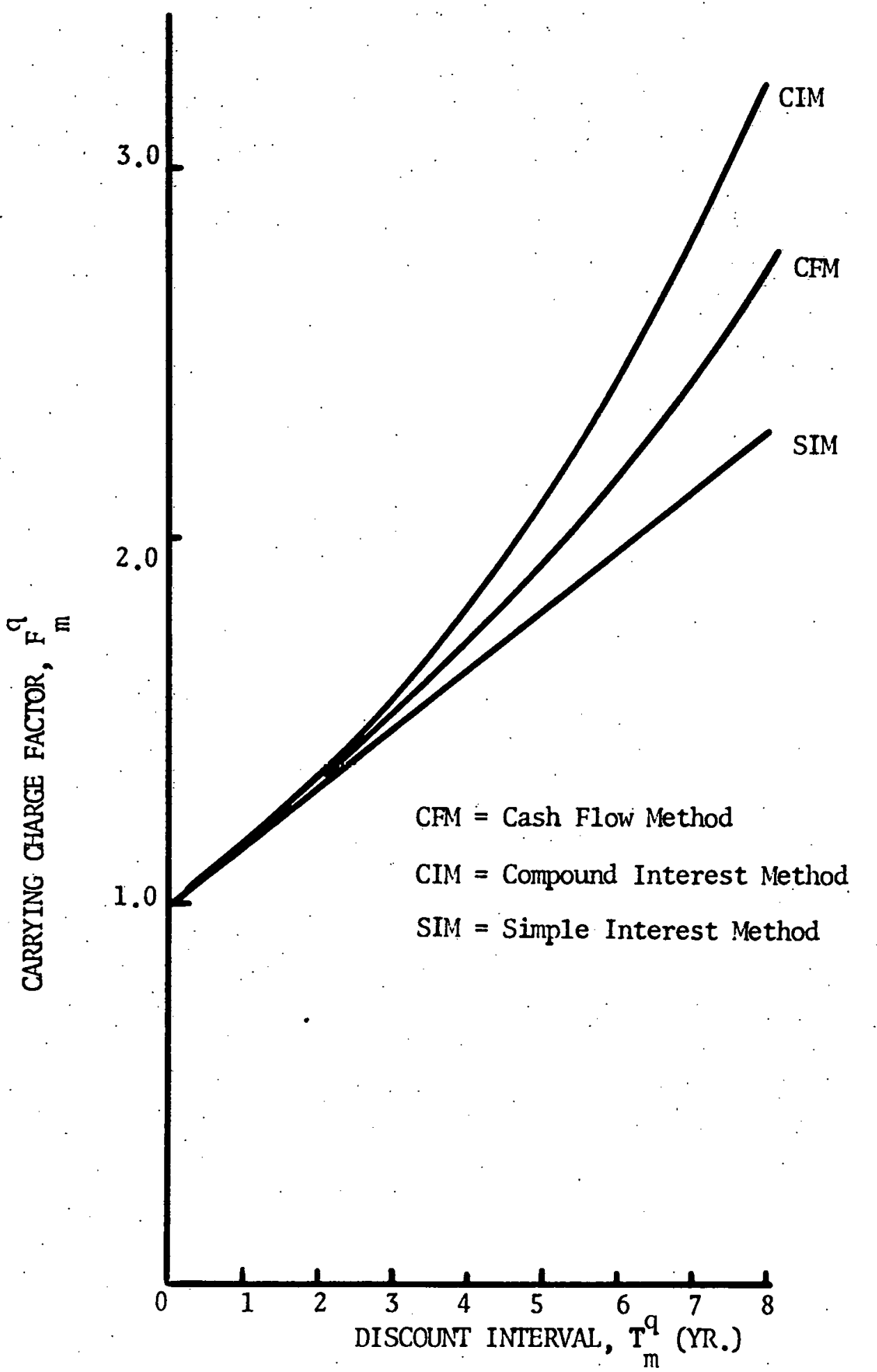

FIG. 2.10 COMPARISON OF CARRYING CHARGE FACTORS FOR CAPITALIZED TRANSACTIONS COMPUTED BY CFM, CIM, AND SIM 
is not sufficient to yield a net revenue.

(2) An optimum exposure point exists, at which the cost is a minimum (most negative).

Figures 2.11 and 2.12 display radial blanket cost components as functions of irradiation time, under Method A. Material purchase (U238) has been ignored in both plots since its contribution is an order of magnitude below other components. Direct material credit is the only negative component; positive costs are shown netted against material credit in both figures. Carrying charges on fabrication and reprocessing components have been combined in "processing carrying charges".

In Figure 2.11 levelized costs are in units of dollars per kilogram of heavy metal $(U+P u)$ loaded. Total reactor energy released during irradiation of the radial blanket, is shown at the top of the figure. Direct material credit, $\left|\mathrm{C}_{\text {fiss }} \in(\mathrm{T})\right|$, is seen to increase (become more negative) as irradiation time increases, but at a decreasing rate. (The depletion model used in generating $\epsilon(T)$ is described in Chapter 3.) Inventory cost, $C_{\text {fiss }} \in(T)\left[F^{m c}(T)-1\right]$, is seen to increase with irradiation time. Direct processing costs, $\mathrm{C}_{\mathrm{fab}}, \mathrm{C}_{\text {repr }}$ are, of course, constant, while their carrying charge, $C_{f a b}\left[F^{f a b}(T)-1\right]+C_{\text {repr }}\left[F^{\text {repr }}(T)-1\right]$, increases with irradiation time.

The costs of Figure 2.11, in dollars per kilogram of heavy metal, are to be assigned to the total reactor energy released during radal blanket irradiation, $\mathrm{E}\left(\mathrm{KWH}_{\Theta}\right.$ year $) \mathrm{T}$ (year). Since $\mathrm{E}$ is constant, one may divide the costs of Figure 2.11 by blanket irradiation time $\mathrm{T}$ to obtain the radial blanket fuel costs in units of dollars per year per kilogram of heavy metal, Figure 2.12. This is the term in brackets in Equation (242), applied to the entire radial blanket. Figure 2.12 also includes a scale indicating the radial blanket levelized power costs in mills/KWHr. 


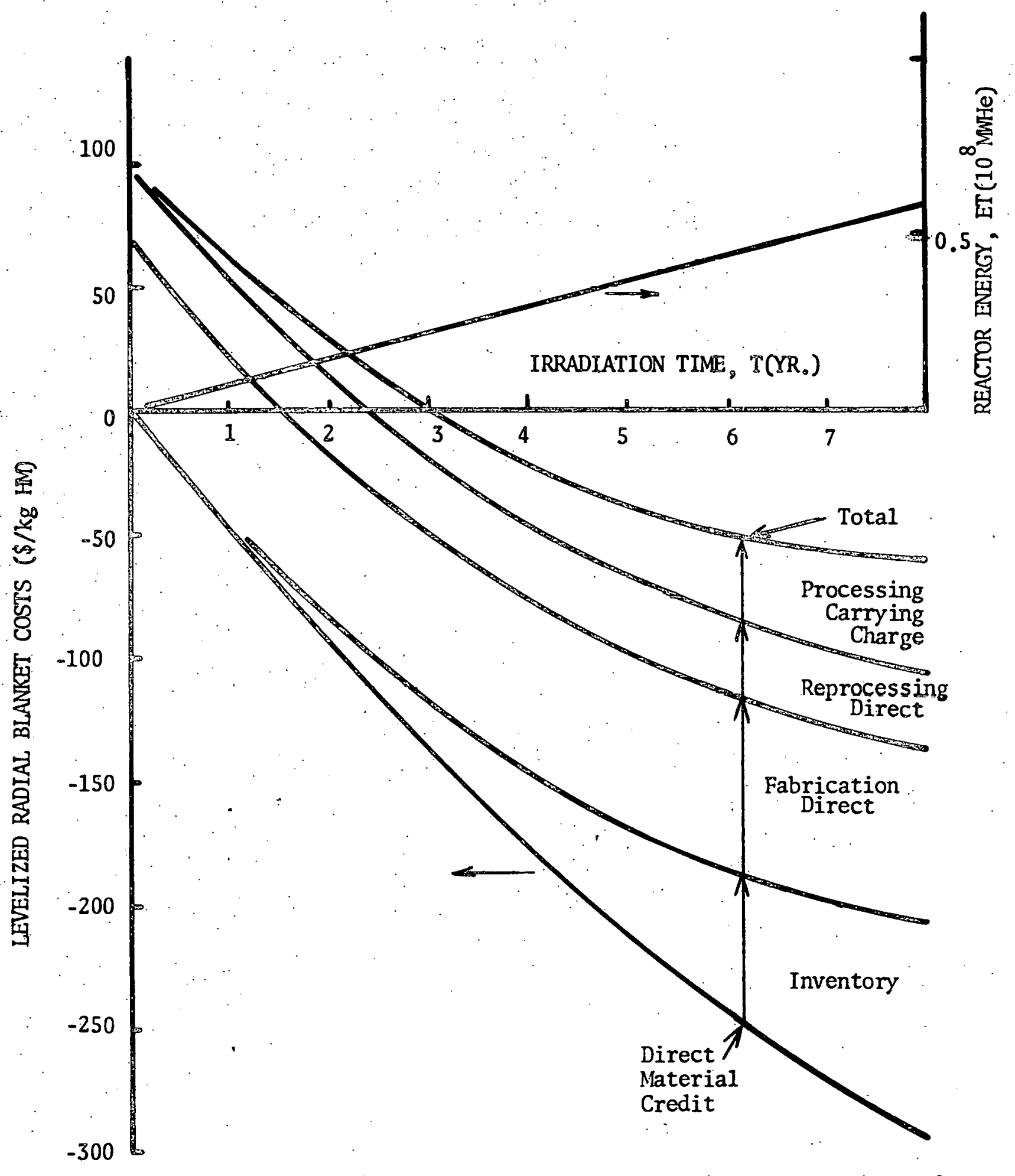

FIG. 2.11 COMPONENTS OF RADIAL BLANKET LEVELIZED COSTS AS FUNCTIONS OF IRRADIATION TIME 


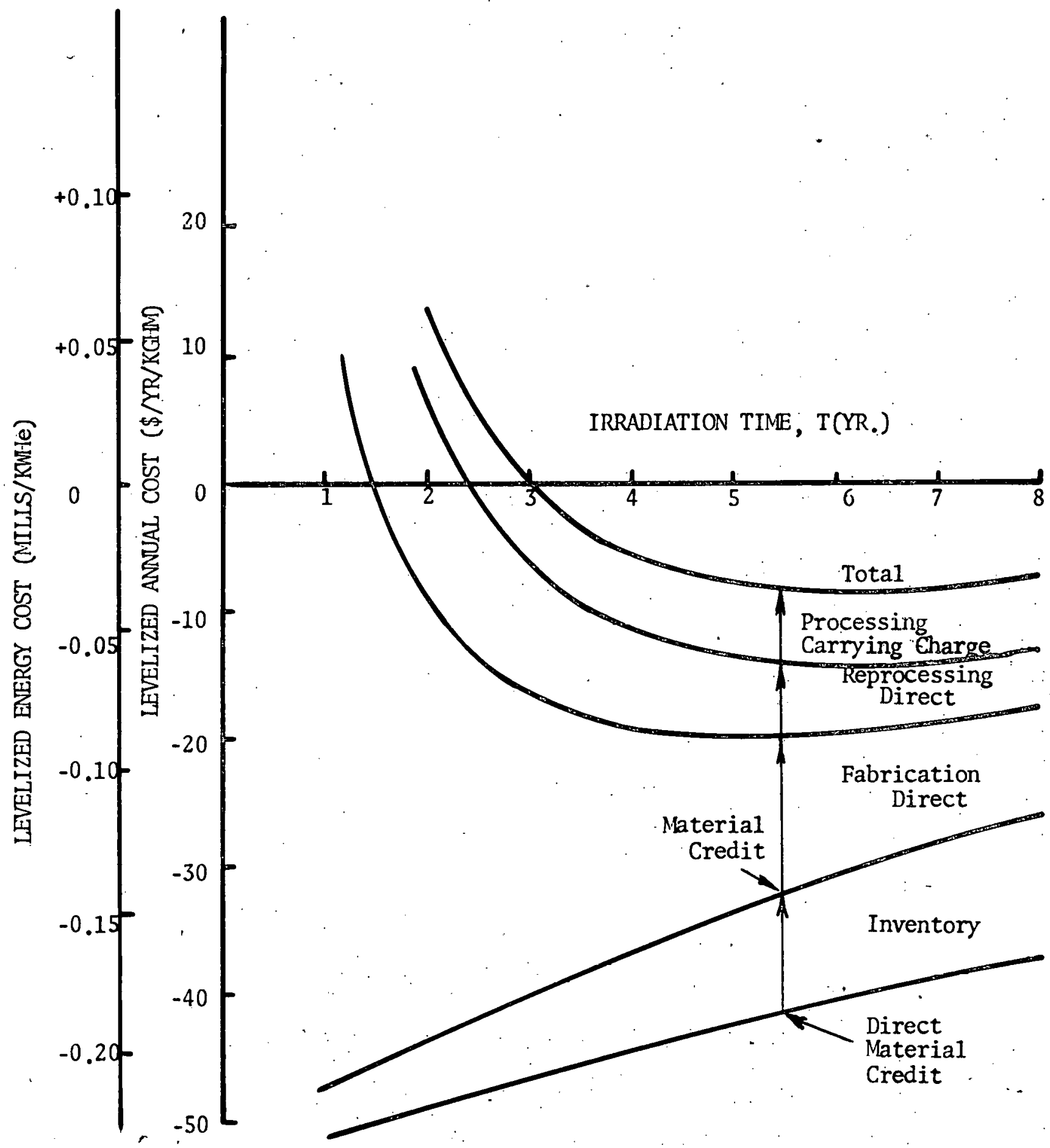

FIG. 2.12 COMPONENTS OF RADIAL BLANKĖT FUEL LEVELIZED ANNUAL COSTS AND ENERGY COSTS AS FUNCTIONS OF IRRADIATION TIME 
From Figure $2.12_{j}$, an optimm radial blanket irradiation time is seen to exist because of the opposing behavior of material credit and processing costs with irradiation time. Material credit decreases (becomes less negative) while processing cost decreases (become less positive).

\subsection{SUMMARY}

A general expression for levelized cost (price) of electricity is derived in Section 2.2. This formulation, labeled the "Cash Flow Method" (CFM) is applied to FBR fuel costs in Section 2.3. When applied to a region (core, axial blanket, or radial blanket) under batch or scatter fuel management, Section 2.4 , the equations reduce to forms giving local fuel economic performance, e.g. in an annular fuel region or at a point. Table 2.6 below summarizes the CFM fuel cost equations.

Effects of the choice of accounting methods are examined in Section 2.5. Within the CFM, two options for treating post-irradiation transactions are identified:

Method A. Tax revenue from the sale of fissile material (material credit) as ordinary income, along with electricity revenue; treat reprocessing costs as tax deductable expenses.

Method B. Capitalize the revenue from the sale of fissile material; capitalize the reprocessing cost. Choice between these two tax interpretations has a significant effect on absolute values of power costs (mills/KWHr), but does not distort comparative and incremental results, e.g. design rankings, optimization of radial blanket residence time, sensitivity studies.

The CFM is related to and compared with two approximate methods of treating carrying charges in Section 2:5: The "Compound Interest Method" (CIM); and the "Simple Interest Method"(SIM). For both capitalized and 
TABLE 2.6 SUMMARY OF FBR FUEL COST ANALYSIS EQUATIONS (CASH FLOW METHOD)

1. Total Reactor Fuel Cost: $\quad \bar{e}($ reactor $)=\sum_{s}\left(e_{s} \ldots \frac{\text { mills }}{\text { KWHe }} \quad s \equiv\right.$ fuel stream index

2. Fuel Stream Cost: $(\overline{\mathrm{e}})_{\mathrm{s}}=\sum_{\mathrm{q}}\left(\overline{\mathrm{e}}_{\mathrm{q}}\right)_{\mathrm{s}} \ldots \ldots \frac{\mathrm{mills}}{\mathrm{kWHe}} \quad \mathrm{q} \equiv$ cost component index

$=\mathrm{mp}, \mathrm{fab}, \mathrm{repr}, \mathrm{mc}$

3. Component Costs of a Stream: $\quad\left(\bar{e}_{q}\right)_{s}=\left(\bar{e}_{q, \text { direct }}\right)_{s}+\left(\bar{e}_{q, \text { CaChg }}\right)_{s} \cdots \cdots \cdots \cdot$ mills

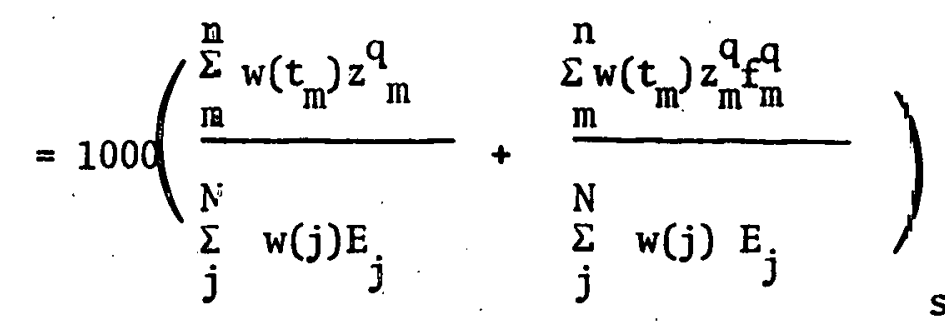

KWHe

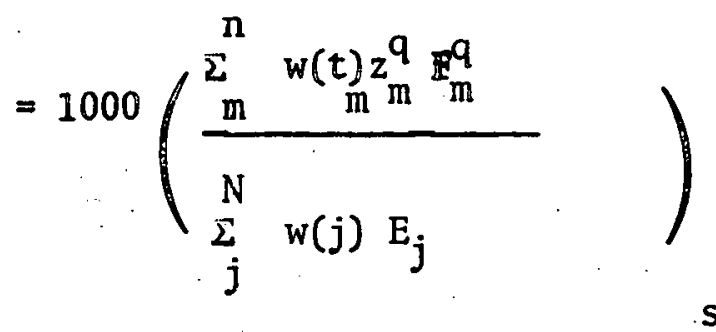

$\mathrm{m} \equiv$ fuel lot index, stream $\mathrm{s}$ 
TABLE 2.6 - continued

4. Carrying Charge Factors:

$\mathrm{F}_{\mathrm{m}}^{\mathrm{q}} \equiv 1+\mathrm{F}_{\mathrm{m}}^{\mathrm{q}} \equiv$ carrying charge factor, component $\mathrm{q}$, fuel lot $\mathrm{m}$ of a given fuel strea

$=\frac{1}{1-\tau}\left[w\left(-T_{m}^{q}\right)-\tau\right] \ldots$ for $q$ capitalized

$=w\left(-T_{m}^{q}\right)$.. for $q$ not capitalized (expensed cost or tax revenues)

where

$$
\begin{aligned}
w(t) & \equiv(1+x)^{-t} \equiv \text { discount factor } \\
x & \equiv(1-\tau) r_{b} f_{b}+r_{s} f_{s} \equiv \text { discount rate } \\
T_{m}^{q} & \text { as defined in Figure } 2.3 \\
\tau & \equiv \text { tax rate. } \\
f_{b} & \equiv \text { bond fraction } \\
f_{s} & \equiv \text { stock fraction } \\
r_{b} & \equiv \text { rate of return to bondholders } \\
r_{s} & \equiv \text { rate of return to stockholders }
\end{aligned}
$$

5. Tax Assumptions

$\frac{\text { Component, q }}{\text { material purchase }}$
Method A

capitalized
Method B

capitalized 
TABLE 2.6 - continued

Component, q
fabrication
reprocessing
material credit

Method A

Method B

capitalized

capitalized

not capitalized

(expensed)

not capitalized

(taxed)

capitalized

capitalized

6. Direct Dollar Costs (per lot, per stream)

$$
\begin{aligned}
& \text { material purchase .. } z_{m}^{m p}=C_{28} M_{28}^{0}+C_{49} M_{49}^{0}+C_{40} M_{40}^{0}+C_{41} M_{41}^{0}+C_{42} M_{42}^{0} \quad \ldots \$ / 1 \text { ot } \\
& \text { fabrication .. } \quad \mathrm{z}_{\mathrm{m}}^{\mathrm{fab}}=\mathrm{C}_{\mathrm{fab}} \mathrm{M}_{\mathrm{HM}}^{\mathrm{O}} \\
& \text { reprocessing .. } \quad \mathrm{z}_{\mathrm{m}}^{\mathrm{repr}}=\mathrm{C}_{\text {repr }} \mathrm{MM}_{\mathrm{HM}}^{0} \\
& \text { material credit .. } \quad \mathrm{z}_{\mathrm{m}}^{\mathrm{mc}}=\mathrm{C}_{28} \mathrm{M}_{28}(\mathrm{~T})+\mathrm{C}_{49} \mathrm{M}_{49}(\mathrm{~T})+\mathrm{C}_{40} \mathrm{M}_{40}(\mathrm{~T})+\mathrm{C}_{41} \mathrm{M}_{41}(\mathrm{~T})+\mathrm{C}_{42} \mathrm{M}_{42}(\mathrm{~T}) \text {. }
\end{aligned}
$$

7. For batch or scatter fuel management of fuel stream $s$ :

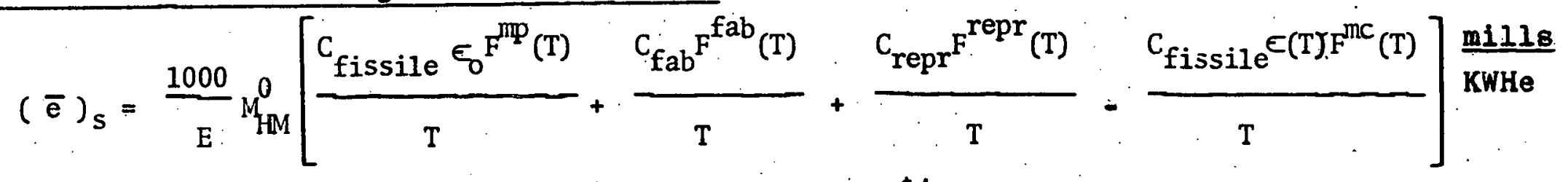

[]$=$ figure of merit, local fuel performance $\cdots \frac{\$ / \mathrm{yr} .}{\mathrm{kg} \mathrm{HM} \text { loaded }}$ 
noncapitalized costs, the carrying charge factors of CIM and CFM are identical. Errors in carrying charge factors, introduced by use of CIM or SIM, are slight for typical core and axial blanket irradiation times about one percent for an irradiation time of two years. At six years, representative of radial blanket batch irradiation, the errors are about $+10 \%$ for the CIM, and $-10 \%$ for the SIM.

The CFM with tax treatment method $A$ is used consistently in the case studies of Chapter 5 . 
Chapter 3

PHYSICS - DEPLETION MODEL

\subsection{INTRODUCTION}

Fuel cost analysis requires that fuel discharge composition be known as a function of irradiation time. The objective of the present chapter is to establish a fast breeder reactor fuel depletion model suitable for fuel economic scoping, survey, ranking and sensitivity studies, but sufficiently simple to permit its use, in the form of a computer code, without incurring excessive computer time or capacity requirements.

Effects of spectral, spatial and time detail on FBR physics-depletion calculations have been the subject of several recent studies (28), (29), (30), (37), (44). In particular, Little et.al. (28) have found that little detail is required for accurate core depletion calculations. This is due to the spatial uniformity of spectrum in the core, and the slow variations of flux magnitude and spectrum with irradiation time.

Blanket physics-depletion is considerably more complex, due to the following:

(1) spectrum softening with distance from the core-blanket interfact;

(2) spectrum hardening with irradiation time due to the relatively large buildup of fissile plutonium in the blanket;

(3) flux shift, i.e. increase in blanket flux with irradiation time, due to the buildup of fissile plutonium in the blanket; and

(4) spatial self-shielding (heterogeneity) effects occasioned by the softer blanket spectrum, and. aggravated, in the case of radial 
blankets, by larger fuel pin diameters.

Effect (1) requires that cross-sections be input to the calculation with sufficient spatial detail, i.e. a separate cross-section set, properly flux weighted, for each of many blanket regions. Effects (2) and (3) suggest that physics calculations be performed sufficiently often, during a time step depletion calculation, to correct the local cross-sections and fluxes.

Parametric and survey studies commonly require the evaluation of numerous cases involving different configurations and compositions, and if models are unnecessarily complex, the computation costs may be prohibitive. In physics-depletion calculations, practically all of the computer time is absorbed by the static physics computations (neutron balances) which yield flux magnitudes and spectra at discrete points in irradiation time and space. The calculations of composition changes between these points in time, using the nuclide depletion equations, require negligible effort in terms of computer time. Hence, computer expense can be significantly reduced by decreasing the number of static physics calculations, i.e. maximizing the length of the irradiation time intervals over which flux magnitudes and spectra are treated as being constant. For this reason, studies were performed, Section 3.4, to assess the effects of item (2), spectrum hardening, and item (3), flux shift, on depletion calculation results.

Conventional multigroup time step depletion (MG-TSD) methods (26), against which simpler methods are to be judged, permit local fluxes and spectra to vary with irradiation. One group time step depletion calcu- lations (IG-TSD) permit local fluxes (flux shape) but not spectra, to vary with irradiation. Both MG-TSD and 1G-TSD models yield reactivity behavior with irradiation, or, altematively, may involve performing 
criticality searches on control poison concentrations. Time step depletion methods are described in Section 3.2.

A simpler (and less expensive) depletion model, the "S-mi-Analytic Depletion Me thod"(SAM), has been developed in this study, and is introduced in Section 3.3. This method is based on the assumptions that both flux (local) and spectrum (local) are constant with irradiation time (or exposure), thus requiring only one multigroup neutron balance for a given reactor configuration. The assumptions of constant local flux and local spectrum, while suitable for the core, may be questionable for the blankets, due to the rapid buildup of fissile plutonium in the blankets. Effects of these assumptions on core, axial blanket, and radial blanket depletion results are evaluated in Section 3.4 by comparing results of three parallel depletion calculations (26G-TSD, 1G-TSD, and SAM) .

In SAM, only one multigroup physics calculation is performed. Thus SAM does not provide the $k_{\text {eff }}$ behavior with irradiation. This limitation is discussed in Section 3.5.

Effects of spatial self-shielding on blanket depletion results are estimated in Section 3.7 .

\subsection{DESCRIPTION OF TIME STEP DEPLETION (TSD) CALCULATIONS}

Depletion calculations are central to several reactor design functions, yielding space-time-dependent power densities for thermal design, reactivity and criticality information for control system design and absorber management, and fuel discharge compositions for fuel management.

Conventional time step depletion (TSD) calculations may be characterized as one or more neutron balance (in space and energy) conputations ("physics"), separated in the irradiation time domain by depletion ("burnup") computations 
describing the changes in nuclide populations at each point or region. This process is shown schematically in Figure 3.1. Preparation for the TSD calculation includes the selection of a standard multigroup cross-section set, e.g. the Russian Set (48), the Yiftah-Okrent-Moldauer Set (49), the Hansen-Roach Set ( $\underline{50}$ ), or cross-section file, e.g. ENDF/B. More refined calculations may require corrections to this parent cross-section data. Such corrections may be performed by a "cross-section generating program", such as $1 D X(27), M C^{2}(\underline{39})$, or TDOWN (40). For example, given a reactor configuration (geometry, composition) and the parent cross-section data, 1WX performs resonance and spatial shielding corrections by region, and collapses to regional few group sets if desired. The resulting multigroup set. is then used as input to the TSD calculation, which may be performed by a computer program such as 2DB (26), PHENIX (31), PYRE (34), or CITATION (47).

With reactor geometry and initial compositions, $\left\{N_{i}(\bar{r}, 0)\right\}$, as input, the TSD begins with a physics calculation at time zero. This calculation yields initial flux shapes and position-dependent spectra, $\phi(\bar{r}, E, 0)$, and the initial effective multiplication constant $k_{\text {eff }}(0)$. (Some programs provide the option of performing a "criticality search" on compositions or dimensions to obtain $k_{\text {eff }}=1$ at each physics calculation.) The flux profile is normalized to the reactor power specified.

Flux shape and spectrum, $\phi(\bar{r}, E, 0)$, serve as input to the depletion calculation and are assumed constant over the next time interval, that is, until the next physics calculation. Depletion calculations are performed individually for each specified zone. Each zone normally consists of several spatial mesh points; zone fluxes are obtained by appropriate spatial averaging, and nuclide composition is assumed uniform over the zone. The zone depletion equation for nuclide $j$ is 


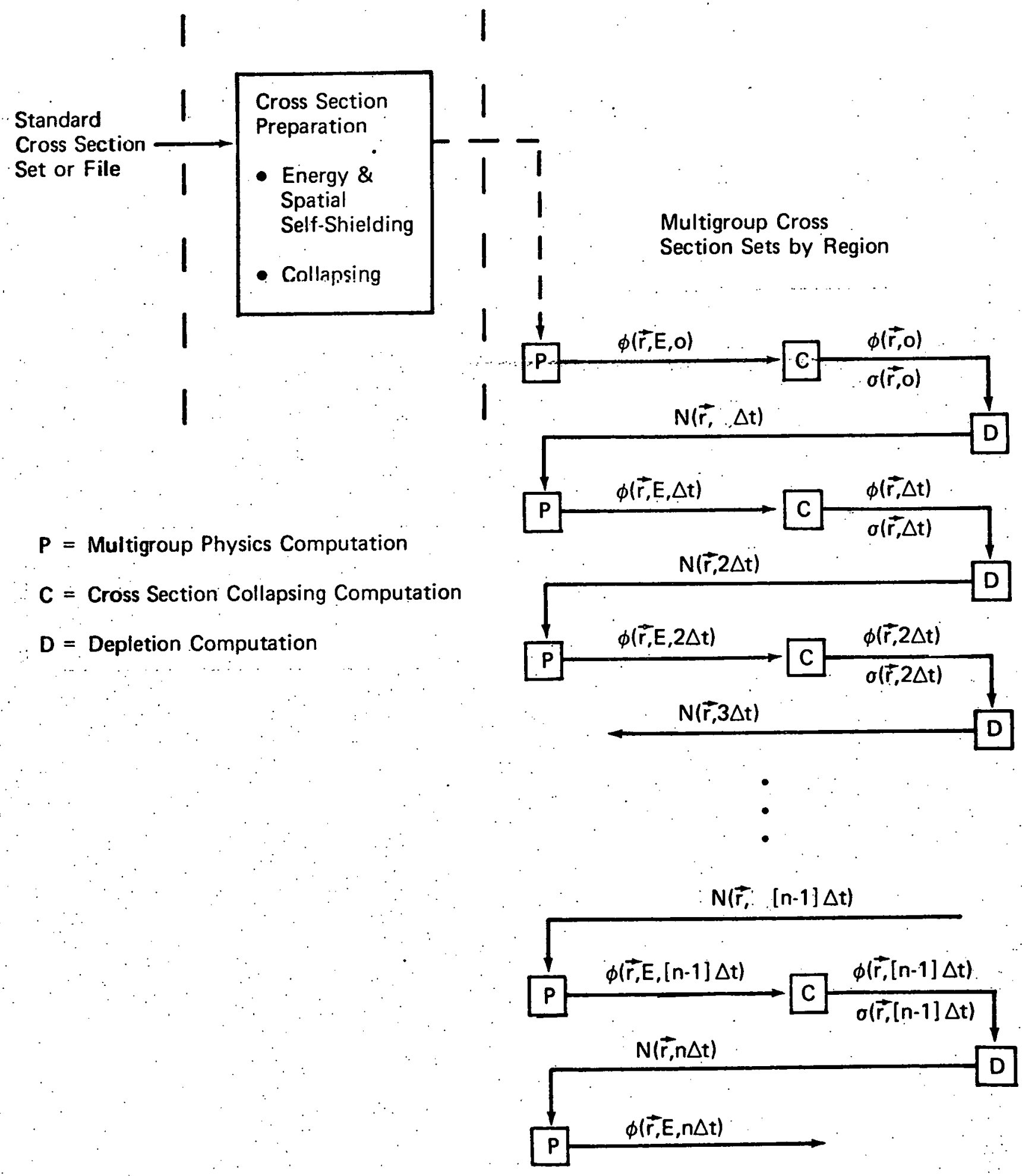


118

$$
\begin{aligned}
& \frac{d N_{j}}{d t}=-\lambda_{j} N_{j} \\
& -N_{j} \sum_{k=1}^{n} \quad \phi_{k} \quad q_{k, a}^{j} \\
& +\lambda_{i} N_{i} \\
& +\sum_{\mathrm{m}} \mathrm{N}_{\mathrm{ml}} \sum_{\mathrm{k}=1}^{\mathrm{n}} \phi_{\mathrm{k}} \underset{\mathrm{k}, \mathrm{c}}{\sigma^{\mathrm{m}}} \\
& +\sum_{q} N_{q} y_{q, j} \underset{k=1}{n} \phi_{k} \sigma_{k, f}^{q}
\end{aligned}
$$

(3-1)

where

$$
\begin{aligned}
j & \equiv \text { nuclide index } \\
k & =\text { energy group index } \\
m & =\text { capture parent index } \\
i & \equiv \text { dec say parent index } \\
q & \equiv \text { fission parent index } \\
N_{j} & \equiv \text { atom density, nuclide } j, \text { in the zone (atoms } / \mathrm{cm}^{3} \text { ) }
\end{aligned}
$$$$
\phi_{k} \equiv \text { group } k \text { neutron flux in the zone }\left(n / \mathrm{cm}^{2} \text { sec }\right)
$$

$$
\begin{aligned}
\sigma_{\mathrm{k}, \mathrm{j}}^{\mathrm{j}} & \equiv \text { microscopic cross-section for event e, group } k \text {, nuclide } j\left(\mathrm{~cm}^{2}\right) \\
e & =a \text {, absorption } \\
& =c \text {, capture } \\
& =f \text {, fission } \\
{ }_{j} & \equiv \text { dec day constant, nuclide } j \quad\left(\sec ^{-1}\right) \\
t & \equiv \text { time (sec) } \\
y_{q, j} & \equiv \text { yield of nuclide } j \text { per fission of nuclide } q .
\end{aligned}
$$


Rates of neutron-induced reactions may be expressed in terms of spectrum-weighted cross sections (collapsed to one group) by noting that, in the zone in question,

$$
\begin{aligned}
\sum_{k=1}^{n} \phi_{k} \sigma_{k, x}^{y} & =\frac{\left(\sum_{k=1}^{n} \phi_{k}\right)\left(\sum_{k=1}^{n} \phi_{k} \sigma_{k, x}^{y}\right)}{\left(\sum_{k=1}^{n} \phi_{k}\right)} \\
& =\phi \sigma_{x}^{y}
\end{aligned}
$$

where

$$
\begin{aligned}
& \phi \equiv \text { total flux } \sum_{\mathrm{k}=1}^{\mathrm{n}} \phi_{\mathrm{k}}
\end{aligned}
$$

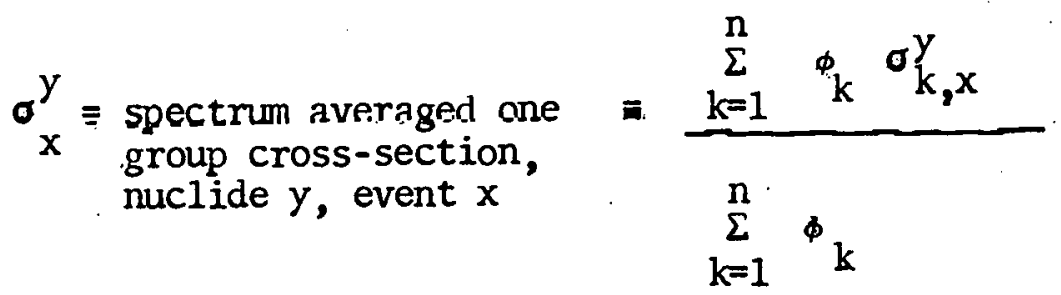

Coefficients of the nuclide depletion equation are thus seen to be one group microscopic cross-sections, collapsed in the zone spectrum, and Equation (3-1) takes the form

$$
\frac{d N_{j}}{d t}=-\lambda_{j} N_{j}-N_{j} \phi \sigma_{a}^{j}+\lambda_{i} N_{i}+\sum_{m} N_{m} \phi q^{m}+\sum_{q} N_{q} y_{q, i} \phi \underset{f}{\sigma q}
$$

The collapsing implied in going from Equation (3-2) to Equation (3-5) does not represent any further approximation or loss of generality.

With the flux information $\phi(\bar{r}, E, 0)$ from the initial physics calculations, zone fluxes and cross-sections are computed with Equations (3-3), (3-4) and used in equations of the form of Equation (3-5) to determine zone 
compositions at the end of the time interval $\Delta t$, assuming the $\phi$ and $\sigma$ are constant over $\Delta t$. Equations (3-5) may be solved analytically, if the important nuclide chains are simple and known, or in a finite difference fashion, if more flexibility in programming is desired.

The reactor composition thus computed, $\left\{N_{j}(\bar{r}, t)\right\}$ at $t=\Delta t$; is used in the next physics calculation to obtain $\phi(\bar{r}, t, E)$ and $k_{\text {eff }}$ at $t=\Delta t$. Again, the flux is normalized to the specified constant reactor power. Zone fluxes and cross-sections collapsed in zone spectra are then used in the depletion calculation for the second time step, yielding $\left\{N_{j}(\bar{r}, t)\right\}$ at $t=2 \Delta t$. This cycle of "physics-collapse-deplete". is repeated until the specified end of the calculation is reached.

The procedure just described accounts for variations in flux shape with irradiation since physics calculations are performed periodically. If these physics calculations are of two or more energy groups, variations in spectra (with irradiation) are also account for. The TSD computation may be made more refined by decreasing the irradiation time interval between physics calculations and increasing the number of energy groups. One group TSD calculations will assess the flux shape variation, but not spectrum variations.

\subsection{SEMI -ANALYTIC DEPLETION METHOD (SAM)}

\subsubsection{Introduction}

If local flux and local spectrum are assumed constant over the entire irradiation time, then only one multigroup physics calculation is necessary. The local $\phi ' s$ and of from this "snapshot" may be used in the analytic solutions of the coupled depletion equations of the form (3-5) to obtain the local fuel composition as a function of irradiation time. Such a procedure will be labeled the "Semi-Analytic Depletion Method (SAM". 
3.3.2 Analytic Solution of Depletion Equations

For a uranium-plutonium fueled FBR, the important nuclides (for fuel economics) are U238, Pu239, Pu240, Pu241, Pu242. Their coupled depletion equations are:

U238: $\frac{\mathrm{dN}_{28}}{\mathrm{dt}}=-\mathrm{N}_{28} \phi \sigma \underset{\mathrm{a}}{28}$

Pu239: $\frac{\mathrm{dN}_{49}}{\mathrm{dt}}=\mathrm{N}_{28} \phi \sigma_{\mathrm{c}}^{28}-\mathrm{N}_{49} \phi \sigma_{\mathrm{a}}^{49}$

Pu240: $\frac{{ }_{40}}{d t}=N_{49} \phi \sigma_{C}^{49}-N_{40} \phi \sigma_{a}^{40}$

Pu241: $\frac{\mathrm{dN}_{41}}{\mathrm{dt}}=\mathrm{N}_{40} \phi \sigma_{\mathrm{C}}^{40}-\mathrm{N}_{41} \phi \sigma_{\mathrm{a}}^{41}-\lambda_{41} \mathrm{~N}_{41}$

Pu242: $\frac{\mathrm{dN}_{42}}{d t}=\mathrm{N}_{41} \phi \sigma_{\mathrm{c}}^{41}-\mathrm{N}_{42} \phi \sigma_{\mathrm{a}}^{42}$

where

$$
\Phi, \sigma_{x}^{y}=\sum_{k=1}^{n} \phi_{k} \cdot \frac{\sum_{k=1}^{n} \phi_{k} \underset{k, x}{\sigma y}}{\sum_{k=1}^{n} \phi_{k}}
$$

Without decay terms, nuclide depletion equations and their solutions may be expressed in more convenient form with flux time $(\theta)$,

$$
\begin{aligned}
\theta(t) & \equiv \int_{\phi}^{t}\left(t^{\prime}\right) d t^{\prime} \\
d \theta(t) & \equiv \phi(t) d t
\end{aligned}
$$

as the independent variable. Of the nuclides involved, only Pu241 suffers 
a significant dec a loss (half life 14 years). Assuming for the moment that Pu241 decay may be neglected, Equations (3-6) take the following form:

U238: $\frac{\mathrm{dN}_{28}}{\mathrm{~d} \theta}+{\stackrel{\sigma}{\sigma^{\circ}}}^{28} \mathrm{~N}_{28}=0$

Pu239: $\frac{\mathrm{dN}_{49}}{\mathrm{~d} \theta}+d_{\theta^{9}} \mathrm{~N}_{49}=\sigma_{c}^{28} \mathrm{~N}_{28}$

Pu240: $\frac{\mathrm{dN}_{40}}{\mathrm{~d} \theta}+{ }_{\mathrm{\sigma}}^{40} \mathrm{~N}_{40}=\sigma_{c}^{49} \mathrm{~N}_{49}$

$\mathrm{dN}$

Pu241: $\frac{41}{d \theta}+\underset{a}{\sigma 1} \mathrm{~N}_{41}=\stackrel{\mathrm{c}}{40}_{40} \mathrm{~N}_{40}$

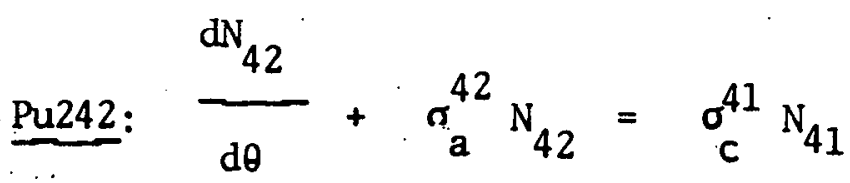

Assuming the cross-sections $\{\sigma\}$ are independent of flux time $(\theta)$, the solutions of the set (3-8), to be applied locally, are

U238: $\quad N_{28}=N_{28}^{0} \exp \left(-\sigma_{a}^{23} \theta\right)$

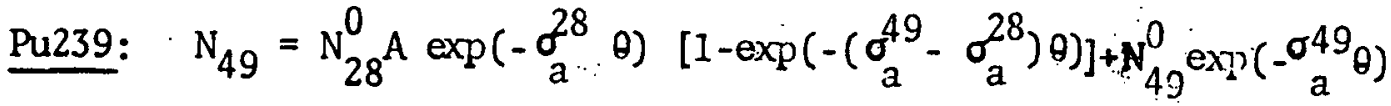

Pu240: $\quad N_{40}=N_{28}^{0} A B \exp \left(-\sigma_{a}^{28} \theta\right)-N_{28}^{0} A B_{2} \exp \left(-\sigma_{a}^{49} \theta\right)$

$$
+N_{49}^{0} B_{2} \exp \left(-\sigma_{a}^{49} \theta\right)+\beta_{1} \exp \left(-\sigma_{a}^{40} \theta\right)
$$

Pu241: $\quad N_{41}=N_{28}^{0} A_{1} C_{1} \exp \left(-\sigma_{a}^{28} \theta\right)-N_{28}^{0} A_{2} C_{2} \exp \left(-\sigma_{a}^{49} \theta\right)$

$$
\begin{aligned}
& +N_{49}^{0} B_{2} C_{2} \exp \left(-\sigma_{a}^{49} \theta\right)+\beta_{1} C_{3} \exp \left(-\sigma_{a}^{40} \theta\right) \\
& +\beta_{2} \exp \left(-\sigma_{a}^{41} \theta\right)
\end{aligned}
$$




$$
\text { Pu242: } \begin{aligned}
N_{42} & =N_{28} A B_{1} C_{1} D_{1} \exp \left(-\sigma_{a}^{49} \theta\right)-N_{28}^{0} A B_{2} C_{2} D_{2} \exp \left(-\frac{\sigma^{49} \theta}{a}\right) \\
& +N_{49}^{0} B_{2} C_{2} D_{2} \exp \left(-\sigma_{a}^{49} \theta\right)+{ }_{1} C_{3} D_{3} \exp \left(-\sigma_{a}^{40} \theta\right) \\
& +\beta_{2} D_{4} \exp \left(-\sigma_{a}^{42} \theta\right)+\beta_{3} \exp \left(-\sigma_{a}^{42} \theta\right)
\end{aligned}
$$

where

$$
\begin{aligned}
& A \equiv \frac{\sigma_{c}^{28}}{\sigma_{a}^{49}-\frac{\sigma_{a}^{28}}{a}} \\
& \mathrm{~B}_{1} \equiv \frac{\sigma^{49}}{\sigma_{a}^{40}-\sigma_{a}^{28}} \\
& B_{2} \equiv \frac{\sigma^{49}}{\sigma_{a}^{40}-\sigma_{a}^{49}} \\
& C_{1} \equiv \frac{\sigma_{c}^{40}}{\sigma_{a}^{41}-\sigma_{a}^{28}} \\
& C_{2} \equiv \frac{\sigma_{c}^{40}}{\sigma_{a}^{41-} \sigma_{a}^{49}} \\
& C_{3} \equiv \frac{\sigma_{c}^{40}}{\sigma_{a}^{41}-\sigma_{a}^{40}} \\
& D_{1} \equiv \frac{\sigma_{c}^{41}}{\sigma_{a}^{42}-\sigma_{a}^{28}} \\
& \mathrm{D}_{2} \equiv \frac{\sigma_{\mathrm{c}}^{41}}{\frac{\sigma_{a}^{42}-\frac{\sigma^{49}}{a}}{\sigma^{49}}} \\
& D_{3} \equiv \frac{\sigma_{c}^{41}}{\sigma_{a}^{42}-\sigma_{a}^{40}} \\
& D_{4}=\frac{\sigma_{c}^{41}}{\sigma_{a}^{42}-\sigma a} \\
& \mathrm{~B}_{1} \equiv \mathrm{N}_{40}^{0}-\left(\mathrm{N}_{28}^{0} \mathrm{AB}{ }_{1}-\mathrm{N}_{28}^{0} \mathrm{AB} \mathrm{B}_{2}+\mathrm{N}_{49}^{0} \mathrm{~B}_{2}\right) \\
& \beta_{2} \equiv N_{41}^{0}-\left(N_{28}^{0} A B_{1} C_{1}-N_{28}^{0} A_{2} C_{2}+N_{49}^{0} B_{2} C_{2}+B_{1} C_{3}\right) \\
& \mathrm{B}_{3}=\mathrm{N}_{42}^{0}-\left(\mathrm{N}_{28}^{0} A \mathrm{~B}_{1} \mathrm{C}_{1} \mathrm{D}_{1}-\mathrm{N}_{28}^{0} \mathrm{AB} \mathrm{B}_{2} \mathrm{C}_{2} \mathrm{D}_{2}+\mathrm{N}_{49}^{0} \mathrm{~B}_{2} \mathrm{C}_{2} \mathrm{D}_{2}{ }^{\mathrm{B}_{1}} \mathrm{C}_{3} \mathrm{D}_{3}+{ }^{\mathrm{B}}{ }_{2} \mathrm{D}_{4}\right)
\end{aligned}
$$

In expressing Equation (3-6d) in terms of flux time, Equation (3-8d), Pu241 decay was neglected. Without this assumption, the details of the flux history and out of pile processing and cooling schedules would be required 
for estimates of Pu241 and Pu242 populations.

Using the representative FBR blanket reaction rate

$$
\sigma^{41} \phi \simeq 1.8 \times 10^{-8} \mathrm{sec}^{-1},
$$

the $\mathrm{Pu} 241$ decay rate is seen to be about $10 \%$ of its absorption loss rate:

$$
\frac{\lambda_{41}}{\sigma_{\alpha}^{41_{\phi}}} \simeq \frac{1.57 \times 10^{-9} \mathrm{sec}^{-1}}{1.8 \times 10^{-8} \mathrm{sec}^{-1}}=0.087 \simeq 10 \%
$$

The solution of Equation (3-6d) assuming constant $N_{40}, \phi$, and $\sigma^{\prime} s$ is

$$
\begin{aligned}
N_{41}= & N_{40}^{0} \frac{\sigma_{c}^{40}}{\sigma_{a}^{41}\left(\frac{\lambda_{41}}{\left(1+\sigma^{41} \phi\right.}\right)}\left[1-\exp \left(-\sigma_{a}^{41} \phi\left(1+\frac{\lambda_{41}}{\sigma_{a}^{41} \phi}\right) t\right)\right] \\
& +N_{41}^{0} \exp \left(-\sigma_{a}^{41} \phi\left(1+\frac{\lambda_{41}}{\sigma_{a}^{41} \phi}\right) t\right)
\end{aligned}
$$

Letting $N_{41}^{*}$ denote the Pu241 concentration calculated by ignoring decay, and assuming no initial Pu241, one finds that for an irradiation time of 10 years,

$$
\frac{\mathrm{N}_{41}}{\mathrm{~N}_{4 \mathrm{i}}^{*}} \simeq 0.97
$$

Under these conditions, the assumption of no Pu241 decay results in an overprediction of about $3 \%$ in $\mathrm{N}_{41}$.

\subsection{3 - Summary}

The semi-analytic depletion method (SAM) assumes that local spectra and local flux magnitudes do not change with irradiation time. The assump- 
tion of constant local fluxes contains another assumption: that the reactor flux shape does not change with irradiation time.

SAM differs from the time step depletion method in that only one multigroup physics computation is performed. Local fluxes and local spectrumweighted cross-sections from this single physics computation are used as input to Equation (3-7) and Equations (3-9) to obtain local fuel compositions as functions of irradiation time.

\subsection{EFFECTS OF THE ASSUMPTIONS OF CONSTANT LOCAL FLUX AND SPECTRUM}

\subsubsection{Description}

The semi-analytic method (SAM) uses neutronic data (local $\sigma$ 's and $\phi$ 's) from a single multigroup neutron balance to obtain local fuel composition as a function of irradiation time. These local $\sigma$ 's and $\phi$ 's are assumed constant throughout the irradiation life of the fuel. The constant $\phi$ and constant $\sigma$ assumptions produce opposing errors in calculations of blanket discharge fissile inventory.

The effects of these assumptions were estimated by comparing results of three parallel depletion calculations (Methods a, b and c) described in Table 3.1 and Figure 3.2. Two sets of comparisons were made:

(1) Reactor \#1: Reference Reactor (sodium radial reflector); no fission products included in the TSD methods; comparison of methods a, $\mathrm{b}$, and $\mathrm{c}$.

(2) Reactor \#2: Identical in all respects to reactor \#1, except that Be metal is used as the radial reflector; fission products included in the TSD method; comparison of methods a and c.

The reference reactor (\#1) configuration is described in Figure 3.3. Selection of this reactor as a reference is discussed in Chapter 4. The Be-reflected reactor $(\# 2)$ is obtained by replacing the $\mathrm{Na}$ of zone 24 with 
TABLE 3.1 DEPLETION CALCULATIONAL METHODS TO DETERMINE EFFECTS OF CONSTANT FLUX, CONSTANT SPECTRUM ASSUMPTIONS

\begin{tabular}{|c|c|c|c|c|c|}
\hline \multirow[b]{2}{*}{ Method } & \multirow[b]{2}{*}{ Description } & \multicolumn{2}{|r|}{ ASSUMPTIONS } & \multicolumn{2}{|c|}{ Allowec to Vary } \\
\hline & & Program & Input Data Source & Local ф's & Local o's \\
\hline a & 26G-TSD & $2 \mathrm{DB}^{*}$ & $\sigma(E)$ 's from $10 X$ & yes & yes \\
\hline b & 1G-TSD & $2 \mathrm{DB} *$ & $\sigma^{\prime} \mathrm{s}$ from a at $t=0$ & yes & no \\
\hline c & SAM & SPPIA & $\begin{array}{c}\phi^{\prime} s \text { and } \sigma \text { 's from } \\
\text { a at } t=0\end{array}$ & no & no \\
\hline
\end{tabular}

* Ref. (26)

** SPPIA is a program written to perform SAM calculations, and is described in Appendix $C$. 


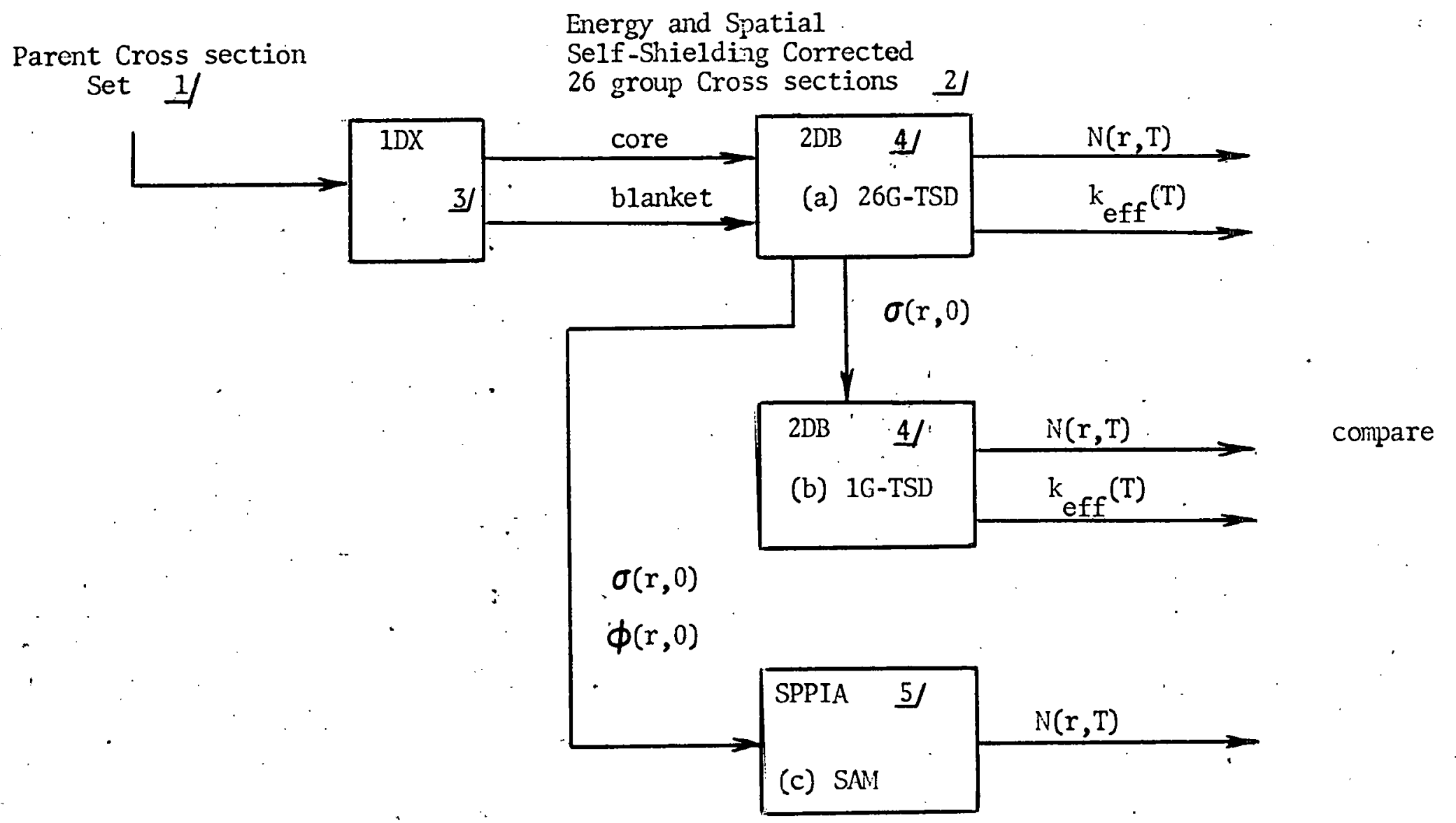

1 Ref. 48

Ref. 81

3 Ref. $\frac{27}{26}$

4 Ref. 26

5 SPPIA is a program written to perform SAM calculations, and is described in Appendix C.

FIG. 3.2 PROCEDURE FOR METHODS COMPARISONS: 26G-TSD vs. 1G-TSD vs. SPM 


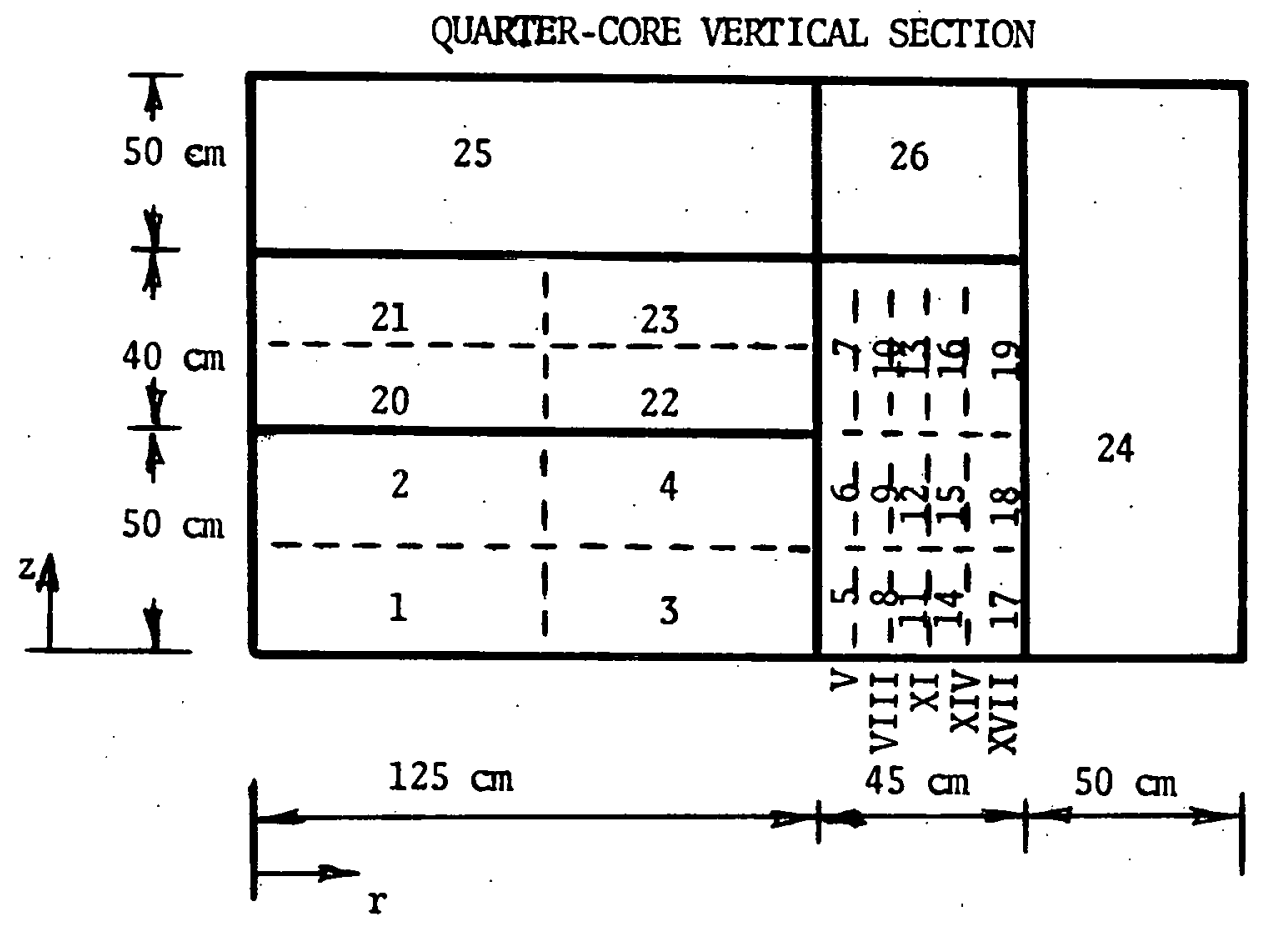

VOLUME FRACTIONS

REGION CORE RADIAL AXIAL RADIAL AXIAL AX.REFL. FOR BLANKET BLANKET REFL. REFL. RAD. BKT.

$\begin{array}{lllllll}\text { ZONE } & 1-4 & 5-19 & 20-23 & 24 & 25 & 26 \\ \text { SODIUM } & 0.50 & 0.30 & 0.50 & 1.00 & 0.50 & 0.30 \\ \text { OXIDE } & 0.30^{*} & 0.50 & 0.30 & 0 & 0 & 0 \\ \begin{array}{l}\text { SS } \\ \text { CR-FE-NI }\end{array} & 0.20 & 0.20 & 0.20 & 0 & 0.50 & 0.70\end{array}$

* INITIAL CORE ENRICHMENT $=14 \%$

FIG. 3.3 RFERENCE LMEBR CONFIGURATION (REACTOR \#1). 
Be metal.

Zone definitions are also shown in Figure 3.3. In all three methods, each burnable zone $(1,2, \ldots, 23)$ was depleted individually, that is, a zone was the basic volume unit over which number densities were "smeared" at each time step. The same zone definitions were used for inputting the space-dependent one group cross-sections for methods b(1G-TSD) and c(SAM) and the flux shape for method $c$ (SAM).

For purposes of displaying results, and for use in fuel economic analysis. (but not in the physics-depletion calculations) zone compositions were combined to form "region" compositions. For example, the inner-most radial blanket region (' $\left."{ }^{\prime \prime}\right)$ is the sum of zones 5, 6 and 7, and

$$
\begin{aligned}
& M_{49}^{V}(t)=M_{49}^{5}(t)+M_{49}^{6}(t)+M_{49}^{7}(t), \\
& \epsilon_{49}^{V}(t)=M_{49}^{V}(t) / M_{H M}^{V}(0)
\end{aligned}
$$

The TSD calculations $(a, b)$ allowed $k_{\text {eff }}$ to vary with burnup; that is, criticality searches were not performed. Effects of this sinplification (neglect of flux shape and spectral perturbations introduced by control poison) are considered negligible (29).

In the TSD runs $(a, b)$, physics computations were performed at 150 equivalent full power day (EFPD) intervals. Each of these physics computations yielded the current $k_{\text {eff }}$, the current flux shape, and in the case of the multigroup run (a), the local spectra. After each physics computation, the flux was normalized to a total reactor power of $2576 \mathrm{MN}_{t}$, corresponding to $1000 \mathrm{MW}_{\mathrm{e}}$ and a plant thermal efficiency of $39 \%$.

In the TSD calculations, the core and axial blanket were assumed discharged at $600 \mathrm{EFPD}$, corresponding to an average core burnup of 100,000 
MWD ${ }_{t} /$ MT. At a plant load factor of $82 \%$, this is consistent with a core residence time of two years. The radial blanket remained in situ until the end of the depletion calculation at 1200 EFPD ( 4 years). Batch fuel management of the radial blanket and the core-axial blanket combination was assuned, which imposes a more severe test of constant flux, constant spectrum assumptions than scatter management.

\subsubsection{Results (with Time as the Independent Variable)}

The results of the methods-comparisons are reported below by major region (core, axial blanket, radial blanket).

Core

Tables 3.2 and 3.3 show the core depletion results (fissile plutonium population) for reactors $\# 1$ and $\# 2$ respectively. Excellent agreement between methods $a, b$ and $c$ is noted: at two years irradiation $\left(100,000 \mathrm{MWD}_{t} / \mathrm{MT}\right)$, discrepancies in fissile masses are about $0.03 \%$ for Pu239 and about $1 \%$ for Pu241. Zone spectra remain practically constant, accounting for the success of method b. This, together with the result that zone fluxes were fairly constant, explains the close agreement of method $c$ with the other two methods.

The second core load (600 to 1200 EFPD) shows a very slight increase in discharge Pu239 and decrease in discharge Pu241, compared to the first core load. This results from the flux shift to the radial blanket, which is not replaced at two years. As fissile Pu builds up in the radial blanket, the radial blanket provides a greater fraction of total reactor power, decreasing somewhat the powerload, and flux, in the core.

\section{Axial Blanket}

Axial blanket depletion results for reactors \#1 and \#2 are shown in 
TABLE 3.2

COMPARISON OF CORE DEPLETION RESULTS FOR

REACTOR \#I (REFERENCE REACTOR)

Equiv.

Reactor

Ful1 Power

Time

(D)

0

300

600

$600+$

900

1200

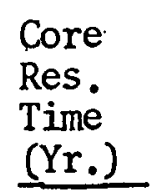

0

1

2

0

1

2
Method

(a)

26G-TSD

$\epsilon_{49}$

$\epsilon_{41}$

$\epsilon_{49}$

$\epsilon_{41}$

12.89

0.062

11.90

0.175

14.05

0

$\epsilon_{49}$

12.93

$\epsilon_{41}$

0.058

11.97

0.168

$M_{49}=$ Pu239 mass

$\mathrm{i}_{41}=$ Pu241 mass

(b)

0

$\epsilon_{49}$

$\epsilon_{41}$ (c)

1G-TSD SAM

$14.05 \quad 14.05$

12.89

12.89

0.062

0.062

11.98

11.90

0.165

0.175

$\epsilon_{41}=100 \times \mathrm{M}_{41} / \mathrm{M}_{\mathrm{H}}^{0}$

Wing $=$ mass of heavy metal loaded (kg) $=12623 \mathrm{~kg}$ 
TABLE 3.3

COMPARISON OF CORE DEPLETION RESULTS FOR

REACTOR \#2 (Be-RADIAL REFLECTOR)

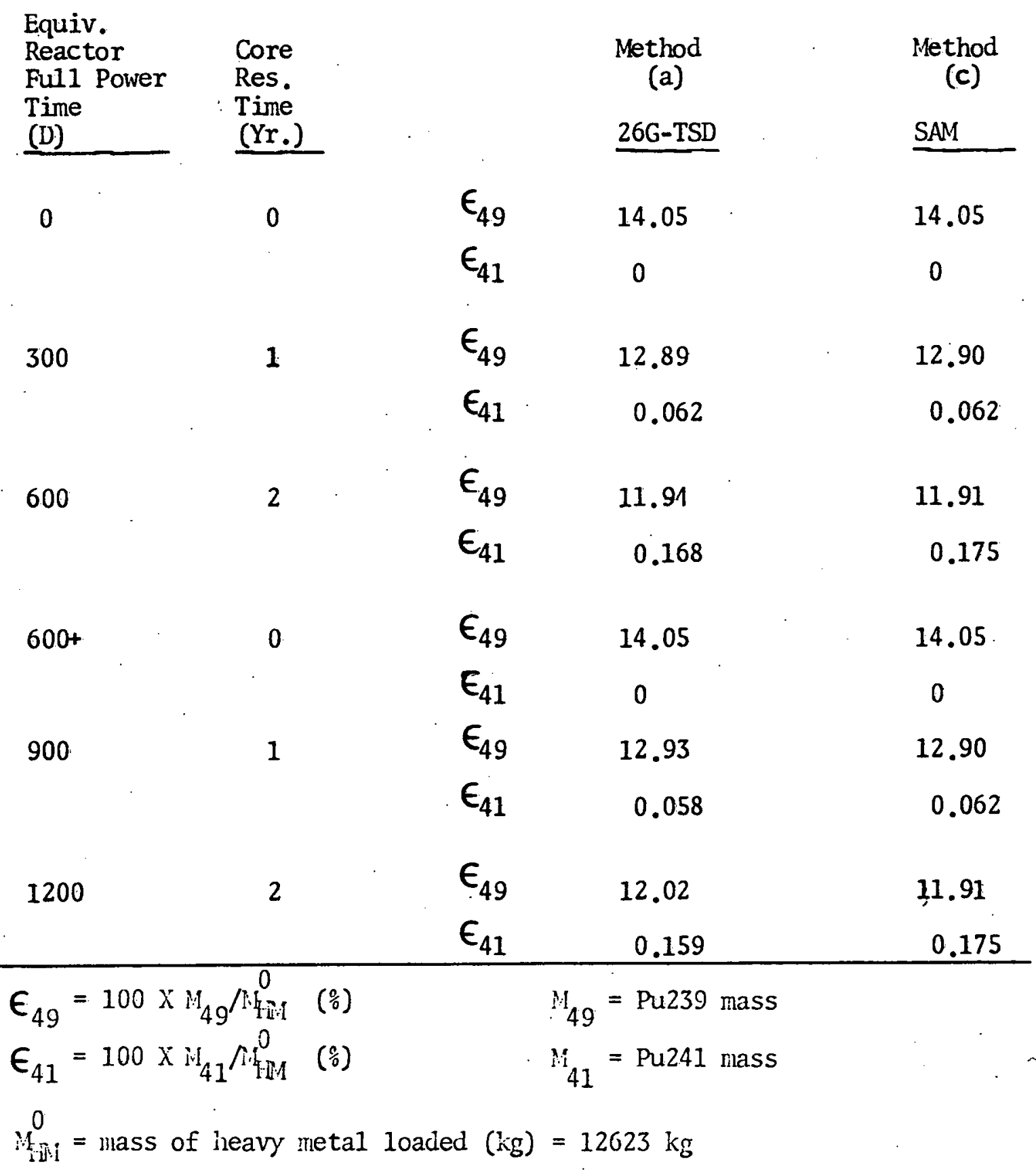


Tables 3.4 and 3.5 respectively.

The 1G-TSD method $b$, which assumes constant spectra but accounts for flux shape changes, overpredicts the discharge Pu239 content at two years by about $4 \%$, relative to method a. This occurs because the cross-sections input to method $b$, obtained by collapsing the spectra from method a's solution at time zers, are too $30 \mathrm{ft}$. (Blanket spectra harden with irradiation due to the fissile buildup.) Method c, SAM, underpredicts Pu239 content by about $4 \%$, in spite of its soft cross-section set, because its input zone fluxes, from the method a time zero solution, are too low. (Blanket flux increases with irradiation due to fissile buildup in the blanket.)

The second axial blanket batch (600 + to 1200 EFPD) suffers a sligint decrease $(\sim 3 \%)$ in discharge fissile content, compared to the first batch. The second axial blanket batch experiences a lower flux than the first, owing to the buildup of flux and power in the radial blanket.

Fission product buildup in the blanket tends to diminish plutonium breeding, by competing with U238 resonance capture and by generally hardening the spectrum. Comparison of 26G-TSD axial blanket results for Reactor \#1 (no fission products) and Reactor \#2 (with fission products) shows that this is not a discernable effect.

\section{Radial Blanket}

Figures 3.4 and 3.5 display the radial blanket depletion method comparisons for reactors $\# 1$ and $\# 2$ respectively. Results for the innermost annular region (zones $5,6,7$ ) and outermost annular region (zones $17,18,19$ ), as well as for the entire radiai blanket, are shown.

As in the axial blanket, the 1G-TSD method consistently overpredicts Pu239 content, while SAM consistently underpredicts Pu239 content. The cross-sections input to 1G-TSD and SAM were obtained by collapsing in the 
TABLE 3.4

COMPARISON OF AXIAL BLANKET DEPLETION RESULTS

FOR REACTOR \#1 (REFERENCE LMFBR)

Equiv.

Reactor

Axial

Full Power Blanket

Time

Res.Time

(D)

(Yr.)

Method

(a)

Method

(b)

Method

(c)

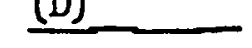

0

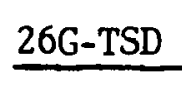

1G-TSD

SAM

$$
0
$$

$\epsilon_{49}$

0

0

0

$\epsilon_{41}$

0

0

0

300

$1 . \quad \epsilon_{49}$

2.09

2.15

2.08

$\varepsilon_{41}$

0.0019

0.0019

0.0019

600

2

$\epsilon_{49}$

3.85

4.00

3.71

$\epsilon_{41}$

0.0113

0.0148

0.0119

$600+$

0

$\epsilon_{49}$

0

$\epsilon_{41}$

0

$\boldsymbol{E}_{49}$

2.03

2.08

2.08

$\epsilon_{41}$

0.0017

0.0018

0.0019

1200

2

$\epsilon_{49}$

3.74

3.89

3.71

$\epsilon_{41}$

0.01006

0.01312

0.0119

$(\%)$

$$
\begin{aligned}
& M_{49}=\text { Pu239 mass } \\
& M_{41}=\text { Pu241 mass }
\end{aligned}
$$

$\underset{1: 1}{0}=$ mass of heavy metal loaded $(\mathrm{kg})=10093 \mathrm{~kg}$ 
TABLE 3.5

COMPARISON OF AXIAL BLANKET DEPLETION RESULTS

FOR REACTOR \#2(Be-RADIAL REFLECTOR)

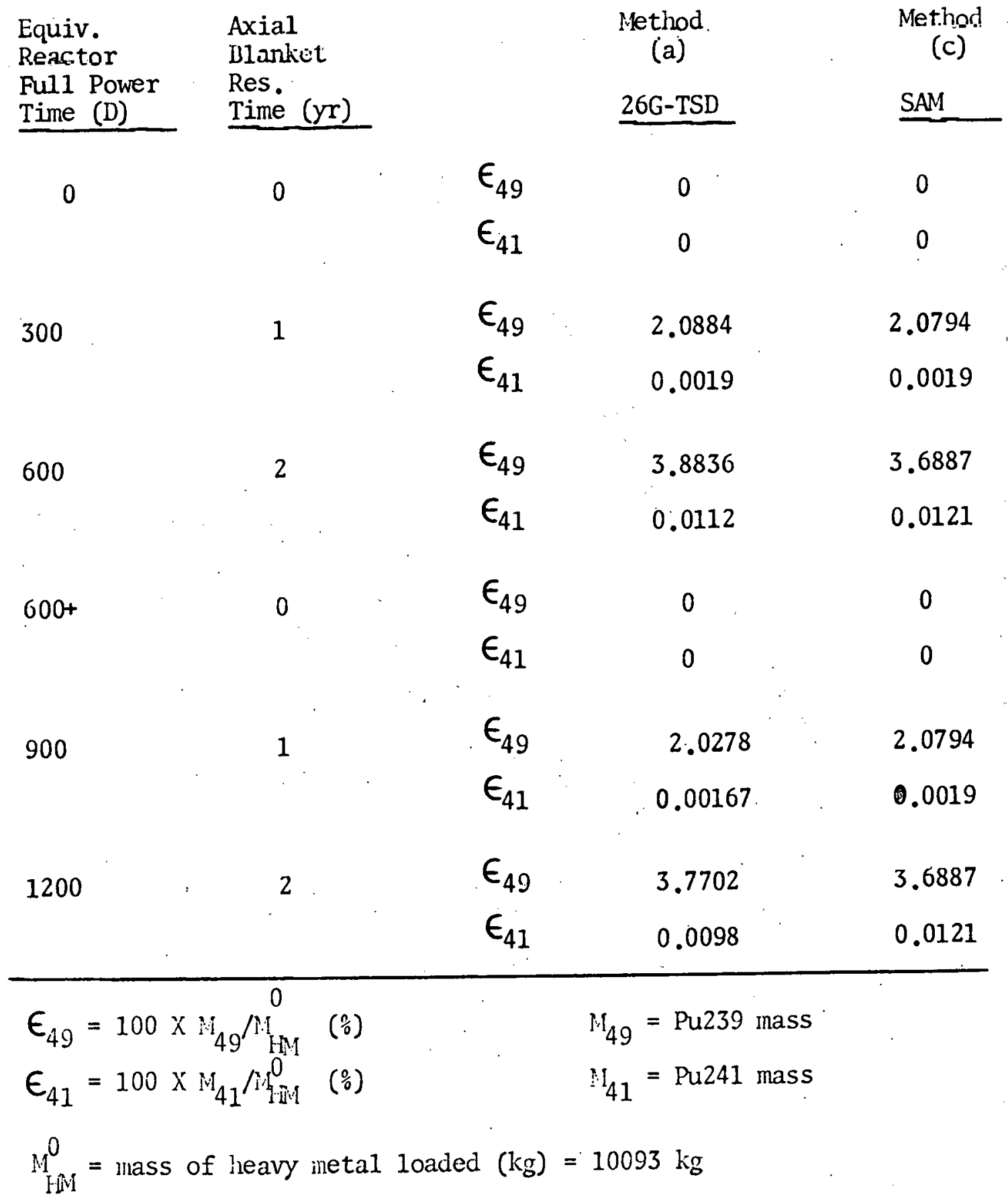




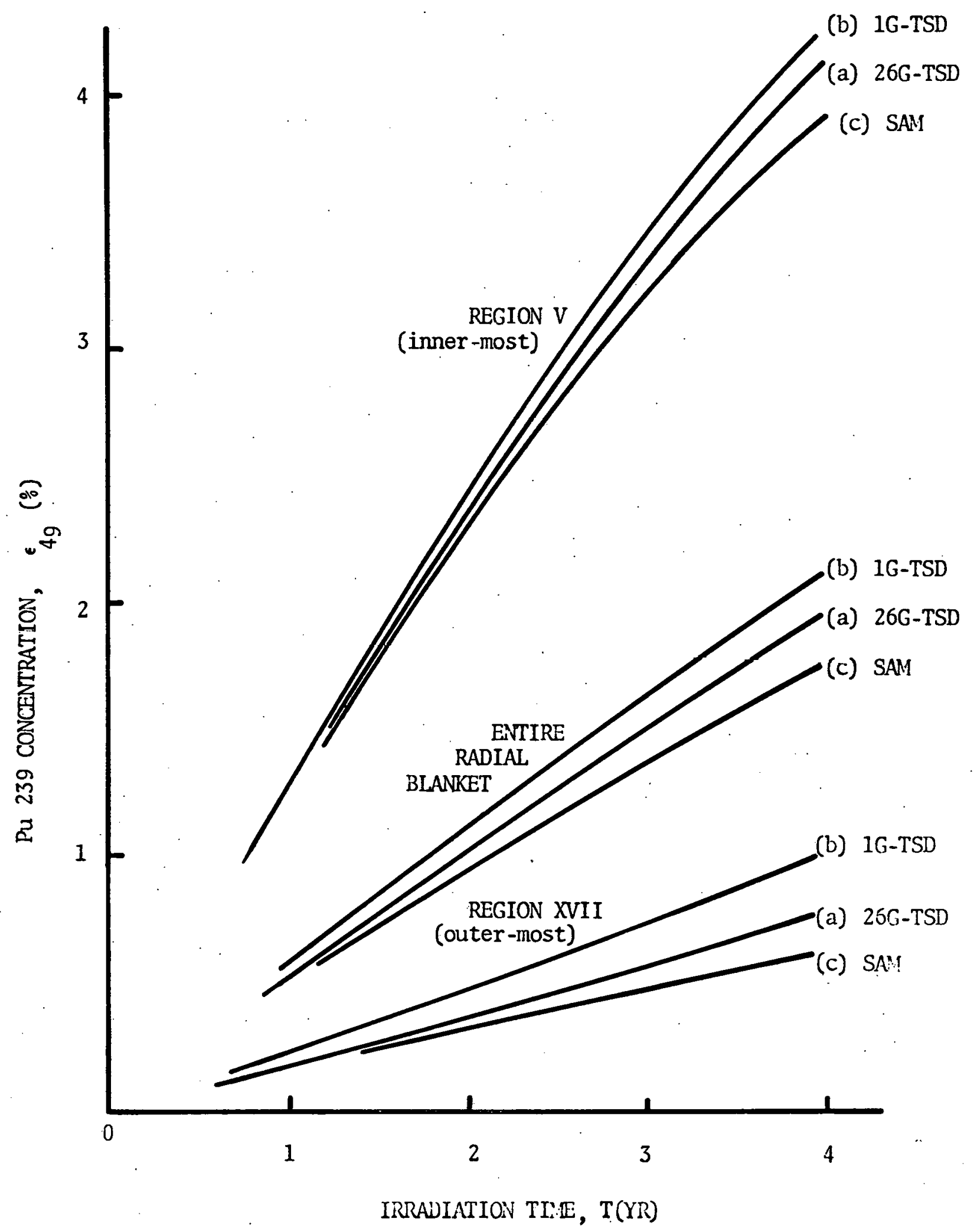

FIG. 3.4 COMPARISON OF RADIAL BLANKET DEPLETION RESULTS FOR REACTOR \#1 (REFERENCE LAFBR) 


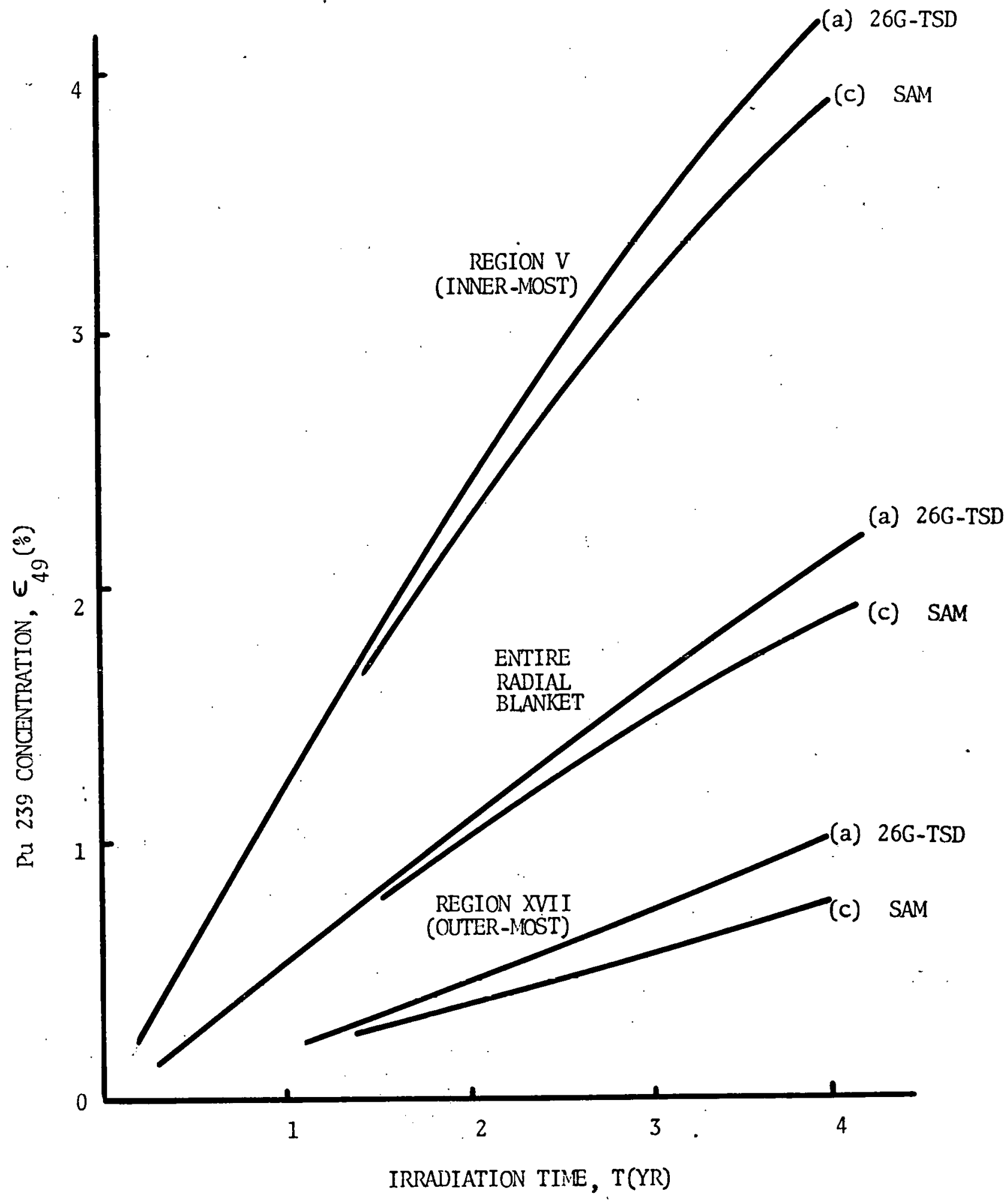

FIG. 3.5 COAPARISON OF RADIAL BLANKET DEPLETION RESULTS FOR REACTOR \#2 (BE-RADIAL REFLECTOR) 
26G-TSD time zero local spectra. Blanket spectra harden with irradiation due to fissile buildup. This accounts for the 1G-TSD overprediction. The zone fluxes input to SAM were taken from the 26G-TSD time zero solution. Blanket flux increases with irradiation, also because of fissile buildup. This explains SAM's underprediction, despite its soft cross-sections. Evidently the flux shift effect overrides the spectrum hardening effect. At four years (1200 EFPD), SAM underpredicts the Pu239 content in the innermost region by about $5 \%$, and that in the outermost region by about $20 \%$. Since regions deep in the blanket produce relatively little plutonium, the relatively large error there has little effect on overall radial blanket Pu239 content, which SAM underpredicts by about $10 \%$ at 4 years .

The core's nearly constant flux and spectra has greatest influence on blanket fuel near the core-blanket interface, tending to validate SAM's assumptions there. SAM's error increases with distance from the core.

Fission product buildup in the blanket tends to diminish plutonium breeding rate, by competing with $\mathrm{U} 238$ resonance capture and by hardening the spectrum. Comparison of 26G-TSD radial blanket results for Reactor \#1 (no fission products) and Reactor \#2 (with fission products) shows that this is not a discernable effect.

Use of initial fluxes and spectrum-weighted cross-sections as input to SAM resulted in SAM's underprediction of blanket Pu239 inventories. Better agreement between SAM and 26G-TSD results would be expected if the fluxes and cross-sections for SAM were generated by a multigroup physics calculation in which a "representative" amount of fissile material were included in the blanket. Choice of the "representative" amount of fissile material would involve a guess, and perhaps an iteration, for each irradiation time to be evaluated. For example, for a 4 year irradiation, the "representative" amount might be the fissile inventory at 2 years; for an 
8 year irradiation, it might be the fissile inventory at 4 years, etc. To test these ideas, a SAM calculation $\left(\mathrm{SAM}_{4}\right)$ was performed using radial blanket fluxes and cross-sections from the $26 \mathrm{G}$ physics solution at 4 years. Results of the $\mathrm{SAM}_{4}$ calculation were compared to those of $\mathrm{SAM}_{0}$ and the 26G-TSD "truth" calculation, as shown schematically in Figure 3.6. Figure 3.7 displays this comparison. As expected, $\mathrm{SAM}_{4}$ overpredicts $\epsilon_{48}(\mathrm{~T})$ while SAM 0 underpredicts $\epsilon_{49}(\mathrm{~T})$. Table 3.6 shows that the discrepancy between $\mathrm{SAM}_{4}$ and $\mathrm{SAM}_{0}$ is about $24 \%$ (of $\mathrm{SAM}_{4}$ ), independent of irradiation time. Comparing the two SAM calculations with the 26G-TSD "truth", one notes that SAM $\mathrm{M}_{0}$ error increase with irradiation time, while $\mathrm{SAM}_{4}$ error decreases. Although the two SAM calculations disagreed in $\epsilon_{49}$, and therefore radial blanket material credit (mills/KWHr) by about $24 \%$, they both yielded an optimum blanket irradiation time of about 6 years.

In the case studies of Chapter 5, clean (initial) conditions are used consistently in SAM,tending to underestimate the economic value of all blanket cases considered.

\subsubsection{Results (With Burnup as the Independent Variable)}

Depletion method comparisoms in Section 3.4.2 were presented with time as the independent variable. With time as the independent variable, SAM requires that one assume constant local flux (and therefore flux shape) throughout the fuel irradiation, or that one use a time-averaged local flux. Table 3.4 and Figure 3.4 of Section 3.4.2 show that the constant flux assumption is the dominant source of error in SAM blanket depletion 


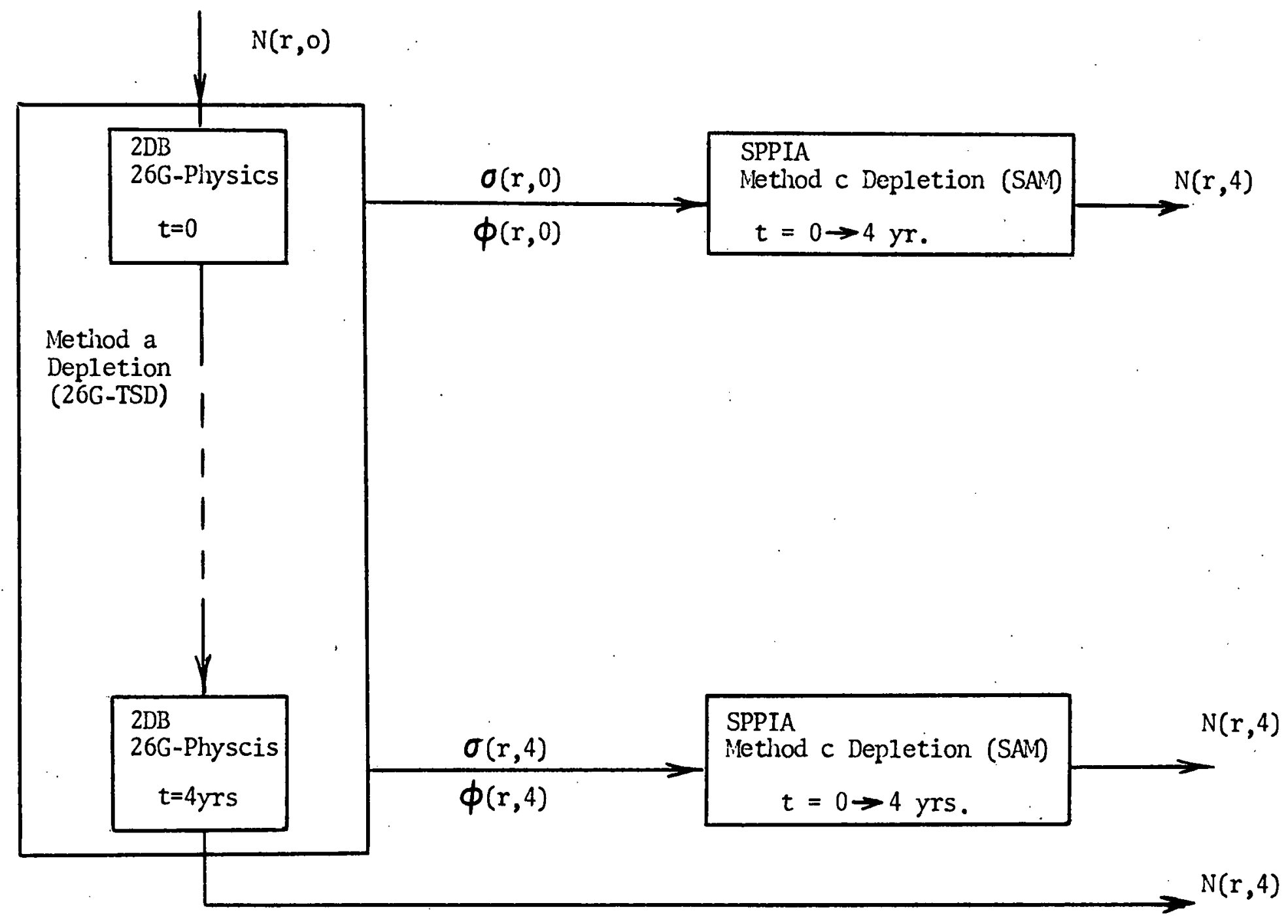

FIG. 3.6 PROCEDURE FOR COMPARING SAM RESULTS USING CLEAN AND IRRADIATED FUEL NEUTRONIC DATA 


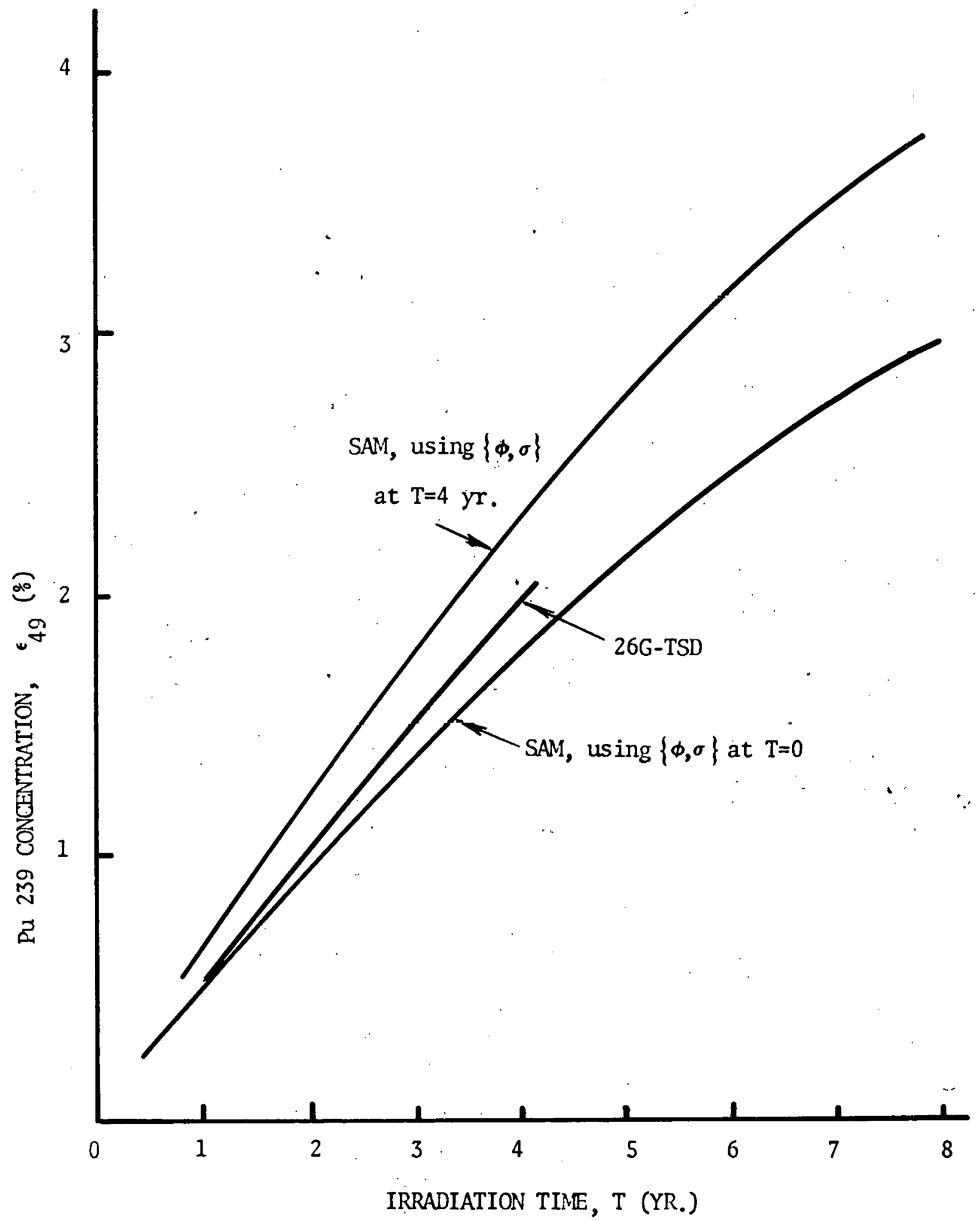

FIG. 3.7 COMPARISON OF SAM RADIAL BLANKET RESULTS USING CLEAN AND IRRADIATED FUEL NEUTRONIC DATA 
TABLE 3.6

COMPARISON OF SAM, $\mathrm{SAM}_{4}$, and 26G-TSD

RADIAL BLANKET DEPLETION RESULTS

Irradiation Time (years)

2

$\begin{array}{ll}4 & 8\end{array}$

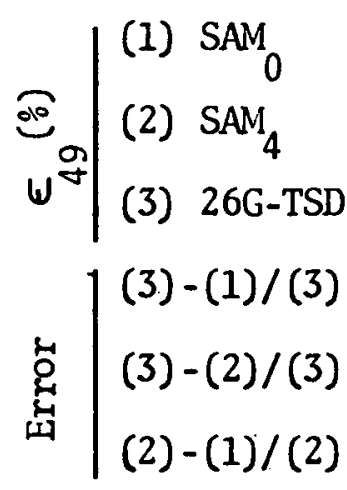

0.975

1.764

2.942

1.295

2.329

3.838

1.030

1.972

0.05

0.10

0.25

0.18

0.24

0.24

0.24 
calculations ${ }^{1}$. This assumption may be relaxed if, instead of time, a time integral property at a point or zone is selected as the independent variable representing degree of exposure, eg. flux-time ( $\theta$ ),

$$
\theta=\int \phi d t
$$

or burnup (B),

$$
B=\therefore \frac{C V}{M_{H M}^{0}} \int_{\theta}\left\{N_{F}\left(\theta^{\prime}\right) \quad \underset{f}{\sigma}\right\} d \theta^{\prime}
$$

where the brackets \{\} represent a summation over fissionable materials, $\mathrm{V}$ is the zone volume, $\mathrm{C}$ is energy released per fission, and $\mathrm{M}_{\mathrm{HM}}^{0}$ is the mass of heavy metals $(U+\mathrm{Pu})$ loaded in the zone.

This section presents a comparison of 26G-TSD and SAM results for. reactor \#2 (Be-reflected), with burnup as the independent variable. Having "normalized out" the local flux variation, any discrepancy between 26G-TSD and SAM results should be attributable to SAM's assumption of constant local spectra. Further, part of the spectral variation is ameliorated since burnup $\left(\sim \sigma_{f} \int d \theta N_{F}(\theta)\right)$, as well as composition $N_{F}(\theta)$, is affected by the spectrum, and in the same direction.

Zone burnup in the 26G-TSD was calculated from fission product inventories. In SAM, the $N(\theta)$ equations (3-9) were integrated and solved directly for burnup.

Figures 3.4 and 3.5 showed the largest discrepancy between 26G-TSD and SAM depletion results (vs. time) to be in the outermost region of the

1. The constant flux and constant spectrum assumptions produce opposing errors in $\epsilon_{\text {. }}$. Refer to Table 3.4 and Figure 3.4. The effect of the constantissiletrum assumption is seen by comparing the 1G-TSD and 26G-TSD results, while comparison of 1G-TSD and SAM results shows the influence of the constant flux assumption. 
radial blanket. This comparison, together with the burnup-normalized results are shown in Figure 3.8. With burnup as the indepr ndent variable, the two methods yield practically identical results. Similar agreement was found in all radial blanket, axial blanket, and core regions and zones. Figure 3.9 displays overall radial blanket depletion results by the two methods, with both time and overall radial blanket burnup as independent variables. Again, excellent agreement is noted when burnup is the independent variable.

The excellent agreement in depletion results, when burnup is the independent variable, reinforces the conclusion of Section 3.2.2 that flux shift is more important than spectral variations with irradiation time. Unfortunately, fuel economic analysis requires time as the independent variable in order to assess carrying charges. With time as the independent variable, SAM requires that constant local fluxes and fixed flux shape be assumed. Future work in developing FBR blanket calculational tools should be aimed at predicting the flux shift to the radial blanket, by simple, inexpensive methods.

Composition - Burnup Characteristics

Figure 3.10 shows the $\epsilon_{49}$ - burnup characteristics for the innermost and outermost annular regions of the radial blanket. Characteristic curves · for the interior regions $1 i e$ in the shaded area. The curve for the outermost region lies above the others because this region enjoys the softest spectrum in the radial blanket. Data for Figure 3.10 was generated by SAM.

Figure 3.11 compares the depletion characteristics of radial blanket, axial blanket, and core. The axial blanket curve lies above that of the radial blanket because of its softer spectrum (more Na). Core Pu239 fraction decreases with burnup, e.g. the internal breeding ratio is less than unity. 
FIG. 3.8 DEPLETION RESULTS FOR OUTER-MOST RADIAL BLANKET REGION:

TIME VERSUS BURNUP AS THE INDEPENDENT VARIABLE

O 26G-TSD

$\nabla$ SAM

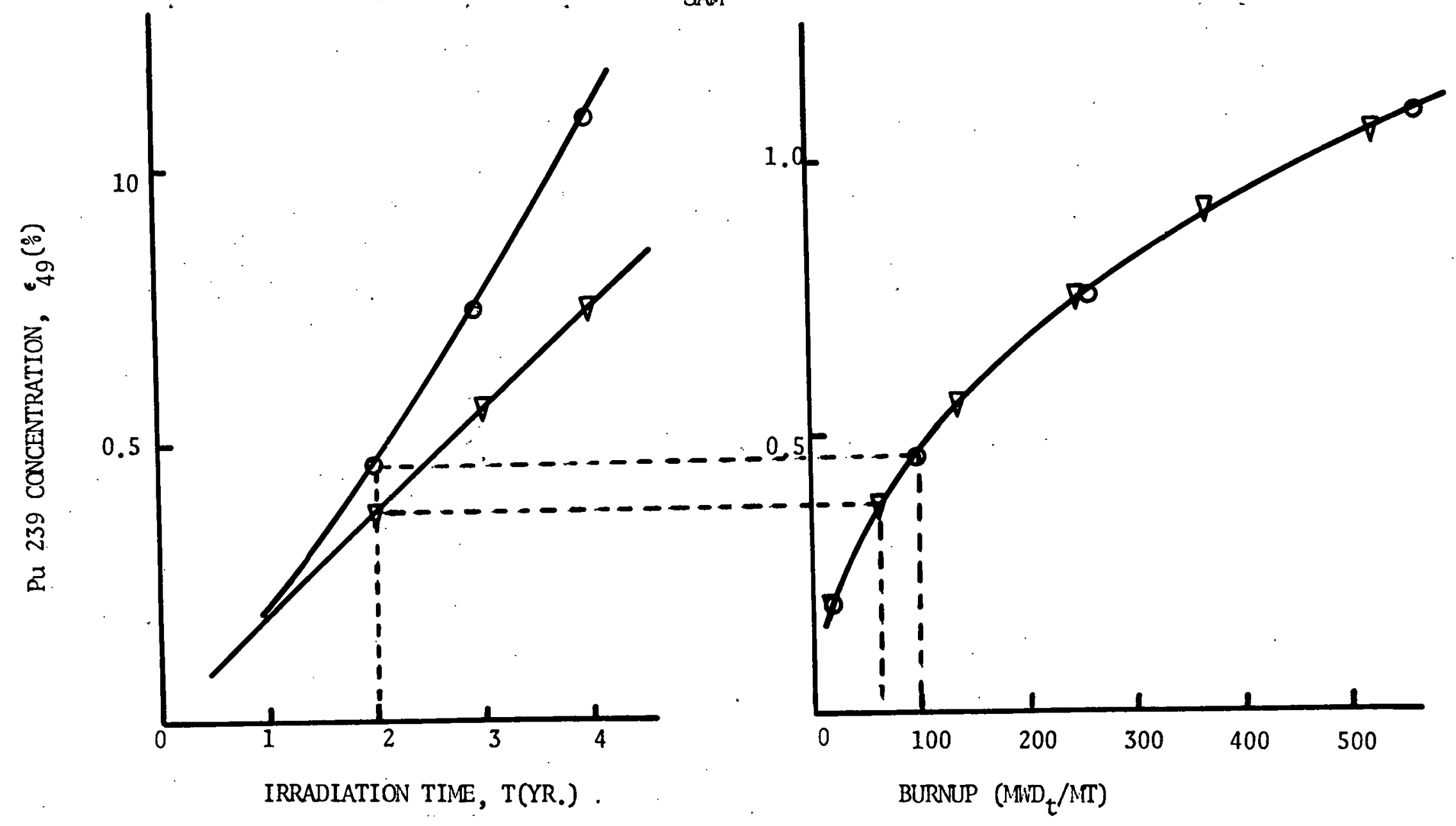


FIG. 3.9 DEPLETION RESULTS FOR TIE ENTIRE RADIAL BLANKET:

TIME VERSUS BURNUP AS TIE INDEPENDENT VARIABLE

$$
\begin{aligned}
& 0^{26 G-T S D} \\
& \nabla \text { SAM }
\end{aligned}
$$
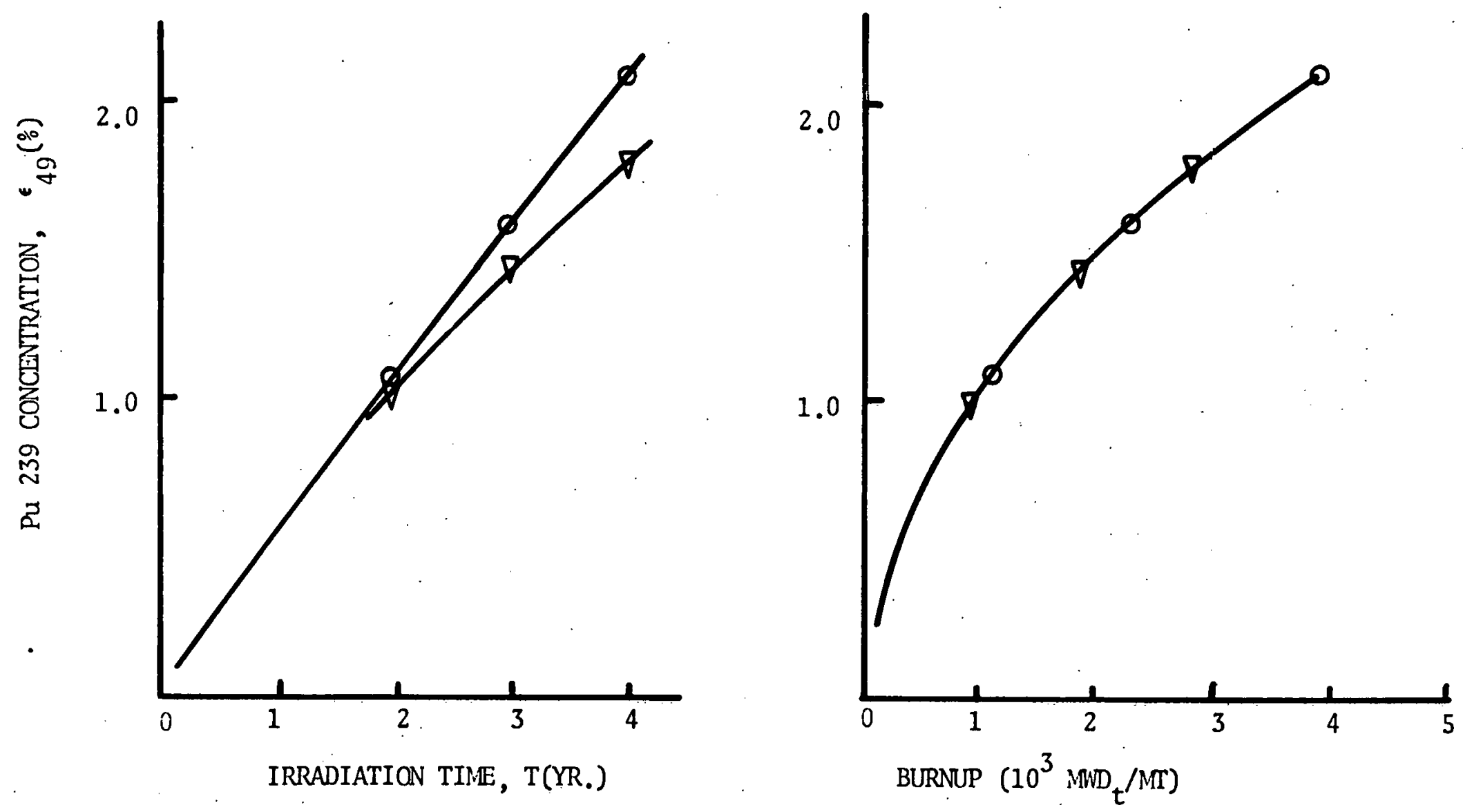


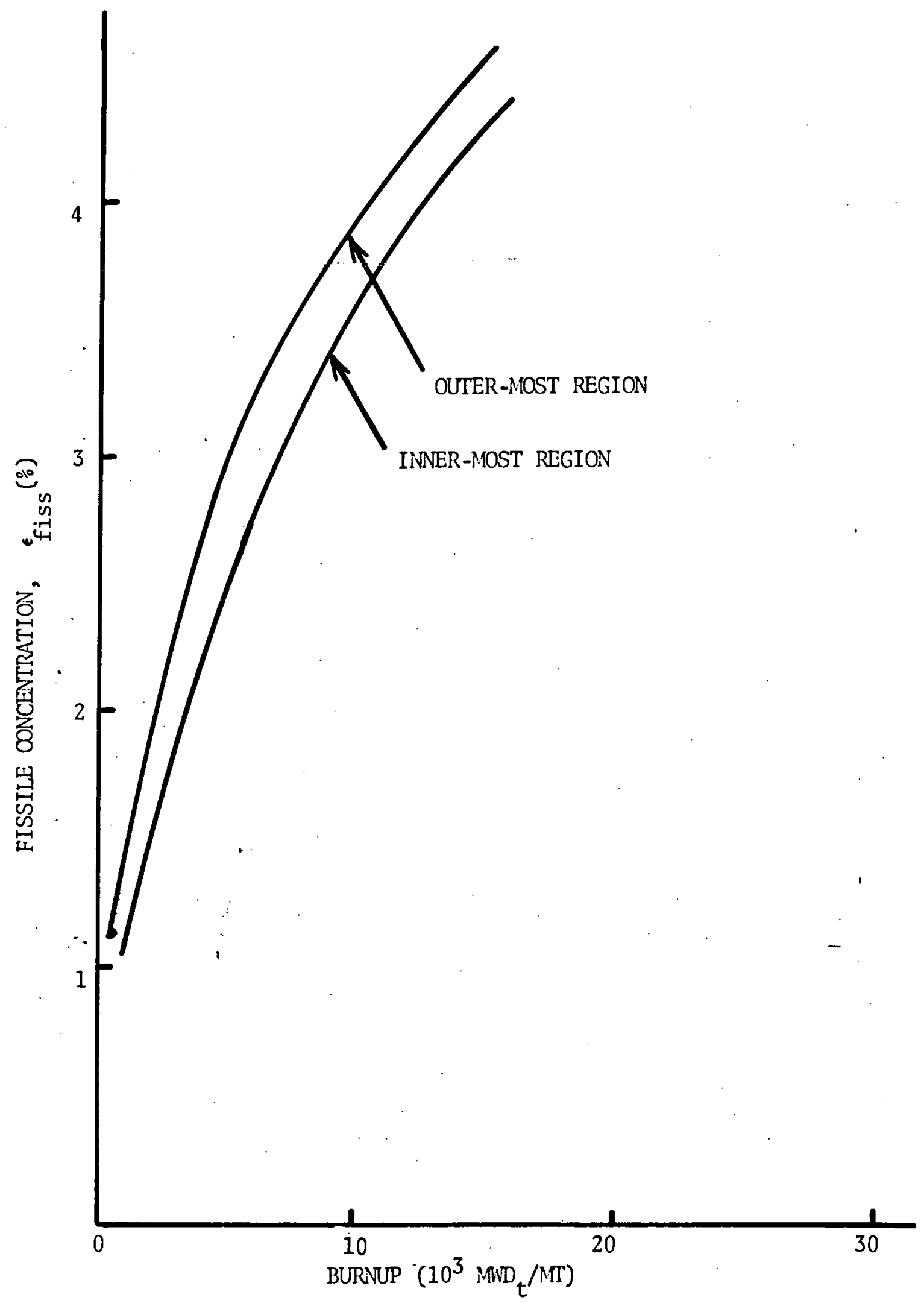

FIG. 3.10 BURNUP-FISSILE CONCENTRATION CHARACTERISTICS FOR INNER-MOST AND OUTER-MOST RADIAL BLANKET REGIONS 


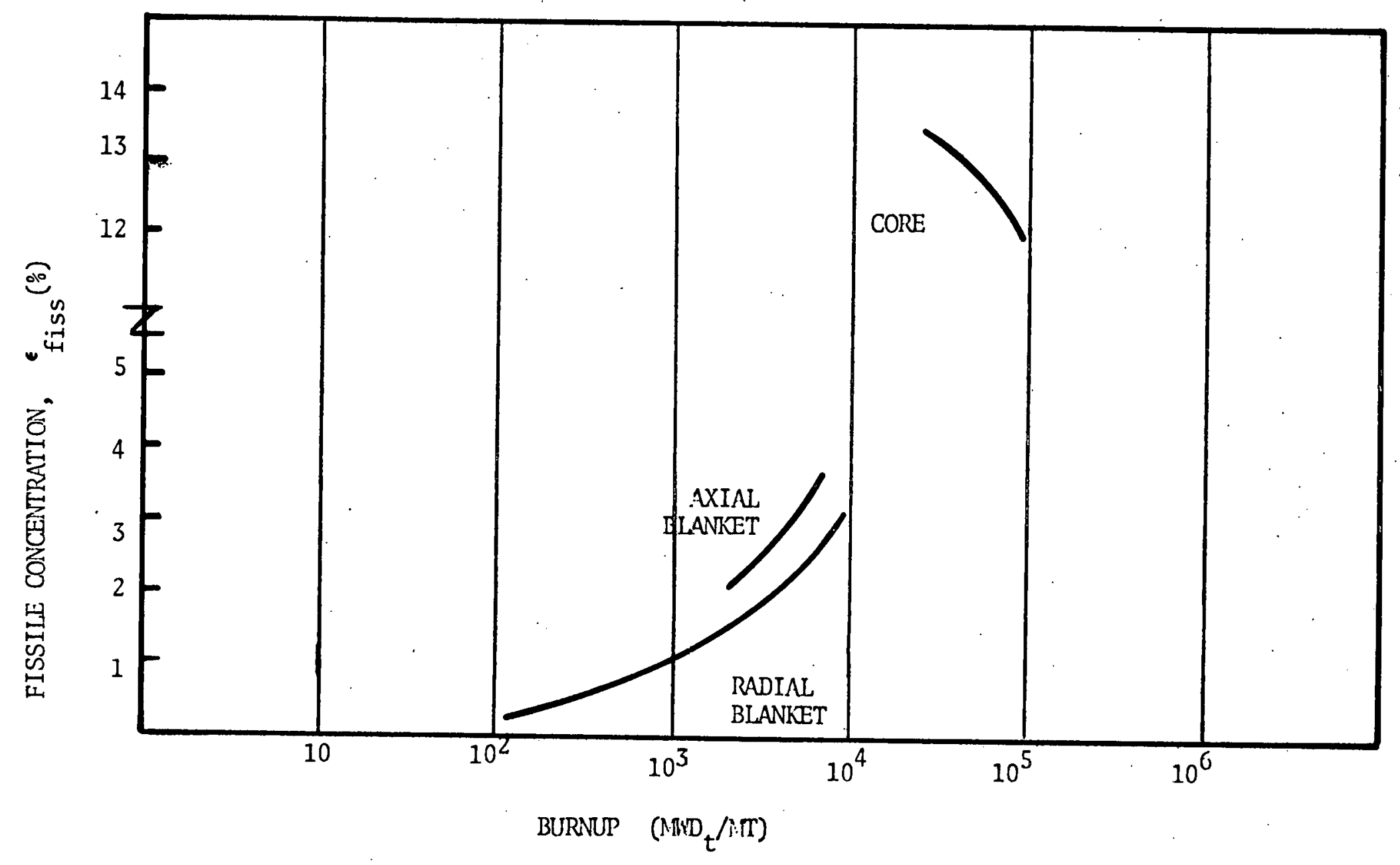

FIG. 3.11 COIPARISON OF BURIUP -FISSILE CONCENTRATION GHARACTERISTICS OF CORE, 


\subsection{CRITICALITY AND REACTIVITY}

In fuel econonic analysis, two major functions of a physics-depletion model are (1) to provide fuel composition as a function of irradiation exposure, and (2) to provide criticality and reactivity information. The first is required for computing direct material costs ("burnup costs"), for core and blanket fuel. The second is closely related to core material carrying charges ("inventory cost"), i.e. carrying charges associated with the excess fissile naterial required to maintain criticality throughout fuel life.

Effects of simplifying assumptions (constant local fluxes and constant local spectra) on irradiated fuel composition results were estimated in Section 3.4 by comparing results of three depletion methods (26G-TSD, 1G-TSD and SAMD. The present section concerns criticality and reactivity information (or lack of $i t$ ) from the two simplified methods (1G-TṢD, SAM).

\section{$3.5 .1 \mathrm{SAM}$}

The SAM procedure as outlined in Section 3.3 includes only one neutron balance computation - to obtain the flux shape, spectra and $k_{\text {eff }}$. Thus the lifetime behavior of $\mathrm{k}_{\text {eff }}$ is not determined in SAM. However, this is not considered a serious restriction in economic sensitivity and scoping studies.

A rigorous model would include the constraint that enough excess reactivity be loaded to ensure criticality at the desired discharge burnup. Computationally, this may require several complete depletion iterations (at various load enrichments, $\epsilon_{0}$ ), as suggested in Figure 3.12 , to determine the correct $\epsilon_{0}$. 


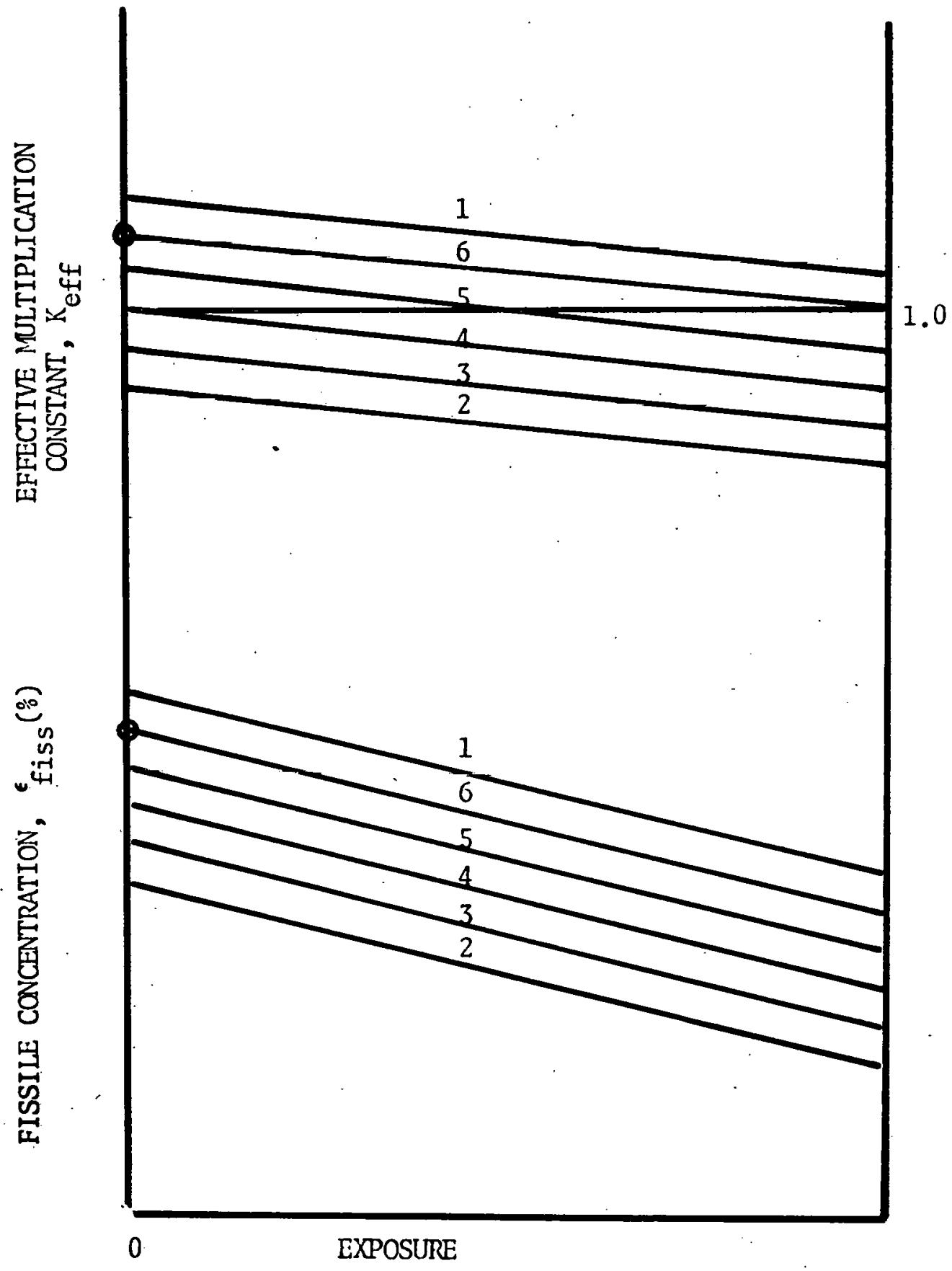

FIG. 3.12 ILLUSTRATION OF DEPLETION ITERATION TO SELECT INITIAL CORE ENRICHMENT 
Load enrichment $\epsilon_{0}$ affects FBR fuel costs through the material components: direct material purchase, direct material credit, and their associated carrying charges (inventory charges).

$$
\text { Effect of } \epsilon_{0} \text { on Direct Material Costs (Core) }
$$

Direct material cost ("burnup cost") represents the difference between direct material purchase costs and direct material credits. The direct material purchase component of FBR core fuel cost is directly proportional to load enrichment, $\epsilon_{0}$. (By contrast, the same component in light water reactors increases in a parabolic fashion with $\epsilon_{0}$, because of the separative work cost.) With flux and cross-sections held constant, Equation (3-9) shows that material credit is also proportional to $\epsilon_{0}$, though with a lower constant of proportionality than direct material purchase because higher $\epsilon_{0}$ implies less fertile material available for breeding. Thus changes in direct material purchase cost and material credit, due to adjustments in $\epsilon_{0}$, tend to cancel.

$$
\text { Effect of } \epsilon_{0} \text { on Material Inventory Costs (Core) }
$$

The effect of $\epsilon_{0}$ on core inventory costs is illustrated in Fig. 3.13. Two cases are shown: (1) reactor critical at beginning of fuel life; and (2) reactor critical at end of fuel life. Assuming simple interest, inventory cost is proportional to the area under the fissile fraction $(\epsilon)$ plot. The difference in inventory costs between the two cases is represented by the shaded area, iT $\Delta \in$. Both plots are practically linear, and have approximately the same slope, i.e. about $2 \%$ in two years, representative of 100,000 $\mathrm{MWD}_{\mathrm{t}} / \mathrm{MT}$ core burmup. The discrepancy in inventory costs for this simple exanple is thus

$$
\frac{(\mathrm{inv})_{2}-(\mathrm{inv})_{1}}{(\mathrm{inv})_{2}}=\frac{\mathrm{iT} \Delta \epsilon}{\mathrm{iT} \epsilon_{\mathrm{c}}+1 / 2 \mathrm{iT} \Delta \epsilon} \simeq 12 \%
$$

The discussion above ignores the slight perturbation of core spectrum 


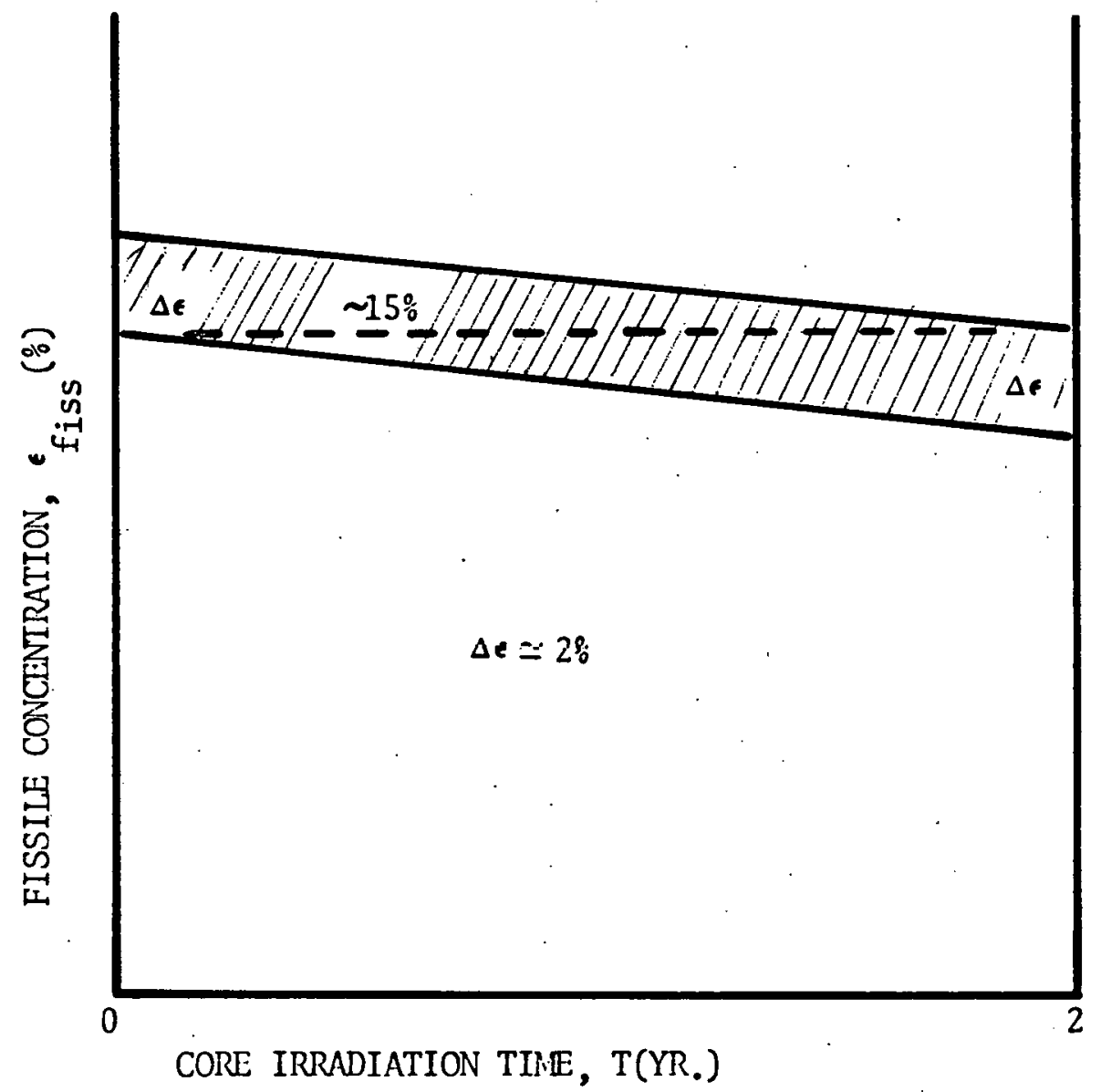

FIG. 3.13 ILLUSTRATION OF TIE EFFECT OF CORE INITIAL ENRIGIENT ON MATERIAL INVENTORY COST 
and flux level (for the same poiver) due to the changes in $\epsilon_{0}$. Results of 26G-TSD calculations, Section 3.4, show that core spectrum and flux were practically constant over a two year irradiation which resulted in a fissile fraction decrease of $\Delta \in \simeq 2 \%$. This suggests that $\epsilon_{0}$ adjustments near criticality, to obtain the desired $\mathrm{BOL}$ excess reactivity, would have little effect on core spectrum, flux, and therefore, on discharge compositions.

The discussion above also ignores the perturbation of core spectrum and flux shape due to control poisons. Other studies (29) lave concluded that the inclusion of control poisons in TSD calculations (criticality search option) has little effect on depletion results.

The SAM procedure is used in Chapter 5 to compare the fuel economics of various radial blanket sizes $(45,30$, and $15 \mathrm{~cm})$ and radial reflector materials. It was found that changing the radial blanket-radial reflector configuration had negligible effect on critical enrichment.

To sumnarize, the inability of SAM to provide the lifetine behavior of reactivity is not a serious limitation for survey-type, comparative econonic studies, provided, of course, that the one snapshot physics calculation is performed at conditions near criticality.

\section{$3.5 .2 \quad 1 \mathrm{G}-\mathrm{TSD}$}

Comparison of $1 \mathrm{G}-\mathrm{TSD}$ versus $26 \mathrm{G}-\mathrm{TSD}$ reactivity information is shown in Taùle 3.7. Using tile expression ${ }^{1}$

$$
\frac{\delta K}{K} \simeq 0.2 \frac{\delta \epsilon}{\epsilon},
$$

the 1G-TSD method would result in an "errcr" of about 15\% in critical mass (or inventory cost). The discrepancy in reactivity swing over one core lifetile is negligible.

1. Fron the 26G-TSD calculation for icactor "1 (no fission products). 
TABLE 3.7

COMPARISON OF MULTIPLICATION CONSTANT VALUES

FROM 26G-TSD AND 1G-TSD CALCULATIONS

Method

$$
\mathrm{k}_{\mathrm{eff}}^{0}
$$

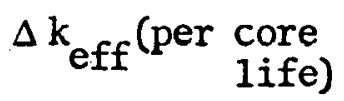

(a) 26G-TSD

$$
1.0004
$$$$
0.0245
$$

(b) 1G-TSD

$$
\delta K_{\text {eff }}^{0.0631}=0.0363 \quad \delta\left(\Delta K_{\text {eff }}\right)=-0.0003
$$

$$
\delta \equiv(a)-(b)
$$


The 1G-TSD method requires one multigroup physics computation, anyway, to generate its position-dependent cross-sections, and the $\mathrm{k}_{\text {eff }}$ from this computation is presumably available. This, together with the $\Delta \mathrm{K}$-lifetime data from the 1G-TSD calculation, may be used to obtain excess reactivity requirements, fissile loading, and inventory costs.

3.6 COMPARISON OF COMPUTER TIME REQUIREMENTS FOR 26G-TSD, 1G-TSD AND SAM

Table 3.8 compares the MIT IBM 360/65 computer time requirements for the 26G-TSD, 1G-TSD, and SAM calculations discussed in Sections 3.4 and 3.5. All physics and TSD calculations were performed by $2 \mathrm{DB}$.

The reactor configuration was the reference LMFBR described in Figure 3.3, with 1232 mesh points $(44 \times 28)$ and 23 active burnup zones. Depletion calculations spanned 1200 EFPD with 150 EFPD time steps for the TSD methods.

\subsection{EFFECT OF HETERÜGENETIY UN BLANKET DEPLETTION RESULTS}

Among the effects making irradiated blanket compositions difficult to predict is spatial self-shielding of resonance capture (heterogeneity effects) resulting from the relatively soft blanket spectrum and, for radial blankets, aggravated by the large pin diameters (30).

Figure 3.14 shows the heterogeneity-corrected core and blanket U238 absorption cross-sections as functions of energy group index. These cross-sections were generated by the 1DX code (27) using the Russian 26 group set (48) as input. The $1 \mathrm{DX}$ rin (a) changed the cross-section format from Russian format to DTF format, (b) corrected group definitions (lethargy interval) from the Russian definitions to uniform lethargy widths of 0.5 , commencing with the upper boundary of group 1 at $10.5 \mathrm{Mev}$, and (c) performed heterogeneity corrections for a typical FBR composition and genmetry. 


\section{TABLE 3.8}

COMPARISON OF COMPUTER TIME* REQUIREMENTS

FOR 26G-TSD, 1G-TSD, and SAM

26G-TSD Method

ten 26G static physics calculations

(e) $30 \mathrm{~min}$.per)

eight depletion step calculations

300 min.

Total 26G-TSD method

negligible

$300 \mathrm{~min}$.

1 G-TSD Method

one $26 \mathrm{G}$ static physics calculation

$30 \mathrm{~min}$.

ten $1 G$ static physics calculations

(a 25 min.per)

25 min.

eight depletion step calculations

negligible

Total, attributable to IG-TSD method

$55 \mathrm{~min}$.

one 26G static physics calculation

$30 \mathrm{~min}$.

one depletion step calculation

neg1igible

Total attributable to SAM

$30 \mathrm{~min}$.

* IBM 360/65 


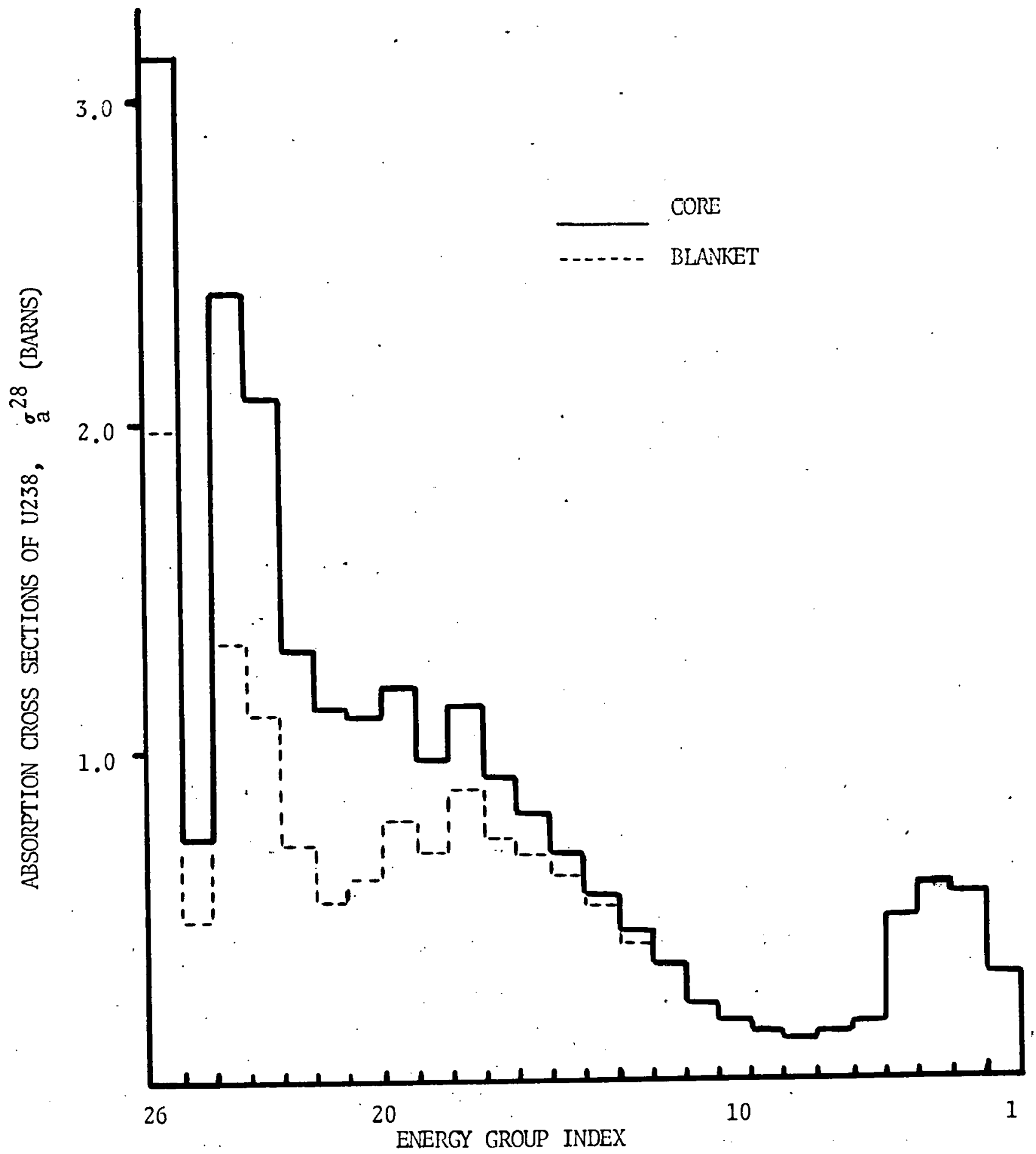

FIG. 3.14 26-GROUP. U238 ABSORPTION CROSS SECTIONS FOR CORE AND BLANKET AS GENERATED BY IDX PROGRAM FROM THE RUSSIAN SET 
Because of the relatively hard core spectrum, the core heterogeneity corrections are slight, and the "core" cross-section sets are not greatly different from the infinitely-dilute Russian set. In this section, the blanket heterogeneity effects will be measured relative to core conditions, i.e. the core cross-sections are considered as infinitely dilute. To avoid confusion, the following notation is used in this section:

$$
\begin{aligned}
& \sigma(j, k) \text { a local cross-section found by collapsing the } \\
& =\text { Ho . . homogeneous (infinitely dilute) core }
\end{aligned}
$$

Figure 3.15 displays $\sigma_{\mathrm{a}}^{28}$ (Ho, $\mathrm{He}$ ) and $\sigma_{\mathrm{a}}{ }^{28}(\mathrm{He}, \mathrm{He}$ ) as functions of radial position along the midplane of the reference reactor(\#1) at time zero. The blanket heterogeneity effect, $\sigma_{a}{ }^{28}(\mathrm{Ho}, \mathrm{He})-\sigma_{a}^{28}(\mathrm{He}, \mathrm{He})$ is seen to increase with depth into the blanket, due to spectrum softening with depth.

Heterogeneity affects blanket fissile production in two opposing ways:

(a) the lower effective U238 microscopic capture cross-section, $\sigma_{c}^{28}$, depresses the U238 to Pu239 conversion rate, leading to lower bred fissile $\mathrm{Pu}$ inventories;

(b) viewing blanket neutronics as an attenuation process, in a macroscopic sense, the lower effective microscopic absorption cross-sections (the most significant being U238) results in higher blanket macroscopic fluxes, tending to increase the U238 capture rate and bred fissile inventories. 


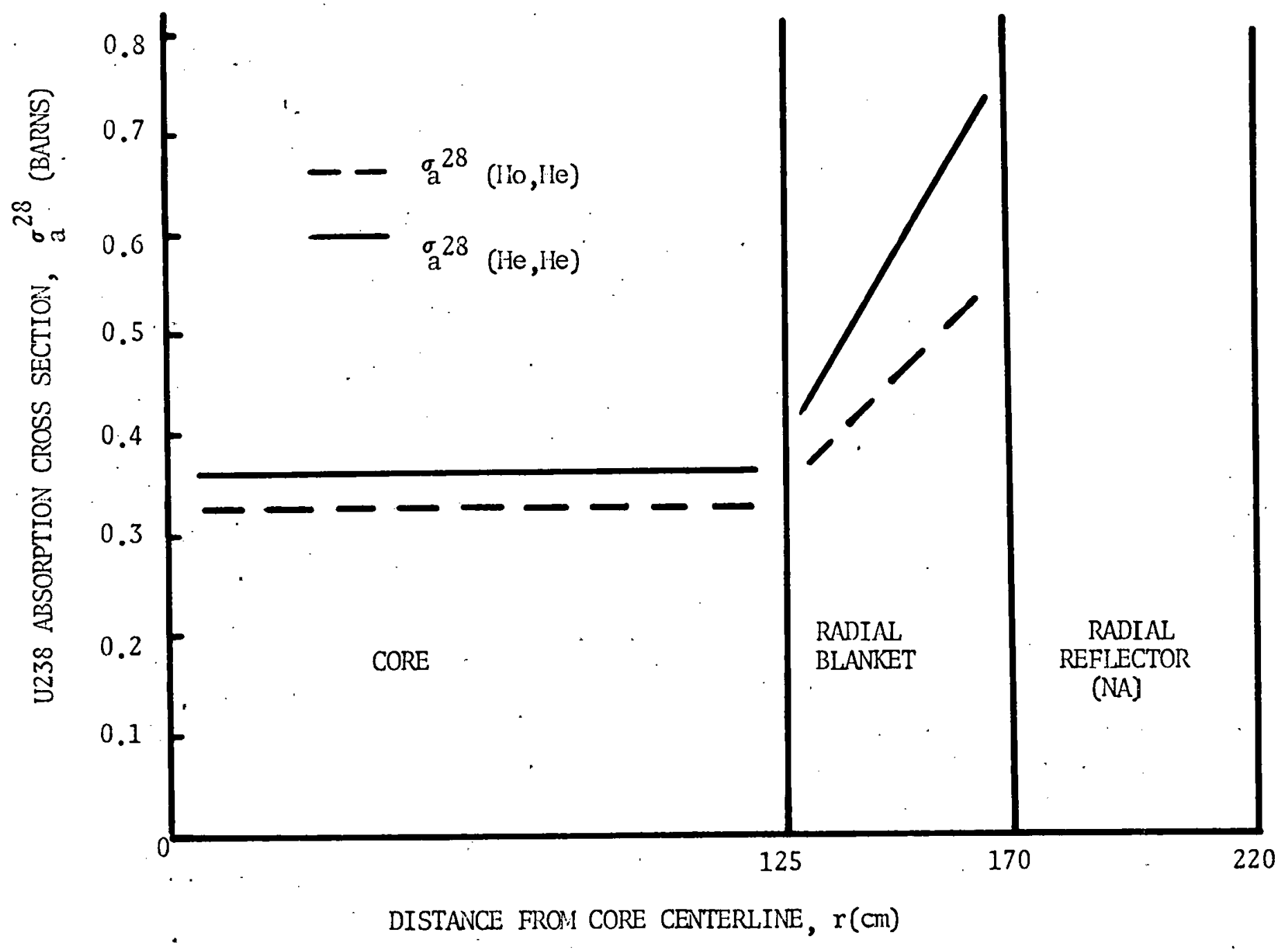

FIG. 3.15 SPECTRUM-WEIGITED ONE-GROUP U238 ABSORPTION CROSS SECTIONS AS . FUNCTIONS OF FADIAL POSITION 
Of the two opposing effects, (a) dominates and heterogeneity influences blanket breeding adversely.

To separate and quantify these effects, three parallel SAM radial blanket calculations were performed, using as local input

(1) $\sigma(\mathrm{Ho}, \mathrm{He}), \phi(\mathrm{He})$

(2) $\sigma(\mathrm{He}, \mathrm{He}), \phi(\mathrm{He})$

(3) $\sigma$ (Ho, Ho), $\phi(\mathrm{Ho})$.

Comparison of (1) and (2) provides a measure of effect (a), the depressed U238 capture cross-section. The overall net effect, on fissile breeding, is shown by comparing (2) and (3). Two separate multigroup physics computations, with the $2 \mathrm{DB}$ program, generated the local $\{\sigma, \phi\}$ data - one using "He" in the radial blanket, and the other using "Ho" in the radial blanket. The reference reactor configuration, Figure 3.3, was assumed in both computations. Spatial detail for depletion purposes and for purposes of inputting cross-sections and fluxes to SAM, was the same as in the studies of Section 3.4. Table 3.9 shows the local U238 capture rate data in zone \#8 (see Figure 3.3) for the three SAM calculations. The overall radial blanket depletion results, by the three SAM calculations, are compared in Figure 3.16. Comparing (1) and (2) isolates effect (a), that of the depressed $\underset{c}{\sigma}$. The discrepancy in discharge Pu239 inventory is about $20 \%$, resulting in a discrepancy of about $20 \%$ in material credit. Effect (a) is offset significantly by effect (b), as can be seen by comparing (1) and (3). The overall self-shielding effect on Pu239 discharge - the combined effects (a) and (b) - is seen by comparing (2) and (3). Self-shielding reduces discharge Pu239 content by about $10 \%$. 


\section{TABLE 3.9}

U238 CAPTURE DATA ILLUSTRATING RADIAL BLANKET HETEROGENEITY EFFECT

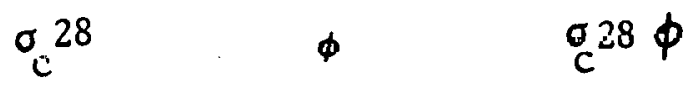

(1) $\sigma^{28}(\mathrm{Ho}, \mathrm{He})$

$$
\phi(\mathrm{He})
$$

0.447

1.879

0.840

(2) $\begin{gathered}\sigma_{\mathrm{c}}{ }^{28}(\mathrm{He}, \mathrm{He}) \\ \phi(\mathrm{He})\end{gathered}$

0.374

1.879

0.703

(3) $\sigma_{c}^{28}(\mathrm{Ho}, \mathrm{Ho})$

$$
\phi(\mathrm{Ho})
$$

0.4168

1.778

0.740 


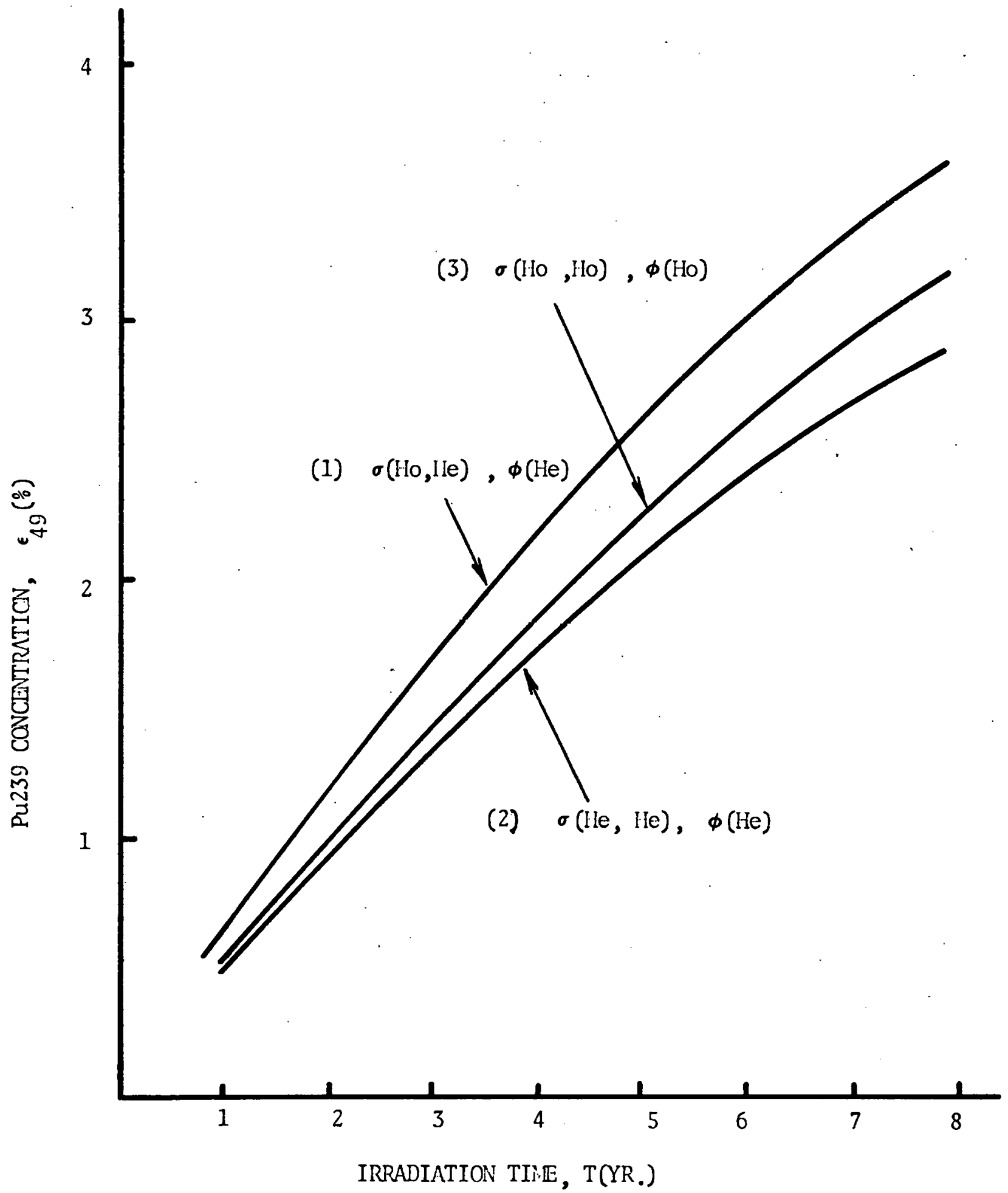

FIG. 3.16 EFFECT OF HETEROGENEITY CORRECTION ON RADIAL BLANKET DEPLETION RESULTS 


\subsection{SUMMARY}

A fast breeder reactor fuel depletion method, suitable for survey, ranking, and sensitivity studies, is established and tested in this Chapter. This method, labeled the Semi-Analytic Method (SAM), assumes that local spectra and fluxes do not vary with irradiation time. These assumptions arc tested by conparing SAM results with those of multigroup (26 group) and one group time step depletion calculations. These assumptions are found to have negligible effect on core depletion results (error in discharge composition is less than $0.1 \%$ ). Error in blanket depletion results is tolerable for purposes of comparative studies: less than $4 \%$ in axial blanket results, and about $10 \%$ in radial blanket results. Batch fuel management is assumed in the test calculations, thus placing maximum strain on the constant flux, constant spectrum assumptions. Of these two assumption s (which result in opposing errors), the constant flux assumption is found to be the most significant.

SAM results in a computer time savings of about $90 \%$, and is selected for application to the case studies of Chapter 5. As applied in this report, SAM is restricted to fixed fuel schemes, i.e. batch or scatter fuel management.

A further limitation of SAM is that it does not yield reactivity history, since only one physics (multigroup) computation is performed per configuration per fuel lifetime. This is not considered a serious restriction in the sensitivity and comparative studies for which it is intended.

Effects of heterogeneity corrections on blanket depletion results are also examined.in this chapter. Blanket heterogeneity is found to reduce fissile discharge inventory by about $10 \%$ for irradiation times of interest (2-7 years). 
CHAPTER 4

INTEGRATED DEPLETION-ECONOMICS MODEL, SELECTION OF REFERENCE LIFBR, REFERENCE LMFBR FUEL ECONOMICS

\subsection{INTRODUCTION}

Fast breeder reactor fuel cost analysis and fuel depletion methods were discussed separately in Chapters 2 and 3, respectively. The"cash flow nethod (CFM" was selected for cost analysis; the "semi-analytic method (SAM)" using neutronic data from a single multigroup calculation (per reactor configuration) was selected for the depletion model.

The purposes of the present chapter are:

1. to combine these two models into a procedure (Section 4.2) useful for scoping, survey, and sensitivity studies;

2. to compare the selected LMFBR reference configuration to other 1000 MNe LMFBR reference designs (Section 4.3); and

3. to apply the integrated depletion_economicsmodel to the reference economic environment (Section 4.4).

Section 4.2 summarizes the calculational procedure used in the remainder of the report. Section 4.4 serves as an illustration of the procedure, while establishing the base case around which the case studies and sensitivity studies of Chapter 5 are performed. Also, the effect of core enrichment zoning on blanket fuel economics is estimated in Section 4.4 .

\subsection{INTEGRATED DEPLETION-ECONOMICS MODEL}

Figure 4.1 is a schematic of the integrated depletion-economics model. The step-by-step procedure is described below.

1. The reactor configuration is set in accordance with normal 


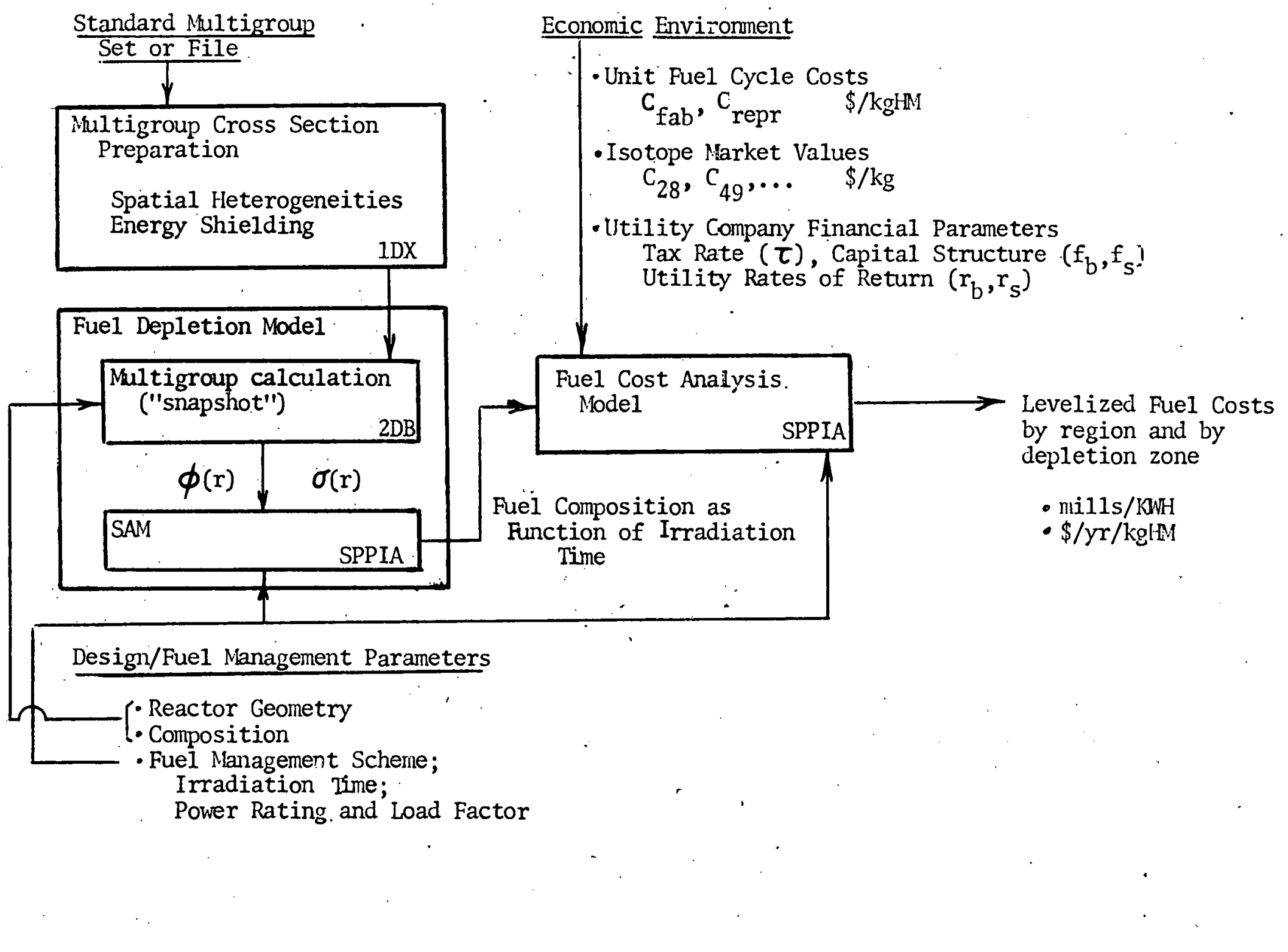

FIG. 4.1 INTEGRATED DEPLETION-ECONOMICS MODEL 
design procedures which need not be the subject of detailed discussion here.

(a) Geometry (shape) and dimensions are established.

(b) Initial compositions of the major regions - core, axial blanket, radial blanket, reflectors - are selected. Reactor geometry and composition are of course chosen to be compatible in terms of achieving criticality, and beginning-of-life (BOL) excess reactivity needed to achieve the rated burnup.

(c) Reactor power rating is specified, satisfying maximum local power density constraints and the desired power shape criteria at the point in life considered, typically BOL.

\section{Depletion Calculation}

2. Each major fuel-bearing region is subdivided into depletion zones. Depletion zones should be sufficiently numerous to give the detailed space-dependent depletion information desired and to account for large flux gradients and spectrun variations.

3. A single "snapshot" physics computation is performed to obtain $\phi(r, E)$. A standard multigroup program such as ANISN (46) or 2DB (26) may be used for this purpose. The program $2 \mathrm{DB}$ was used throughout the present study. In the present study, BOL nuclide inventories are used in the "snapshot" calculation. Flux shape and local spectra are used to obtain zone flux magnitudes, $\tilde{\phi}$, normalized to rated reactor power, and zone one-group cross sections:

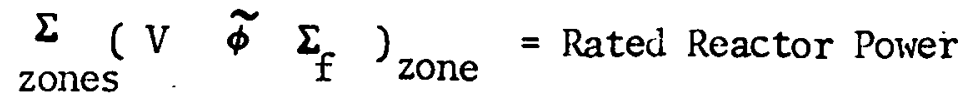

$$
\begin{aligned}
& \sigma=\sum_{g} \tilde{\phi}_{g} \sigma_{g} / \tilde{\phi} \\
& \widetilde{\phi}=\sum_{\mathrm{g}} \tilde{\boldsymbol{\phi}}_{\mathrm{g}}
\end{aligned}
$$


where $\tilde{\phi}$ is the zone flux (total, integrated over energy and zone volume) at rated reactor power, $V$ is the zone volume, $\Sigma_{f}$ is the total macroscopic fission cross section for the zone, $\tilde{\phi}_{g}$ is the zone flux in energy group $g$. Input to the multigroup physics computation includes, in addition to reactor configuration information, a multigroup cross section set. This multigroup set could be obtained from a cross section processing program such as $1 \mathrm{DX}\left(\underline{27)}\right.$ or $\mathrm{MC}^{2}(\underline{39})$, making appropriate corrections, regionally, on a standard set or file, for self-shielding. Multigroup cross section data used in this report consisted of the 26 group Russian set (48), 1DXcorrected $(27,81)$ for the core and blanket.

4. Zone fluxes and zone cross sections, found in step 3, and plant load factor (L) are input to the "semi-analytic depletion method (SAM" calculation, Equations (3-9), to obtain zone compositions as a function of flux time, burnup, and irradiation time. The load factor is used to scale the fluxes for Equations (3-7) and (3-9):

$$
\phi=L \tilde{\phi}
$$

Equations (3-9) yield the zone number densities at irradiation time $\mathrm{T}$ : $\mathrm{N}_{28}(\mathrm{~T}), \mathrm{N}_{49}(\mathrm{~T}), \ldots, \mathrm{N}_{42}(\mathrm{~T})$. The nuclide number densities are converted to masses by equations of the form

$$
M_{i}(T)=N_{i}(T) V \frac{\tilde{I}_{i}}{N_{a v}}
$$

where

$$
\begin{aligned}
M_{i}(T) & =\text { mass of nuclide } i \text { in the depletion zone at irradiation } \\
& \text { time } T, \mathrm{~kg} ; \\
V & =\text { zone volume, liters; } \\
\tilde{M}_{i} & =\text { atomic mass of nuclide } i
\end{aligned}
$$




$$
\mathrm{N}_{\mathrm{av}}=\text { Avogadro 's number }
$$

Since many economics parameters are normalized to mass of heavy metals $(\mathrm{U}, \mathrm{Pu})$ loaded, it is convenient to define the nuclide fractions

$$
\epsilon_{i}(T)=M_{i}(T) / M_{H M}^{0}
$$

where

$$
\begin{aligned}
M_{H M}^{0} & =\text { mass of heavy metals }(U, \text { Pu) loaded in zone } \\
& =M_{28}^{0}+M_{49}^{0}+\ldots+M_{42}^{0}
\end{aligned}
$$

5. Zone masses may be summed over an annular region which is batch or scatter-managed to obtain the masses discharged from fuel lots irradiated in that region:

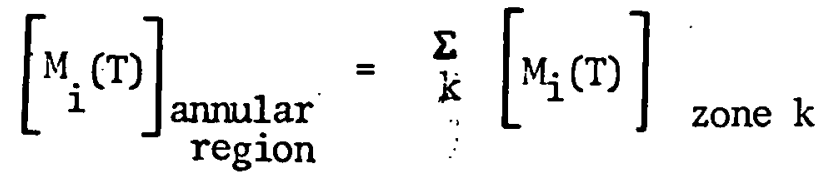

$$
\begin{aligned}
& {\left[\epsilon_{i}(\mathrm{~T})\right]_{\substack{\text { annular } \\
\text { region }}}=\frac{\left[\mathrm{M}_{i}(\mathrm{~T})\right]_{\text {annular region }}}{\left[\mathrm{M}_{\mathrm{HM}}^{0}\right]_{\text {annular region }}}}
\end{aligned}
$$

Cost Calculations

6. The following economics parameters are set:

- Unit fuel processing costs, dollars per $\mathrm{kg}$ of heavy metal,

$$
\mathrm{C}_{\text {fab }}, \mathrm{C}_{\text {repr }} \quad[\$ / \mathrm{kg} \text { HM }]
$$

- Isotope market values, dollars per $\mathrm{kr}$ of isotope,

$$
\mathrm{C}_{28}, \mathrm{C}_{49}, \ldots, \mathrm{C}_{42} \quad[\$ / \mathrm{kg}]
$$


- Financial paraneters

Tax $\operatorname{rate}(\tau)$

Capital structure $\left(f_{b}, f_{s}\right)$

Utility rates of return $\left(\mathrm{r}_{\mathrm{b}}, \mathrm{r}_{\mathrm{s}}\right)$

7. Using the economics parameters of step 6 and the nuclide masses fron step 4 (local, depletion zone) or step 5 (annular region), fuel costs are calculated from the CFM cost equations developed in Chapter 2 : The levelized cost of electricity (mills/KWH ) associated with a depletion zone or annular region is given by

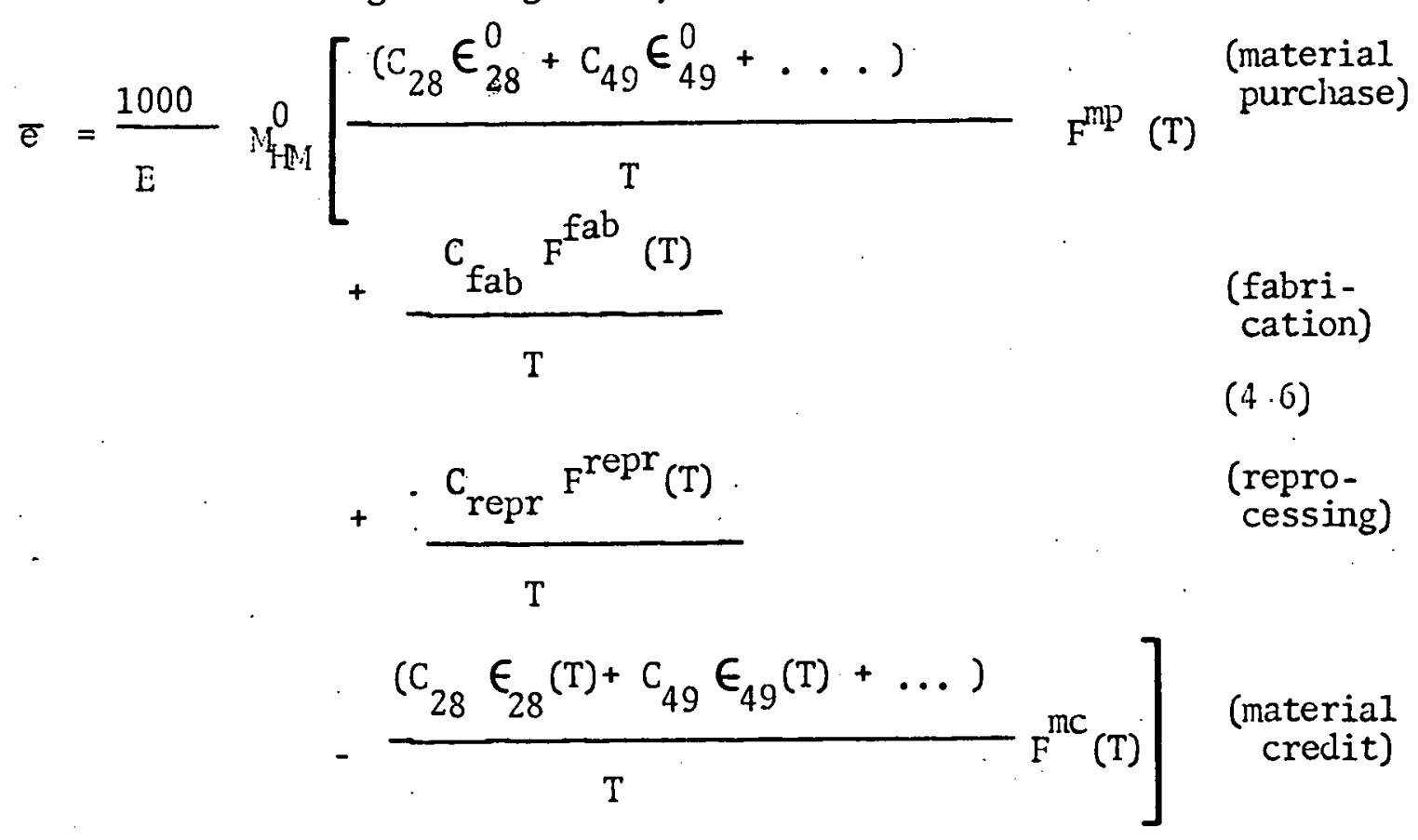

where $H_{4 M}^{0}, \epsilon_{28}^{0}, \epsilon_{49}^{0}, \ldots, \epsilon_{28}(\mathrm{~T}), \epsilon_{49}(\mathrm{~T}), \ldots$ are either depletion zone quantities (step 4) or annular region quantities (step 5). Other terms in Equation (4-6) are defined below:

$$
\begin{aligned}
& E=\text { electrical energy produced by the plant per year, } \frac{k w h e}{y r} \\
& 1000=\text { conversion factor, mills/dollar } \\
& \mathrm{F}^{\mathrm{q}}(\mathrm{T})=\begin{array}{l}
\text { carrying charge factor for cost component } \mathrm{q} \text {, defined such } \\
\text { that }
\end{array} \\
& \text { Total cost }(\mathfrak{q})=\text { direct cost }(q) \times F^{q}(T) \\
& \text { carrying charge }(q)=\text { direct cost }(q) \times\left[F^{q}(T)-1\right] \text {. }
\end{aligned}
$$


The cost components of Equation (4-6) above correspond to chronological events in the fuel cycle, e.g. material purchase $\rightarrow$ fabrication $\rightarrow$ (ir radiation) $\rightarrow$ reprocessing $\rightarrow$ material credit. Costs may be restructured as desired, e.g.

$$
\begin{aligned}
\text { material costs } & =\text { material, direct + material, carrying charge } \\
& =\text { "burnup cost" + "inventory cost" } \\
\text { processing costs } & =\text { fabrication + reprocessing } \\
& =\text { processing, direct + processing, carrying charge }
\end{aligned}
$$

The bracketed term in Equation (4-6) may be regarded as a figure of merit representing local fuel economic performance, having units of dollars per year per local kilogram of heavy metal loaded.

8. Steps 4 through 7 generate local (by depletion zone), annular region, and major regional (core, axial blanket, radial blanket) depletion and economics results as a function of irradiation time.

The process may be repeated for different economic environments (step 6), using a single set of neutronics data from step 3 , that is, the multigroup physics computation need be performed only once per reactor configuration.

A computer program, SPPIA, was developed to perform steps 4, 5, and 7, e.g. to perform SAM depletion calculations and CFM cost calculations, using, as input, the zone neutronic information from step 3 and the economic parameters set in step 6. This program is described in Appendix C.

\subsection{REFERENCE LMFBR CONFIGURATION}

In order to select a representative LMFBR configuration for blanket case studies, a brief survey was made of U.S. reactor manufacturers' 1000

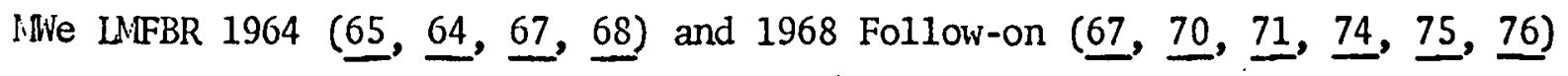
designs, the Karlsruhe $(\underline{77}, \underline{78})$ designs, the reference reactors used in 
design calculations for the MIT Blanket Test Facility (60), and reference reactors used in other blanket analytical studies $(\underline{1}, \underline{4}, \underline{5})$. Only uraniumplutoniun ceramic fueled reactors were considered. Modular and annular geometries were excluded. Key variables surveyed were those base design parameters which affect blanket fuel economics directly and prominently: core height-to-diameter ratio, core power density, blanket size, and core and blanket compositions. Table 4.1 sumarizes this data for the reactors considered, together with the LMFBR reference design adopted for the present studies. The reference LAFBR arrangement is shown in Figure 4.2.

The reference LMFBR adopted is identical to that used in the depletion method studies of Chapter 3. It closely resembles the Karlsruhe designs, and the reference LMFBR used for the MIT Blanket Test Facility design calculations. The two subcases $\left(1,1^{\prime}\right)$ of the reference LIFBR are identical except that $1^{\prime}$ has two core enrichment zones while 1 has a single uniform load enrichment.

\subsection{REFERENCE LMFBR FUEL ECONOMICS \\ One-Zone Core}

In this section, the procedure outlined in Section 4.2 is applied to the reference LAFBR described in Section 4.3.

The reference economic environment assumed for these calculations is summarized in. Table 4.2. This data is representative of base data used in LMFBR design studies $(\underline{62}, \underline{63}, \underline{64}, \underline{65}, \underline{66}, \underline{69}, \underline{70}, \underline{71}, \underline{72}, \underline{73})$ and falls within ranges projected for the mature U.S. nuclear fuel cycle economy (18). Unit fuel cycle costs are sensitive to national nuclear fuel cycle throughput and capacity, and are closely coupled to reactor design and operation (fuel pin design, discharge enrichnent). Since these concerns lie beyond the purvue of this study, the economic environment is treated parametrically 
19641000 MWe LMFBR Designs

\begin{tabular}{|c|c|c|c|}
\hline & & $\begin{array}{c}\mathrm{GE} \\
\operatorname{Ref} .(\underline{65}, \underline{67}, \underline{68)}\end{array}$ & 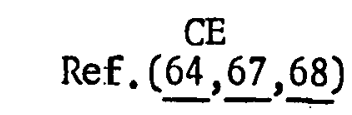 \\
\hline $\begin{array}{l}\text { Core Height } \\
\text { Diameter } \\
\text { Height/Diameter } \\
\text { Volume }\end{array}$ & $\begin{array}{l}(\mathrm{cm}) \\
(\mathrm{cm}) \\
\text { (1iters) }\end{array}$ & $\begin{array}{c}60.96 \\
356.62 \\
0.1709 \\
6030\end{array}$ & $\begin{array}{c}76.2 \\
219.46 \\
0.347 \\
2895\end{array}$ \\
\hline Axial Blanket Thickness $\times 2$ & $(\mathrm{~cm})$ & 91.4 & 91.4 \\
\hline Radial Blanket Thickness & $(\mathrm{cm})$ & 38.1 & 42.6 \\
\hline Core Power Density & $\left(\mathrm{kw}_{\mathrm{t}} / 1 \mathrm{iter}\right)$ & 365 & 695 \\
\hline $\begin{array}{l}\text { Core \& Axial Blanket Composition } \\
\text { Fuel } \\
\text { Structural Metal } \\
\text { Sodiun }\end{array}$ & $\begin{array}{l}(v / 0) \\
(v / o) \\
(v / o)\end{array}$ & $\begin{array}{l}34.8 \\
18.8 \\
46.4\end{array}$ & $\begin{array}{r}25.6 \\
7.9 \\
66.5\end{array}$ \\
\hline $\begin{array}{l}\text { Radial Blanket Composition } \\
\text { Fuel } \\
\text { Structural Metal } \\
\text { Sodium }\end{array}$ & $\begin{array}{l}(v / 0) \\
(v / 0) \\
v / o\end{array}$ & $\begin{array}{l}50.7 \\
17.2 \\
32.1\end{array}$ & $\begin{array}{l}45 \\
12 \\
43\end{array}$ \\
\hline $\begin{array}{l}\text { Fue1 Enriclument Zoining } \\
\text { No.of Core Enrichment Zones } \\
\text { Enrichnent Zone \# } \\
\text { Load Enrichment } \\
\text { Enriciment Zone Volume }\end{array}$ & $\left\{\begin{array}{l}\% \\
0 \\
l i \text { ters }\end{array}\right)$ & \begin{tabular}{lll} 
I & \multicolumn{3}{c}{ II $_{1}$} & III \\
15.67 & 17.96 & 20.24 \\
2010 & 2010 & $20 i_{0}$
\end{tabular} & $\begin{array}{cc}I & 2 \\
10.68 & \text { II } \\
1447.5 & 1447^{28} .5\end{array}$ \\
\hline
\end{tabular}


TABLE 4.1 - Continuation

19681000 Me LFER Follow-on Designs

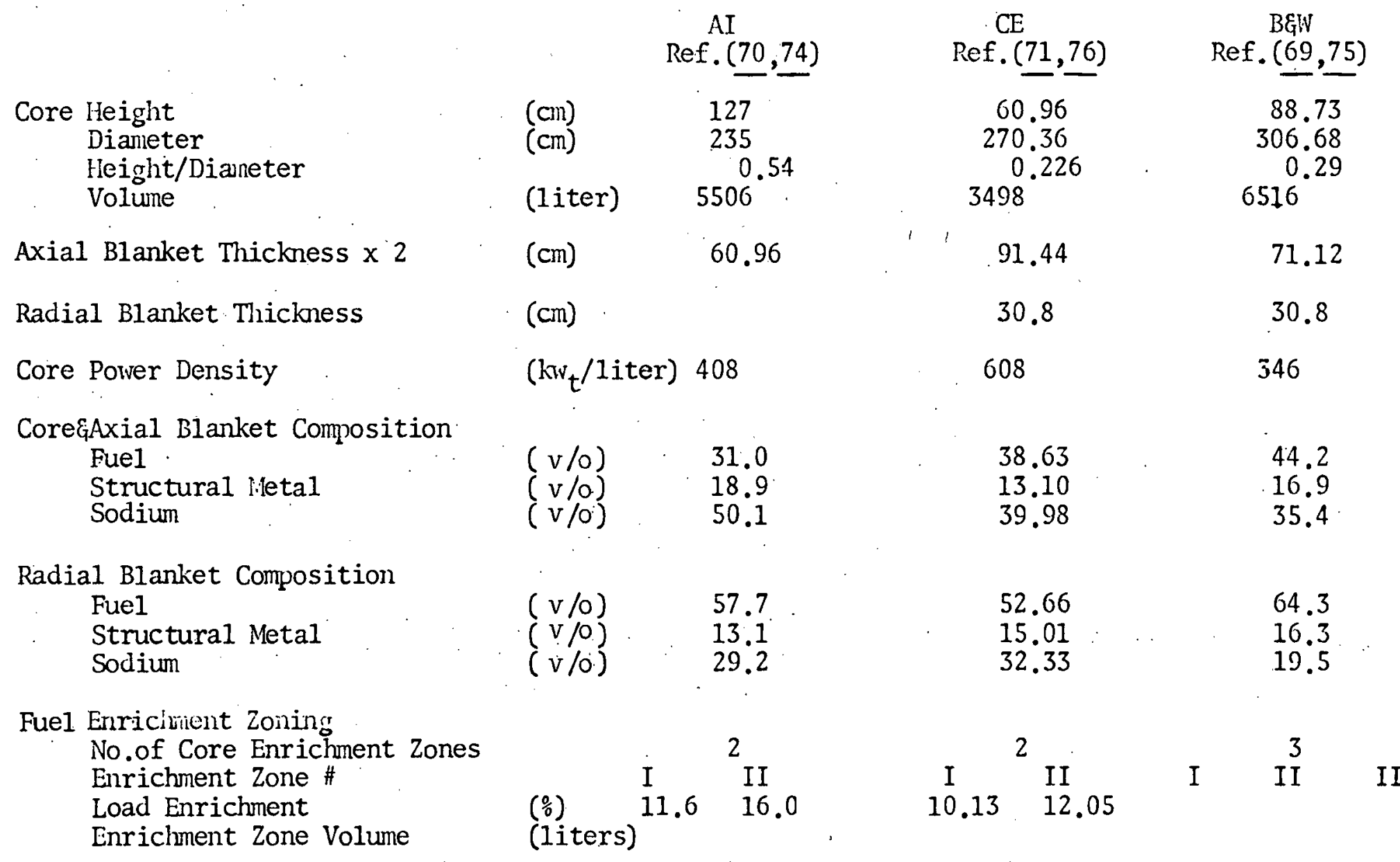


TADLE 4.1. Continuation

Karlsruhe

Ref. (77)

Core Height

Diameter

Height/Diameter

Volune

Axial Blanket Thickness $x 2$

Radial Blanket Thickness

Core Power Density

Core \& Axial Blanket Composition

Fue1

Structural Metal

Solium

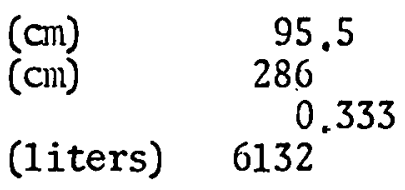

$\begin{array}{ll}(\mathrm{cm}) & 80 \\ (\mathrm{~cm}) & 45.3\end{array}$

$\left(\mathrm{kw}_{\mathrm{t}} /\right.$ liter $) 393$

$\begin{array}{ll}(v p) & 30.4 \\ v / o & 19.6 \\ v / o & 50.0\end{array}$

Radial blanket Composition

Fuel

Structural Metal

Sodium

$\begin{array}{ll}(\mathrm{v} / \mathrm{o}) & 48.3 \\ \mathrm{v} / \mathrm{O}) & 21.9 \\ \mathrm{v} / \mathrm{O}) & 29.8\end{array}$

Fuel Enricinient Zoning

No. of Core Enricinnent Zones

Enriclument Zone \#

Load Enrichment

Enrichment Zone Volume

$\begin{array}{lll} & & 2 \\ (\%) & 1 & \text { II } \\ (10.66 & 13.93 \\ \text { (iters) } & 3066 & 3066\end{array}$

$$
\begin{array}{ll}
\text { Karlsruhe(Jansen) } & \text { Forbes } \\
\text { Ref.(78) } & \text { Ref. (60) }
\end{array}
$$

94
282
0.333
5868

$$
95
$$$$
0.475
$$$$
2983
$$

80

80

46

45

$\begin{array}{ll}30 & 35 \\ 20 & 15 \\ 50 & 50\end{array}$

$\begin{array}{ll}50 & 50 \\ 20 & 20 \\ 30 & 30\end{array}$

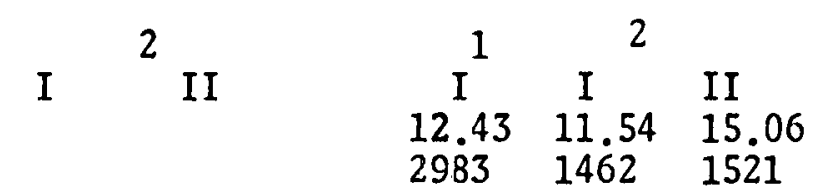


TABLE 4.1 Continuation

Core Height

Diameter

Height/Diameter

Volume

Axial Blanket Thickness $\times 2$

Radial Blanket Thickness

Core Power Density

Core \& Axial Blanket Composition

Fuel

Structural Metal

Sodium

Radial Blanket Conposition

Fue1

Structural Metal

Sodium

Fuel Enriciwient Zoning

No. of Core Enriciment Zones

Enriclnnent Zone \#

Load Enriciment

Enrichment Zone Volume

Plant Rated Thermal Power

Plant Rated Electrical Power

\section{Klickman}

Ref. (1)

$\begin{array}{lc}(\mathrm{cm}) & 105 \\ (\mathrm{~cm}) & 131 \\ & 0.801 \\ \text { (1iters) } & 1414\end{array}$

(cm)

92

(cm)

40

$\left(\mathrm{kw}_{1}\right) \quad 443$

1iter)

$\left(\begin{array}{l}v / 9 \\ \mathrm{v} / 0\end{array}\right.$

( v/o)

50

14

36

$(\mathrm{v} / \mathrm{o})$

$(v / o)$
Hasnain

Ref. (4)

93

104

0.9

800

80

45

1000

30

20
50

60

18

22

\begin{tabular}{|c|c|}
\hline $\begin{array}{l}(\stackrel{0}{0}) \\
\text { (1iter) }\end{array}$ & $\begin{array}{r}1 \\
1418\end{array}$ \\
\hline $\begin{array}{l}\left(\mathrm{MN}^{2}\right) \\
\left(\mathrm{MN}_{\mathrm{e}}^{\mathrm{e}}\right)\end{array}$ & $\begin{array}{l}620 \\
230\end{array}$ \\
\hline
\end{tabular}

800
Perks

Ref. (5)

119.38

193.04

0.62

3400

122

61

329

30.8

25.0

36.4

varied. 
Reference LMFBR

for Present Studies

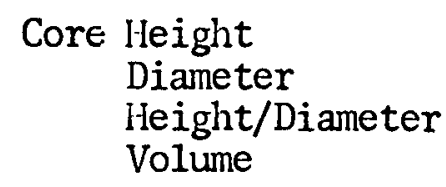

$(\mathrm{cm})$
$(\mathrm{cm})$

(1iters)

Axial Blanket Thickness x 2

(cm)

(cm)

$\left(\mathrm{kw}_{\mathrm{t}} /\right.$ 1iter $)$

Core Power Density

Core \& Axial Blanket Composition Fuel

Structural Metal

Sodium

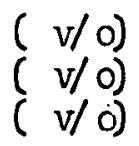

Radial Blanket Composition

Fuel

Structural Metal

Sodiun

Fue1 Enriciment Zoning

No. of Core Enriciment Zories Enriclunent. Ztene \#

Load Enriciment

Eirichnent Zone Voiwne

Plant Rated Thermal Power

Plant Rated Electrical Power

$$
\begin{aligned}
& v / 0) \\
& v / 0) \\
& v / 0)
\end{aligned}
$$

(MWt)

$\left(\mathrm{MN}_{\mathrm{e}}\right)$

$$
\begin{gathered}
100 \\
250 \\
0.4 \\
4906 \\
\\
80 \\
45 \\
500 \\
\\
30 \\
20 \\
50
\end{gathered}
$$

20

20

30

$\begin{array}{rrr}1^{*} & & 2 * * \\ I & I & \text { II } \\ 14 & 11 & 17 \\ 4906 & 2540 & 2366 \\ & 2560 & \\ & 1000 & \end{array}$

\footnotetext{
* Reactor \#1

** Reactor \#1
} 
QUARTER-CORE VERTICAL SECTION

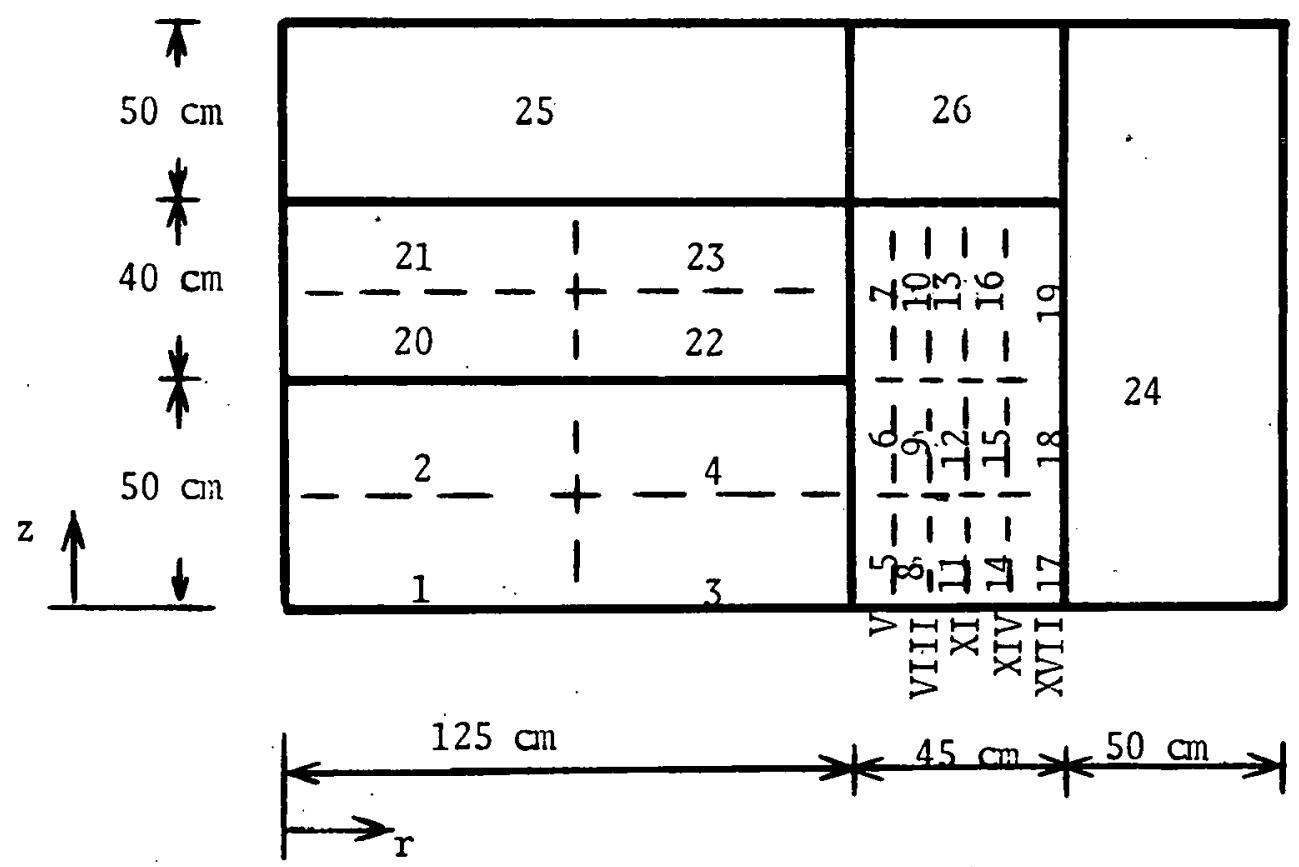

VOLUNE FRACTIONS

$\begin{array}{lcccccc}\text { REGION } & \text { CORE } & \begin{array}{c}\text { RADIAL } \\ \text { BLANKET }\end{array} & \begin{array}{l}\text { AXIAL } \\ \text { BLANKET }\end{array} & \begin{array}{l}\text { RADIAL } \\ \text { REFL. }\end{array} & \begin{array}{l}\text { NXIAL } \\ \text { REFL. }\end{array} & \begin{array}{c}\text { AX.REFL. FOR } \\ \text { RAD.BKT. }\end{array} \\ \text { ZONE } & 1-4 & 5-19 & 20-23 & 24 & 25 & 26 \\ \text { SODIUR } & 0.50 & 0.30 & 0.50 & 1.00 & 0.50 & 0.30 \\ \text { OXIDE } & 0.30 * & 0.50 & 0.30 & 0 & 0 & 0 \\ \text { SS } & 0.20 & 0.20 & 0.20 & 0 & 0.50 & 0.70\end{array}$

* INITIAl CORE ENRICHMENT $=14 \%$

FIG. 4.2 REFERENCE LAFBR CONFIGURATION (REACTOR \#1) 
TABLE 4.2

REFERENCE ECONOMIC ENVIRONMENT

Unit Fuel Processing Costs

$\$ / \mathrm{kg}$ HM

\begin{tabular}{|c|c|c|c|}
\hline & Core & Axial Blanket & Radial Blanket \\
\hline abrication $\left(\mathrm{C}_{\mathrm{fab}}\right)$ & 314 & 80 & 69 \\
\hline Reprocessing $\left(\mathrm{C}_{\text {repr }}\right)$ & 31.5 & 31.5 & 31.5 \\
\hline
\end{tabular}

Isotope Market Values

$\$ / \mathrm{kg}$

U238 $\left(\mathrm{C}_{28}\right)$

0

Pu239 $\left(\mathrm{C}_{49}\right)$

10,000

Pu240 ( $\left.\mathrm{C}_{40}\right)$

0

Pu241 ( $\left.\mathrm{C}_{41}\right)$

10,000

Pu242 (C $\left.{ }_{42}\right)$

0

Financial Parameters

Income Tax Rate $(\tau)$

0.5

Capital Structure

Bond(Debt) Fraction

$\left(f_{b}\right)$

0.5

Stock (Equity) Fraction

0.5

Rates of Return

Bonds

Stocks

$\left(\mathrm{r}_{\mathrm{b}}\right)$

0.07

0.125

Discount Rate *

(x)

0.08

${ }^{*} x=(1-\tau) r_{b} f_{b}+r_{s} f_{s}$ 
in Chapter 5, where the sensitivity of LFBR fuel costs (mills/Kilie) to econonic enviroument is estimated.

Table 4.3 lists pre-irradiation, irradiation, and post-irradiation tines assumed for these reference calculations. Table 4.4 surmarizes the reference plant power data.

Figures 4.3, 4.4, and 4.5 silow fuel costs (mills/Kilie) versus irradiation tine for the reference LFBR (\#1) core, axial blanket, and radial blanket. Batch fuel managenent of each of these regions is assunled. The reference one-zone core irradiation time of two years corresponds to an average core burnup of $102,000 \mathrm{~mm}_{t} / \mathrm{MT}$. Core fuel cost at this exposure is seen to be $0.97 \mathrm{mills} / \mathrm{kWHe}$. It is assumed, for practical reasons, that the axial blanket must be operated on the same fueling scledule as the core, i.e. two year irradiation time. The optimum irradiation time for the axial blanket, under the reference economic enviromment, is about two years (Figure 4.4). At two years, the axial blanket fuel cost is $-0.141 \mathrm{mills} / \mathrm{kWH}$, a net revenue.

Unlike the axial blanket, the irradiation time for the radial blanket may be fixed independently of the core. Figure 4.5 shows its "breakeven" irradiation time to be about three years. Its optimum irradiation time is about six years, corresponding to a fuel cost of $-0.036 \mathrm{mills} / \mathrm{KWHe}$, $(-8.1 \$ / \mathrm{yr} . / \mathrm{kg} \mathrm{lin})$, a net revenue.

Comparing the fuel economics of the axial and radial blankets, one notes: (a) the relatively low net revenue provided by the radial blanket at its optimum irradiation time, i.e. 8.1 $\$ / \mathrm{yr} . / \mathrm{kg} / \mathbb{M}$ for the radial blanket vs. $100 \$ / y r . / k g l M$ for the axial blanket; and (b) the relatively "sluggish" behavior of the radial blanket, i.e. the radial blanket is slow in reaching its maximum net revenue. The comparatively poor radial blanket performance is the result of its relatively 
TABLE 4.3 REFERENCE FUEL CYCLE TIMING

\begin{tabular}{|c|c|c|c|c|c|c|}
\hline \multirow[t]{3}{*}{ Region } & \multirow[t]{3}{*}{ Scheme } & \multirow{2}{*}{\multicolumn{2}{|c|}{$\frac{\text { Pre-Irradiation }}{\text { Imes (yr.) }}$}} & \multirow{3}{*}{$\frac{\text { Irradiation }}{\text { Iime (yr.) }}$} & \multicolumn{2}{|c|}{ Post-Irradiation } \\
\hline & & & & & Tim & \\
\hline & & $\begin{array}{l}\text { Material } \\
\text { Purchase }\end{array}$ & $\begin{array}{l}\text { Fabri- } \\
\text { cation }\end{array}$ & & $\begin{array}{l}\text { Repro- } \\
\text { cessing }\end{array}$ & $\begin{array}{l}\text { material } \\
\text { credit }\end{array}$ \\
\hline core & batch & 0.5 & 0.5 & 2 & 0.5 & 0.5 \\
\hline $\begin{array}{l}\text { axial } \\
\text { blanket }\end{array}$ & batch & 0.5 & 0.5 & 2 & 0.5 & 0.5 \\
\hline $\begin{array}{l}\text { radial } \\
\text { blanket }\end{array}$ & batch & 0.5 & 0.5 & variable & 0.5 & 0.5 \\
\hline
\end{tabular}


TABLE 4.4

REFERENCE PLANT POWER PARAMETERS

Plant Rated Power, electrical

1000 MWe

Plant Thermal Efficiency $(\eta)$

$39 \%$

Plant Load Factor

(L)

$83 \%$ 


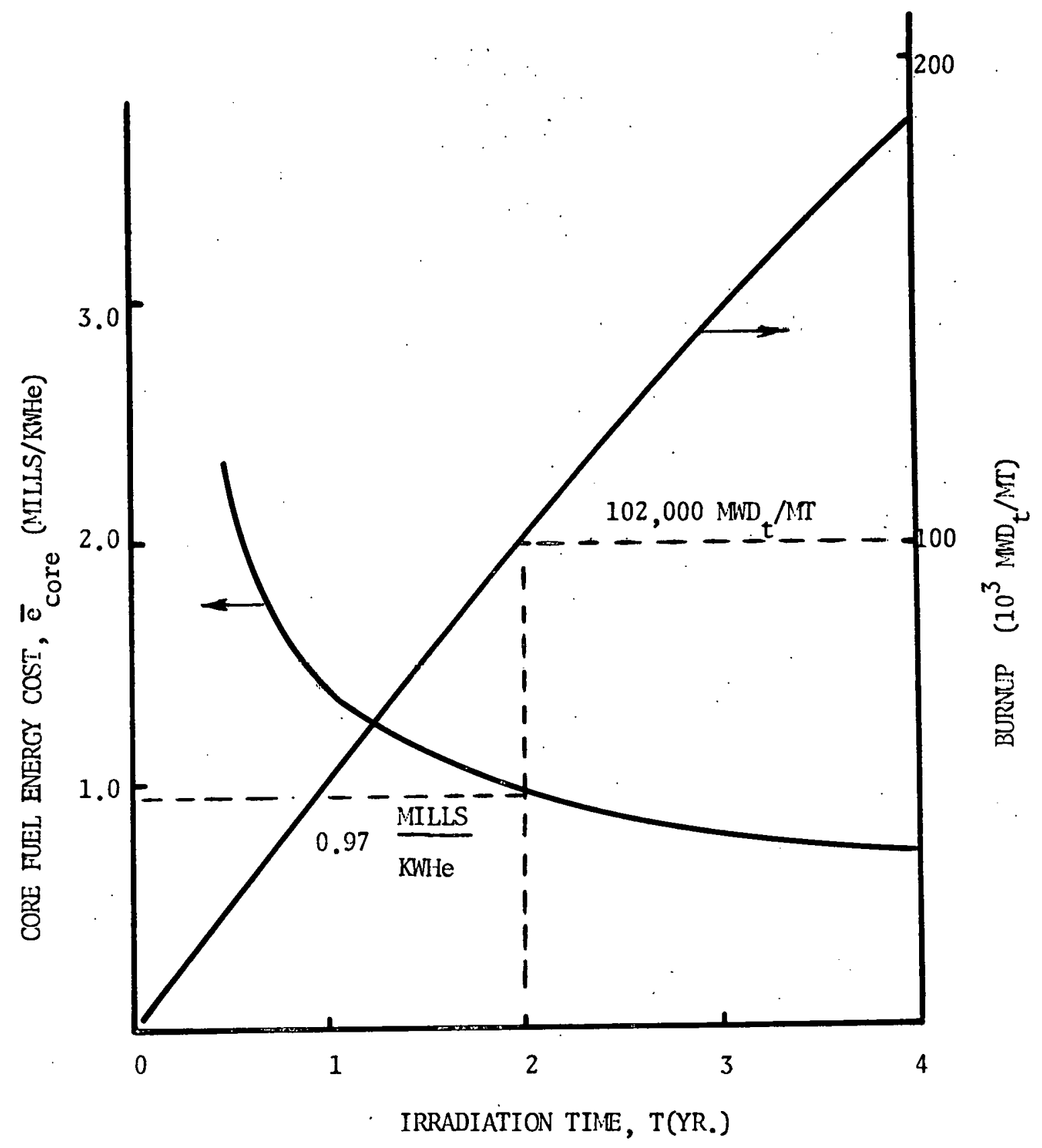

FIG. 4.3 REFERENCE 'LMFBR CORE FUEL ENERGY COST AS A FUNCTION OF EXPOSURE 


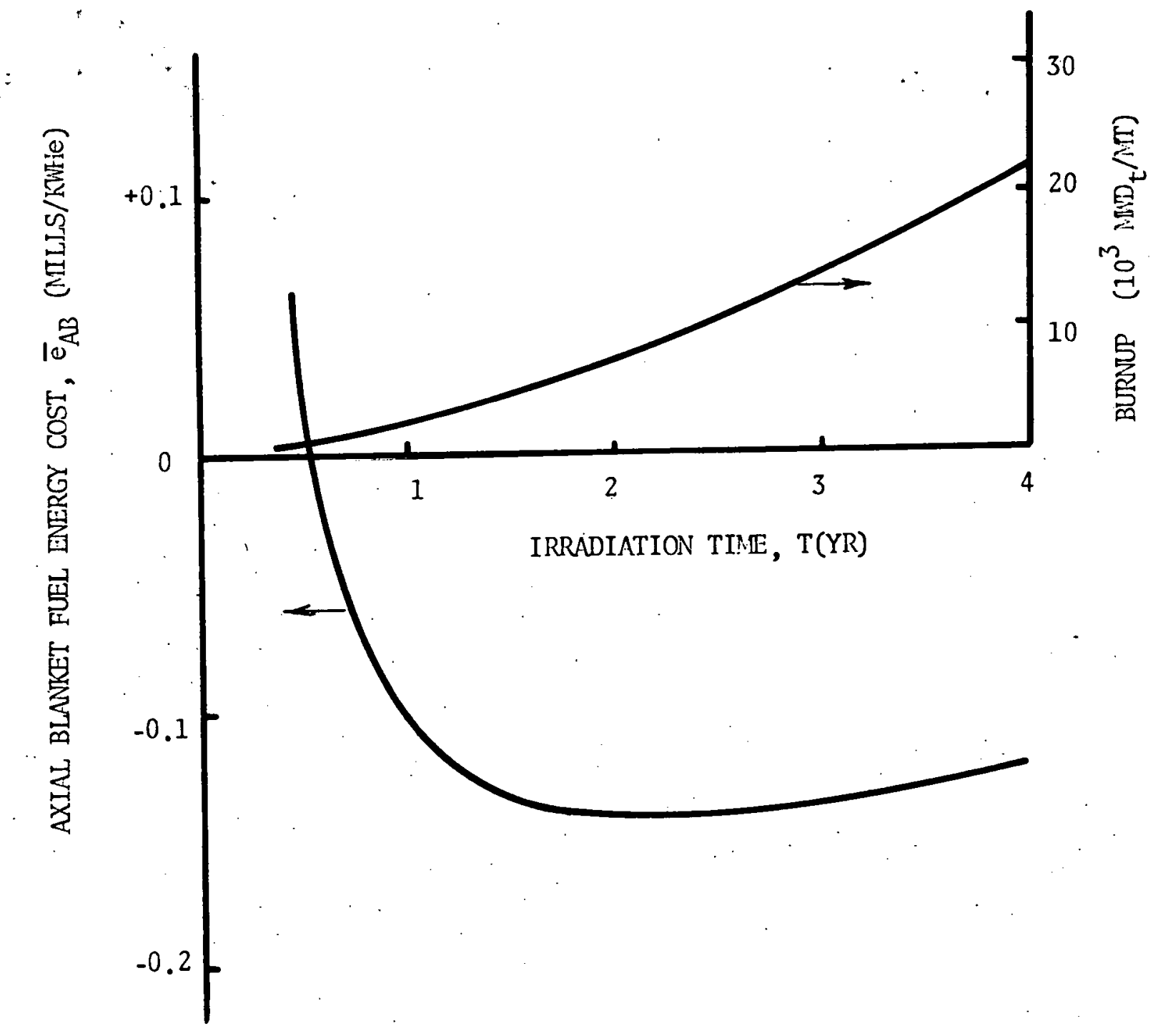

FIG. 4:4 REFERENCE LIFBR AXIAL BLANIET FUEL ENERGY COST AS A FUNCTION OF EXPOSURE 


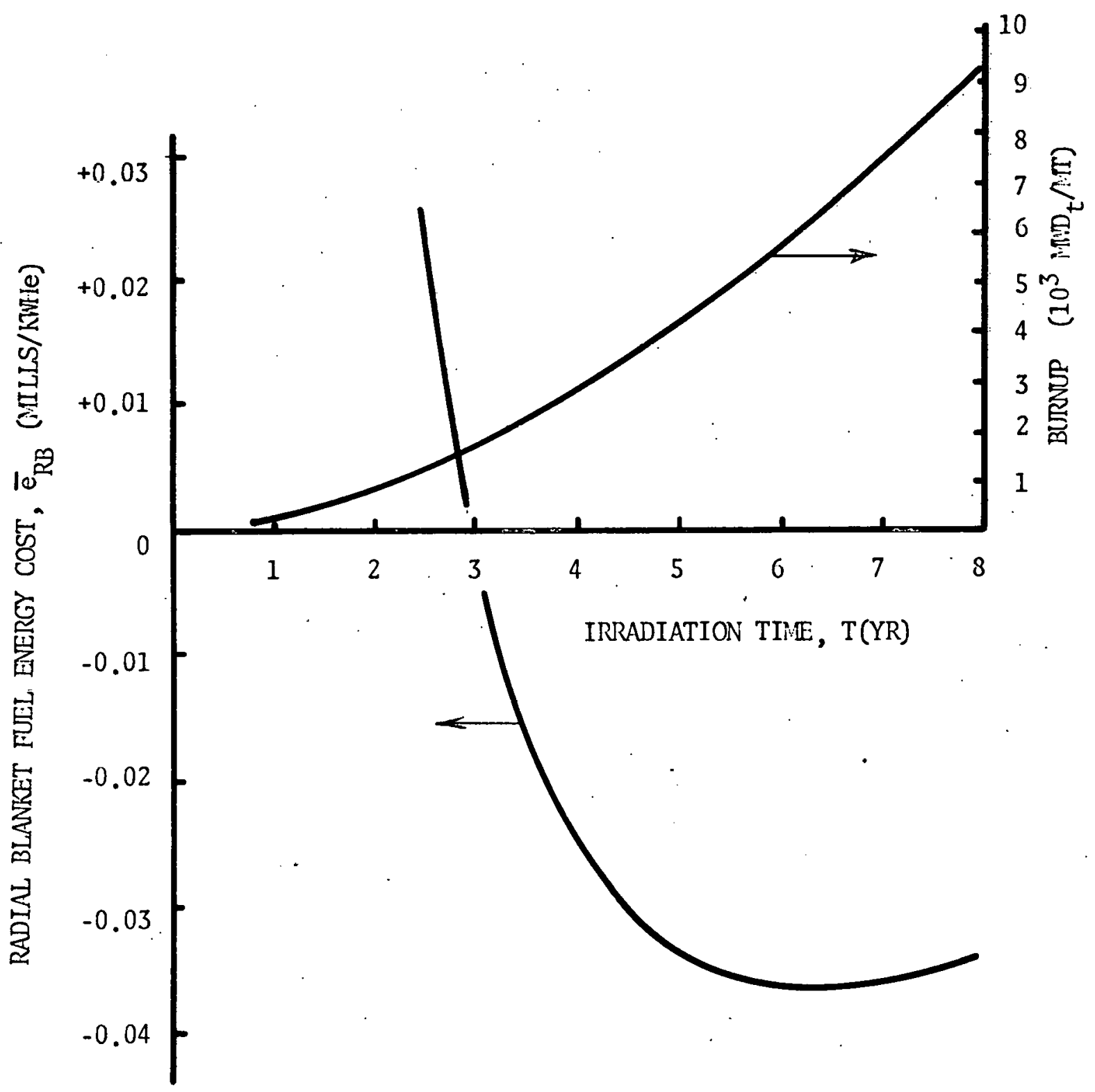

FIG. 4.5 REFERENCE LUFBR RADIAL BLANKET FUEL COST AS A FUNCTION OF EXPOSURE 
low average neutron flux (axial leakage predominates) and its somewhat harder spectrun (the radial blanket contains less sodium per unit volume).

Figures 4.6, 4.7 and 4.8 display the reference LMFBR (\#1) radial blanket neutronic and fuel economic spatial characteristics. Figure 4.6 shows $\phi, \sigma_{C}^{28}$, and $\phi \sigma_{C}^{28}$ as functions of radial position along the midplane $(Z=0)$ determined by the $2 \mathrm{DB}$ computation, step 3 , Section 4.2 . Figure 4.7 shows the resulting local fuel economic performance ( $\$ / \mathrm{yr} / \mathrm{kg} \mathbb{M})$ versus irradiation tine, for the annular regions labeled V, VIII, XI, XIV, and XVII in Figure 4.2. Breakeven and ontimum irradiation times increase with distance from the core-blanket interfact because the fissile plutonium buildup is nost rapid in the high flux regions near the core. Regions near the core show relatively sharp optima, compared to the regions XIV, XVII deep in the blanket. The optimum irradiation time (6.5years) for the batch-managed radial blanket is indicated by the dotted line. At the optimum, annular region XVII (outermost) incurs a net cost, rather than a net revenue, indicating that the radial blanket, under the economic environment assuned, is too thick.

Figure 4.8 displays the variation of local fuel performance $(\$ / \mathrm{yr} / \mathrm{kg} \mathbb{M})$ with distance from the core, at irradiation times of 2, 4, 6, and 8 years. Net revenue from the entire radial blanket may be identified with the net area under $(+)$ and above $(-)$ the curve. For astwo year irradiation, about two-thirds of the $45 \mathrm{~cm}$ radial blanket incurs a net cost, i.e. the fissile produced is not enough to offset fabrication, reprocessing, and carrying charges. At 6.5 years, the optimum, the outer one-third (outer row of fuel assemblies) is unprofitable. The slope of the plot $(\$ / \mathrm{yr}-\mathrm{kg} / \mathrm{M}-\mathrm{cm})$ decreases with irradiation time, as the inner regions pass their optimum irradiation times. 


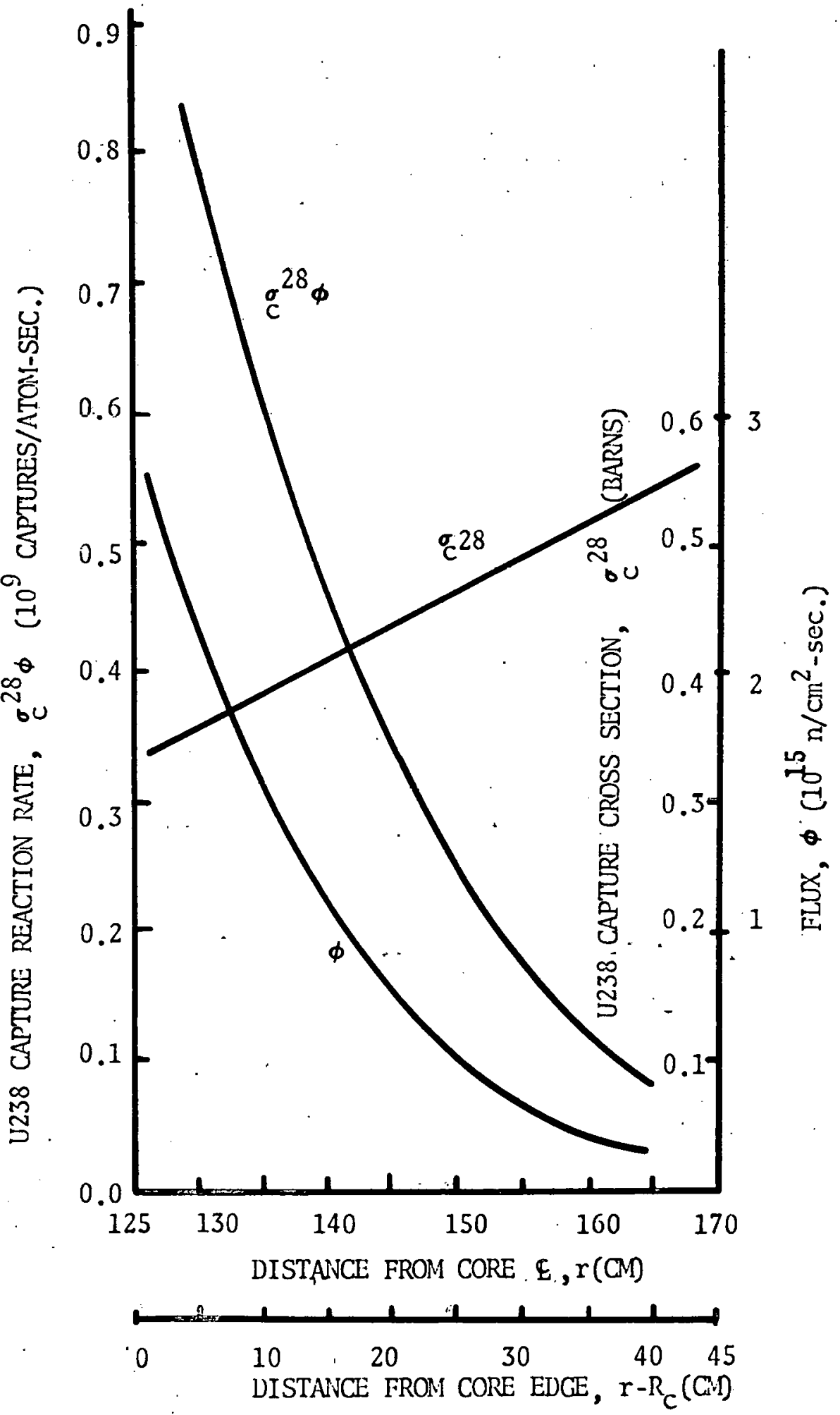

FIG. 4.6 LOCAL NEUTRONICS OF TI-E REFERENCE LIFBR RADINL BLANKET 


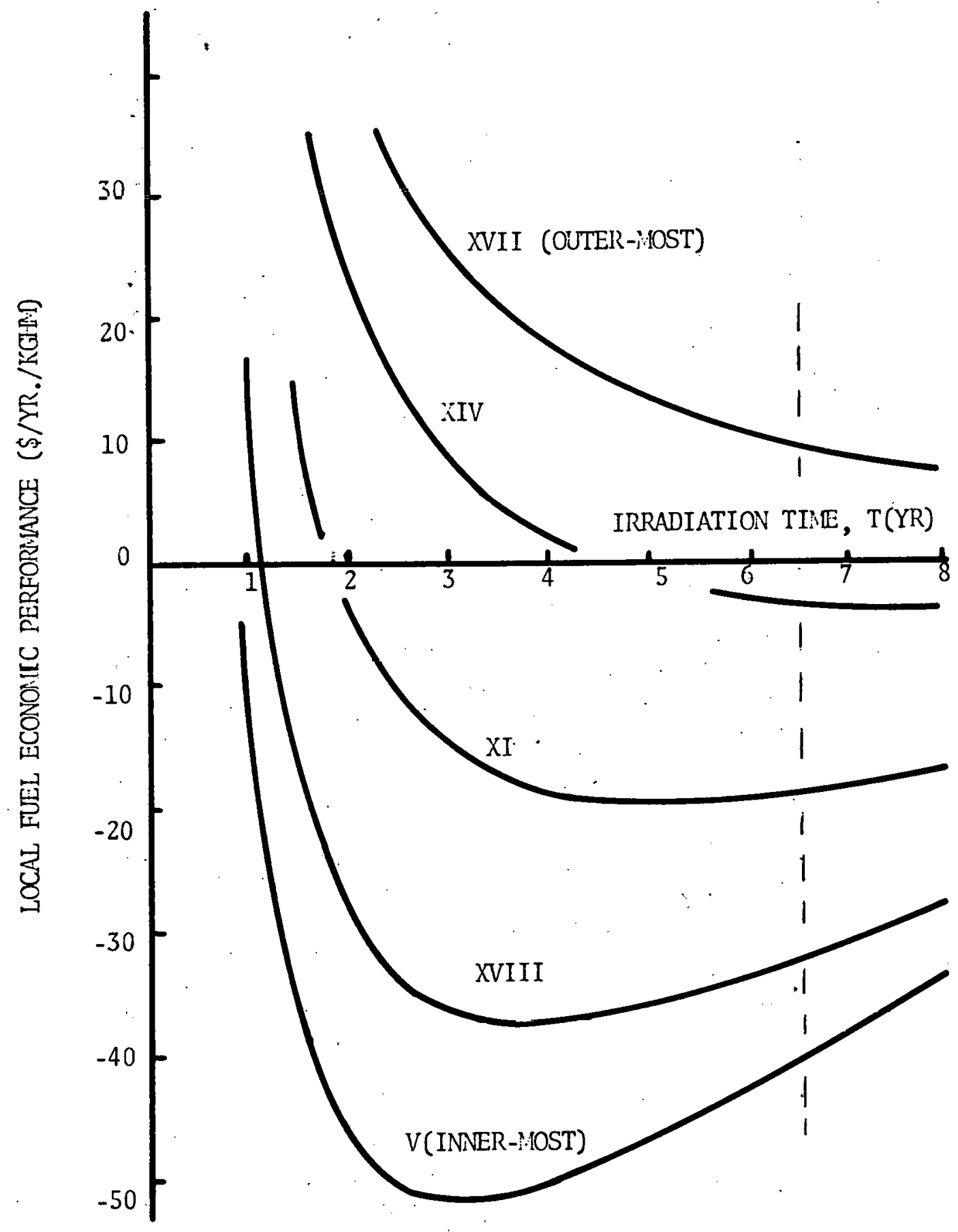

FIG: 4.7 FUEL ECONOMIC PERFORMANCE OF ANNULAR REGIONS IN TI IE REFERENCE LMFBR RADIAL BLANKET 


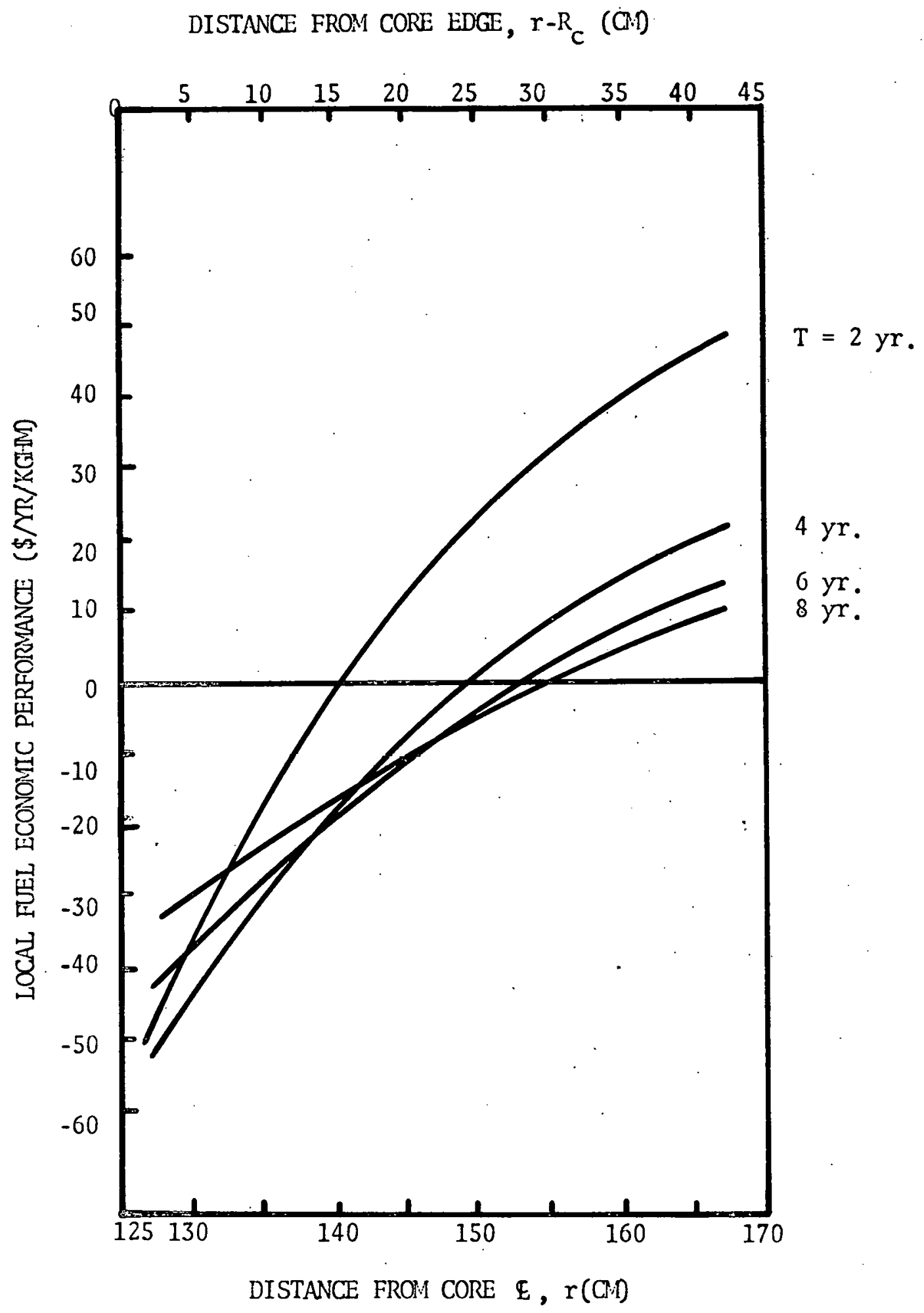

FIG. 4.8 FUEL ECONOHIC PERFORMANICE AS A FUNCTION OF RADIAL POSITION IN THE REFERENCE LMFBR RADIAL BLANKET 
One Versus Two Core Enrichment Zones

In addition to its advantages to core economics (53), core enrichment zoning enhances blanket breeding by increasing blanket flux. In order to estimate the effect of core enrichnent zoning on blanket depletion economics, a two_zone core reactor (Reactor \#1') was compared to the one-zone core reactor (Reactor \#1) evaluated above. In this comparison, core fissile inventory loaded, rated reactor power, and core size were fixed.

Since both rated power and core size are held fixed, the effect of power flattening on core fuel depletion economics (either more allowable power, or a smaller core and lower critical mass are possible) are not accounted for. Also unaccounted for is the inventory cost of the additional fissile mass required for $k_{\text {eff }}$-equivalence with the one zone core reactor. These two unaccounted for effects tend to cancel. Since primary interest liere is the blanket fuel economics, the adjustments in core conditions are not deemed necessary, although the net improvement in core fuel economics may, because core fuel costs (mills/KWHe) dominate, be more significant than the increased blanket revenue.

The comparison is shown in Table 4.5. When the core is zoned as prescribed, radial blanket revenue increases by about $150 \%$, the axial blanket revenue by about $6 \%$. Taken together, the incremental improvement in blanket revenue is about $0.07 \mathrm{mills} / \mathrm{KWHe}, \mathrm{a}$ savings of the order of 5 to $10 \%$ in total reactor fuel cost.

\subsection{SUMMARY}

The fuel economics and depletion methods established in Chapters 2 and 3, respectively, are combined in this Chapter to form a simple step-by-step procedure. (Appendix C describes the computer program, SPPIA, developed to perform the fuel econonics-depletion computations:) 
TABLE 4.5

EFFECT OF CORE ENRICHMENT ZONING ON BLANKET FUEL ECONOMICS

Reactor \#1 Reactor \#2

(1-zone core) (2-zone core)

Core

Enrichment Zone \#

Zone Enrichment, :

Zone Volume, liters

Average Enriclment, :

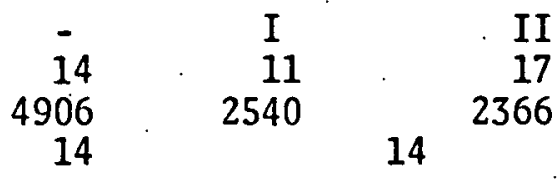

Radial Blanket

Fue1 Cost, $\operatorname{mills} / \mathrm{KWHe}$

$-0.036$

6.5

6.294

$-0.093$

4.5

$\phi(0,0) / \phi(125,0)$

years

2.831

Axial Blanket

Fuel Cost, mills/KWHe

$-0.141$

$-0.150$

$\Phi(0,0) / \phi\left(\begin{array}{l}0,50) \\ (110,50)\end{array}\right.$

2.526

7.297

2.507

3.759 
A reference 1000 WW LMFBR configuration, representative of those used in current design studies, is specified; the depletion-economics model is applied to this reference design. Major characteristics of FBR depletionecononics are noted. The beneficial effect of core enrichnent zoning on blanket fuel economics is demonstrated. 


\section{CHAPTER 5}

1000 MNE LMFBR CASE STUDIES

\subsection{INTRODUCTION}

In this chapter, the calculational procedure outlined in Section 4.1 is applied to a number of case studies. Objectives of these case studies are:

(1) to determine the effects, on reactor fuel economic performance, of radial blanket thickness and radial reflector material;

(2) to determine the economic advantage of operating each radial blanket region (annular) on its own local optimum irradiation schedule; and

(3) to examine the sensitivity of core, axial blanket, and radial blanket fuel energy costs (mills/KWHe) to the economic environment. Radial blanket thickness and radial reflector are varied, as shown in Table 5.1. All other design parameters - core and axial blanket geometry and compositions, and radial blanket composition: - are held fixed at reference reactor values given in Section 4.3, i.e. Reactor \#1. Core and axial blanket fuel power costs (mills/KWHJ) are found to be quite insensitive to radial blanket thickness and choice of radial reflector material (Section 5.2), and are thus ignored in evaluating the radial blanket configurations. Results of the radial blanket thickness radial reflector material case studies are presented in Section 5.3.

The assumption of a one-zone core in these studies penalizes radial blanket economics in all cases considered. Thus, the absolute values of net radial blanket revenue (in mills/KWHe) of individual configurations should not be taken as representative or typical. However, comparative 
TABLE 5.1 CASE DEFINITIONS

Reactor Configuration \#

1 (reference)

$1 \mathrm{~A}$

$1 B$

2

$2 \mathrm{~A}$

$2 \mathrm{~B}$
Radial Blanket

Thickness (cm)

45

30

15

45

30

15
Radial Reflector Material

$\mathrm{Na}$

$\mathrm{Na}$

$\mathrm{Na}$

Be metal

Be metal

Be metal 
conclusions and trends demonstrated by these studies are unaffected by the one-zone assumption.

Two radial blanket fuel management schemes are compared in Section 5.4: (a) "whole blanket" management, in which all blanket fuel sees the sane irradiation tine, the optimum for the blanket as a whole; and (b) "regional"management, in which each annular region is exposed to its own local optimum irradiation time. In either case, fuel sees only one position in the reactor.

The sensitivity of core, axial blanket, and radial blanket fuel power costs to changes in the economic environment is evaluated in Section 5.5. Also, simple linear forms of the cost equations are obtained in Section 5.5.

5.2 EFFECTS OF RADIAL BLANKET THICKNESS AND RADIAL REFLECTOR MATERIAL ON CORE AND AXIAL BLANKET FUEL DEPLETION ECONOMICS

Assessment of the economic (energy costs) effects of radial configuration design changes may be simplified considerably by ignoring their influence on core and axial blanket fuel depletion economics, that is by considering only the radial blanket depletion economics. For the reference geometry selected $(H / D=0.4)$, one would expect such changes in core and axial blanket fuel economic performance to be small because of the relatively small radial leakage from the core. That these changes are smaller, by orders of magnitude, than the simultaneous changes in radial blanket fuel depletion economics, is demonstrated in this section.

Changes in radial blanket thickness and/or radial reflector material can affect core and axial blanket fuel economics in two ways: (1) by affecting the core fissile inventory required for criticality, and thereby affecting core inventory cost; and (2) by perturbing the flux magnitude and spectra in the core and axial blanket, causing changes in 
$x$ depletion and material credit results.

(1) Core inventory cost is closely proportional to $y \mathrm{~T} \epsilon$, where $y$ is the carrying charge rate (per annum), $T$ is the time the fissile material is in the possession of the utility company, and $\epsilon$ is the critical enriclment. Thus the fractional change in core inventory cost, Inv.(mills/KWHe), caused by a change in critical enrichment is given by

$$
\frac{\Delta \text { Inv. }}{\text { Inv. }}=\frac{\Delta \epsilon}{\epsilon}
$$

or

$$
\frac{\Delta \text { Inv. }}{\text { Inv. }} \simeq 5 \frac{\Delta \cdot K}{K}
$$

where the expression ${ }^{1}$

$$
\frac{\Delta K}{K} \simeq 0.2 \frac{\Delta \epsilon}{\epsilon}
$$

has been used.

To illustrate the insensitivity of core inventory cost to radial configuration changes, Cases 1 ( $45 \mathrm{~cm}$ radial blanket with $\mathrm{Na}$ radial reflector) and 2B (15 cm radial blanket with Be radial reflector) are compared. From a reactivity point of view, these are the two most disparate cases. The nultigroup physics computations for the two cases showed that for the same core fissile content, their values of $\mathrm{K}_{\text {eff }}$ differ by less than 0.0002 . Thus

$$
\frac{\Delta \text { Inv. }}{\text { Inv. }}=5 \times \frac{0.0002}{1.0}=0.001 \text {. }
$$

The core inventory cost (Inv.) for Case 1 is 0.4147 mills/KWHe. Thus

1. From the 26G-TSD calculation for Reactor \#1 (no fission products). 


$$
\begin{aligned}
\Delta \text { Inv. }_{.} \text {Inv. } x \frac{\Delta \text { Inv. }}{\text { Inv. }} & \simeq 0.4147 \times 0.001 \\
& \simeq 0.00042 \mathrm{mills} / \mathrm{KWHe}
\end{aligned}
$$

The difference in optimum radial blanket fuel costs between the two cases is $0.05 \mathrm{mills} / \mathrm{KWH}^{1}$, which dwarfs the difference in core inventory costs. Of the six $\mathrm{Na}$ and Be reflected cases considered (Table 5.1), the minimum difference between radial blanket fuel costs is found to be 0.004 mills/KWhe (Cases 1 and 2$)^{1}$, which is an order of magnitude greater than the maximuin difference in core inventory costs.

(2) To illustrate the insensitivity of core and axial blanket fuel costs to the changes in flux shape and spectra occasioned by a radial configuration change, Table 5.2 shows the fuel costs of core, axial blanket and radial blanket for Cases 1 and $2 B$. The core results do not include the core inventory correction $(0.0004 \mathrm{mills} / \mathrm{KWHe})$ estimated above.

To summarize, core and axial blanket fuel depletion-economics is quite insensitive to choice of radial reflector material and radial blanket tnickness:

$$
\begin{aligned}
& \text { (1) } \Delta \bar{e}_{\mathrm{RB}} \gg \Delta \text { Inv }{ }_{\text {core }} \\
& \text { (2) } \Delta \bar{E}_{\mathrm{RB}} \gg \Delta \overline{\mathrm{e}}_{\text {core }}, \Delta \overline{\mathrm{e}}_{\mathrm{AB}}
\end{aligned}
$$

For this reason, only the radial blanket fuel economic perfornance was considered in ranking the reactor configurations of Table 5.1.

5.3 RADIAL BLANKET THICKAESS AND RADIAL REFIECTOR MATERIAL

Reducing the radial blanket thickness has several effects on the radial blanket fuel econoinic performance:

1. Section 5.3. 
TABLE 5.2

EFFECTS OF RADIAL CONFIGURATION CHANGES

ON CORE AND AXIAL BLLANKET FUEL COSTS

\begin{tabular}{|c|c|c|c|c|c|}
\hline $\begin{array}{l}\text { Reactor } \\
\text { Configuration } \\
\# \#\end{array}$ & $\begin{array}{l}\text { Radial } \\
\text { Blanket } \\
\text { Thickness } \\
\quad \text { (cm) }\end{array}$ & $\begin{array}{l}\text { Radial } \\
\text { Reflecto= } \\
\text { Material }\end{array}$ & $\overline{\mathrm{e}}_{\mathrm{RB}}$ & $\overline{\mathbf{e}}_{\text {core }}$ & $\overline{\mathrm{e}}_{\mathrm{AB}}$ \\
\hline 1 & 45 & $\mathrm{Na}$ & -0.03635 & 0.96975 & -0.14130 \\
\hline $2 \mathrm{~B}$ & 15 & $\mathrm{Be}$ & -0.08687 & 0.96981 & -0.14176 \\
\hline & & $=$ & -0.05052 & $0.00006^{*}$ & -0.00046 \\
\hline
\end{tabular}

* Does not include core inventory correction. 
(a) fabrication and reprocessing costs for the region eliminated are saved;

(b) the plutonium which would have been bred in the region eliminated is forfeited;

(c) the breeding performance $\left(\overline{\left.\sigma_{c}^{28} \phi\right)}\right.$ of the remaining radial blanket is improved, by bringing the high-albedo and moderating reflector nearer to the high flux regions of the blanket; and

(d) coolant pumping power requirements for the radial blanket are reduced. These effects suggest that an economic optimun thickness may exist.

Radial reflector compostion influences radial blanket fuel economic performance through

(e) improved albedo, i.e. a beneficial effect on neutron econony through flux enhancement in the blanket, as well as overall flux flattening; and

(f) improved moderating ratio, softening radial blanket spectra and enhancing capture by U238 .

Other economic considerations associated with choice of reflector material and reflector design are:

(g) radial reflector coolant pumping requirenents;

(h) radial reflector material purchase and fabrication costs and exposure limits; and

(i) shielding performance of the radial reflector.

The economic consequences of changes in (d) radial blanket coolant puriping requirements, $(g)$ radial reflector coolant pumping requirements, (h) radial reflector material and fabrication costs, and exposure limits, and (i) radial reflector shielding performance, are currently being investigated by others at MIT (13). The studies reported here enbrace only 
the depletion-economics considerations listed above, (a), (b), (c), (e), and $(f)$. Further, the depletion-economics cormparisons are biased toward the exotic moderating reflector: a solid reflector ( $100 \mathrm{v} / \mathrm{O}$ Be metal) is assumed. A real reflector would probably consist of clad BeO, with as mucin as $20 \mathrm{v} / \mathrm{o}$ required for coolant. Also, the costs of the Be reflector are not included in the tradeoff study.

Figure 5.1 shows the radial blanket fuel costs (mills/Kile) as functions of irradiation time for the cases $1,2,1 A, 2 A, 1 B$, and $2 B$ defined in Table 5.1. The reference economic environment, Tables 4.2 and 5.4, was assumed. Table 5.3 summarizes the optinum irradiation times, fuel costs, fissile plutonium breeding rates, and disciarge fissile plutonium inventories in both reference and more favorable economic environments defined in Table 5.4. Figure 5.2 sumnarizes the radial blanket fuel costs (at. optimum irradiation time) for the six combinations of radial blanket thickness and radial reflector material, under the two economic environments.

Several features are noted in the results presented in Figure 5.1 and Table .5.3.

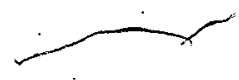

(1) The importance of reflector material choice, with respect to blanket fuel economics, decreases with increased blanket thickness. Choice of beryllium results in an improvenent in blanket revenue of about $60 \%$ over sodium, for a $15 \mathrm{~cm}$ radial blanket. For a $45 \mathrm{~cm}$ blanket, the iuprovenent is only about $8 \%$.

(2) For either sodium or beryllium reflectors, reducing the blanket thickness always reduces the plutonium bred by the blanket, i.e. effect (c) mentioned above is not sufficient to offset effect (b).

(3) Optinum irradiation time decreases with decreased radial blanket thiclness. 


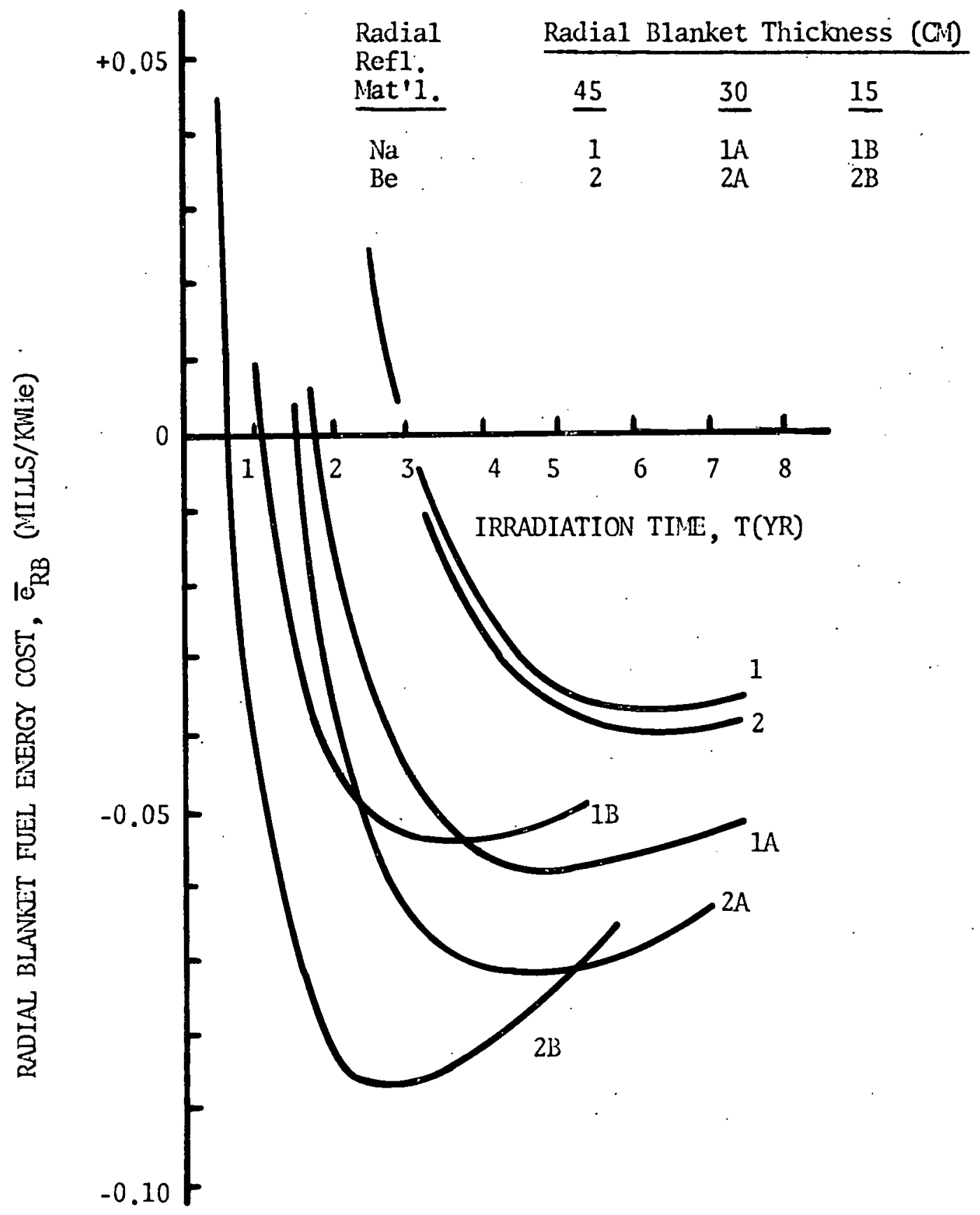

FiG. 5.1 EFFECT OF RADIAL BLANKET THICKNESS AND RADIAL REFLECTOR MATERIAL ON RADIAL BLANKET FUEL ECONOMICS 


\section{TABLE 5.3}

EFFECT OF RADIAL BLANKET THICKNESS AND RADIAL REFLECTOR MATERIAL ON RADIAL BLANKET FUEL ECONOMICS

\begin{tabular}{|c|c|c|c|c|c|c|c|c|c|}
\hline \multirow[b]{2}{*}{$\begin{array}{l}\text { Config- } \\
\text { uration \# }\end{array}$} & \multirow[b]{2}{*}{$\begin{array}{l}\text { Radial } \\
\text { Blanket } \\
\text { Thickness } \\
\text { (cm) }\end{array}$} & \multirow[b]{2}{*}{$\begin{array}{l}\text { Radial } \\
\text { Reflector } \\
\text { Material }\end{array}$} & \multirow[b]{2}{*}{$\begin{array}{l}{ }_{49} / \mathrm{T} \\
0 \mathrm{~T}=2 \mathrm{yr} \\
(\mathrm{kg} / \mathrm{yr})\end{array}$} & \multicolumn{3}{|c|}{$\begin{array}{l}\text { Reference Economic } \\
\text { Environment }\end{array}$} & \multicolumn{3}{|c|}{$\begin{array}{l}\text { More Favorable } \\
\text { Economic Environment }\end{array}$} \\
\hline & & & & $\begin{array}{l}\text { Topt } \\
(y r)\end{array}$ & $\begin{array}{l}\bar{e}_{R B} \\
\text { e Topt } \\
\text { (mills/kiHe) }\end{array}$ & $\begin{array}{l}M_{49} \\
\text { e Topt } \\
\text { (kg) }\end{array}$ & $\begin{array}{l}\text { Topt } \\
\text { (yr) }\end{array}$ & $\begin{array}{l}\mathrm{e}_{\mathrm{RB}} \\
\mathrm{e} \text { Topt } \\
\text { (mills/ } \\
\text { KWHe) }\end{array}$ & $\begin{array}{l}M_{49} \\
\stackrel{\text { Topt }}{(\mathrm{kg})}\end{array}$ \\
\hline 1 & .45 & $\mathrm{Na}$ & 158 & $6-1 / 2$ & -0.037 & 825 & $3-1 / 2$ & -0.237 & 512 \\
\hline 2 & 45 & Be-metal & 160 & $6-1 / 2$ & -0.040 & 845 & $3-1 / 2$ & -0.243 & 521 \\
\hline $1 \mathrm{~A}$ & 30 & $\mathrm{Na}$ & 141 & $4-3 / 4$ & -0.058 & 596 & $2-1 / 2$ & -0.242 & 342 \\
\hline $2 \mathrm{~A}$ & 30 & Be-metal & 157 & $4-1 / 2$ & -0.072 & 610 & $2-1 / 2$ & -0.279 & 380 \\
\hline $1 \mathrm{~B}$ & 15 & $\mathrm{Na}$ & 97 & $3-1 / 2$ & -0.055 & 304 & 2 & -0.188 & 194 \\
\hline $2 \mathrm{~B}$ & 15 & Be-netal & 130 & $2-3 / 4$ & -0.087 & 308 & $1-1 / 2$ & -0.276 & 205 \\
\hline
\end{tabular}


TABLE 5.4

REFERENCE AND MORE FAVORABLE

ECONOIIC ENVIROMMFNTS

Reference

More Favorable

Radial Blanket Fabriçation Cost, $\$ / \mathrm{kgHM}$

69

40

Radial Blanket Reprocessing Cost, $\$ / \mathrm{kgl}$ M

31.50

31.50

Fissile Market Value, $\$ / \mathrm{kg}$

$10 ; 000$

20,000

8

8

Discount Rate, : 


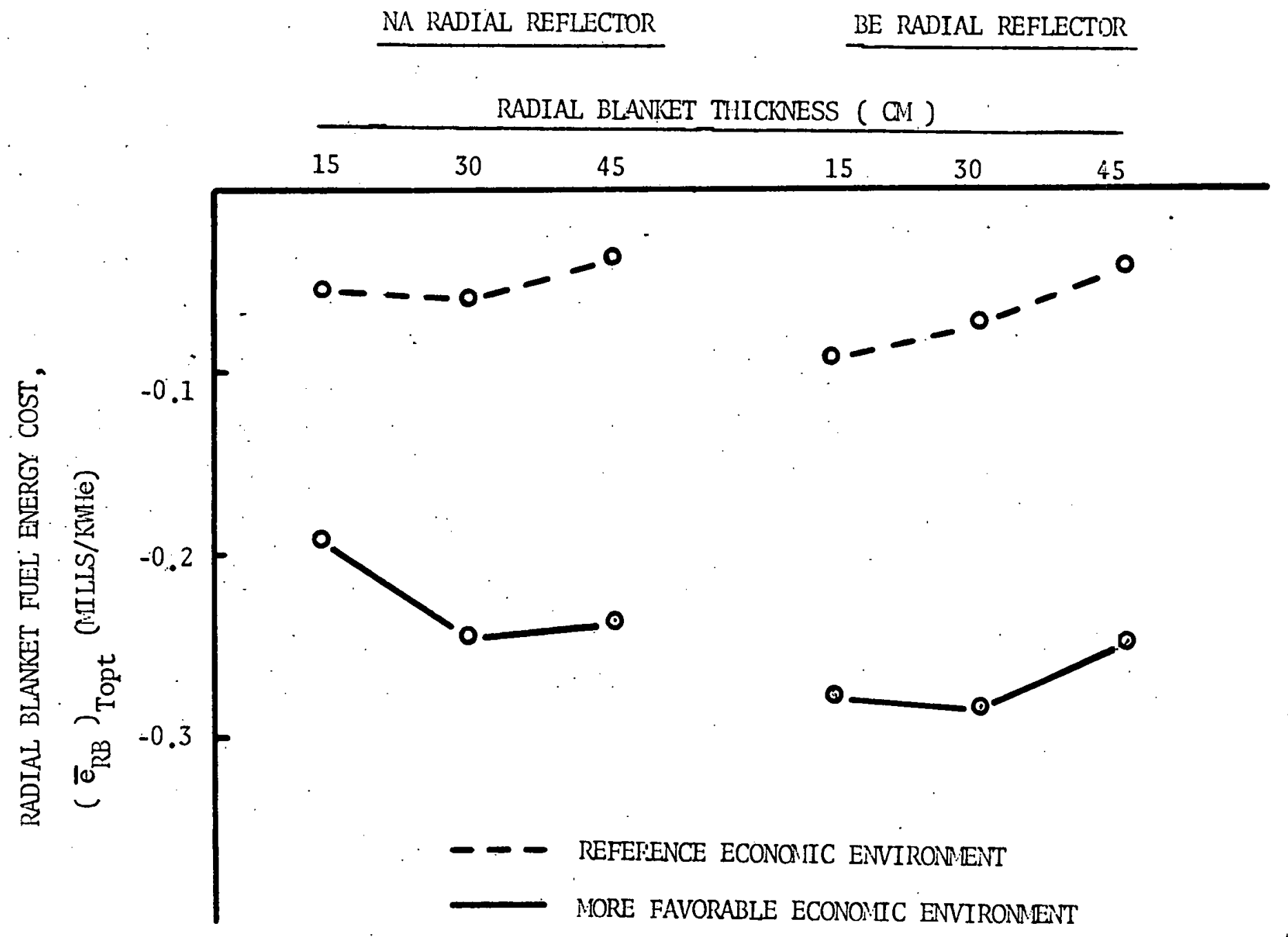

FIG. 5.2 EFFECT OF ECONOMIC ENVIRONMENT ON OPTIMUM RADIAL BLANKET THICINESS 
(4) The effect of the choice of radial reflector material on the optinum irradiation time is more pronounced the thinner the blanket.

(5) Optimum irradiation time decreases as the economic environment improves.

(6) In the reference economic environment, the sodium reflected radial blanket displays a weak optimum thickness between 15 and $30 \mathrm{~cm}$. For the beryllium reflected radial blanket, the optimum, if it exists, is between 0 and $15 \mathrm{~cm}$, that is, the $15 \mathrm{~cm}$ beryllium reflected blanket is superior to the 30 and $45 \mathrm{~cm}$ blankets, owing to effect (c) above.

The increment of $15 \mathrm{~cm}$ is a representative thickness for a row of fuel sabassemblies. LMFBR operators may have the option of adding or subtracting radial blanket rows in accordance with current economic conditions - fissile market value, fabrication and reprocessing costs, etc. Thicker radial blankets are indicated when (i) fabrication and reprocessing costs decreases, and/or (ii) fissile market value increases, as iseen. in Figure 5.2.

Figures 5.3 and 5.4 show the local neutronics obtained from the multigroup "snapshot" physics computations (2DB). In Figure 5.3 the beginning of fuel life capture reaction rate per U238 atom, $\sigma_{c}{ }^{28} \phi$, is plotted along the radial blanket midplane $(z=0)$. Breeding performance, for a particular case, may be associated qualitatively with the area under that case's ${ }_{c} 28 \phi$ vs. $r$ curve. The improvement, of the breeding performance of inner regions by reducing the blanket thickness, effect (c) above, is noted. This effect is quite weak for the sodium reflected blanket, e.g. ${ }_{0}^{28} \phi$.in the inner $15 \mathrm{~cm}$ of radial blanket is insensitive to the location of the radial reflector. However, the improvement is quite pronounced for the Be reflected blanket, and the advantage of the Be reflector (over the $\mathrm{Na}$ reflector) is seen to increase as blanket thickness decreases. 


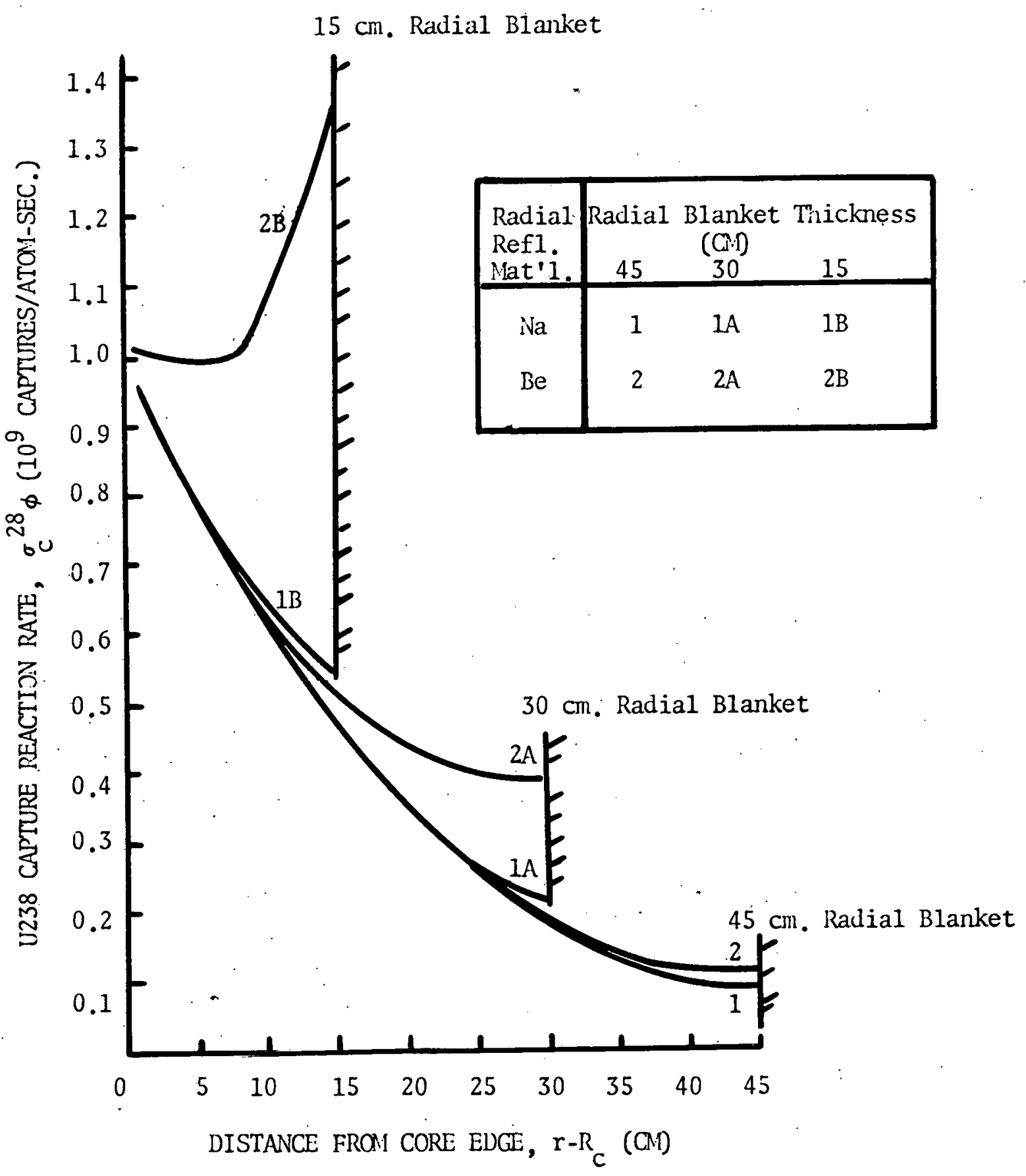

FIG. 5.3 LOCAL U238 CAPTURE REACTION RATES $\left(\sigma^{28} \phi\right)$ FOR VARIOUS RADIAL 


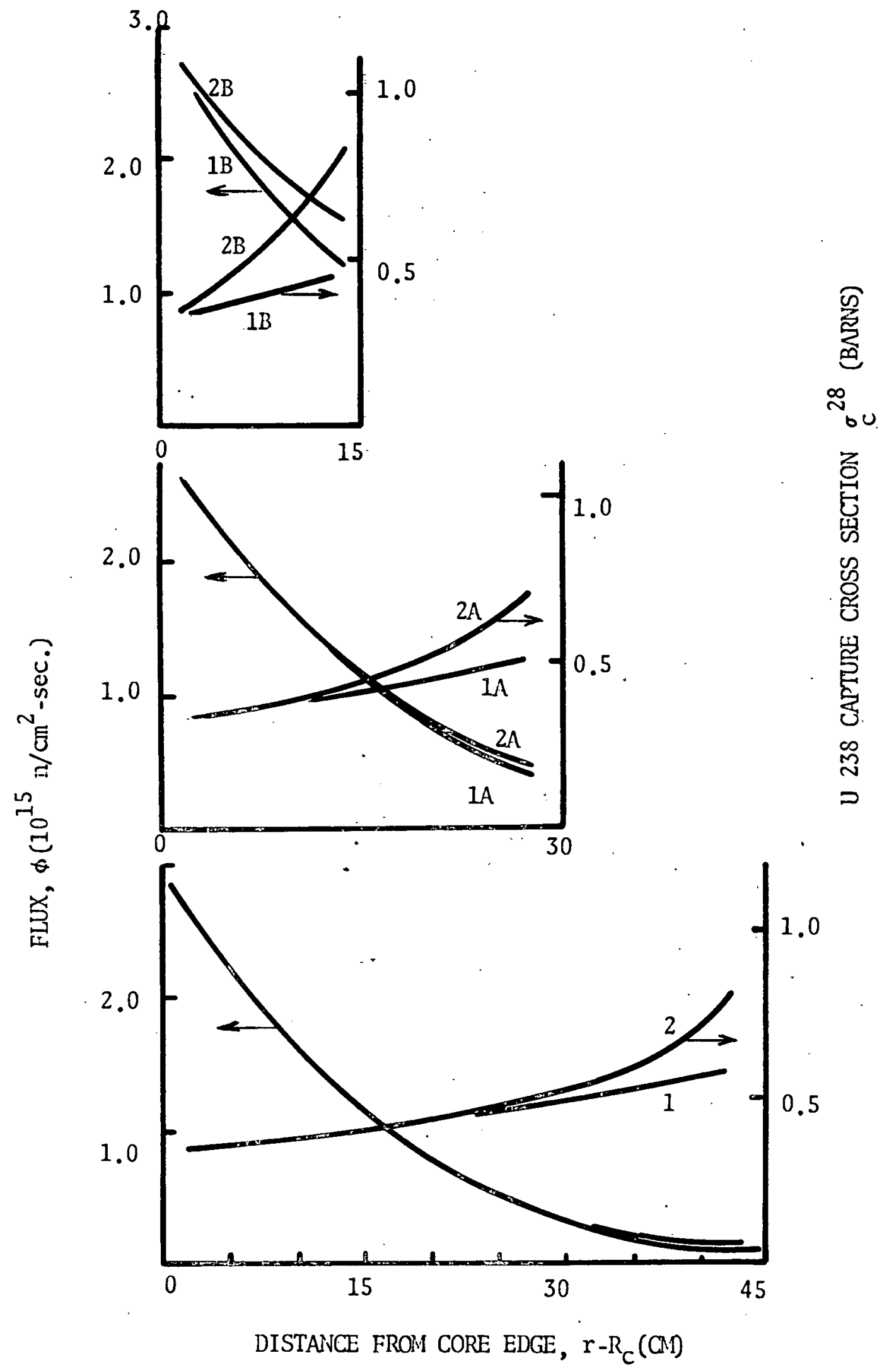

FIG, 5.4 LOCAL NEUTRONICS IN TIE RADIAL BLANKET 
Figure 5.4 shows the resolution of the U238 capture rate into its components, $\underset{\mathrm{C}}{\sigma 28}$ and $\phi$. Both reflective (blanket $\phi$ ) and moderating (blanket $\sigma_{C}^{28}$ ) properties of Be are superior to those of $\mathrm{Na}$.

\subsection{RADIAL BLANKET FUEL MANAGEMENT SCHEMES}

Case studies discussed elsewhere in this report assume that all radial blanket fuel sees the sane irradiation time, the optimum for the blanket as a whole. From Figure 4.7, the optimum irradiation times of the annular regions range from about three years for the innermost region to about ten years for the outermost. At the "whole blanket" irradiation tine of 6.5 years, the inner regions are past their optimum, while outer regions are under-exposed.

Clearly, an improvement in radial blanket performance would result if each annular region were irradiated to its own local optimum exposure. This scheme is labeled "regional" management in this report. Table 5.5 compares the radial blanket fuel energy costs (nills/Kilie) under whole blanket and regional managenent schemes. The regional scheme improves blanket profit by about $30 \%$. Other advantages of the regional scheme, not implicit in Table 5.5, are power flattening and reduction of power buildup in the inner regions over an irradiation cycle.

Otiler fuel management schemes proposed for FBR radial blankets are:

- out-in (4)

- in-out $(10,73)$, and

- fuel assembly rotation (10)

The out-in scheme has been evaluated by Hasnain and Okrent (4) for a somewhat smaller reactor (800 liter core) than the reference reactor 
TABLE 5.5

WHOLE BLANKET VS. REGIONAL

FUEL MANAGEMENT SCIEIMES

Reactor Configuration

Radial Blanket Fuel Energy Costs (mills/KMIe)

Whole Blanket

Regional

Management

Nanagement

\#1 (reference):

$45 \mathrm{~cm}$ radial blanket;

$\mathrm{Na}$ radial reflector

$-0.0364$

$-0.0494$

\#2: 45 cm radial blanket;

Be radial reflector

$-0.0394$

$-0.0519$ 
assumed in the present study. In this scheme, fresh fuel is loaded in the outermost blanket region, then moved inward in the following consecutive cycles, and discharged, finally, from the innermost region. The fuel econonic advantage of out-in management, relative to batch and scatter schemes, is that uniformity of discharge composition may be achieved. Ilowever, Hasnain and Okrent found little fuel economic advantage in this schene. A major engineering advantage is that local power density change with time is lessened, thereby reducing orificing control requirenents. The out-in scheme would not, however, be expected to assist in power flattening.

Although it was not demonstrated quantitatively in their study, Hasnain and Okrent (4) argued that in-out management would be uneconomic, due to the holdup of bred plutonium. Froelich (10) has shown that in-out management has a strong power flattening effect, as well as reducing the power swing of radial blanket fuel over an irradiation cycle.

Froelich (10) has also shown that rotation of fuel assemblies implements power flattening and decreases power swing.

Advantages and disadvantages of various radial blanket fuel management options are summarized in Table 5.6.

\subsection{SENSITIVITY OF FUEL ENERGY COSTS TO THE ECONOMIC ENVIRONMENT}

\subsubsection{Introduction}

The purpose of this section is to examine the sensitivity of the reference LMFBR (Reactor \#1) fuel energy costs (mills/KWHe) to changes in economic environment.

Unit costs ( $\$ / \mathrm{kgHM}, \$ / \mathrm{kg}$ fissile), credits ( $\$ / \mathrm{kg}$ fissile), and carrying charges throughout the nuclear fuel cycle are ultimately transferred to the utility company, burdened to the production of electricity, and, together 
TABLE 5.6 RADIAL BLANKET FUEL MANAGEMENT SCHEMES

Fuel

Management

Scheme

References

Advantages

Disadvantages

1. Fixed-Fuel Schemes

A. Batch and Scatter

(1) Whole Bianket Management

$$
\text { (this }
$$$$
(69,70,71 \text {, }
$$
(tinis' report)

(2) Regional Management

B. Batch

C. Scatter

2. Moving-Fue1 Schemes
A. Out-in

$(10,73)$

$$
72,73\}
$$

(tiiss report)

B. In-out

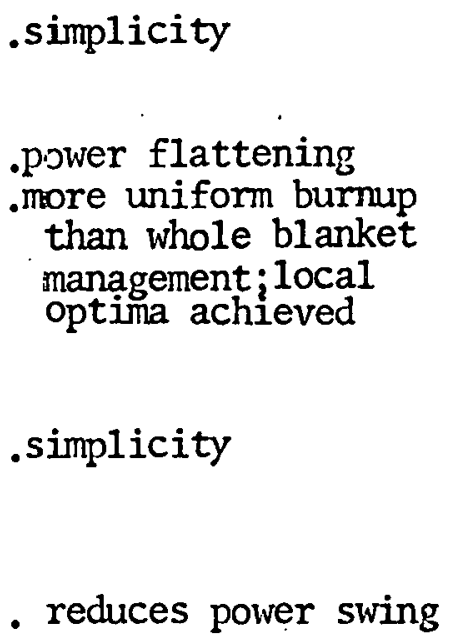

.uniform burnup uniforn burnup reduction in power swing .reduction in power swing .power flattening .non-uniform burnup .power tilt across blanket

- complexity

.more severe power swing than scatter management

. aggravates power tilt across blanket 
with utility company carrying charges, borne by the electricity consumer via a levelized price (cost) of electricity in mills/KWIle. These unit costs, credits, and carrying charges are determined largely by factors outside the scope of this report, e.g. supply-demand effects in the market place, technical-economic characteristics of fuel cycle processes, fuel processing capacities and throughputs, availability and structure of capital, fuel element design, etc. Thus, in this report, the following variables are regarded as comprising the "economic environment" and are treated in parametric fashion, as input to the depletion-economics calculations:

unit costs for fabrication and reprocessing, - $f_{a b}$ and $C_{\text {repr' }}$, in dollars per kilogram of heavy metal $(U+P u)$; nuclide market values, $\mathrm{C}_{28}, \mathrm{C}_{49}, \ldots, \mathrm{C}_{42}$ in dollars per kilugran of the respective nuclide;

utility company financial paramters i.e. tax. rate $(\tau)$, capital structure $\left(f_{b}, f_{s}\right)$ and rates of return $\left(r_{b}, r_{s}\right)$ from which the discount rate $(x)$ may be determined, $x=(1-\tau) r_{b} f_{b}+r_{s} f_{s}$.

In the sensitivity studies reported below, the economic parameters were varied over the ranges shown in Table 5.7. Reference values are shown in parentheses. Reference values of $C_{f a b}$ and $C_{\text {repr }}$ are typical of those projected for oxide-fueled IMFBR's by the USAEC Fuel Recycle Task Force (18), and of those assumed in the several 1000 MVe LAFBR design studies. Reference values of the utility company financial parameters, leading to a reference discount rate of $8 \%$, are typical of those of the Commonwealth Edison Company in the late 1960's (2).

The fuel energy costs (mills/KWHe) associated with the major regions (core, axial blanket, radial blanket) were cormuted by the procedure 


\section{TABLE 5.7}

RANGES OF ECONORIIC ENVIRONMENT PARAMETERS *

\section{Unit Processing Costs [\$/kglM]}

$$
\begin{array}{lr}
\text { Fabrication }\left(C_{f a b}\right) & \\
\text { Core } & 150-(314)-330 \\
\text { Axial Blanket } & 20-\left(\begin{array}{l}
80 \\
\text { Radial Blanket }
\end{array}\right. \\
20-(69)-100
\end{array}
$$

$$
\begin{array}{cc}
\text { Reprocessing }\left(C_{\text {repr }}\right) & 15-(31)-60 \\
\text { Core } & 15-(31)-60 \\
\text { Axial Blanket } & 15-(31)-60 \\
\text { Radial Blanket } & 15
\end{array}
$$

Nuclide Market Values [\$/kg]

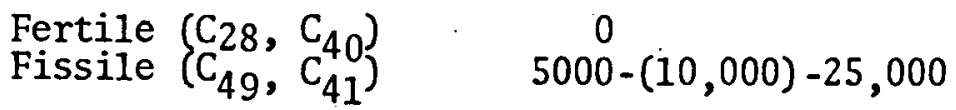

Utility Company Financial Parameters

$$
\text { Income Tax Rate }(\tau) \quad(0.5)
$$

Discount Rate $(x) \quad 0.06-(0.08)-0.10$

* Reference values are given in parentheses ( ). 
outlined in Section 4.1. Each economic parameter was varied individually, holding all other parameters fixed at their reference values.

\subsubsection{Core and Axial Blanket}

Figures 5.5 through 5.12 display the behavior of reference reactor core and axial blanket fuel energy costs as the economic environment is varied around the reference environment.

Since the core and axial blanket irradiation times are fixed by the core burnup limit, core and axial blanket fuel energy cost equations can be reduced to convenient linear forms. From Equation (4-6), the fuel energy cost associated with region s (core, axial blanket, or radial blanket) is given by

$$
\begin{aligned}
& \bar{e}_{s}=\bar{e}_{\text {fab }, s}+\bar{e}_{\text {repr }, s}+\bar{e}_{\text {mat'l,s }} \\
& =1000 M_{\text {TMM }}^{0}\left[C_{\text {fab }, s} F_{\text {fab }}(T)+C_{\text {repr, } s} F_{\text {repr }}(T)\right.
\end{aligned}
$$

ET

$$
\left.+C_{\text {fiss }}\left(\epsilon_{s}^{0} F_{m p}(T)-\epsilon_{s}(T) F_{m c}(T)\right)\right]
$$

With irradiation time (T) fixed, Equation (5-1) reduces to a linear expression in the unit $\cos t \mathrm{C}_{\mathrm{fab}, \mathrm{s}}, \mathrm{C}_{\text {repr, }, \mathrm{s}}, \mathrm{C}_{\text {fiss }}$ :

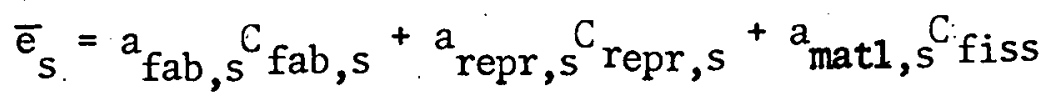

where the constants $\left\{a_{q, s}\right\}$ are given by

$$
a_{q, s}=\left(\frac{\bar{e}_{q, s}}{c_{q, s}}\right)=\left(\frac{{ }_{x}^{\bar{e}} q, s}{c_{q, s}}\right)_{0}=\frac{1000}{E T} M_{H M}^{0} g(T) .
$$




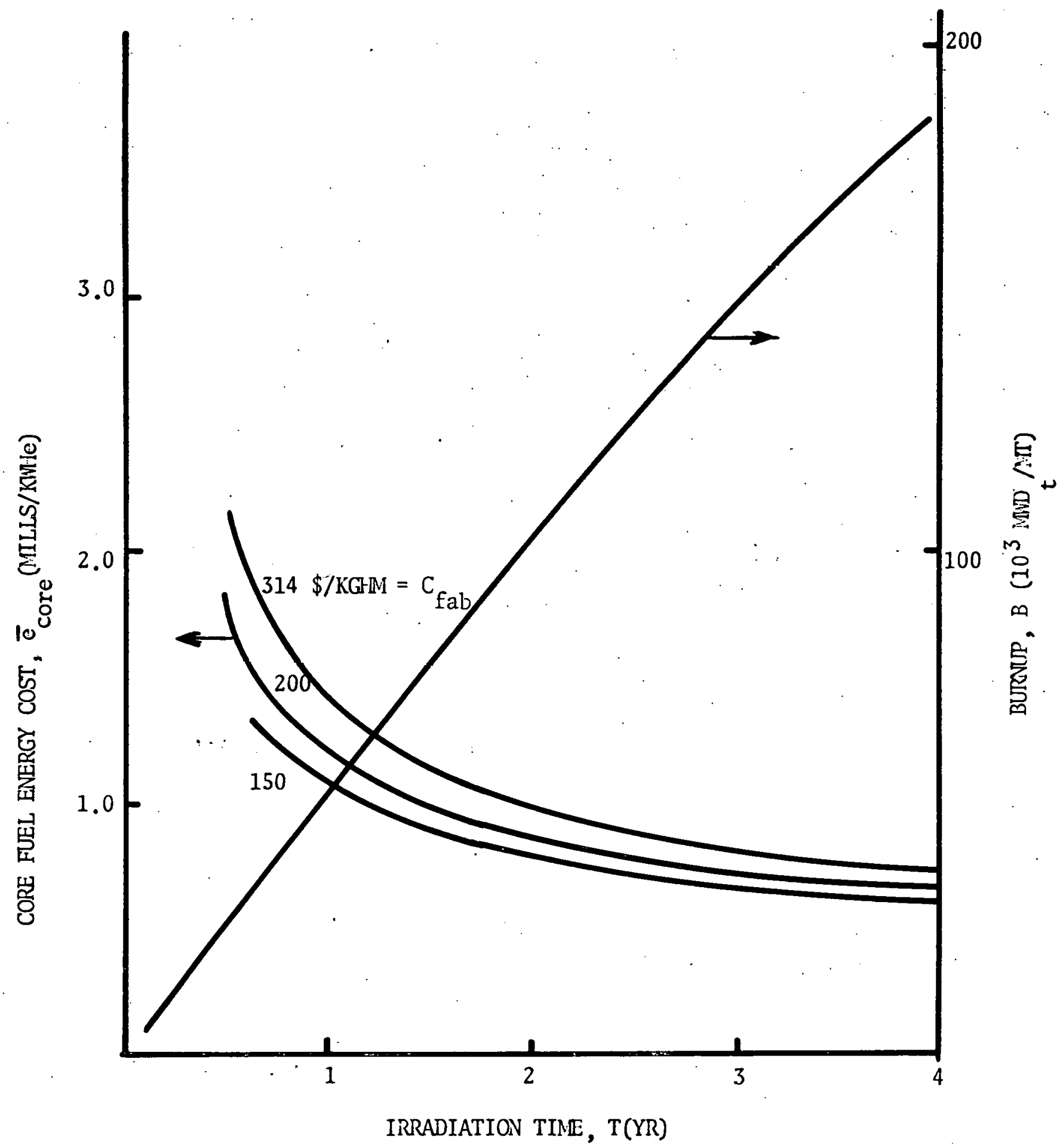

FIG. 5.5 EFFECT OF UNIT FABRICATION COST ON CORE FUEL ENERGY. COST 


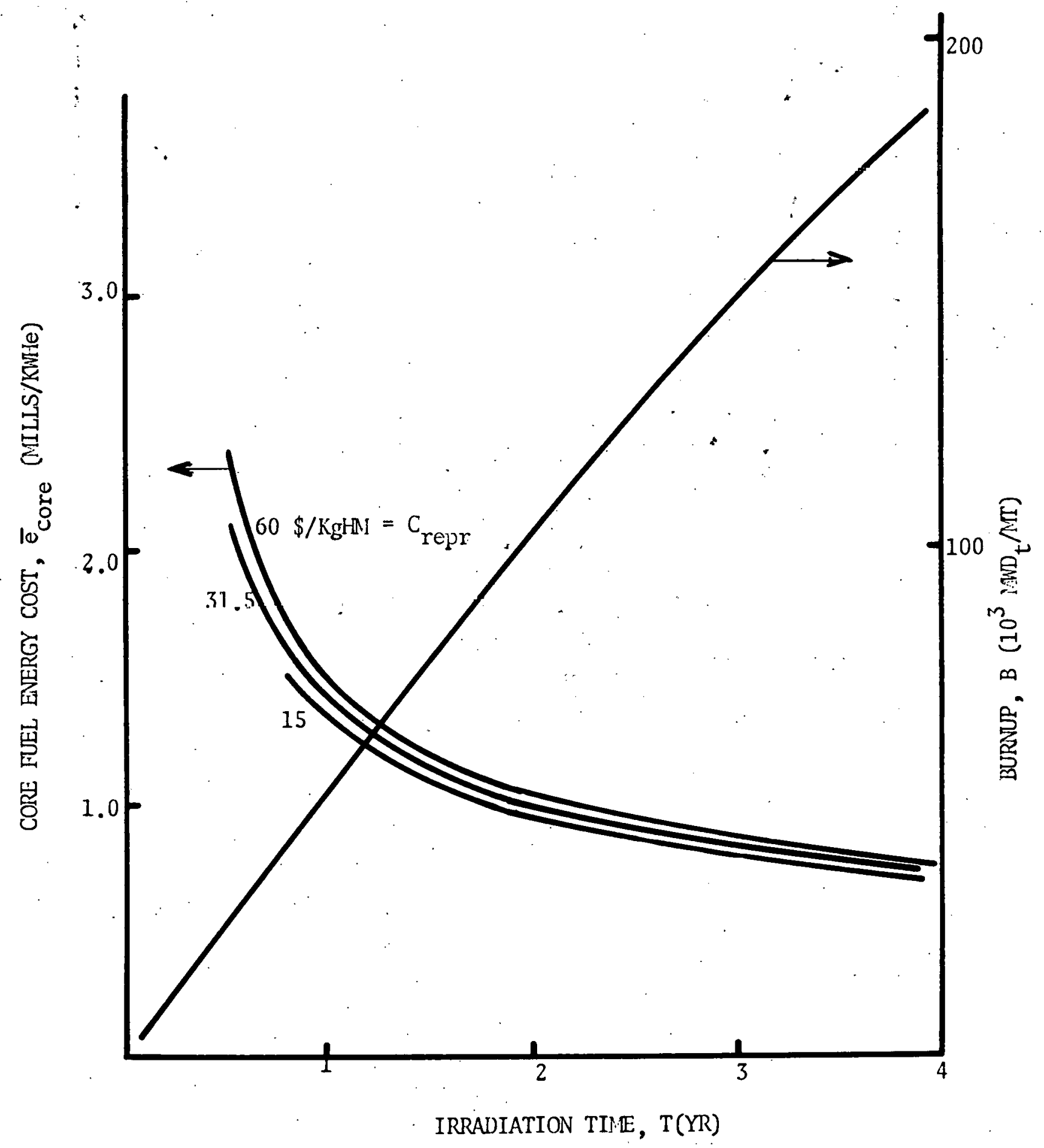

FIG. 5.6 EFFECT OF UNIT REPROCESSING COST ON CORE FUEL ENERGY COST 


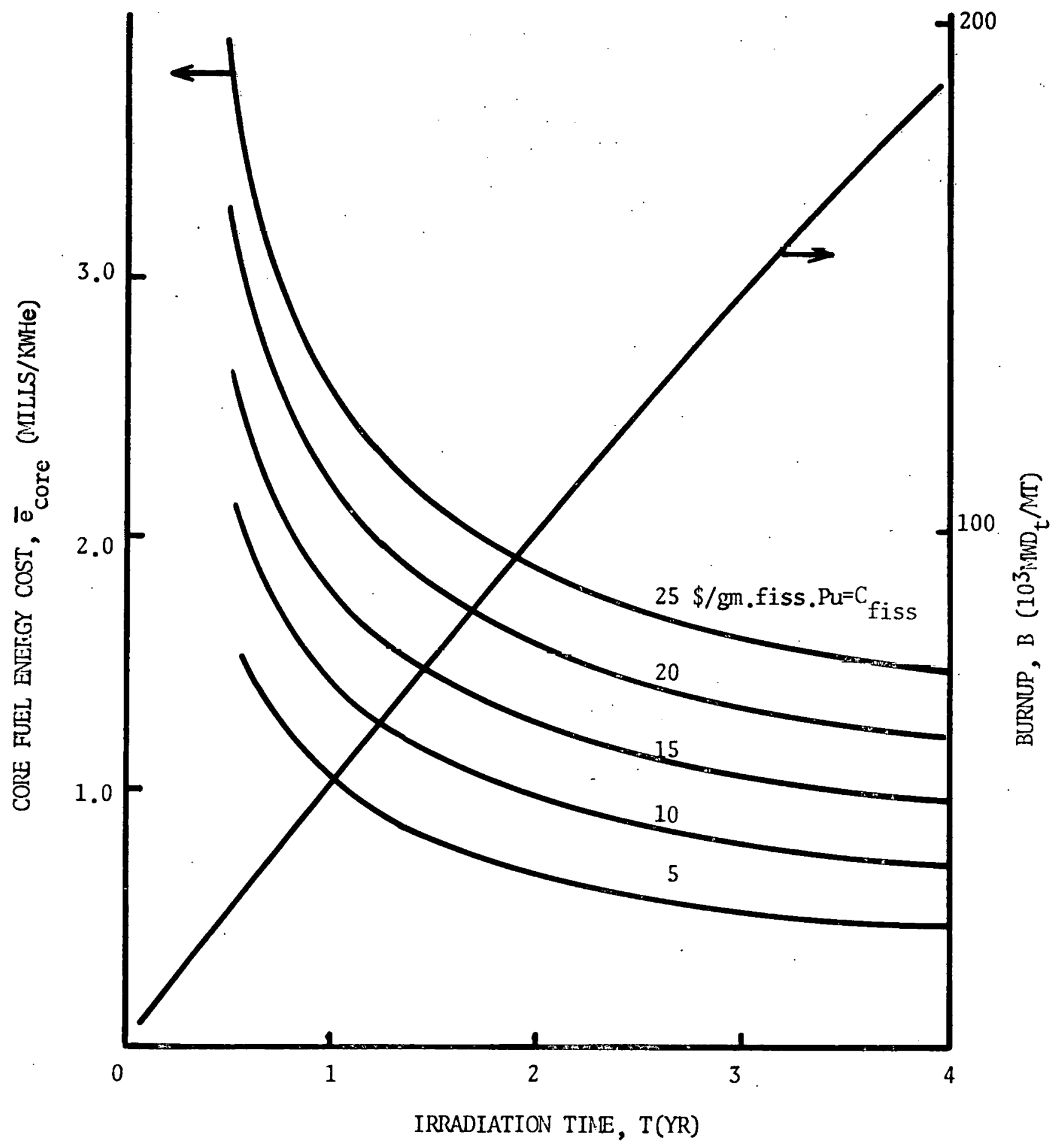

FIG. 5.7 EFFECT OF FISSILE PLUTONIUM PRICE ON CORE FUEL ENERGY COST 


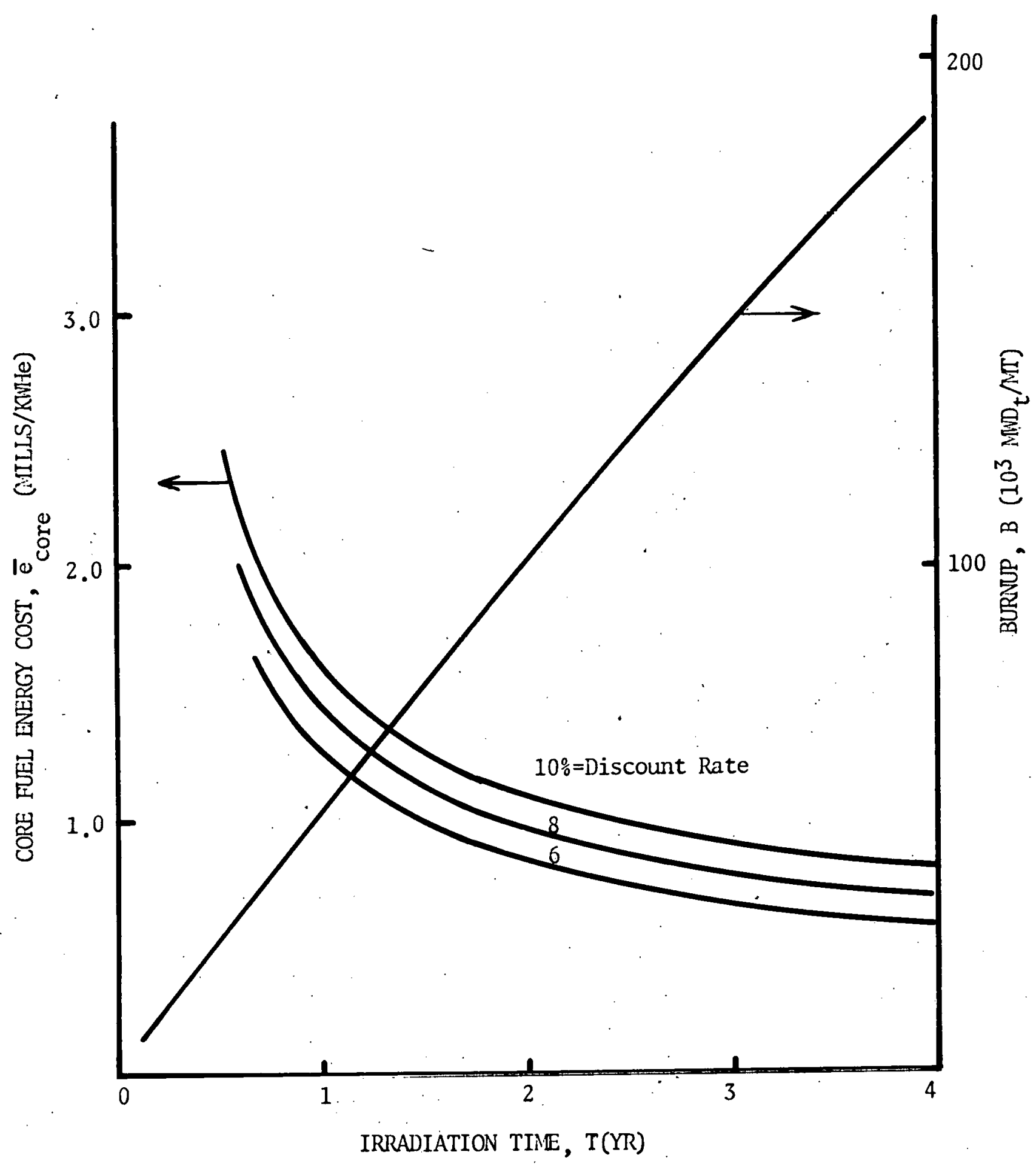

FIG. 5.8 EFFECT OF DISCOUNT RATE ON CORE FUEL ENERGY COST 


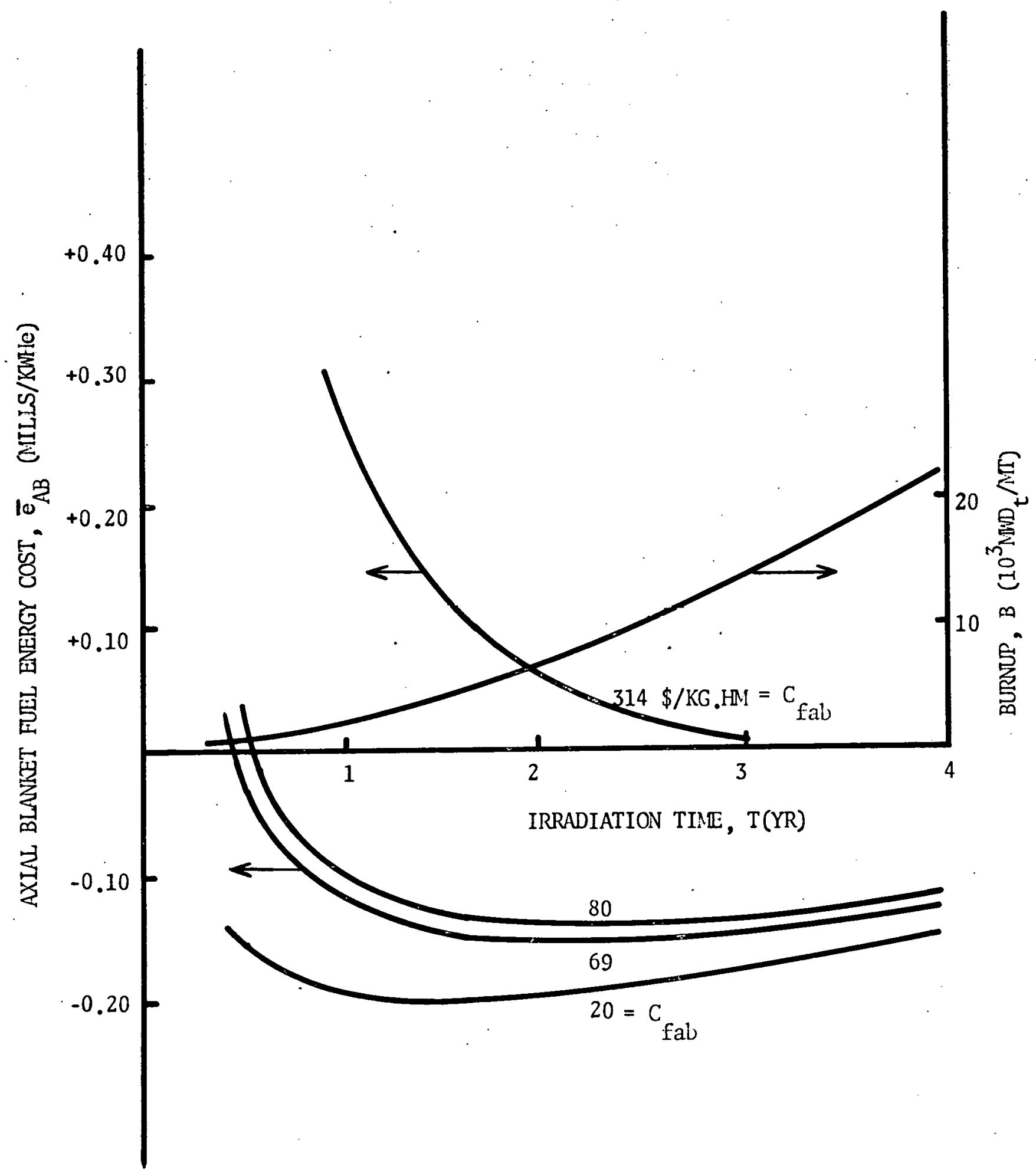

FIG. 5.9 EFFECT OF UNIT FABRICATION COST ON AXIAL BLANKET FUEL ENERGY COST 


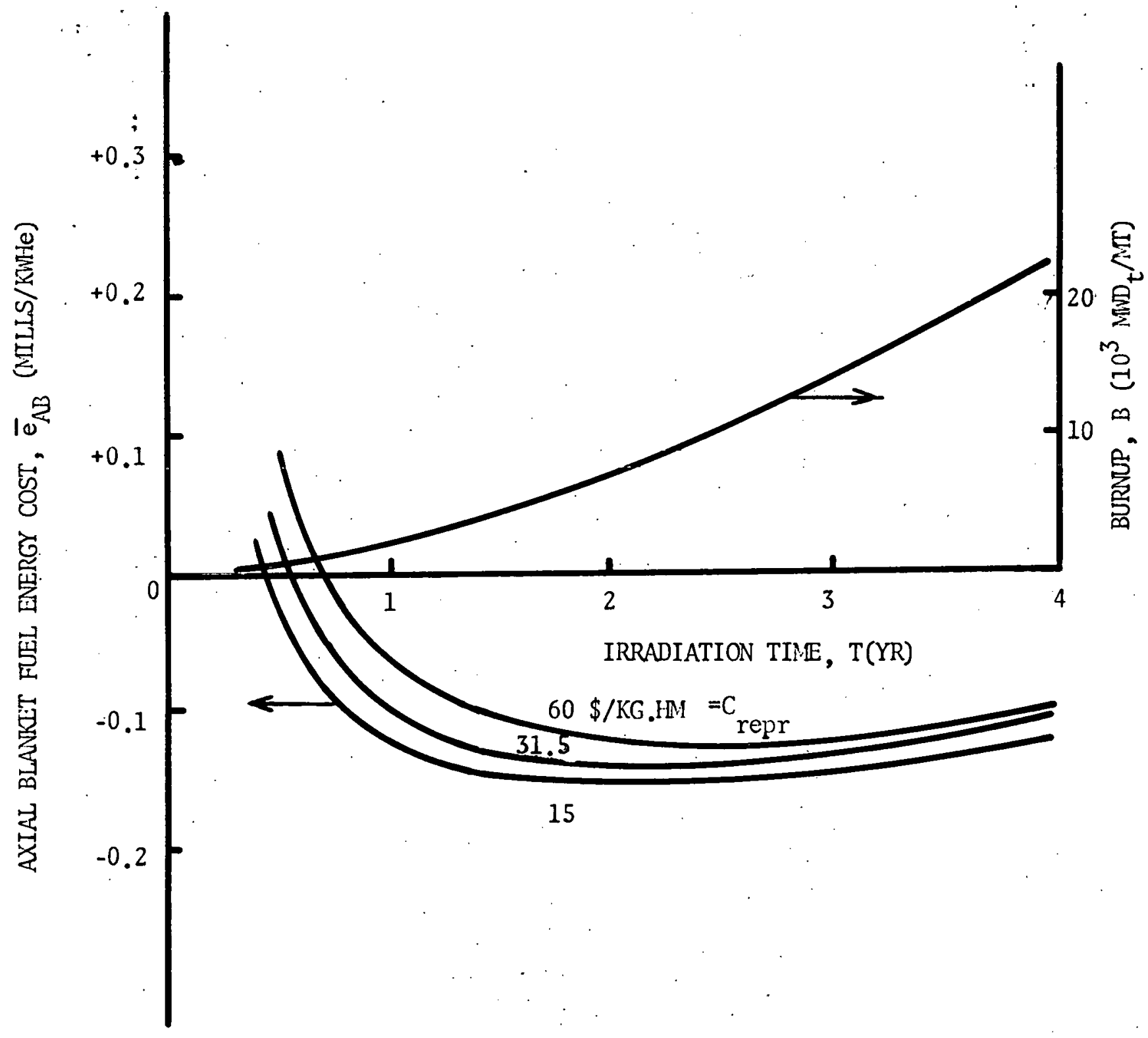

FIG. 5.10 EFFECT OF UNIT REPROCESSING COST ON AXIAL BLANKET FUEL ENERGY COST 


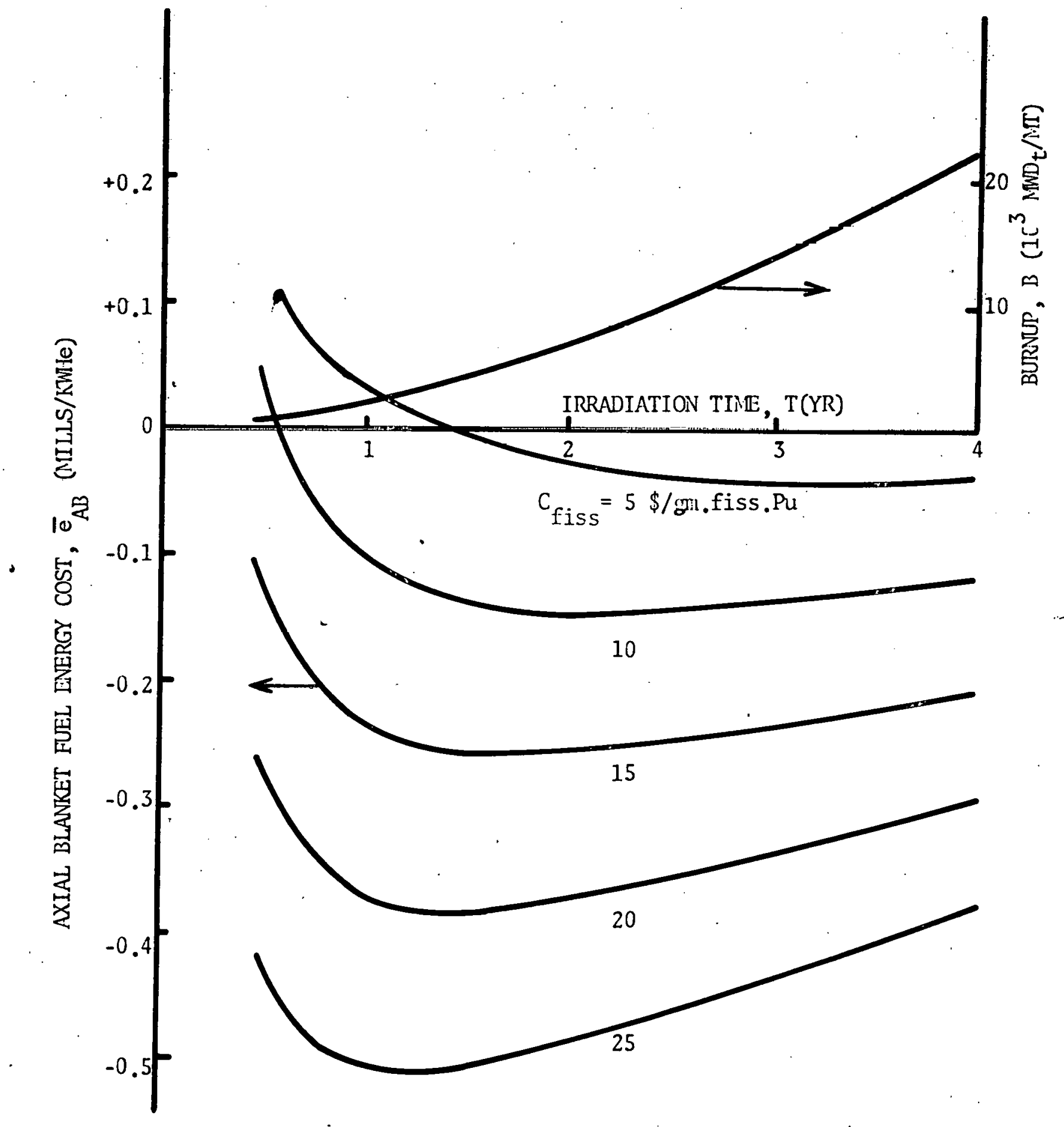

FIG. 5.11 EFFECT OF FISSILE PLUTONIUM PRICE ON AXIAL BLANKET FUEL ENERGY COST 


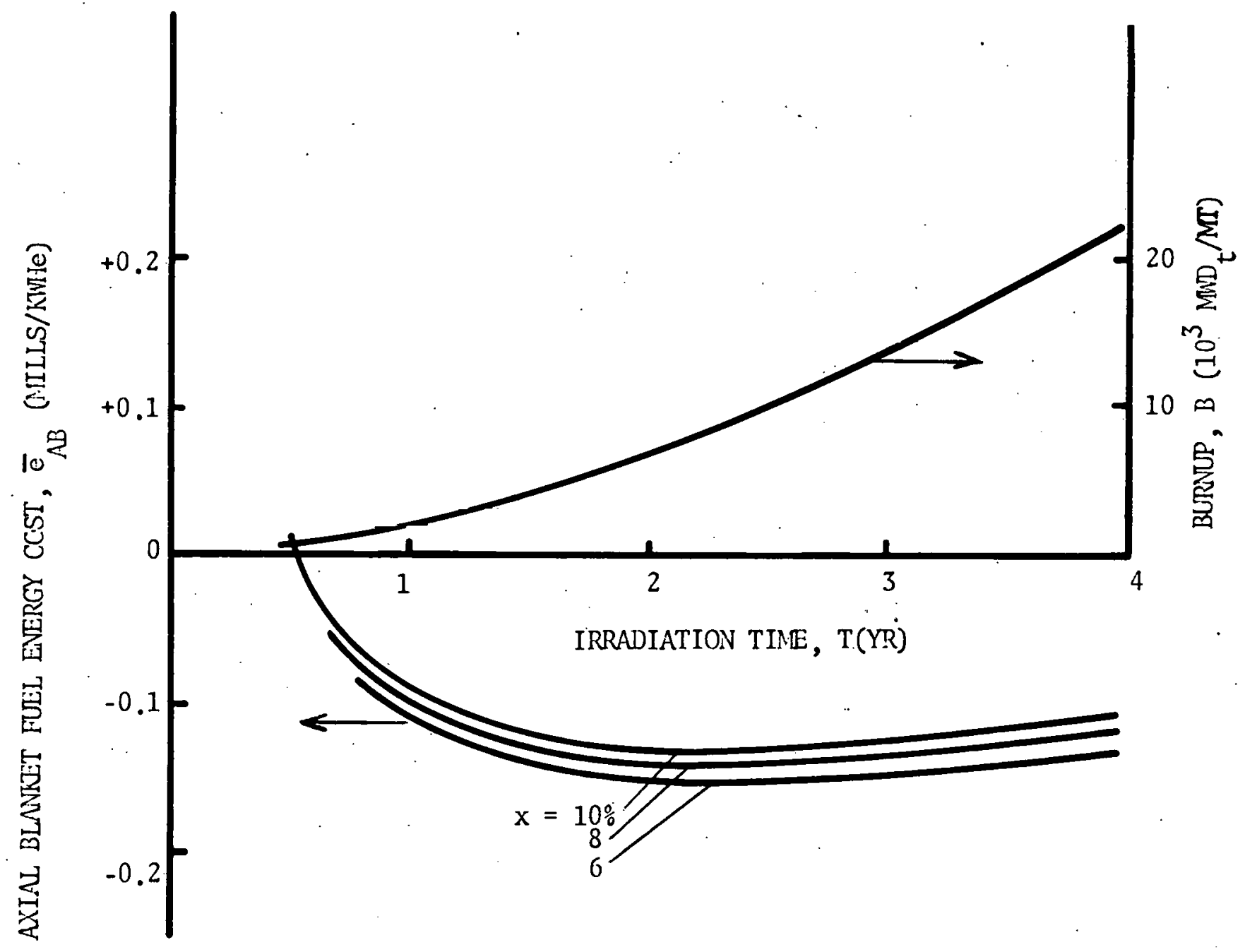

FIG. 5.12 EFFECT OF DISCOUNT RATE ON AXIAL BLANKET FUEL ENERGY COST 
The subscript $q$ denotes the cost component (fabrication, reprocessing, material); the subscript 0 denotes the reference economic condition, while $x$ refers to an arbitrary economic condition.

Core and axial blanket irradiation time is set by the burnup limit of the core, in this case, 2 years, corresponding to an average core burnup of $102,000 \mathrm{MND}_{t} / \mathrm{MT}$. Equation (5-2) for the core is

$$
\begin{gathered}
\bar{e}_{\text {core }}=1.09 \times 10^{-3} C_{\text {fab, core }}+0.784 \times 10^{-3} C_{\text {repr,core }} \\
+0.06027 \times 10^{-3} C_{\text {fiss }} .
\end{gathered}
$$

For the axial blanket,

$$
\begin{gathered}
\bar{e}_{A B}=0.872 \times 10^{-3} C_{\text {fab }, A B}+0.625 \times 10^{-3}{ }_{\text {repr }, A B} \\
-0.02307 \times 10^{-3} C_{\text {fiss }}
\end{gathered}
$$

$A^{\prime \prime}$ sensitivity coefficient", $\left(A_{q, s}\right)_{0}$, is defined, to measure the sensitivity of $\bar{e}_{s}$ to changes in parameter $C_{q, s}$ from its reference value, all other parameters remaining fixed at their reference values:

$$
\begin{aligned}
\left(A_{q, s}\right)_{0} & =\left(\frac{C_{q, s}}{\bar{e}_{s}}\right)_{0} \frac{\partial \bar{e}_{s}}{\partial c_{q, s}} \\
& =\frac{\Delta \bar{e}_{s} /\left(\bar{e}_{s}\right)_{0}}{\Delta C_{q, s} /\left(C_{q, s}\right)_{0}} \\
& =\left(\frac{c_{q, s}}{\bar{e}_{s}}\right)_{a, s}^{a}=\left(\frac{\bar{e}_{q, s}}{\bar{e}_{s}}\right)_{0}
\end{aligned}
$$


Values of $\left(\mathrm{A}_{\mathrm{q}, \mathrm{s}}\right)_{0}$ for the core and axial blanket are summarized in Table 5.8. For both the core and axial blanket, the material (fissile)

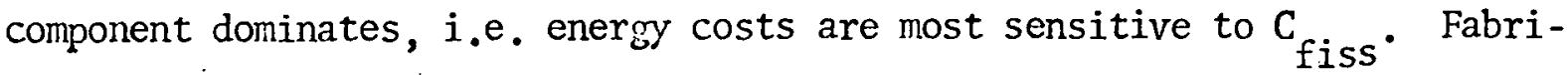
cation is the next most important corponent, followed by reprocessing.

Changes in $\overline{\mathrm{e}}_{\mathrm{s}}$ due to sirultaneous changes in several economic paraneters may be computed by linear superposition:

$$
\Delta \bar{e}_{\mathrm{s}}=\mathrm{a}_{\text {fab }, \mathrm{s}} \Delta \mathrm{C}_{\mathrm{fab}, \mathrm{s}}+\mathrm{a}_{\text {repr,s}} \Delta \mathrm{C}_{\text {repr }, \mathrm{s}}+\mathrm{a}_{\text {matl }, \mathrm{s}} \Delta \mathrm{C}_{\text {fiss }}
$$

or

$$
\frac{\Delta \bar{e}_{s}}{\bar{e}_{s}}=A_{f a b, s} \frac{\Delta C_{f a b, s}}{C_{f a b, s}}+A_{\text {repr }, s} \frac{\Delta C_{\text {repr }, s}}{C_{\text {repr }, s}}+A_{\text {fiss }} \frac{\Delta C_{\text {fiss }}}{C_{\text {fiss }}}
$$

\subsubsection{Radial Blanket}

Figures 5.13 through 5.16 display the behavior of radial blanket fuel power costs as the economic environment is varied around the reference environnent. The optimum irradiation tine (Tont) is seen to decrease as $C_{\text {fiss }}$ increases, as $C_{f a b, R B}$ decreases, as $C_{\text {repr, } R B}$ decreases, or as the discount rate $(x)$ increases.

Unlike the axial blanket, the radial blanket may be fuel-managed independently of the core. The radial blanket may thus be irradiated to its optinum exposure, which occurs somewhat beyond the two year core burnup limit. One is concerned, then, with the sensitivity of the optinum radial blanket fuel energy cost, $\left(\bar{e}_{\mathrm{RB}}\right)_{\text {Topt }}$; to the economic environment.

The optinum irradiation time, Topt, is an implicit function of the econonic environment. Hence, the fuel energy cost expression (5-1) does not reduce exactly to a linear form $(5-2)$ in the unit costs $C_{f a b}, C$ repr, 
TABLE 5.8

\section{CORE AND AXIAL BLANKET SENSITIVITY COEFFICIENTS, $\left(\mathrm{A}_{\mathrm{q}, \mathrm{s}}\right)_{0}$ *}

$\begin{array}{lll}\mathrm{q} \uparrow \mathrm{s} \rightarrow & \frac{\text { Core }}{0.357} & \frac{\text { Axial Blanket }}{-0.495 * *} \\ \text { Fabrication } & 0.025 & -0.140 * * \\ \text { Reprocessing } & \frac{0.628}{1.000} & \frac{1.635}{1.000} \\ \text { Material } & \left.\mathrm{A}_{\mathrm{q}, \mathrm{s}}\right)_{0}=\frac{\overline{\mathrm{e}}_{\mathrm{s}} /\left(\overline{\mathrm{e}}_{\mathrm{s}}\right)_{0}}{\mathrm{C}_{\mathrm{q}, \mathrm{s}} /\left(\mathrm{C}_{\mathrm{q}, \mathrm{s}}\right)_{0}} .\end{array}$

** These terms are negative because $\left(\bar{e}_{A B}\right)_{0}$ is negative. 


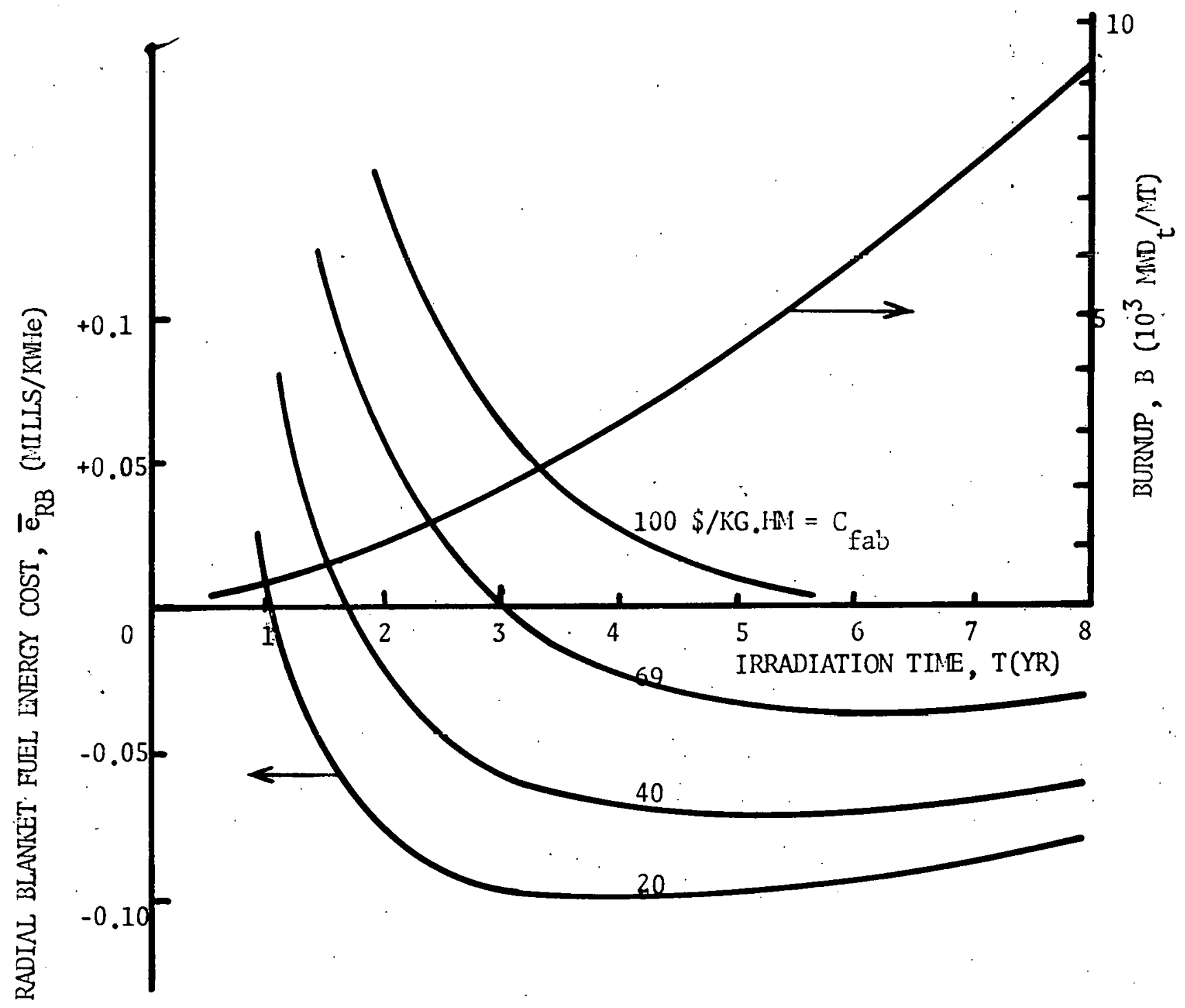

FIG. 5.13 EFFECT OF UNIT FABRICATION COST ON RADIAL BLANKET FUEL ENERGY COST 


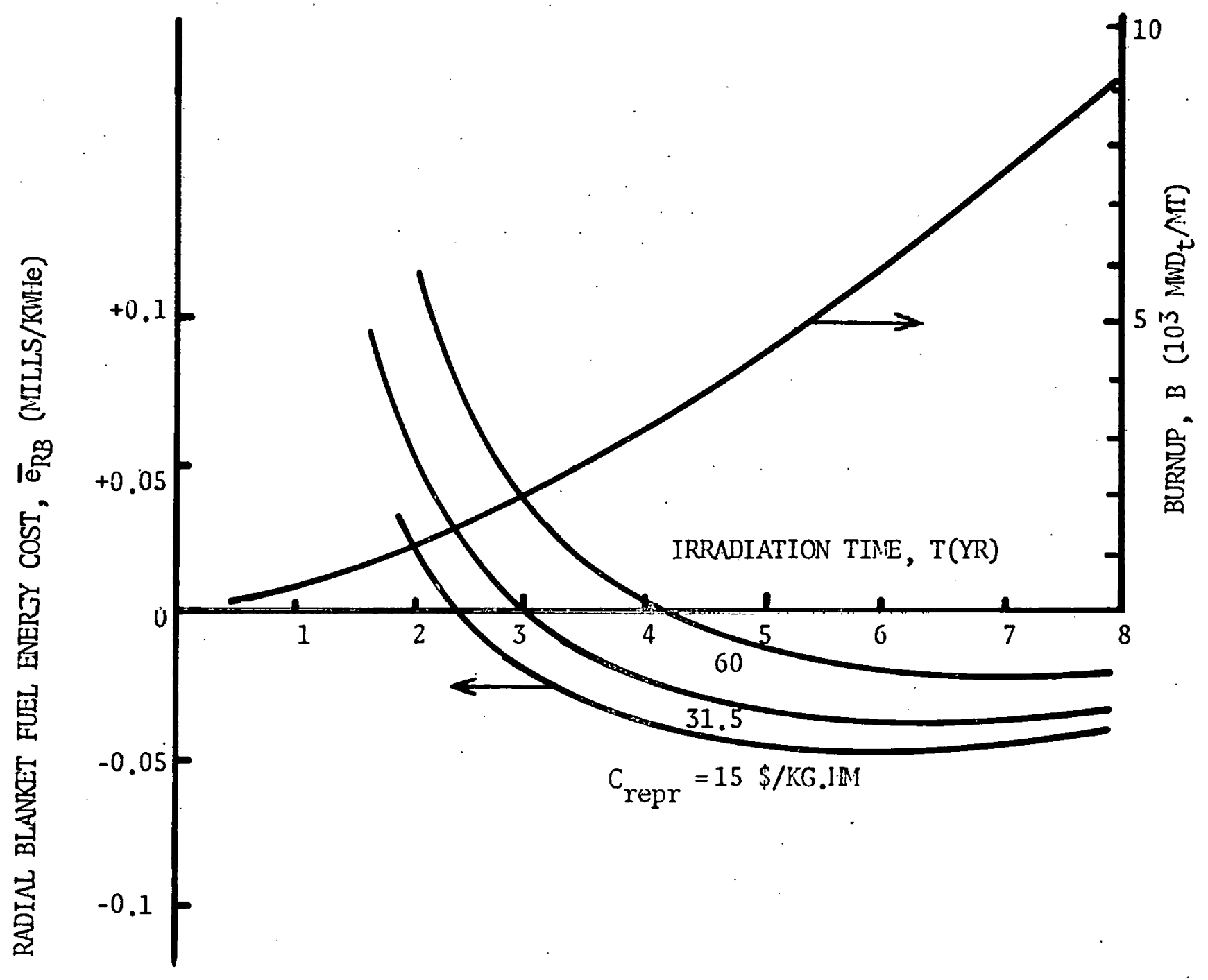

FIG. 5.14 EFFECT OF UNIT REPROCESSING COST ON RADIAL BLANKET FUEL ENERGY COST 


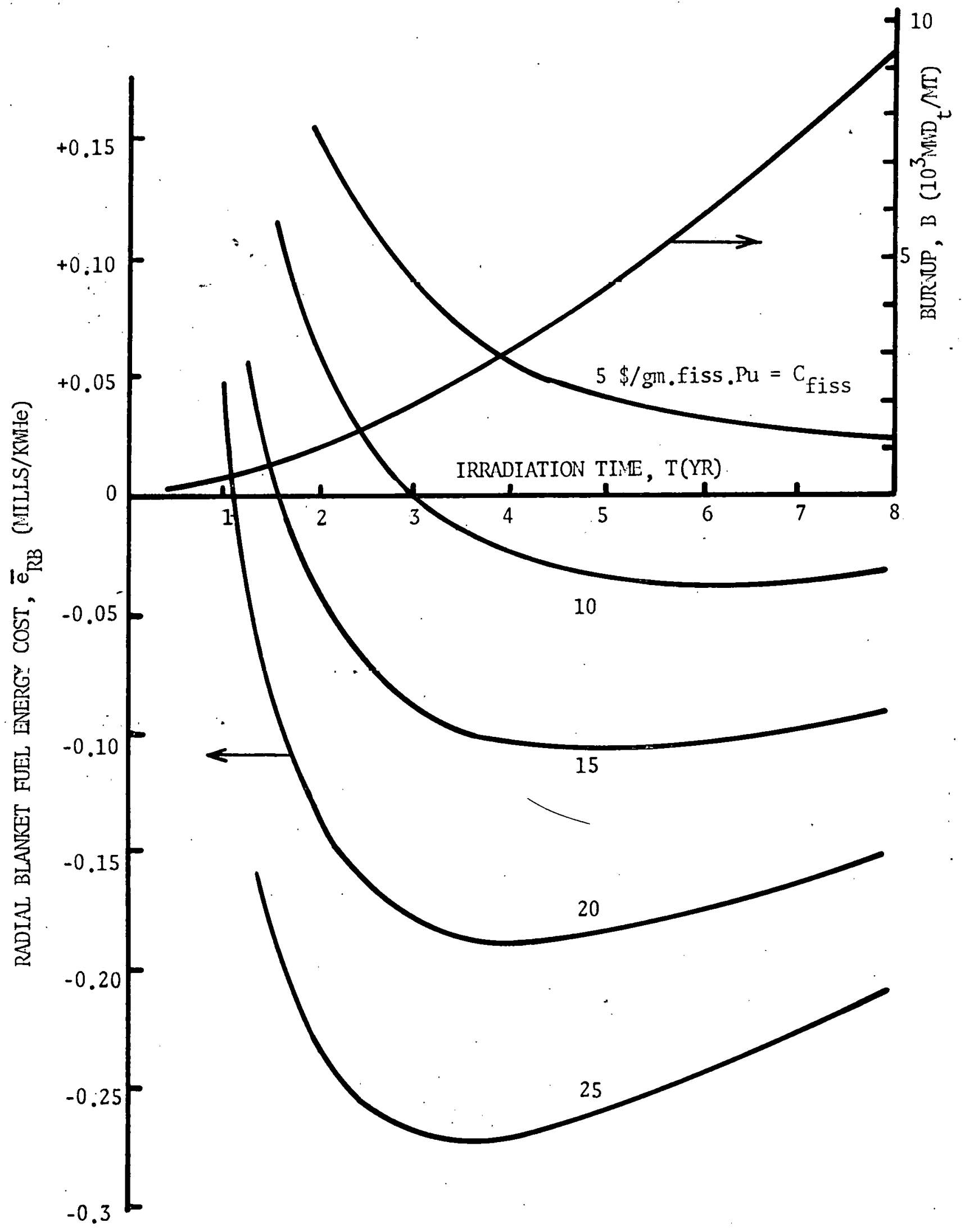

FIG. 5.15 EFFECT OF FISSILE PLUTONIUM PRICE ON RADIAL BLANKET FUEL ENERGY COST 


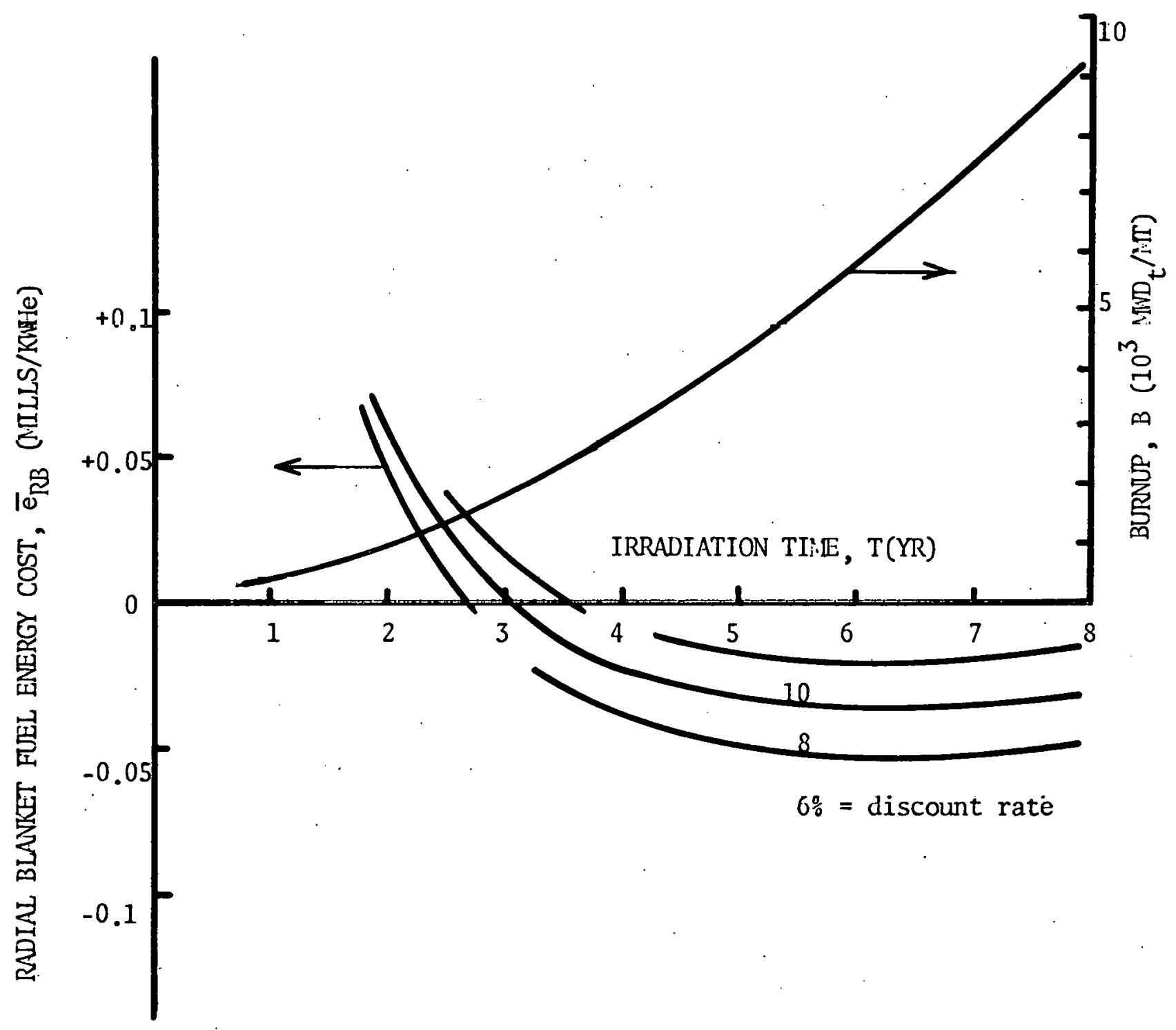

FIG. 5.16 EFFECT OF DISCOUNT RATE ON RADIAL BLANKET FUEL ENERGY COST 
$\mathrm{C}_{\mathrm{fiss}}$ as is the case for core and axial blanket. However, plots of $\left(\bar{e}_{\mathrm{R}_{\mathrm{B}}}\right)_{\text {Topt }}$ versus the unit costs, Figures $5.17,5.18$ and 5.19 show that $\left(\overline{\mathrm{e}}_{\mathrm{RB}}\right)_{\text {Topt }}$ is nearly linear in $\mathrm{C}_{f a b}, \mathrm{C}_{\text {repr }}$, and $\mathrm{C}_{\text {fiss }}$.

For small perturbations in the economic environment $(\Delta C)$ the assumption of linearity is especially good. This is shown by the broken lines in Figurec 5.17, 5.10 ald 5.19, which represent linearizations at the reference conditions, e.g.

$$
\begin{aligned}
\left(E_{R B}\right)_{T_{\text {opt }}}= & \left(\frac{\bar{e}_{f a b, R B}}{C_{\text {fab }, R B}}\right)_{0, \text { Topt }} C_{f a b, R B} \\
& +\left(\bar{e}_{\text {repr, }, R B}\right)_{0, \text { Topt }}+\left(\bar{e}_{\text {mat }, R B}\right)_{0, \text { Topt }}
\end{aligned}
$$

The constants of proportionality, $\left(\frac{\bar{e}_{q, R B}}{\bar{C}_{f a b, R B}}\right)_{0, T o p t}$, in units of $10^{-3} \mathrm{~kg} / \mathrm{killt}$ are

$$
\left(\frac{\overline{\mathrm{e}}_{\mathrm{fab}, \mathrm{RB}}}{\mathrm{C}_{\mathrm{fab}, \mathrm{RB}}}\right)_{0, \mathrm{Topt}}=1.154 \times 10^{-3}
$$

$$
\begin{aligned}
& \left(\frac{\bar{e}_{\text {repr,RB }}^{\bar{C}}}{C_{\text {repr }, R B}}\right)_{0, \text { Topt }}=0.519 \times 10^{-3} \\
& \left(\frac{\bar{e}_{\text {matl }, R B}}{C_{\text {fiss }, R B}}\right)_{0, \text { Topt }}=-0.0132 \times 10^{-3}
\end{aligned}
$$

A composite linear form, analogous to Equation (5-2), valid near reference economic conditions, is 


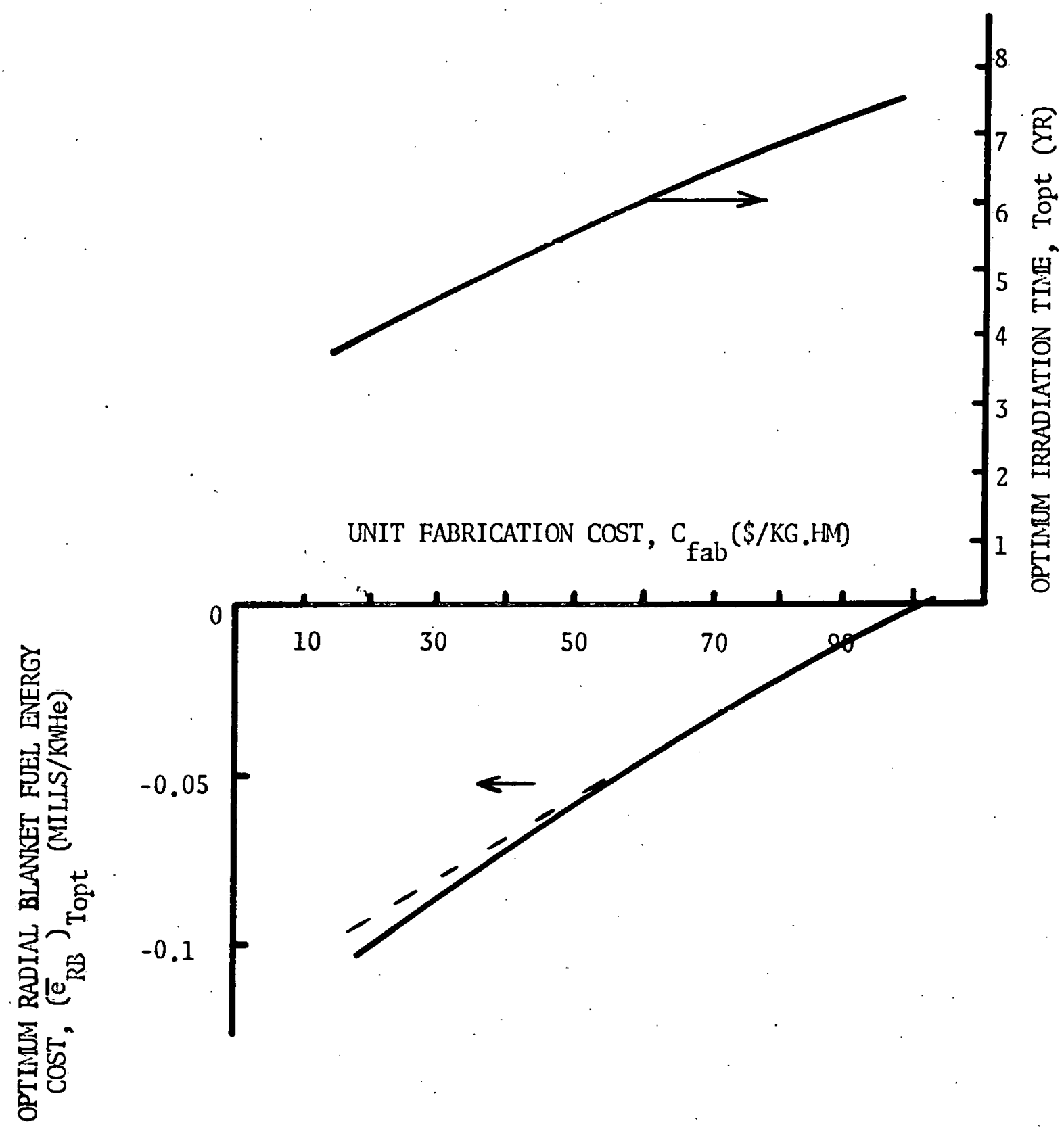

FIG. 5.17 SENSITIVITY OF OPTIMUM RADIAL BLANKET FUEL

ENERGY COST TO UNIT FABRICATION COST 


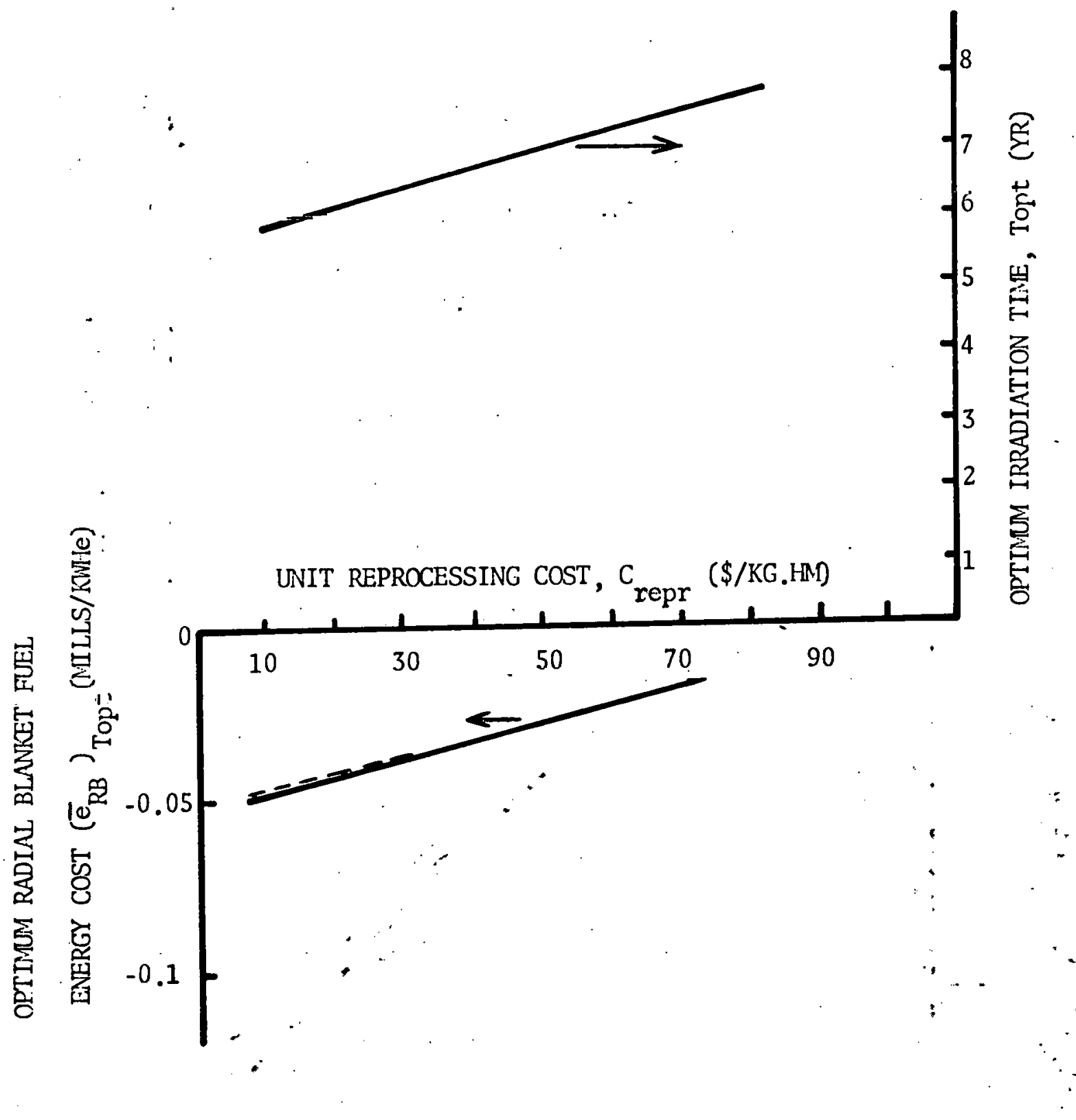

FIG. 5.18 SENSITIVITY OF OPTIMUM RADIAL BLANKET FUEL ENERGY COST TO UNIT REPROCESSING COST 


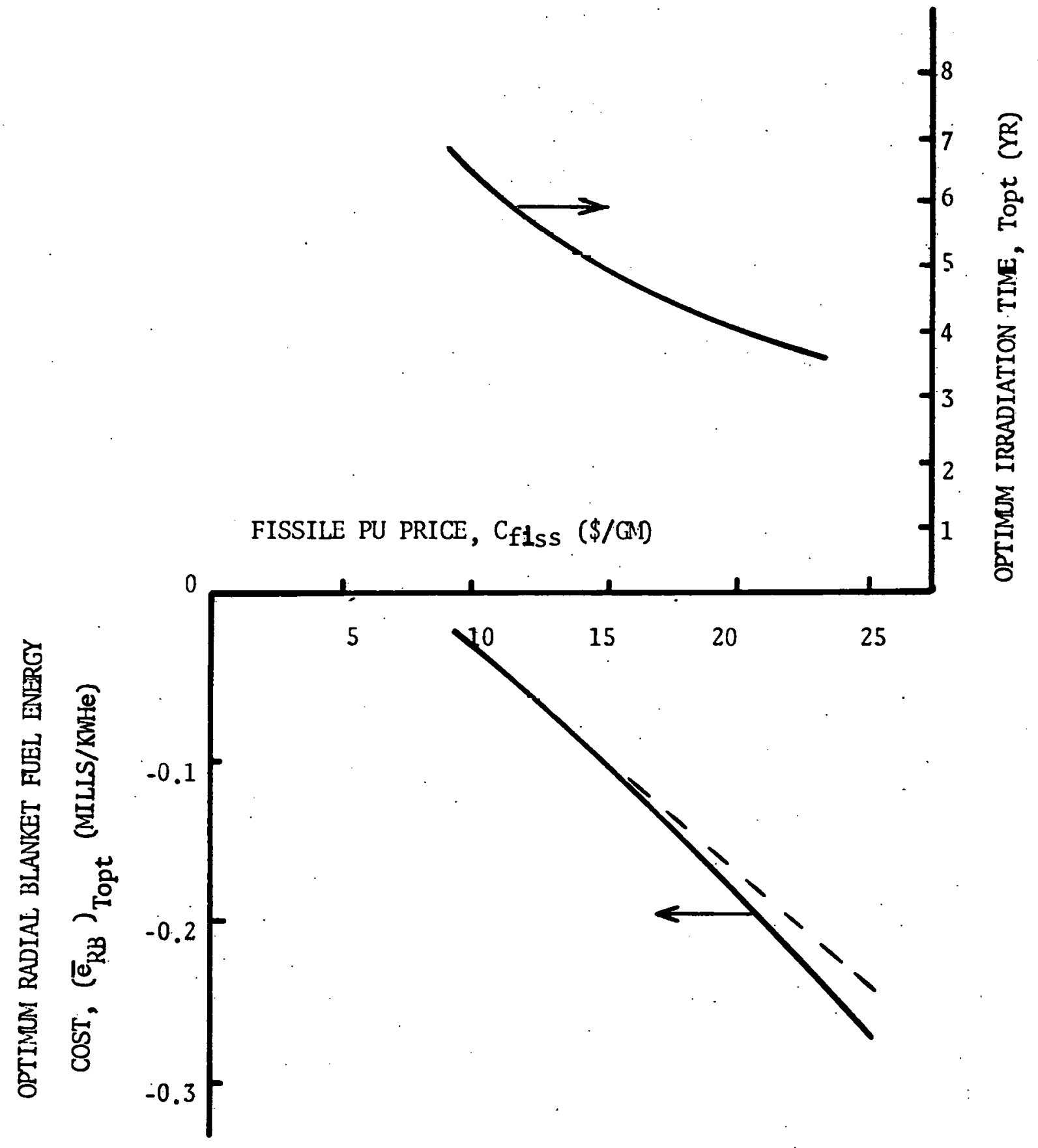

FIG.5.19 SENSITIVITY OF OPTIMUM RADIAL BLANKET FUEL ENERGY COST TO FISSILE PLUTONIUM PRICE 


$$
\begin{aligned}
& \left(\bar{e}_{R B}\right)_{\text {Topt }}=a_{\text {fab,RB }} C_{\text {fab }, R B}+a_{\text {repr, } R B} C_{\text {repr, } R B}+a_{\text {matl, } R B} C_{\text {fiss }}
\end{aligned}
$$

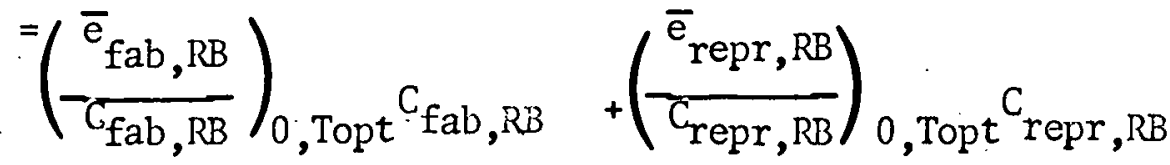

$$
\begin{aligned}
& +\left(\frac{\bar{e}_{\text {mat } 1, R B}}{C_{\text {fiss }}}\right)_{0, \text { Topt }} L_{\text {fiss }} \\
& =1.154 \times 10^{-3} \mathrm{C}_{\mathrm{fab}, \mathrm{RB}}+0.519 \times 10^{-3} \mathrm{C}_{\mathrm{repr}, \mathrm{RB}} \\
& -0.0132 \times 10^{-3} C_{\text {fiss }}
\end{aligned}
$$

Values of the radial blanket sensitivity coefficients, defined as in Section 5.5.2, are given in Table 5.9. Optimum radial blanket fuel energy cost is seen to be most sensitive to fissile price, and least sensitive to unit reprocessing cost.

5.5.4 Fissile Market Price and the Economic Potential of LMFBR Blankets

In Sections 5.5.2 and 5.5.3, core, axial blanket, and radial blanket fuel energy costs were found to be most sensitive to fissile market price $\left(C_{\text {fiss }}\right)$. It was also shown that $\overline{\mathrm{e}}_{\text {core }}$ and $\overline{\mathrm{e}}_{\mathrm{AB}}$, assuming a fixed irradiation tine, are linear in the unit costs $\left\{\mathrm{C}_{q}, \mathrm{~s}\right\}$. while $\left(\overline{\mathrm{e}}_{\mathrm{RB}}\right)_{\mathrm{Topt}}$ is approxinately linear in the $\left\{\mathrm{C}_{\mathrm{q}, \mathrm{RB}}\right\}$.

Figure 5.20 shows the reactor fuel energy costs as a function of fiss. The total reactor fuel energy cost is the sum of the energy costs associated with each region:

$$
\bar{e}_{\text {reactor }}=\bar{e}_{\text {core }}+\bar{e}_{A B}+\left(\bar{e}_{R B}\right)_{\text {Topt }} \quad \frac{\text { mills }}{\text { KWHe }}
$$




\section{TABLE 5.9}

\section{RADIAL BLANKET SENSITIVITY COEFFICIENTS*, $\left(\mathrm{A}_{\mathrm{q}, \mathrm{RB}}\right)_{0, \text { Topt }}$}

q

$$
\left(A_{\mathrm{q}, \mathrm{RB}}\right)_{0, \text { Topt }}
$$

Fabrication

$$
-2.15 * *
$$

Reprocessing

$$
-0.44 * *
$$

Material (fissile)

$$
\frac{+3.59}{1.00}
$$

$$
*\left(A_{q, R B}\right)_{0, T o p t}=\frac{\left(\Delta \bar{e}_{R B}\right)_{T o p t} /\left(\bar{e}_{R B}\right)_{0, T o p t}}{\Delta C_{\dot{q}, R B} /\left(C_{q, R B}\right)_{0, T o p t}}
$$

** These terms are negative because $\left(\bar{e}_{R B}\right)_{0, \text { Topt }}$ is negative. 


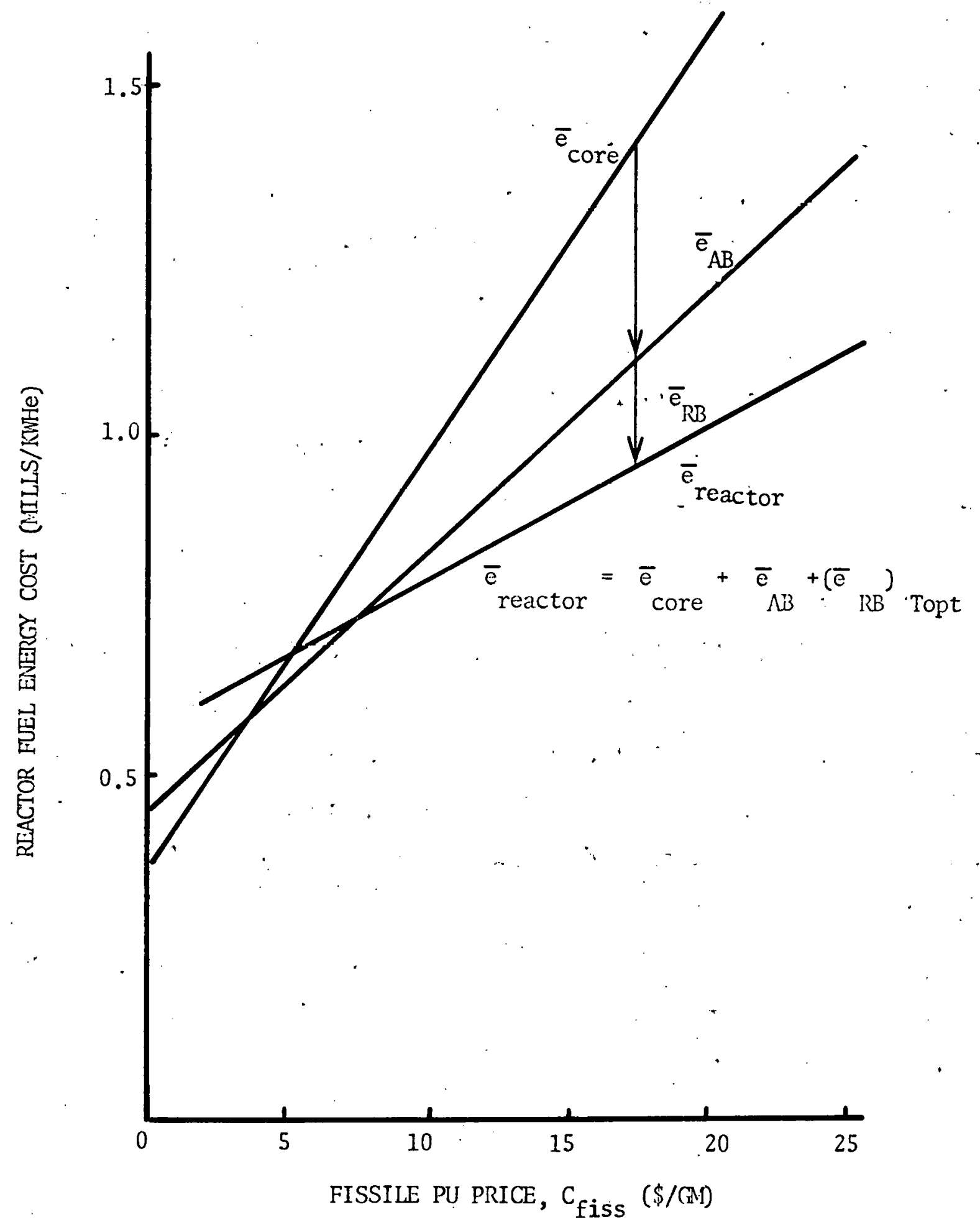

FIG. 5.20 EFFECT OF FISSILE PU PRICE ON TOTAL REACTOR FUEL ENERGY COST 
The values of $\left(\bar{e}_{\mathrm{RB}}\right)_{\text {Topt }}$ used in constructing Figure 5.20 were taken from actual computed results, Figures 5.19 and 5.15, rather than the linear approximation, Equation (5-8).

Figure 5.20 displays several features:

(a) $\bar{e}_{\text {reactor }}$ increases with $C_{\text {fiss }}$ despite the fact that the reactor produces more fissile material than it consunes. This is due to the high core fissile inventory cost. An increase in $\mathrm{C}_{\text {fiss }}$ results in an increase in net direct material revenue, but this advantage is overcome by the increased core inventory costs.

(b) The axial blanket is more profitable than the radial blanket, because the axial blanket sees more neutrons $(I \mathrm{H} / \mathrm{D}=0.4)$. A two enrichment zone core configuration (Reactor 1 ', Section 4.4), of course, upgrades radial blanket performance by enhancing radial leakage.

(c) Below $\mathrm{C}_{\text {fiss }} \simeq 8 \mathrm{\$} / \mathrm{gm}$, the blankets are of marginal importance. As the fissile price increases, the blankets become more viable, substantially offsetting the high core inventory cost.

(d) The axial blanket breakeven point, from Figure 5.20, occurs at $3.88 \$ / \mathrm{gm}$. This is confirmed by solving Equation (5-4) for $C_{\text {fiss }}$ with $\overline{\mathrm{e}}_{\mathrm{AB}}=0$.

(e) The radial blanket breakeven point, from Figure 5.20, occurs at $7.25 \$$ gm. This agrees with the solution of the linear approximation, Equation (5-8), with $\left(\bar{e}_{\mathrm{RB}}\right)_{\text {Topt }}=0$. 


\section{CHAPTER 6}

\section{CONCLUSIONS AND RECOMENDATIONS}

In the preceding chapters, a variety of specific conclusions have been reacheu in regard to a broad spectrun of FBR fuel economic questions. An FBR fuel depletion-economics nodel was developed and applied to a nuniver of 1000 ifie LIFBR case studies. In this chapter, the specific conclusions, in both the methods development and application phases, are reviewed as a prelude to a discussion of broader issues and recommendations as to tile scope and direction of future work.

\subsection{CONCLUSIONS}

The najor conclusions of this study are sumnarized below.

Depletion-Lconomics Methods

1. Blankets impose several unique accounting problems: blanket fuel appreciates with irradiation, thus raising certain income tax questions; and the long irradiation times in the radial blanket make the accounting treatment of blanket carrying charges important. Two methods of treating post-irradiation transactions were compared:

Wethod $A$. Tax the revenue from sale of fissile material (material creciit) as ordinary incorie, along with electricity revenue; treat reprocessing costs as tax deductible expenses in the year in which they occur; Hethod B. Capitalize fissile revenue and reprocessing costs. Method A results in significantly lower values of levelized fuel costs (mills/kille). While the choice between fuel cost accounting methods 
has a significant effect on absolute values of energy costs, it does not distort comparative and incremental results, e.g. design rankings, optimization of radial blanket residence times, etc. However, cloice of method $B$ would lead to the selection of thinner blankets, since under method $B$ more of the radial blanket is unprofitable.

The question of whether or not to tax fissile revenue must ultimately be resolved by taxing authorities or by conmon usage. Fast breeder reactors have two major products: electricity and fissile material. Thus it would appear that fissile revenue should properly be taxed as ordinary income, along with the revenue from the sale of electricity. For this reason, metizod A is recomended for future studies.

2. Several effects complicate the physics-depletion of FBR blankets: spectrun softening with distance from the core-blanket interface; spectrum hardening and flux shift with irradiation; and heterogeneity effects. The two exposure dependent effects - spectrum hardening and flux shift influence the blanket breeding rate in opposing directions. The flux shift effect dominates. A single multigroup physics computation, to obtain the flux shape and local spectra for depletion calculations, is sufficient for evaluating blanket/reflector design changes, scoping studies, and sensitivity studies. The major source of error in computing fissile buildup by this procedure is the assumption of constant flux over an irradiation cycle.

Corrections (to the U238 capture cross section) for blanket heterogeneity effects influence computed fissile production in two opposing ways: (a) reduction in ${ }_{\mathrm{c}}{ }_{\mathrm{C}}^{28}$, tending to reduce the bred fissile inventory; and (b) reduction in neutron attenuation, tending to increase blanket fluxes and increase breeding rate. Of these effects, (a) dominates, and heterogeneity leads to a net adverse effect on blanket breeding. For a 
typical radial blanket, heterogeneity corrections lead to a reduction in discharge fissile inventories of about $10 \%$.

It was also found that core and axial blanket fuel costs are insensitive to radial blanket/reflector configuration changes.

\section{Inte LAFR Case Studies}

3. Subsititution of a moderating reflector (e.g. Be) for the outer radial blanket row/s can improve overall radial blanket economic performance significantly. Choice of radial reflector material, e.g. Be vs. Na has little effect on the fuel economics of thick $(\sim 45 \mathrm{~cm})$ radial blankets. Tile relative advantage of a moderating reflector increases as the reflector is moved nearer the high flux zones of the blanket, that is, as the blanket thickness ciecreases.

4. Reducing blanket thiclness (by replacing outer blanket regions with reflector) reduces the bred fissile inventory of the blanket, that is, the plutoniun forfeited in the region elininated is greater than the additional plutonium ured in the remaining region due to its inprov ed. breeding performance $\left(\sigma_{c}^{28} \phi\right)$. This loss of plutonium revenue is opposed by savings in fabrication and reprocessing costs of the blanket elements elininated. Radial blanket thickness optinnization is weak, i.e. net blanket revenue does not display a sharp peak as radial blanket thickness is reduceu from 3 rows to 2 rows to 1 row.

5. Core enriclment zoning, in addition to its advantages to core fuel economics, significantly enhances breeding in the radial blanket, and can increase net radial blanket revenue by a factor of two or more.

6. Optimuil radial blanket fuel residence tines increase with distance from the core, ranging from approximately 2 years for fuel assemblies nearest the core to about 10 years for fuel in the outer row of a $45 \mathrm{~cm}$ 
blanket. Thus, if the blanket is irradiated to a single irradiation tirie (whole blanket nianagement), the optinum irradiation time for the blanket as a whole, then inner blanket fuel is overexposed and the outer blanket fuel is underexposed. Significant irprovement $(\sim 30 \%$ increase in net blanket revenue) results from irradiating each annular region to its own, local optirimu irradiation time.

7. For a fixed irradiation time set by the burnip linit of core fuel, core and axial blanket fuel costs (mills/KWlie) are simple linear functions of the unit costs for fabrication, reprocessing ( $\$ / \mathrm{kg} / \mathrm{M})$ and fissile material ( $\$ / \mathrm{kg}$ fissile). Core and axial blanket fuel costs are most sensitive to fissile value. Fabrication is the next most important component.

Unlike the axial blanket, the radial blanket may be fuel-managed independently of the core, and thus may be irradiated to its optimum exposure which occurs somewhat beyond core residence times. The radial blanket fuel cost (or net revenue) at its optimum irradiation time is an inplicit function of the unit costs for fabrication, reprocessing and fissile material, as is the optimum irradiation time. Thus the optimum radial blanket fuel cost is not exactly linear in the unit costs, as is the case for core and axial blanket. However, both the optimum ir radiation time and the corresponding radial blanket fuel cost (or net revenue) are approxinlately linear functions of the unit costs. Optimun radial blanket fuel cost (mills/KMie) is most sensitive to fissile price.

For increased fissile prices, both blankets (axial and radial) become more inportant in offsetting the increased core fissile inventory costs. 


\subsection{RECOMMNDDATIONS}

1. Blanket Power and Blaniet Seeding

The availability of neutrons for fertile-to-fissile conversion is a key factor in blanket econoinics. Deep in the blanket (far fron the core), where neutrons are relatively scarce, the conversion rate may be too low to overcome the rates of increase of fabrication and fissile carrying cilarges with residence time, resulting in net positive costs for fuel assemblies there. Thus design or fuel manangement options which tend to increase blanket flux have the potential of enhancing blanket econonics.

Overall reactor fuel economic performance, represented by the net total fuel costs of core and blankets (mills/kilie), is improved by increasing blanket power. This statement assumes that the maximum local power density in the core is held fixed.

A scheme which increases both blanket multiplication (and hence blanket flux) and blanket power is the inclusion of fissile material in blanket load fuel, or blanket seeding. Depending on the orificing scheme adopted, other advantages of blanket seeding are increased coolant exit temperatures (reducing the mixed mean temperature degradation) and reduced blanket power-swing over an irradiation cycle. Another incentive for seeding, or some equivalent accomodation; is the desirability of llodifying a given blanket so that the theoretically optirium blanket thickness matches the discrete thickness allowed by fixed subassembly dimensions. Blanket seeding has a number of disadvantages, including increased inventory cost, increased pumping power requirements, decreased fertile material load available for conversion, and, in the case of uraniun seeding, additional processing charges, for enriclment. 
Table 0.1 summarizes the advantages and disadvantages of blanket seeding. A parametric study to examine these tradeoffs in a more quantitative manner is recommended.

Other investigators (12) have shown that reducing the load fissile enrichnent from that of natural uranium $(0.7 \%$ U235) to zero has negligible effect on blanket breeding. Thus substitution of natural uranium for enriciment plant tails ( $\sim 0.2 \%$ U235) would offer no improvement in blanket breeding.

Figure 3.11 shows that the local breeding ratio decreases from greater than unity to below unity as load enrichment is increased from zero (blankets) to about $14 \%$ (core), because of the enhanced competition for neutrons by the fissile species. At some intermediate point, the local blanket breeding ratio will be unity. Offsetting the diminished local blanket breeding ratio is the increased blanket flux, which tends to increase net blanket revenue at the local optinum irradiation time and to decrease the local optimum irradiation time.

2. Radial Blanket Fuel Managenent

The literature search, Appendix D, failed to render a comprehensive, conparative evaluation of altemate fuel nanagement strategies for a fixed reactor configuration. This is perhaps due to the complexity of fuel management calculations and the lack, until recently, of computer programs flexible enough to survey all feasible options with ease. Several recently developed prograns promise to be useful for Fis fuel managenent studies: PIENIX (31), REBUS (2), FUISLE (45), and 2DSCOST (17). A comparative evaluation of scatter, batch, out-in, and in-out equilibriun radial blanket fuel managenent schenes is recommended. Table 0.2 gives qualitative advantages and disadvantages of these options. 
TABLE 0.1 AWVANTAGES AND DISADVANTAGES OF BLANKET SEEDING

ADVAITAGES

- Increased blanket nultiplication (more neutrons available for fertile-to-fissile conversion)

."Bonus power". For a fixed local power density linit in the core, increased reactor power.

- Reduced mixed nean temperature degradation from blanket coolant.

- Decreased poiver swing over an irradiation cycle.
DISADVANTAGES

- For the same fuel volune fraction, slightly less fertile material available for conversion.

- Increased blanket coolant punping requirements.

- Increased fissile inventory costs.

- In the case of U235, a possible increase in processing costs (enrichment). 
TABLE 6.2 RADIAL BLNNET FUEL NANAGE ENT SCIEMS

Fuel Management

Sclieme

References

Advantages

1. Fixed-Fuel Schemes

A. Batch and Scatter

(1) Whole

Blanket

Management (this report) .simplicity

(2) Regional

Management $(69),(70),(71)$,

(72), (73)

(this report)

B. Batch

C. Scatter

(this report)

$(69),(70),(71)$,

(72), (73), (this

report)

2. Moving-Fuel Schemes

A. Out-in .non-uniform burnup

.power tilt across blanket

.complexity

- power flattening

.more uniform burnup

than whole blanket management; local optina aclieved.

Jnore severe power swing than scatter management.

.complexity .uniform burnup

-reduction in power swing .aggravates power tilt across blanket

.large amount of handling per fuel element 
TABLE 6.2 (continued)

Fuel Hanagenent

Schemes

B. In-out

$\underline{(10)},(\underline{73)}$
Advantages

. uniform burnup

reduction in power swing

.power flattening

\section{Disadvantages}

. large anount of handling per fuel element 
Once tive reactor is in operation, the radial blanket offers the major reliaining area of fuel management flexibility. The operator may tailor its size (or number of rows of subassenblies), load coliposition (enricinment in fissile plutonium or uranium, or possibly the use of fertile thorium), and fuel management scheme to current and projected econonic environnents. Thus, for example, if higher plutonium prices and/or lower fabrication and reprocessing costs are forecast, he may decide to ald a row of subassomblies. Under other conditions, he may elect to alter the radial reflector design, include moderating liaterial in the radial blanket, etc. A recent study (17) has addressed the general problern of optinizing FBR fuel management options in a variable econonic enviromient. Continued effort in this area is recomnended, with the aim of parameterizing and simplifying fuel nanagement decision-making.

3. FBR Fuel jianagement and Design

In-reactor fuel management, particularly that of the blanket, is comnonly treated an an after-thought in reactor design. The reactor is designed first; then fuel management is optinized, subject to tire configuration selected and its engineering limitations and constraints. Ideally, the tasks of design and of setting the fuel management scheme. should be intinately coupled, with the goal of reaching a more "global" optimum.

For exarple, the power swing (and hence orificing requirements) over an irradiation cycle in a radial blanket region, $i$, may be dininished by decreasing the fraction, $g_{i}$, of fuel replaced in that region per refueling event. This, in turn decreases the region throughput, increases the irradiation time, and increases the fissile inventory in the region, which may affect the net blanket fuel revenue adversely. Similarly, a degree of power flattening across the blanket can be achieved 
by dividing the radial blanket into annular regions and assigning them refueling fractions $\left(g_{1}, g_{2}, \ldots\right)$ which decrease with distance from the core. The design benefits of power shaping should be included explicitly in the analysis of fuel management strategies.

Whatever aspects of blanket fuel managenent are subjected to further scrutiny should be approached on a more global basis; at the minimum taking into consideration the strong interaction of management schemes and the flow orificing pattern adopted.

Finally, since unit sizes are projected to increase to $2000 \mathrm{Mre}$ and beyond after the year 2000, a more thorougin parametric study of blanket perfomance versus reactor rating is recomnended. The reactor sizeblanket fuel economics prelininary study in Appendix B identifies some of the design-fuel nianagenent issues which should be addressed by such an effort. 


\section{APPENDIX A - NOMENCLATURE}

Chapter 2 - Nomenclature

Subscripts, Superscripts and Abbreviations.

4

$m p$

fab

repr

mc

28

49

40

41

42

HI

CFII

CIM

SIM cost component index; mp, fab, repr or mc material purchase

fabrication

reprocessing

material credit

U238

Pu239

Pu240

Pu241

Pu242

heavy metal $(U+P u)$

cash flow method

compound interest method

simple interest method

Levelized Cost (Price)of Electricity

$\overline{\mathrm{e}}$

levelized cost (price)of electricity mills associated with fue1.

KWHe

Depending on context, the symbol $\bar{e}$ denotes:

*total reactor levelized fuel cost (sum over all fuel streams)

*levelized fuel cost associated with a given fuel stream (sum over the cost components, $q$, of the fuel stream).

Unit Costs

$\mathrm{C}_{\mathrm{fab}}$

unit fabrication cost for a given type fuel 
$\mathrm{C}_{\text {repr }}$

$\mathrm{C}_{\mathrm{j}}$ unit reprocessing cost for a given type fuel

market value of isotope $j$
$\frac{\$}{\mathrm{kglM}}$

$\$$

$\mathrm{kg}$

Annual Quantities for CFM Derivation

$\mathrm{E}_{j} \quad$ electrical energy generated by the plant, year $j \quad \mathrm{KWHe}$

$V_{j}$ taxable revenue from sources other than the sale of electricity, year $j$

$\mathrm{O}_{j} \quad$ tax deductable cost, year $j$

$\$$

$D_{j} \quad$ depreciation for tax purposes, year $j$

$V_{j}^{\prime}$ non-taxable revenue, year $j$

$Z_{j}$ capitalized cost (new capitalization), year $j$

$\mathrm{Y}_{\mathrm{j}} \begin{aligned} & \text { book value (1iability to investors) in effect } \\ & \text { during year } \mathrm{j}\end{aligned}$

$\mathrm{T}_{j} \quad$ income tax, year $\mathrm{j}$

$w(j)$ discount factor, $(1+x)^{-j}$

Costs Associated with a Fuel Lot

$z_{m}^{q} \cdot$ direct cost, cost component $q$, fuel lot $m$

$\left(\mathrm{z}_{\mathrm{m}}^{\mathrm{q}}\right)$ ** carrying charge associated with cost component $\mathrm{q}$, fuel lot $m$

$\left(z_{m}^{q}\right) *$ total cost associated with component $q$, fuel lot $\mathrm{m}$;

$=z_{m}^{q}+\left(z_{m}^{q}\right)^{* *}$ 
$t_{m}^{q} \quad$ time from beginning of plant life to trans action $q$, fuel $10 t \mathrm{~m}$ yr.

$t_{\mathrm{m}} \quad$ time from beginning of plant life to

$\mathrm{m} \quad$ irradiation midpoint of fuel lot $\mathrm{m} \quad \mathrm{yr}$.

$\mathrm{T}_{\mathrm{m}} \quad$ irradiation time of fuel lot $\mathrm{m} \quad \mathrm{yr}$.

$\mathrm{T}_{\mathrm{m}}^{, q} \quad$ pre-irradiation time, component $\mathrm{q}$, fuel lot $\mathrm{m}$; $\quad \mathrm{yr}$. time between transaction $q$ and start of irradiation

$T_{m}^{\prime \prime q}$ post-irradiation time, component $q$, fuel lot $m$; $\quad y r$. time between end of irradiation and transaction $q$

$\mathrm{T}_{\mathrm{m}}^{\mathrm{q}} \quad$ time between transaction $\mathrm{q}$ of $10 \mathrm{t} \mathrm{m}$, and mid- $\quad \mathrm{yr}$. point of irradiation

Financial Parameters

$x$ discount rate

$f_{b} \quad$ fraction of capital from bondholders

$f_{s} \quad$ fraction of capital from stockholders

$r_{b}$ bondholders' rate of return

$r_{s}$ stockholders' rate of return

+ income tax rate

$\mathrm{F}_{\mathrm{m}}^{\mathrm{q}} \quad$ carrying charge factor associated with cost component $\mathrm{q}$, fuel lot $\mathrm{m}$;

$$
\left(z_{m}^{q}\right)^{*} / z_{m}^{q}
$$

$y_{q} \quad$ carrying charge rate associated with cost component $q$

Fuel Composition

$\mathrm{M}_{28}(\mathrm{~T}), \quad$ Nass of indicated nuclide after irradiation $\mathrm{kg}$ $\mathrm{M}_{49} \mathrm{~T}$...

$\mathrm{M}_{28}^{\mathrm{O}}$, Initial mass of indicated nuclide $\mathrm{kg}$ $\mathrm{M}_{49}^{\mathrm{O}}, \cdots$ 


$$
\begin{array}{ll}
\epsilon_{(\mathrm{T})} & \text { Fissile concentration after irradiation time } \mathrm{T}, \\
& \mathrm{M}_{49}(\mathrm{~T})+\mathrm{M}_{41}(\mathrm{~T}) / \mathrm{M}_{\mathrm{HM}}^{0} \\
\epsilon_{0} & \text { Initial fissile concentration (enrichment) } \\
& \mathrm{M}_{49}^{0}+\mathrm{M}_{41}^{0} / \mathrm{M}_{\mathrm{HM}}^{0}
\end{array}
$$

Chapter 3 - Nomenclature

$$
\begin{aligned}
& \sigma^{j} \quad \text { microscopic cross-section for event } e \text {, barns } \\
& k, e \quad \text { energy group } k \text {, nuclide } j \\
& \sigma_{e}^{j} \quad \begin{array}{l}
\text { spectrum averaged one group cross-section, } \\
\text { event } e, \text { nuclide } j
\end{array} \\
& \sum_{\mathrm{k}=1}^{\mathrm{n}} \cdot \phi_{\mathrm{k}} \quad \sigma_{\mathrm{k}, \mathrm{e}}^{\mathrm{j}} / \sum_{\mathrm{k}=1}^{\mathrm{n}} \phi_{\mathrm{k}} \\
& \phi_{k} \quad \text { neutron flux in energy group } k \text {. } \mathrm{n} / \mathrm{cm}^{2} \mathrm{sec} \\
& \phi \quad \text { total flux, } \mathrm{n} / \mathrm{cm}^{2} \sec \\
& \sum_{k=1}^{n} \quad{ }_{k} \\
& \mathrm{~N}_{\mathrm{j}} \quad \text { atom density, nuclide } \mathrm{j} \quad \text { atoms } / \mathrm{cm}^{3} \\
& \mathrm{~N}_{\mathrm{j}}^{0} \text { : initial atom density, nuclide } \mathrm{j} \quad \text { atoms } / \mathrm{cm}^{2} \\
& \theta \quad \text { flux time } \\
& \equiv \int^{t} \phi\left(t^{\prime}\right) d t^{\prime}
\end{aligned}
$$

Appendix B - Nomenclature

$\begin{array}{lll}R_{C} & \text { core radius } & \mathrm{cm} \\ V_{c} & \text { core volume } & \text { liter } \\ \mathrm{B}_{\mathrm{C}}^{2} & \text { critical core buckling } & \mathrm{cm}^{-2} \\ \epsilon_{C} & \text { critical core enrichment } & \end{array}$


$\mathrm{b}_{i} \quad \begin{gathered}\text { internal breeding ratio, } \\ \text { fissile production } \\ \text { rate in core }\end{gathered} / \begin{gathered}\text { fissile destruction } \\ \text { rate in core }\end{gathered}$

$b_{x} \quad$ external breeding ratio,

fissile production / fissile destruction
rate in blanket

$\theta_{\mathrm{c}, \mathrm{ox}}$ oxide volume fraction in core

$\theta_{b, o x}$ oxide volume fraction in blanket

$f$ fraction of reactor themal power produced in blanket

$\Delta \mathrm{M}_{\mathrm{c}, 49}\left(\mathrm{~T}_{\mathrm{c}}\right)$ change in core Pu239 inventory during core irradition

$\mathrm{M}_{\mathrm{C}, 49}^{0} \quad$ initial core Pu239 inventory $\mathrm{kg}$

$\Delta \mathrm{M}_{\mathrm{b}, 49}\left(\mathrm{~T}_{\mathrm{b}}\right)$ change in blanket Pu239 inventory during $\mathrm{kg}$ blanket irradiation time $\mathrm{Tb}$

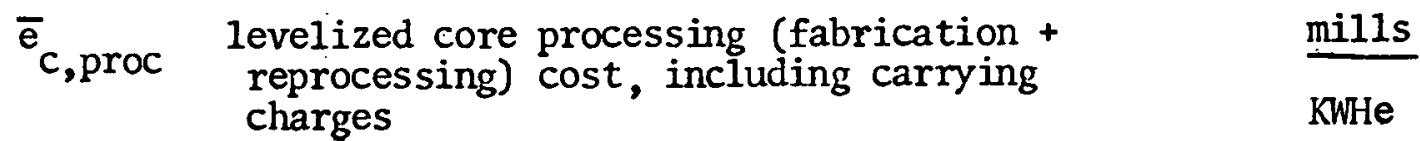

$\begin{array}{lll}\overline{\mathrm{e}}_{\mathrm{b}, \text { proc }} & \begin{array}{l}\text { levelized blanket processing (fabrication }+ \\ \text { reprocessing) cost, including carrying charges }\end{array} & \text { mills } \\ \mathrm{KWHe}\end{array}$

$\bar{e}_{\mathrm{C}, \mathrm{BU}} \quad$ levelized core burnup (direct material) cost, mills including material purchase and material credit

KWHe

$\bar{e}_{\mathrm{c}, \text { Inv. }} \quad$ levelized core inventory cost mills

(material carrying charge) KWHe

$\overline{\mathrm{e}}_{\mathrm{b}, \text { mat }} \begin{aligned} & \text { levelized blanket material cost (revenue), } \\ & \text { including carrying charge }\end{aligned}$

$\overline{\mathrm{e}}_{\mathrm{c}} \quad$ total levelized core fuel cost, mills

$\bar{e}_{c, p r o c}+\bar{e}_{c, B U}+\bar{e}_{c, I n v .}$ KWHe

$\overline{\mathrm{e}}_{\mathrm{b}} \quad$ total levelized blanket fuel cost mills

$\overline{\mathrm{e}}_{\mathrm{b}, \text { proc }}+\overline{\mathrm{e}}_{\mathrm{b}, \text { mat }} \quad$ KWHe

$\overline{\mathrm{e}}$ total levelized reactor fuel cost mills

$$
\overline{\mathrm{e}}_{\mathrm{c}}+\overline{\mathrm{e}}_{\mathrm{b}} \quad \text { KWHe }
$$


APPENDIX B

REACTOR SIZE AND BLAPNKET FUEL ECONOMICS

\section{B.1 INTRODUCTION}

Very large reactors ( $>1000 \mathrm{MWe}$ ), advantaged by economics of scale, have been predicted. For example, the EEI "Fast Breeder Reactor Report" (58) suggests that light water reactors and fast breeder reactors may have unit ratings in excess of 2000 Mwe by the year 1990. The purpose of this appendix is to examine relationslips between FBR core size (or power rating) and FBR blanket fuel econonics.

As core size is increased, (holding shape fixed), core neutron leakage (per core fission) and external breeding ratio decrease. Net blanket revenue (plutonium credit less fabrication and reprocessing costs), per unit of power, decreases. At the same time, core critical enrichment decreases, resulting in lower core fissile inventory costs. With a higher fertile concentration in the core, the internal breeding ratio is enhanced, diminishing the burnup (direct material) component of core fuel energy cost. Indeed, for a sufficiently large core, the internal breeding ratio exceeds unity and the burnup component becomes a revenue.

For these reasons, the economic inportance of the blanket tends to decrease with reactor size. In fact, it may be worthwhile, for a sufficiently large core, to substitute a non-breeding reflector for the breeding blanket. This would eliminate fabrication and reprocessing costs, although this advantage may be offset by the cost of the added reflector. In addition, the core neutron economy may be improved, provided the reflector has superior neutronic properties compared to the breeding blanket, ${ }^{1}$

1. Design studies for the FFTF (84) have shown that $\mathrm{Ni}$ is superior to a breeding blanket, as a core reflector. 
resulting in eve lower critical enrichment (lower core inventory cost) and higher internal breeding ratio (lower burnup cost). If the reflector is merely sodium coolant, it need not be fabricated or cooled in situ and blanket fabrication costs and pumping requirements are eliminated. Against these advantages of a non-breeding reflector must be weighed its obvious disadvantage - the loss of blanket plutonium revenue.

The arguments above are largely academic. First, the core shape was assumed to be held fixed as core size increases. In reality, high leakage geometries (e.g. pancake, annular) may be required for large cores to enhance the negative component of the sodium void coefficient. Another reason for spoiling large core geometry is to hold the internal breeding rate near unity, thus minimizing reactivity control requirements, control systems costs, and parasitic loss of neutrons available otherwise for breeding.

The purpose of this appendix is to examine some of these qualitative arguments in a semi-quantitative way. Using simple, one energy group, spherical geometry neutronics equations, the fuel economics of reactors with and without blankets were compared as core size (power rating) is increased. Three cases are considered:

Case A: Spherical core with a breeding blanket, assuming no Pu239 burmup in the blanket ${ }^{1}$;

Case $A^{*}$ : Spherical core with a breeding blanket, corrected for Pu239 burnup in the blanket, blanket power fraction = $0.1^{1}$

Case B: Spherical core with a sodium reflector (no breeding blanket).

1. Case $A^{*}$, a refinement of Case $A$, is included to examine the effect of blanket burnup on overall energy costs (mills/KWlie). 
The spherical core size limit for a negative sodium void coefficient (50\% sodiun 1oss) have been determined in an extensive parametric study by Terasawa, et.al. (55). This limit is indicated in the results of Section B.3.

\section{B.2 EQUNTIONG}

\section{B.2.1 Summary}

The neutron balance, depletion, and economics working equations used in this study are summarized in Table B.1. Major assumptions are listed in Table B.2. Table B.3 gives the region compositions and one group physics data. Table B.4 presents the economic data. Residence times and powerrelated parameters are given in Table B.5. The equations of Table B.1 are used as follows:

1. For a given core volume $\left(\mathrm{V}_{\mathrm{c}}\right)$, the core critical buckling $\left(B_{C}^{2}\right)$ is found by solving the transcendental critical Equation (B-4A) or (B-4B) .

2. With this value of critical buckling, critical core enrichment $\left(\epsilon_{c}\right)$ is computed, using Equation $(B-15)$. Critical mass $\left(M_{C, 49}\right)$ may also be computed at this time, from $\epsilon_{C}$ and $V_{C}$, using Equation ( $B-17$ ).

3. The internal breeding ratio $\left(b_{i}\right)$, a function of $\epsilon_{c}$, is determined from Equation $(B-20)$. The external breeding ratio $\left(b_{x}\right), a$ function of both $\epsilon_{c}$ and $B_{c}$, is found from Equation (B-24).

4. Masses of Pu239 discharged from core and blanket $\left(M_{c, 49}\right.$, $\mathrm{M}_{\mathrm{b}, 49}$ ) are found from Equations $(B-36)$ and $(B-37)$ respectively, with the known values of $v_{c}, \epsilon_{c}, b_{i}$ and $b_{x}$. This step may be by-passed since the economics equations incorporate $(B-36)$ and $(B-37)$.

5. Core and blanket levelized fuel energy costs are determined from Equations (B-48) through (B-78), with the values of $\epsilon_{C}, b_{i}$ and $b_{x}$ 
Neutronic and Depletion Equations

(a) Critical Core Buckling:

$$
\begin{aligned}
& 6.24 V_{C}^{1 / 3} B_{C} \cot 6.24 V_{C}^{1 / 3} B_{C}=-0.3 V_{C}^{1 / 3}-0.1915 \ldots . .\left(\text { Case } A, A^{*}\right) \ldots . . . \cdot(B-4 A) \\
& =-0.04815 V_{c}^{1 / 3}-1.4561 \ldots(\text { Case } B) . . . \cdot(B-4 B)
\end{aligned}
$$

(b) Critical Core Enrichment:

$$
\epsilon_{c}=0.0651+62.76 \mathrm{~B}_{\mathrm{C}}^{2} \ldots . . . . . .\left(\text { Case } A, A^{*}, B\right) \ldots(B-15)
$$

(c) Critical Core Mass:

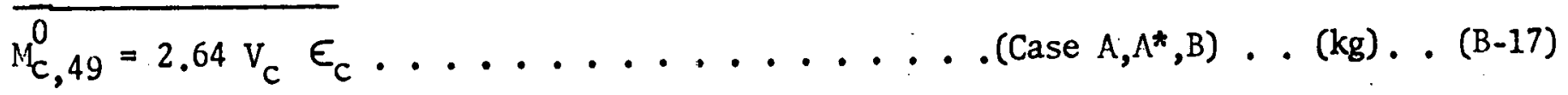

(d) Breeding Ratios:

$$
\begin{aligned}
& \left.b_{i}=0.1255\left(\frac{1-\epsilon_{c}}{\epsilon_{c}}\right) \cdot \ldots \cdot \ldots \ldots \text { (Case } A, A^{*}, B\right) \ldots \ldots(B-20)
\end{aligned}
$$

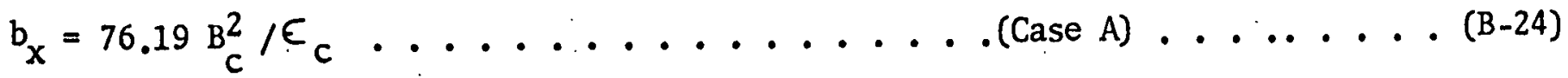

(e) Discharge Pu239 Mass

$$
\begin{aligned}
& M_{c, 49}=2.64 V_{c} \epsilon_{c}+0.3250\left(b_{i}-1\right) V_{c} \ldots . . . .\left(\text { Case } A, A^{*}, B\right) . .(k g) .(B-36)
\end{aligned}
$$

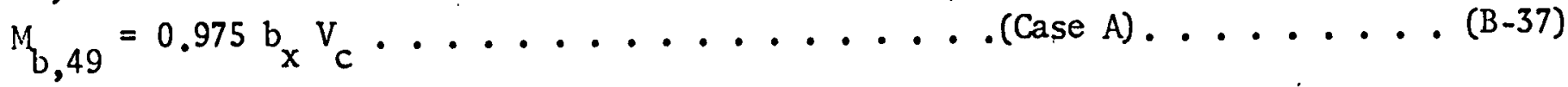

Cost Equations

(f) Core

Burnup, $\bar{e}_{C, B U}=-1.16\left(b_{i}-1\right) . . . . . . . . .(C a s e ~ A, B) .(\operatorname{mi} 11 s / K W H e) \cdot(B-48)$ 
Inventory, $\bar{e}_{c, i n v}=3.335 \epsilon_{c}+0.1250\left(b_{i}-1\right) \ldots \ldots($ Case $A, B) \ldots($ mills $/ K W H e) .(B-49)$ Processing, $\bar{e}_{, c, p r o c}=0.3964 \ldots \ldots($ Case $A, B) \ldots(\operatorname{mi11s} / \mathrm{KWHe}) .(B-50)$

(g) Blanket

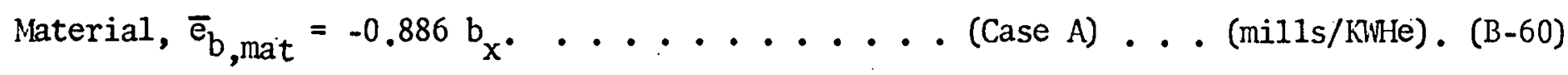

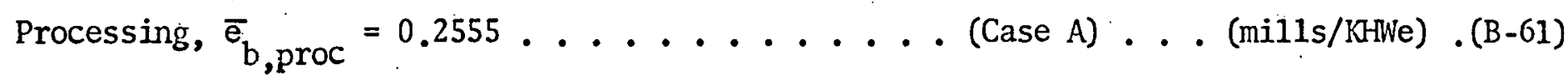

Corrections for Blanket Pu239 Burnup (Case $A^{*}$ )

(e)* Discharge Pu239 Mass (Blanket):

$\mathrm{M}_{\mathrm{b}, 49}^{*}=0.8 \mathrm{M}_{\mathrm{b}, 49}=0.78 \mathrm{~b}_{\mathrm{x}} \mathrm{v}_{\mathrm{c}} \ldots \ldots\left(\right.$ Case $\left.\mathrm{A}^{*}\right) \ldots \ldots(\mathrm{kg}) \ldots \ldots(\mathrm{B}-69)$

(f)* Core Cost Equations:

$\overline{\mathrm{e}}_{\mathrm{C}, \mathrm{BU}}^{*}=0.9 \overline{\mathrm{e}}_{\mathrm{c}, \mathrm{BU}} \ldots \ldots \ldots\left(\right.$ Case $\left.\mathrm{A}^{*}\right) \ldots \ldots(\operatorname{mills} / \mathrm{KWH \textrm {He }}) .(\mathrm{B}-75)$

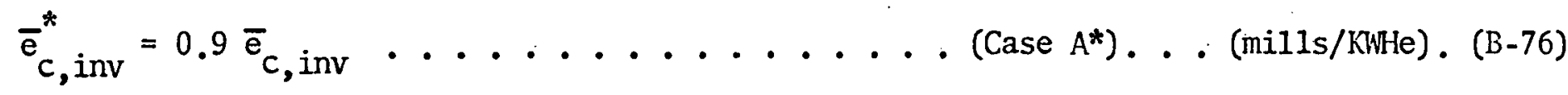

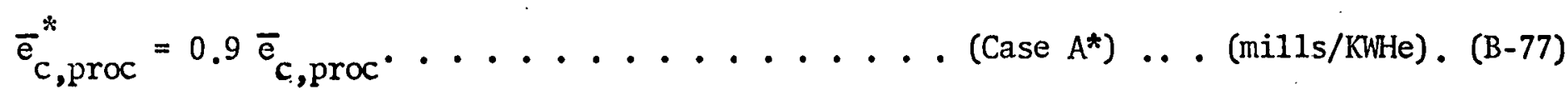

$(\mathrm{g})$ * Blanket Cost Equations:

$\mathrm{e}_{\mathrm{b}, \text { mat }}^{*}=0.72 \overline{\mathrm{e}}_{\mathrm{b} \text {,mat }} \ldots \ldots \ldots\left(\right.$ Case $\left.\mathrm{A}^{*}\right) \ldots \ldots(\operatorname{mills} / \mathrm{KWHe}) .(\mathrm{B}-79)$

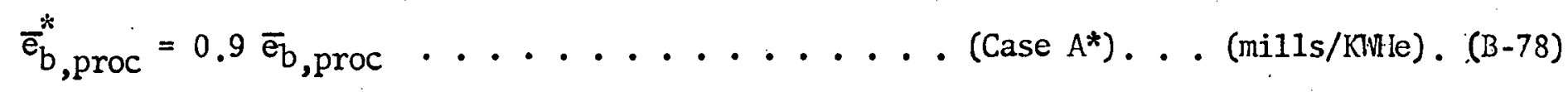




$$
\begin{aligned}
& \text { Core: } \bar{e}_{c}=\bar{e}_{c, B U}+\bar{e}_{c, i n v}+\bar{e}_{c ' p r o c} \ldots \ldots . . . . . . \text { (Case A,B) ... (millis/KWHe) } \\
& \overline{\mathrm{e}}_{\mathrm{c}}^{*}=\overline{\mathrm{e}}_{\mathrm{c}, \mathrm{BU}}^{*}+\overline{\mathrm{e}}_{\mathrm{c}, \mathrm{inv}}^{*}+\overline{\mathrm{e}}_{\mathrm{c}, \mathrm{proc}}^{*} \cdot \ldots . . . . . .\left(\text { Case } \mathrm{A}^{*}\right) . . .(\mathrm{mi} 11 \mathrm{~s} / \mathrm{KWHe}) \\
& \text { Blanket: } \quad \overline{\mathrm{e}}_{\mathrm{b}}=\overline{\mathrm{e}}_{\mathrm{b}, \text { mat }}+\overline{\mathrm{e}}_{\mathrm{b}, \text { proc }} \ldots . . . . . . . \text { (Case A) ... (mills/KWle) } \\
& \overline{\mathrm{e}}_{\mathrm{b}}^{*}=\overline{\mathrm{e}}_{\mathrm{b}, \mathrm{mat}}^{*}+\overline{\mathrm{e}}_{\mathrm{b}, \mathrm{proc}}^{*} \cdot \ldots . . . \cdot \ldots\left(\text { Case } \mathrm{A}^{*}\right) . . .(\mathrm{mills} / \mathrm{KWHe})
\end{aligned}
$$

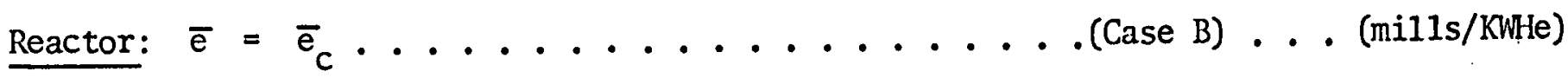

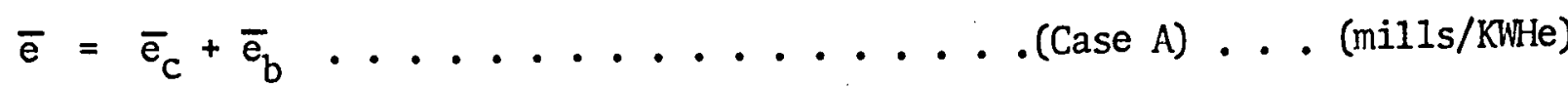

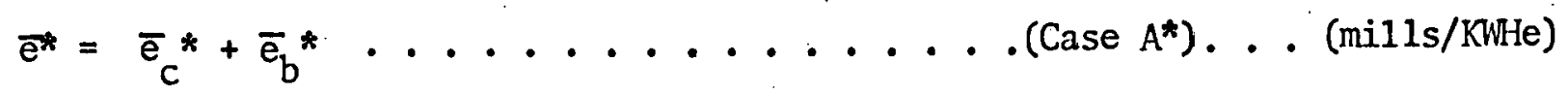

Plant Power Rating

$$
\begin{aligned}
& \mathrm{Pe}=0.2 \mathrm{v}_{\mathrm{c}} \ldots \ldots \ldots \ldots \ldots(\mathrm{C} \text { (Case A,B) } \ldots \ldots(\mathrm{MNe}) \ldots \ldots(\mathrm{B}-64)
\end{aligned}
$$

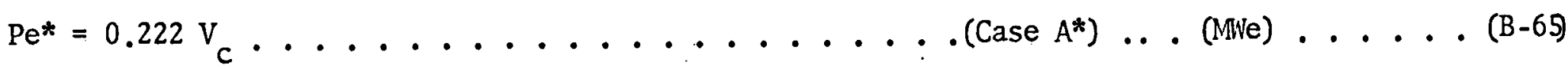

$$
\begin{aligned}
& \left(\mathrm{V}_{\mathrm{c}} \text { in liters }\right)
\end{aligned}
$$


TABLE B.2 - ASSUMPTIONS

1. Geometry

- Spherical core

- Infinite outer region (for criticality calculation)

- Blanket Volume $=3 \times$ core volume (for blanket processing cost calculation)

2. For Case A, there is no Pu239 burnup in the blanket (blanket power fraction is zero).*

For Case $A^{*}$, Pu 239 burnup in the blanket is accounted for (blanket power fraction is 0.1$). *$

3. Core rated power density is independent of core size.

4.: No fissile material is loaded in the blanket.

5. Core and blanket have the same one group cross sections (no spectral effects).

6. No higher isotopes of Plutonium are considered.

7. Core enrichnent is uniform (no zoned enrichment scheme).

8. Increased control requirements for internal breeding ratios substantially above unity are ignored.

9. There are no sodium void coefficient restrictions on the size of a spherical core.

* For blanket irradiation times near six years, U238 fission provides about $15 \%$ of blanket energy. 
TABLE B.3 - REGION COMPOSITIONS AND ONE-GROUP DATA

\begin{tabular}{|c|c|c|c|c|c|c|c|c|}
\hline$\underline{\text { Region }}$ & Nuclide & $\begin{array}{l}\text { Volume } \\
\text { Fraction } \\
\end{array}$ & $\begin{array}{l}\text { Theoretical } \\
\text { Atom Density } \\
\text { atom } \\
\text { barn-cm }\end{array}$ & $\begin{array}{c}\sigma_{a} \\
\text { (barns) } \\
\end{array}$ & $\begin{array}{c}v \sigma_{f} \\
\text { (barns) }\end{array}$ & $\begin{array}{c}\sigma_{t} \\
\text { (barns) } \\
\end{array}$ & $\eta$ & $\begin{array}{l}\text { Composite } \\
\text { Parameters } \\
\end{array}$ \\
\hline \multirow[t]{4}{*}{ Core } & U238 (oxide) & 0.3 & 0.024 & 0.35 & 0.14 & 7.65 & 0,4 & 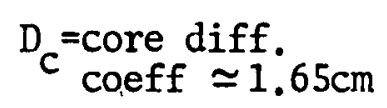 \\
\hline & Pu239 (oxide) & & 0.025 & 2.36 & 5.66 & 8.0 & 2.4 & $\Sigma_{a, p}=$ non-fuel \\
\hline & $\mathrm{Na}$ & 0.55 & 0.025 & 0.0016 & & 3.29 & & absorption \\
\hline & $\mathrm{Fe}$ & 0.15 & 0.085 & 0.010 & & 2.50 & & $\simeq 0.0002 \mathrm{~cm}^{-1}$ \\
\hline Blanket & U238 (oxide) & 0.6 & 0.024 & 0.35 & 0.14 & 7.65 & 0.4 & $\mathrm{D}_{\mathrm{b}}=\mathrm{blanket}$ diff \\
\hline (Case A, & $\mathrm{Na}$ & 0.2 & 0.025 & 0.0016 & & 3.29 & & $\mathrm{~cm}$ \\
\hline$\left.A^{*}\right)$ & $\mathrm{Fe}$ & 0.2 & 0.085 & 0.010 & & 2.50 & & $x_{b}=0.04 \mathrm{~cm}^{-2}$ \\
\hline $\begin{array}{l}\text { Na Reflec- } \\
\text { tor (case B) }\end{array}$ & $\mathrm{Na}$ & 1.0 & 0.024 & 0.0016 & & 3.29 & & $\begin{array}{l}D_{b}=4.05 \mathrm{~cm} \\
x_{b}=0.00314 \mathrm{~cm}^{-2}\end{array}$ \\
\hline
\end{tabular}


TABLE B.4 - ECONOMICS DATA

Pu239

$\left(\mathrm{C}_{49}\right) \ldots \ldots 10 \rho 0$ \$ $/ \mathrm{kg}$ Pu239

Fabrication Costs

core

$\left(\mathrm{C}_{\mathrm{c}, \mathrm{fab}}\right) . .314 \$ / \mathrm{kgHM}(\mathrm{Pu}+\mathrm{U})$

Blanket

$\left(\mathrm{C}_{\mathrm{b}, \mathrm{fab}}\right) \cdots 69$

Reprocessing Costs

core

$\left(\mathrm{C}_{\mathrm{c}, \text { repr }}\right) \cdot 31.5 \$ / \mathrm{kgHM}(\mathrm{Pu}+\mathrm{U})$

Blanket

$\left(\mathrm{C}_{\mathrm{b}, \mathrm{repr}}\right) \cdot 31.5$

Utility Company Financial Paramters

Income Tax Rate

$$
(\tau) . . .0 .5
$$

Capital Structure

Bond Fraction $\left(f_{b}\right) \ldots . .0 .5$

Stock Fraction $\left(f_{s}\right) \ldots . .0 .5$

Rates of Return

Bonds

$\left(r_{b}\right) \ldots .0 .07$

Stocks

$\left(r_{s}\right) \ldots . .0 .125$

Discount Rate*

(x)

* $x=(1-r) f_{b} r_{b}+r_{s} f_{s} \cdots 0.08$ 
TABLE B.5 - PLANT POWER RELATED PARAMETERS

AND BATCH FUEL TIMING

Rated Core Power Density

(q"') $\quad 500 \mathrm{kw}_{\mathrm{t}} / 1$ iter

Plant Load Factor

(L)

0.8

Net Thermal Efficiency

$(\eta)$

0.4

Fuel Irradiation Times

core

$\left(\mathrm{T}_{\mathrm{C}}\right)$

2 years

blanket

$(\mathrm{T})$

6 years

Pre and Post-Irradiation Times (core and Blanket)
material purchase
$\left(T_{m p}^{\prime}\right)$
0.5 years
fabrication
$\left(T_{f a b}\right)$
0.5
reprocessing
$\left(\mathrm{T}_{\text {repr }}^{\prime \prime}\right) \cdot 0.5$
material credit
$\left(\mathrm{T}_{\mathrm{mc}}^{\prime \prime}\right) \quad 0.5$. 
determined above.

\section{B.2.2 Derivation of Equations}

B.2.2.1 Neutronic and Depletion Equations

Critical Core Buckling

The one-group criticality equation for a spherical core surrounded by an infinite outer region is

$$
B_{c} R_{c} \cot B_{c} R_{c}=1-\frac{D_{b}}{D_{c}}\left(x_{b} R_{c}+1\right)
$$

where

$$
\begin{aligned}
B_{c}^{2} & =\text { (critical core buckling) } \\
& =\frac{k_{c}-1}{L_{c}^{2}}=\frac{1}{D_{c}}\left[v \Sigma_{f, c}-\Sigma_{a, c}\right], \\
& 1-k_{o} \\
x_{b}^{2} & =\frac{L_{b}^{2}}{R_{c}}=-B_{b}^{2}=\frac{1}{D_{b}}\left[\Sigma_{a, b}-v \Sigma_{f, b}\right], \\
R_{c} & \equiv \text { core radius } \\
D_{i} & \equiv \text { diffusion coefficient, region } i \\
\Sigma_{f, i} & \equiv \text { macroscopic fission cross section, region } i \\
\Sigma_{a, i} & \equiv \text { macroscopic absorption cross section, region } i \\
v & \equiv \text { neutron yield per fission } \\
\text { subscript } i=c \text { (core) } & =b \text { (outer region) }
\end{aligned}
$$

The"outer region (b)" is either a breeding blanket (Case A) or a sodium reflector (Case B). In the latter case, the outer region is not a multiplying medium, and $x_{b}^{2}=1 / L_{b}^{2}$, as usual. 
The core radius expressed in terms of core volume $\left(\mathrm{V}_{\mathrm{c}}\right)$ is given by

$$
\begin{aligned}
R_{c} & =\left(3 / 4 \pi v_{c}\right)^{1 / 3} \\
& =6.24 v_{c}^{1 / 3}
\end{aligned}
$$

where $V_{c}$ is in liters, and $R_{c}$ is in centimeters. Equation (B-1) thus becomes

$$
B_{c}\left(6.24 v_{c}^{1 / 3}\right) \cot B_{c}\left(6.24 v_{c}^{1 / 3}\right)=-\frac{D_{b}}{D_{c}}\left[X_{b}\left(6.24 v_{c}^{1 / 3}\right)+1\right]
$$

Using the data of Table 6.3, Equation (B-3) becomes

$$
\begin{aligned}
6.24 \mathrm{~V}_{\mathrm{c}}^{1 / 3} \mathrm{~B}_{\mathrm{c}} \cot \left(6.24 \mathrm{~V}_{\mathrm{c}}^{1 / 3} \mathrm{~B}_{\mathrm{c}}\right) & =-0.3 \mathrm{~V}_{\mathrm{c}}^{1 / 3}-0.1915 . . \text { Case } \mathrm{A} \\
& =-0.04815 \mathrm{~V}_{\mathrm{c}}^{1 / 3}-1.4561 \text { Case } \mathrm{B}
\end{aligned}
$$

Critical Core Enrichment

For a given core volume, the transcendental Equation (B-4A) or (B-4B) is solved for critical core buckling, by trial and error, or graphically. An expression relating critical core enrichment $\left(\epsilon_{c}\right)$ and critical core buckling is developed below.

The core diffusion equation, for criticality, is

$$
\mathrm{D}_{\mathrm{c}} \nabla^{2} \phi-\Sigma_{\mathrm{a}, \mathrm{c}} \boldsymbol{c}^{\phi}+v \Sigma_{\mathrm{f}, \mathrm{c}} \mathrm{c}^{\phi}=0
$$

or

$$
\nabla^{2} \phi+B_{C}^{2}=0
$$

where

$$
\mathrm{B}_{\mathrm{c}}^{2}=\frac{\bar{v} \Sigma_{\mathrm{f}, \mathrm{c}}-\mathrm{\Sigma}_{\mathrm{a}, \mathrm{c}}}{\mathrm{D}_{\mathrm{c}}}
$$

or

$$
-D_{c} B_{c}^{2}-\Sigma a, c+v \sum_{f, c}=0
$$


But

$$
\begin{aligned}
v \sum_{f, c} & =v_{28} \sum_{f, c, 28}+v_{49} \Sigma_{f, c, 49} \\
& =\eta_{28} \sum_{a, c, 28}+\eta_{49} \Sigma_{a, c, 49}
\end{aligned}
$$

where the subscripts 28 and 49 denote U238 and Pu239 respectively. Substituting $(B-7)$ into $(B-G)$,

$$
\eta_{28} \sum_{a, c, 28}+\eta_{49} \dot{\Sigma}_{a, c, 49}=\Sigma_{a, c}+D_{c} B_{c}^{2}
$$

Letting

$$
\begin{gathered}
\Sigma, c, p . \begin{array}{c}
\text { non-fuel, macroscopic absorption cross section } \\
\text { in the core, }
\end{array} \\
\text {. }
\end{gathered}
$$

the total core macroscopic cross section is given by

$$
\Sigma_{a, c}=\Sigma_{a, c, 28}+\Sigma_{a, c, 49}+\Sigma_{a, c, p}
$$

Substituting (B-9) into (B-8) one obtains

$$
\begin{aligned}
& \left(\eta_{28}-1\right) \sum_{a, c, 28}+\left(\eta_{49}-1\right) \Sigma_{a, c, 49} \\
& =\sum_{a, c, p}+D_{c} B_{c}^{2}
\end{aligned}
$$

The heavy metals uranium and plutonium have approximately the same theoretical number densities in the form of oxides (Table B.3). Thus their macroscopic cross sections may be expressed in terms of enrichment, as follows:

$$
\begin{aligned}
& \Sigma_{a, c, 49}=N_{49}^{*} \epsilon_{c} \theta_{c, o x} \sigma_{a, 49} \\
& \Sigma_{a, c, 28}=N_{28}^{*}\left(1-\epsilon_{c}\right) \theta_{c, 0 x} \sigma_{a, 28}
\end{aligned}
$$

where 


$$
\begin{aligned}
& \mathrm{N}_{49}^{*}, \mathrm{~N}_{28}^{*} \equiv \begin{array}{l}
\text { theoretical number densities of Pu239 and U238 } \\
\text { in the form of oxides, atoms/barn- } \mathrm{cm}
\end{array} \\
& \epsilon_{\mathrm{c}} \equiv \text { critical core enrichment } \\
& \equiv \text { Pu239 number density/(Pu239 number density }+ \\
& \text { U238 number density) }
\end{aligned}
$$

Substituting ( $B-11)$ and $(B-12)$ into $(B-10)$ and solving for critical core enrichment,

$$
\begin{aligned}
& \Sigma_{a, c, p}+D_{c} B_{c}^{2}-\left(\eta_{28}^{-1)} N_{28}^{*} \theta_{c, o x} \sigma_{a, 28}\right. \\
& \epsilon_{c}=\overline{\left({ }_{49}^{\eta}-1\right) N_{49}^{*} \theta_{c, o x}{ }_{a, 49}^{\sigma}-\left(\eta_{28}-1\right) N_{28}^{*} \theta_{c, o x}{ }_{a, 28}^{\sigma}}
\end{aligned}
$$

Assuming the representative values

$$
\begin{aligned}
& \Sigma_{a, c, p}=0.0002 \mathrm{~cm}^{-1} \\
& \theta_{c, o x}=0.3
\end{aligned}
$$

and using the one group data of Table B.3, Equation (B-14) becomes

$$
\epsilon_{c}=0.0651+62.76 B_{c}^{2}
$$

Critical Core Mass (Pu239)

Equation $(B-15)$ is used to determine the critical core enrichment, using the critical core buckling found from Equation (B-4A) or (B-4B). Critical core mass (Pu239), $\mathrm{M}_{C, 49}^{0}$, may be computed from enrichment as follows: 


$$
\mathrm{M}_{\mathrm{c}, 49}^{0}=\epsilon_{\mathrm{c}} \mathrm{M}_{\mathrm{c}, \mathrm{HM}}=\epsilon_{\mathrm{c}} \mathrm{V}_{\mathrm{c}}{ }_{\mathrm{c}, \mathrm{ox}} \dot{\varphi}_{\mathrm{ox}} \mathrm{C}
$$

where

$$
\begin{aligned}
\mathrm{M}_{49}^{0} & \equiv \text { critical core fissile mass }(\mathrm{kg}) \\
\varphi_{\mathrm{ax}} & \equiv \text { oxide density } \simeq 10(\mathrm{~kg}+\mathrm{M} \text { oxide/1iter } \mathrm{HM} \text { oxide) } \\
\mathrm{C} & =0.88(\mathrm{~kg} I \mathrm{M} / \mathrm{kg} \text { IM oxide }) \\
M_{\mathrm{C}, \mathrm{HM}} & =\text { mass of heavy metal }(\mathrm{U}+\mathrm{Pu}) \text { in the core }(\mathrm{kg}) .
\end{aligned}
$$

For an oxide volume fraction of 0.3 ,

$$
\begin{aligned}
& \mathrm{M}_{\mathrm{c}, 49}=2.64 \mathrm{v}_{\mathrm{c}} \epsilon_{\mathrm{c}} \\
& \mathrm{M}_{\mathrm{c}, \mathrm{H}}=2.64 \mathrm{v}_{\mathrm{c}}
\end{aligned}
$$

Breeding Ratios

The Pu239 inventories in discharged core and blanket fuel are to be expressed in terms of internal (core) and external (blanket) breeding ratios, respectively. Intermal breeding ratio $\left(b_{i}\right)$ is defined as

$$
b_{i} \equiv \frac{\text { Pu239 production rate in the core }}{\text { Pu239 consumption rate in the core }}
$$

Thus

where

$$
b_{i}=\frac{N_{c, 28}{ }_{c, 28}^{\sigma}}{N_{c, 49} \sigma_{a, 49}^{\sigma}}=\frac{1-\epsilon_{c}}{\epsilon_{c}} \frac{\sigma_{c, 28}}{\sigma_{a, 49}}
$$

$$
\begin{aligned}
& \sigma_{c, 28} \equiv \text { U238 microscopic capture cross section } \\
& \sigma_{a, 49} \equiv \text { Pu239 microscopic absorption cross section. }
\end{aligned}
$$

Using the cross section data of Table B.3,

$$
\mathrm{b}_{i}=0.1255 \frac{1-\epsilon_{c}}{\epsilon_{c}}
$$


The external breeding ratio $\left(b_{x}\right)$ is defined as follows:

$$
\mathrm{b}_{\mathrm{x}} \equiv \frac{\text { Pu239 production rate in the blanket }}{\text { Pu239 consumption rate in the core }}
$$

Thus,

$$
\begin{aligned}
b_{x}= & \left\{\frac{\text { core neutron leakage rate }}{\text { Pu239 consumption rate in core }}\right\} \\
& \left\{\frac{\text { U238 capture rate in the blanket }}{\text { core neutron leakage rate }}\right\}
\end{aligned}
$$

Assuming no leakage from the outer face of the blanket, and no blanket multiplication,

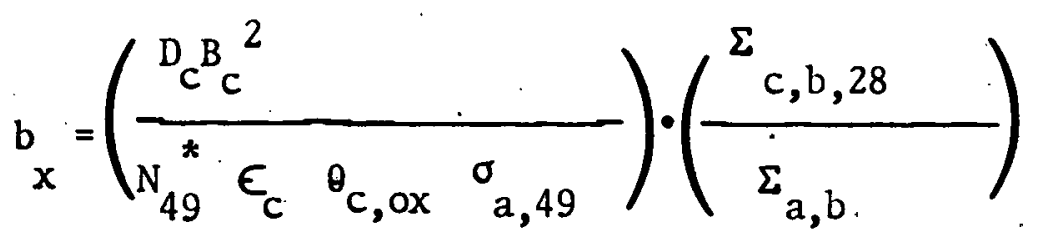

where

$$
\begin{aligned}
& \Sigma_{\mathrm{c}, \mathrm{b}, 28}=\text { U238 macroscopic capture cross section in the blanket } \\
& \Sigma_{\mathrm{a}, \mathrm{b}} \equiv \text { total macroscopic absorption cross section }
\end{aligned}
$$

Using the data of Tabe $B, 3$,

$$
b_{x}=76.19 \cdot \frac{B_{c}^{2}}{\epsilon_{c}}
$$

Discharge Pu239 Inventories

The change in core Pu239 inventory over the fuel lifetime in the core is given by

$$
\Delta M_{c, 49}\left(T_{c}\right) \equiv M_{c, 49}\left(T_{c}\right)-M_{c, 49}^{0}
$$


$=($ Pu239 atom production rate -

Pu239 atom consumption rate core $\mathrm{XT} \mathrm{T}_{\mathrm{c}} \mathrm{G}$

$=\left(\frac{\text { Pu239 atom production rate }}{\text { Pu239 atom consumption rate }}\right.$

$$
\begin{aligned}
& x \frac{\text { Pu239 atom consumption rate }}{\text { total fission rate }} \\
& x \text { total fission rate })_{\text {core }} \times T_{c} G \\
& \text { - ( } \left.\frac{\text { Pu239 atom consumption rate }}{\text { total fission rate }} \times \text { total fission rate }\right)_{\text {core }} \times \mathrm{T}_{c} \mathrm{G} \\
& =b_{i}\left(\frac{1+\alpha_{49}}{1+\delta_{c}}\right) \frac{(1-f) . L Q}{E P F} T_{c} G \\
& -\left(\frac{1+\alpha_{49}}{1+\delta_{C}}\right) \frac{(1-f) L Q}{E P F} \quad T_{c} G \\
& =\left(\frac{1+\alpha_{49}}{1+\delta_{c}}\right) \frac{(1-f) L Q}{E P F} T_{c} G\left(b_{i}-1\right),
\end{aligned}
$$

where

$\Delta M_{c, 49}\left(T_{c}\right) \equiv \begin{gathered}\text { change in core Pu239 inventory over fuel life- } \\ \text { time, kg }\end{gathered}$

$\mathrm{M}_{\mathrm{c}, 49}\left(\mathrm{~T}_{\mathrm{c}}\right) \equiv$ discharge Pu239 inventory, core, $\mathrm{kg}$.

$$
\begin{aligned}
\alpha_{49} & \equiv \sigma_{c, 49} / \sigma_{f, 49} \\
\delta_{c} & \equiv N_{c, 28} \sigma_{f, 28} / N_{c, 49} \sigma_{f, 49} \\
f & \equiv \text { fraction of reactor power produced in the blanket } \\
Q & \equiv \text { rated reactor thermal power, } \mathrm{kw}_{t}
\end{aligned}
$$




$$
\begin{aligned}
T_{C} & \equiv \text { fuel residence time in core, years } \\
\mathrm{L} & \equiv \text { plant load factor } \\
\mathrm{G} & \equiv 39.67 \times 10^{-26} \mathrm{~kg} \text { Pu239/atom Pu239 } \\
\mathrm{EPF} & \equiv \text { energy per fission }=1.016 \times 10^{-21} \mathrm{kw}-\mathrm{yr} / \text { fission }
\end{aligned}
$$

Evaluating the constant, G/EFr, and substituting

$$
\Delta M_{c, 49}\left(T_{c}\right)=\frac{1+\alpha_{49}}{1+\delta_{c}} \quad(1-f) \text { LQ } T_{c}\left(b_{i}-1\right)
$$

$$
\times 3.9045 \times 10^{-4}
$$

Letting

$$
\frac{1+\alpha_{49}}{1+\delta_{c}} \simeq 1.04
$$

and assuming negligible blanket power,

$$
f \simeq 0 \text {, }
$$

equation (B-26) becomes

$$
\Delta \mathrm{H}_{c, 49}\left(\mathrm{~T}_{c}\right)=\operatorname{LQT} \mathrm{T}_{c}\left(\mathrm{~b}_{\mathrm{i}}-1\right) \times 4.06 \times 10^{-4}
$$

A similar development for the blanket yields

$$
\begin{aligned}
& \Delta M_{b, 49}\left(T_{b}\right) \equiv M_{b, 49}\left(T_{b}\right)-M_{b, 49}^{0} \\
& =\left[b_{x}(1-f)\left(\frac{1+\alpha_{49}}{1+\delta_{c}}\right)-f\left(\frac{1+\alpha^{49}}{1+\delta_{b}}\right)\right] T_{b} \text { LQ } \times 3.9045 \times 10^{-4}
\end{aligned}
$$




$$
\begin{aligned}
& \begin{array}{c}
\Delta M_{b, 49}\left(T_{b}\right) \equiv \text { cliange in blanket Pu239 inventory over } \\
\text { fuel lifetime, }
\end{array} \\
& \mathrm{M}^{0}, 49 \quad \equiv \text { load Pu239 inventory in blanket } \mathrm{kg} \\
& \mathrm{I}_{\mathrm{b}, 49}\left(\mathrm{~T}_{\mathrm{b}}\right) \equiv \text { discharge Pu239 inventory, blanket } \mathrm{kg} \\
& \delta_{b} \equiv N_{b, 28} \quad{ }_{f, 28}^{\sigma} / N_{b, 49} \quad{ }_{f, 49} \\
& \mathrm{~T}_{\mathrm{b}} \equiv \text { fuel residence time in blanket }
\end{aligned}
$$

Using Equations (B-27) and $B-28)$, Equation (B-30) reduces to

$$
\Delta \mathrm{i}_{\mathrm{b}, 49}\left(\mathrm{~T}_{\mathrm{b}}\right)=\mathrm{LQT}_{\mathrm{b}} \mathrm{b}_{\mathrm{x}} \times 4.06 \times 10^{-4}
$$

Rated thermal power $(Q)$ is given by

$$
Q=q_{c}^{\prime \prime \prime} V_{c}
$$

where $q_{C}^{\prime \prime \prime}$ is the rated core thermal power density in $\mathrm{kw}_{t} / \mathrm{liter}$. Equations $(B-29)$ and $(B-31)$ become

$$
\Delta M_{c, 49}\left(T_{c}\right)=L_{c}^{\prime \prime \prime} V_{c} T_{c}\left(b_{i}-1\right) \times 4.06 \times 10^{-4}
$$

and

$$
\Delta M_{b, 49}\left(T_{b}\right)=\operatorname{Liq} c_{c} T_{b} b_{x} \times 4.06 \times 10^{-4}
$$

Using the values for $q_{c}^{\prime \prime \prime}, L, T_{c}$ and $T_{b}$ from Table $B .5$, Equations(B-32) and $(B-33)$ become

$$
\begin{aligned}
& \Delta M_{c, 49}=0.325\left(b_{i}-1\right) v_{c} \\
& \Delta M_{b, 49}=0.975 b_{x} v_{c} .
\end{aligned}
$$

The Pu239 inventory changes during irradiation were defined above as

$$
\begin{aligned}
& \Delta M_{c, 49}\left(T_{c}\right)=M_{c, 49}\left(T_{c}\right)-M_{c, 49}^{0} \\
& \Delta M_{b, 49}\left(T_{b}\right)=M_{b, 49}\left(T_{b}\right)-M_{b, 49}^{0}
\end{aligned}
$$


Combining these definitions with $(B-34)$ and $(B-35)$, using Equation (B-17) for $\mathrm{M}_{\mathrm{C}, 49}^{0}$, and assuming that no Pu239 is loaded in the blanket, one obtains

$$
\mathrm{M}_{\mathrm{c}, 49}=2.64 \mathrm{v}_{\mathrm{c}} \in_{\mathrm{c}}+0.325\left(\mathrm{~b}_{\mathrm{i}}-1\right) \mathrm{v}_{\mathrm{c}}
$$

and

$$
M_{b, 49}=0.975 b_{x} V_{c}
$$

\section{B.2.2.2 Economics Equations}

The expressions for levelized unit energy costs (mills/KMHe) associated with regions under batch management are derived in Chapter 2 . The following cost components are identified with each region: material purchase, fabrication, reprocessing, and material credit. Each of these components are further subdivided into direct and carrying charge subcomponents, such that for region " $s$ ", component " $q$ ",

$$
\begin{aligned}
(\cos t)_{s, q}=(\text { direct cost })_{s, q}{ }_{q}\left(T_{s}\right) & \\
(\text { carrying charge })_{s, q} & =(\text { direct } \cos t)_{s, q}\left(F_{q}\left(T_{s}\right)-1\right) . \\
& =(\text { direct } \cos t)_{s, q} f_{q}\left(T_{s}\right) .
\end{aligned}
$$

where $\mathrm{F}_{\mathrm{q}}\left(\mathrm{T}_{\mathrm{s}}\right)$ is a carrying charge factor emerging from the levelizing process and $T_{s}$ is the residence time of region "s" fuel.Expressions for the carrying charge factors are derived in terms of utility company financial parameters in Chapter 2.

For the purposes of this study, the cost components and subcomponents are re-aggregated as follows:

(1) core direct material components (direct material purchase and direct material credit) are combined to form the core "burnup" or "depletion" component, $\bar{e}_{c, B U}$ (mills/KWHe); 
(2) carrying charges associated with the core material components (material purchase and material credit) are combined to form the core "inventory" component, $\bar{e}_{c, \text { inv }}$ (mills/KWHe);

(3) core fabrication and reprocessing components (including their direct and carrying charges) are combined to form the core "processing" component, $\bar{e}_{c, p r o c}(\operatorname{mills} / K W H e)$;

(4) blanket material components (including their direct and carrying charges) are combined to form the blanket material component, $\bar{e}_{b, \text { mat }}(\mathrm{mills} / \mathrm{KWHe}) ;$ and

(5) blanket fabrication and reprocessing components (including their direct and carrying charges) are combined to form the blanket "processing" component, $\bar{e}_{\mathrm{b}}$,proc (mills/KWHe).

Core Fuel Energy Costs

From the cost equations derived in Chapter 2, the core fuel energy costs defined above are given by

$$
\begin{aligned}
& \overline{\mathrm{e}}_{\mathrm{c}, \mathrm{BU}}=\frac{1000}{\mathrm{ET}_{\mathrm{c}}} \mathrm{C}_{49}{ }_{\mathrm{c}, 49}\left(\mathrm{~T}_{\mathrm{c}}\right)=\frac{1000}{\mathrm{ET}_{\mathrm{c}}} \mathrm{C}_{49}\left[\mathrm{M}_{\mathrm{c}, 49}^{0}-\mathrm{M}_{\mathrm{c}, 49}\left(\mathrm{~T}_{\mathrm{c}}\right)\right] \\
& \overline{\mathrm{e}}_{\mathrm{c}, \text { inv }}=\frac{1000}{\mathrm{ET}_{\mathrm{c}}} \mathrm{C}_{49}\left[\mathrm{M}_{\mathrm{c}, 49}^{0} \mathrm{f}_{\mathrm{mp}}\left(\mathrm{T}_{\mathrm{c}}\right)-\mathrm{H}_{\mathrm{c}, 49}\left(\mathrm{~T}_{\mathrm{c}}\right) \mathrm{f}_{\mathrm{mc}}\left(\mathrm{T}_{\mathrm{c}}\right)\right] \\
& \overline{\mathrm{e}}_{\mathrm{c}, \text { proc }}=\frac{1000}{E T_{c}} \mathrm{M}_{\mathrm{c}, \mathbb{M}}\left[\mathrm{C}_{\mathrm{c}, \mathrm{fab}} \mathrm{F}_{\mathrm{fab}}\left(\mathrm{T}_{\mathrm{c}}\right)+\mathrm{C}_{\mathrm{c}, \mathrm{repr}} \mathrm{F}_{\mathrm{repr}}\left(\mathrm{T}_{\mathrm{c}}\right)\right]
\end{aligned}
$$

where

$E \equiv$ electric energy produced per year, kwhe/year

$$
=8760 \eta \mathrm{L} q_{c}^{m} V_{c}
$$

$\eta \equiv$ net thermal efficiency, $k w_{e} / \mathrm{kw}_{\mathrm{t}}$ 
Chapter 2 gives expressions for the carrying charge factors, $F(=1+f)$, in terms of utility company financial parameters:

$$
\begin{aligned}
f_{m p}\left(T_{c}\right) & =F_{1 i p}\left(T_{c}\right)-1 \\
& =\frac{1}{1-\tau}\left[(1+x)^{\left.T_{m p}^{\prime}+1 / 2 T_{c}-\tau\right]-1}\right. \\
f_{m c}\left(T_{c}\right) & =F_{m c}\left(T_{c}\right)-1 \\
& =(1+x)-\left(T_{m c}^{\prime \prime}+1 / 2 T_{c}\right)-1 \\
F_{\text {fab }}\left(T_{c}\right) & =\frac{1}{1-\tau}\left[(1+x)^{T_{f a b}^{\prime}}+1 / 2 T_{c}-\tau\right] \\
F_{\text {repr }}\left(T_{c}\right) & =(1+x)
\end{aligned}
$$

Using the data of Tables B.4 and B.5,

$$
\begin{aligned}
& f_{m p}\left(\mathrm{~T}_{c}=2\right)=0.2445 \\
& f_{m c}\left(T_{c}=2\right)=-0.1089 \\
& F_{f a b}\left(T_{c}=2\right)=1.2445 \\
& F_{\text {repr }}\left(T_{c}=2\right)=0.8911
\end{aligned}
$$

Further, using Equations (B-36) (B-17) and the data of Tables B.4 and B.5, Equations $(B-40),(B-41)$, and $(B-42)$ become

$$
\begin{aligned}
& e_{c, B U}=-1.16\left(b_{i}-1\right) \\
& \bar{e}_{c, i n v}=3.335 \epsilon_{c}+0.1260\left(b_{i}-1\right) \\
& \bar{e}_{c, \text { proc }}=0.3964
\end{aligned}
$$

The total fuel energy cost associated with the core, $\bar{e}_{c}$, is given by 


$$
\begin{aligned}
\overline{\mathrm{e}}_{c} & =\overline{\mathrm{e}}_{c, B U}+\overline{\mathrm{e}}_{c, \text { inv }}+\overline{\mathrm{e}}_{\mathrm{c}, \text { proc }} \\
& =3.335 \epsilon_{c}-1.034\left(\mathrm{~b}_{i}-1\right)+0.3964
\end{aligned}
$$

Blanket Fuel Energy Costs

From the cost equations derived in Chapter 2, the blanket fuel exiergy costs defined above are

$$
\begin{aligned}
& \bar{e}_{b, \text { mat }}=\frac{1000}{\mathrm{ET}_{\mathrm{b}}} \mathrm{C}_{49}\left[\mathrm{M}_{\mathrm{b}, 49}^{0} \mathrm{~F}_{\mathrm{mp}}\left(\mathrm{T}_{\mathrm{b}}\right)-\mathrm{M}_{\mathrm{b}, 49}\left(\mathrm{~T}_{\mathrm{b}}\right) \mathrm{F}_{\mathrm{mc}}\left(\mathrm{T}_{\mathrm{b}}\right)\right] \\
& \overline{\mathrm{e}}_{\mathrm{b}, \mathrm{proc}}=\frac{1000}{\mathrm{ET}_{\mathrm{b}}} \mathrm{M}_{\mathrm{b}, \mathrm{HM}}\left[\mathrm{C}_{\mathrm{b}, \mathrm{fab}} \mathrm{F}_{\mathrm{fab}}\left(\mathrm{T}_{\mathrm{b}}\right)+\mathrm{C}_{\mathrm{b}, \text { repr }} \mathrm{F}_{\text {repr }}\left(\mathrm{T}_{\mathrm{b}}\right)\right]
\end{aligned}
$$

where $E$ is given by Equation (B-43).

From Chapter 2,

$$
\begin{aligned}
& F_{m p}\left(T_{b}\right)=\frac{1}{1-\tau}\left[(1+x)^{\left.T_{m p}^{\prime}+1 / 2 T_{b}-\tau\right]}\right. \\
& F_{m c}\left(T_{b}\right)=(1+x)^{-\left(T_{m c}^{\prime \prime}+1 / 2 T_{b}\right)} \\
& F_{f a b}\left(T_{b}\right)=\frac{1}{1-\tau}\left[(1+x)^{\left.T_{f a b}^{\prime}+1 / 2 T_{b}-\tau\right]}\right. \\
& F_{\text {repr }}\left(T_{b}\right)=(1+x)
\end{aligned}
$$

Using the data of Tables B.4 and B.5,

$$
\begin{array}{ll}
\mathrm{F}_{\mathrm{mp}_{\mathrm{p}}}\left(\mathrm{T}_{\mathrm{b}}=6\right) & =1.6175 \\
\mathrm{~F}_{\mathrm{mc}}\left(\mathrm{T}_{\mathrm{b}}=6\right) & =0.7641 \\
\mathrm{~F}_{\mathrm{f}_{\mathrm{ab}}}\left(\mathrm{T}_{\mathrm{b}}=6\right) & =1.6175 \\
\mathrm{~F}_{\text {repr }}\left(\mathrm{T}_{\mathrm{b}}=6\right) & =0.7641
\end{array}
$$


For the purposes of estimating blanket processing costs, the blanket volume is assumed to be three times the core volume,

$$
\mathrm{V}_{\mathrm{b}}=3 \mathrm{~V}_{\mathrm{c}}
$$

and

$$
M_{b, H M}=3 v_{c} \theta_{b, o x} \varphi_{o x} C
$$

where

$$
\begin{aligned}
\theta_{\mathrm{b}, \mathrm{Ox}} & \equiv \text { oxide volume fraction, blanket } \\
\varphi_{\mathrm{Ox}} & \equiv \text { oxide density } \\
\mathrm{C} & \equiv 0.88(\mathrm{kgHN} / \mathrm{kgHM} \text { oxide })
\end{aligned}
$$

Further it is assumed that no Pui239 is loaded in the blanket,

$$
\mathrm{M}_{\mathrm{b}, 49}^{0}=0
$$

Using Equations (B-54), ( $B-55),(B-43),(B-59)$, the material carrying charges factor above, and data from Tables B.4 and B.5, Equation (B-52) becomes

$$
\overline{\mathrm{e}}_{\mathrm{b}, \text { mat }}=-0.886 \mathrm{~b}_{\mathrm{x}}
$$

Using Equations (B-56), (B-57), (B-43), the processing carrying charge factors above, and data from Tables B.4 and B.5, Equation (B-53) becomes

$$
\overline{\mathrm{e}}_{\mathrm{b}, \text { proc }}=0.2555
$$

The total fuel energy cost associated with the blanket, $\bar{e}_{b}$, is given by

$$
\begin{aligned}
\bar{e}_{b} & =\bar{e}_{b, \text { mat }}+\bar{e}_{b, \text { proc }} \\
& =-0.886 b_{x}+0.2555
\end{aligned}
$$




\section{B.2.2.3 Rated Power and Core Volume}

Core rated thermal power is given by

$$
Q=q_{c}^{\prime \prime \prime} v_{c} \quad k w_{t}
$$

where $q_{c}^{m}$ is the rated core power density in $\mathrm{kw}_{t} /$ liter and $v_{c}$ is the core volume in liters. If the blanket is assumed to produce negligible power (Case $A$ ), then plant rated electrical power, $P_{e}$, in MWe is

$$
P_{e}=\eta Q \times 10^{-3}=\eta q_{c}^{\prime \prime \prime} V_{c} \times 10^{-3} \quad \text { MWe }
$$

where $\eta$ is the net thermal efficiency. For rated core power density of $500 \mathrm{kw}_{\mathrm{t}} /$ liter and a net thermal efficiency of $40 \%$,

$$
\mathrm{P}_{\mathrm{e}}=0.2 \mathrm{~V}_{\mathrm{c}}
$$

If the blanket is assumed to produce $10 \%$ of the total thermal power (Case $A^{*}$ ), then plant rated electrical power, $\mathrm{P}_{\mathrm{e}}^{*}$, is

$$
\mathrm{P}_{\mathrm{e}}^{*}=0.22 \mathrm{~V}_{\mathrm{c}} . \quad \text { MWe }
$$

B 2.3.4 Corrections for the Blanket Pu239 Burmup Assumption: Case A*

In deriving the equations above, it was assumed that there was no burnup of Pu239 in the blanket, i.e. that blanket power contribution was approximately zero, and that all of the bred Pu239: was available at end of blanket fuel life.

The assumption has several effects on fuel energy costs. For the same core power rating, the cost components $\bar{e}_{c, B U}, \bar{e}_{c, i n v}, \bar{e}_{c, p r o c}$, and $\overline{\mathrm{e}}_{\mathrm{b}}$,proc are over estinated, since the total delivered energy $\mathrm{E}$, in the denominators of the cost equations, is underestimated. The assumption effects the blanket material component, $\bar{e}_{b}$, mat, a revenue, in two ways, botin tending toward an overestination of this revenue: the total delivered 
energy $\mathrm{E}$ is underestimated (denominator) and the discharge Pu239 inventory $\mathrm{M}_{\mathrm{b}, 49}$ (numerator) is overestimated.

Corrections for the assumption are developed in this section. Numerical comparisons of Cases $\mathrm{A}$ ard $\mathrm{A}^{*}$ are given in Section B.4. Correction Factors for Blanket Discharge Pu239 Inventory

The assumption in question causes the blanket Pu239 discharge inventory to be overestimated. To compensate for this, a correction factor (C F ) is defined

$$
C F \equiv M_{b, 49}^{*}\left(T_{b}\right) / M_{b, 49}\left(T_{b}\right)
$$

where

$$
\begin{gathered}
M_{b, 49}\left(T_{b}\right) \equiv \begin{array}{c}
b 1 \text { anket Pu239 discharge inventory assuming } \\
\text { no Pu239 burnup (Case } A) .
\end{array} \\
M_{b, 49}\left(T_{b}\right) \equiv \begin{array}{c}
\text { blanket Pu239 discharge inventory, allowing } \\
\text { for Pu239 burnup (Case } A^{*} \text { ) }
\end{array}
\end{gathered}
$$

The correction factor $\mathrm{CF}$ is estimated by two methods below.

Method (1)

The "true" discharge inventory, $\mathrm{M}_{\mathrm{b}, 49}^{*}\left(\mathrm{~T}_{\mathrm{b}}\right)$, is given by Equation (B-30) while the assumed discharge inventory $\mathrm{M}_{\mathrm{b}, 49}\left(\mathrm{~T}_{\mathrm{b}}\right)$ is found by setting blanket power fraction ( $f$ ) equai to zero in Equation (B-30). Using Equation $(B-30)$ and Equation (B-66),

$$
C F=1-f-\left(f / b_{x}\right)\left[\left(1+\delta_{c}\right) /\left(1+\delta_{b}\right)\right] .
$$

The parameters $\delta_{c}$ and $\delta_{b}$ are given by

$$
\delta_{c}=\frac{N_{c, 28}}{N_{c, 49}} \frac{\sigma_{f, 28}}{\sigma_{f, 49}}=\frac{1-\epsilon_{c}}{\epsilon_{c}} \frac{\sigma_{f, 28}}{\sigma_{f, 49}}
$$

and

$$
\delta_{b}=\frac{N_{b, 28}}{N_{b, 49}} \frac{{ }_{f, g}^{\sigma, 28}}{\sigma_{f, 49}}=\frac{1-\epsilon_{b}}{\epsilon_{b}} \frac{{ }_{f, 28}}{\sigma_{f, 49}}
$$


where $\epsilon_{b}$ is some representative Pu239 fraction in the blanket, i.e. at nidpoint of an equilibrium cycle. Letting

$$
\begin{aligned}
& \epsilon_{c} \simeq 0.15 \\
& \epsilon_{b} \simeq 0.02
\end{aligned}
$$

and using the cross section data of Table $\mathrm{B} .3$, one finds

$$
\frac{1+\delta_{c}}{1+\delta_{b}}=0.5
$$

Assuming an external breeding ratio $\left(b_{x}\right)$ of $\sim 0.5$ and a blanket power fraction ( $f$ ) of $\sim 10 \%$,

$$
\mathrm{CF} \simeq 0.8
$$

Method (2)

The U238, Pu239 population equations, in terms of flux time $(\theta)$, are

$$
\begin{aligned}
& \frac{\mathrm{dN}_{\mathrm{b}, 28}}{\mathrm{~d} \theta}+\sigma_{\mathrm{c}, 28} \mathrm{~N}_{\mathrm{b}, 28}=0 \\
& \frac{\mathrm{dN}_{\mathrm{b}, 49}}{\mathrm{~d} \theta}+\sigma_{\mathrm{a}, 49} \mathrm{~N}_{\mathrm{b}, 49}=\sigma_{\mathrm{c}, 28} \mathrm{~N}_{\mathrm{b}, 28}
\end{aligned}
$$

Assuming $\mathrm{N}_{\mathrm{b}, 49}^{0}=0$, and that $\sigma_{\mathrm{a}, 49} \mathrm{~N}_{\mathrm{b}, 49} \neq 0$, the solution for $\mathrm{N}_{\mathrm{b}, 49}$ is

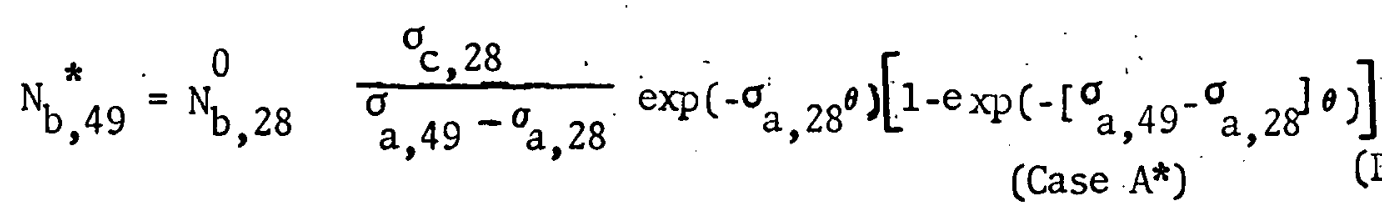

The solution, assuming that $\mathrm{N}_{\mathrm{b}, 49}^{0}=0$ and that $\sigma_{\mathrm{a}, 49} \mathrm{~N}_{\mathrm{b}, 49}=0$, is 


$$
\mathrm{N}_{\mathrm{b}, 49}=\mathrm{N}_{\mathrm{b}, 28}^{0} \frac{\sigma_{c, 28}}{\sigma_{\mathrm{a}, 28}}\left[1-\exp \left(-\sigma_{\mathrm{a}, 28} \theta\right)\right]
$$

(Case A)

Thus,

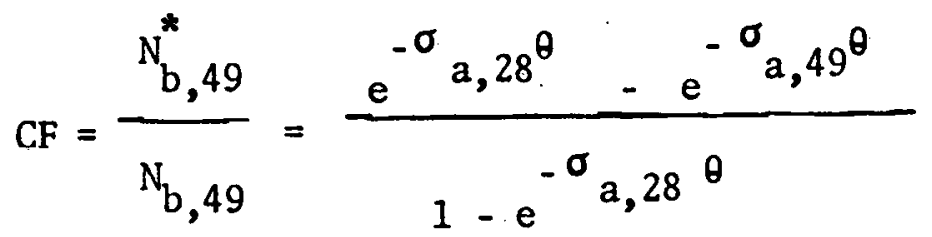

For a blanket flux of $10^{15} \mathrm{n} / \mathrm{cm}^{2}{ }^{2} \mathrm{sec}$ and irradiation time of six years,

$$
\theta \simeq 1.9 \times 10^{23} \mathrm{n} / \mathrm{cm}^{2}
$$

Using the cross section data of Table B.3,

$$
\mathrm{CF} \simeq 0.76
$$

which is in rough agreement with the CF computed by the first method.

Corrections to the Economic Equations

A blanket power fraction of $10 \%$ and blanket discharge Pu239 correction factor (CF) of 0.80 are assumed (Method 1).

Quantities with a superscript asterisk (*) denote Case $A^{*}$ (with blanket burnup) values; those without asterisks denote Case A (without blanket Pu239 burnup).

With $f=10 \%$,

$$
E^{*}=E / 0.9
$$

and

$$
\begin{aligned}
& \overrightarrow{\mathrm{e}}_{\mathrm{c}, \mathrm{BU}}^{*}=0.9 \overline{\mathrm{e}}_{\mathrm{c}, \mathrm{BU}} \\
& \overline{\mathrm{e}}_{\mathrm{c}, \mathrm{in} \mathrm{N}}^{*}=0.9 \overline{\mathrm{e}}_{\mathrm{c}, \mathrm{inv}}
\end{aligned}
$$




$$
\begin{aligned}
& \overline{\mathrm{e}}_{\mathrm{c}, \text { proc }}^{*}=0.9 \overline{\mathrm{e}}_{\mathrm{c}, \text { proc }} \\
& \bar{e} \text { * } \\
& \mathrm{b}, \text { proc }=0.9 \overline{\mathrm{e}}_{\mathrm{b}, \text { proc }}
\end{aligned}
$$

The blanket material component is corrected both for $E$ and $M_{b, 49}$

$$
\bar{e}_{b, \text { mat }}^{*}=(0.9)(0.8) \bar{e}_{b, \text { mat }}=0.72 \bar{e}_{b, \text { mat }}
$$

\section{B.3 SAMPLE CALCULATION}

Table B. 6 presents sample calculations for Cases $A, A^{*}$ and $B$, for a core of 4000 liters.

\section{B. 4 RESULTS}

\section{Neutronics}

Principal neutronics results are given in Figures B.1 and B.2. Core critical enrichnents for Cases $A, A^{*}$ (breeding blanket) and Case B (sodium reflector) are plotted versus core volune in Figure B.1. Breeding ratios are shown as a function of core volune in Figure B.2.' Enrichments and breeding ratios are independent of the blanket burnup assumption, with core volume as the independent variable. Another scale is shown to relate core volume to plant power rating.

As expected, critical enrichment and external breeding ratio decirease with core size, while internal breeding ratio increases. Case $B$ (sodium reflector) enjoys slightly lower critical enrichment than Cases $A, A^{*}$ (breeding blanket). The lower critical enrichment of Case B improves its internal breeding ratio, but not enough to offset the sacrifice of external breeding. 
$\underline{\text { CASE }}^{(1)}$

Core Volume, $\mathrm{V}_{\mathrm{c}}$ (1iters)

Reactor Power Rating, Pe(MWe)

Critical Buckling, $\mathrm{B}_{\mathrm{c}}^{2}\left(\mathrm{~cm}^{-2}\right)$

Critical Mass, $\mathrm{m}_{\mathrm{c}, 49}^{0}(\mathrm{~kg})$

Internal Breeding Ratio, $b_{i}$

External Breeding Ratio, $b_{x}$

Total Breeding Ratio, b

Discharge P1123.9

$\operatorname{Core}\left(\mathrm{T}_{\mathrm{c}}=2 y \mathrm{r}\right), \mathrm{H}_{\mathrm{c}, 49}(\mathrm{~kg})$

1181

Blanket $\left(\mathrm{T}_{\mathrm{b}}=6 \mathrm{yr}\right), \mathrm{M} \mathrm{b}, 49(\mathrm{~kg})$

800

1155

1940
Critical Enrichment, $\epsilon_{c}$

$\underline{A}$

4000

0.0007156

0.1096

1.0198

0.4976

1.5174

Fuel Energy Costs (mills/Kivie):

Core Burnup, $\bar{e}_{\mathrm{c}, \mathrm{BU}}$

Core Inventory, $\overline{\mathrm{e}}_{\mathrm{c}, \mathrm{inv}}$

Core Processing, $\overline{\mathrm{e}}_{\mathrm{c} \text {, proc }}$

Core Total, $\bar{e}_{\mathrm{C}}$

Blanket Material, $\overline{\mathrm{e}}_{\mathrm{b}}$, nat

Blanket Processing, $\bar{e}_{b}$,proc

Blanket Total, $\bar{e}_{\mathrm{b}}$

Reactor Total, $\overline{\mathrm{e}}$
$-0.0229$

0.3675

0.3964

0.7410

$-0.441$

0.2555

$-0.1855$

0.5555
$\frac{A^{*}}{4000}$

890

0.0007156

0.1096

1155

1.0198

0.4976

1.5174

1.1367

1181

1228

1550

$$
-0.0203
$$

$-0.1585$

0.3300

0.3490

0.357

0.3964

0.666

0.5869

$-0.318$

0.230

$-0.088$

0.4805

0.5869

(T) Case A: Spherical core with breeding blanket (No Pu239 burnup in blanket) Case $A^{*}$ : Spherical core with breeding blanket (with Pu239 burnup in blanket) Case B: Spherical core with sodium reflector 
FIG. B.I CRITICAL CORE ENRIQIENT AS A
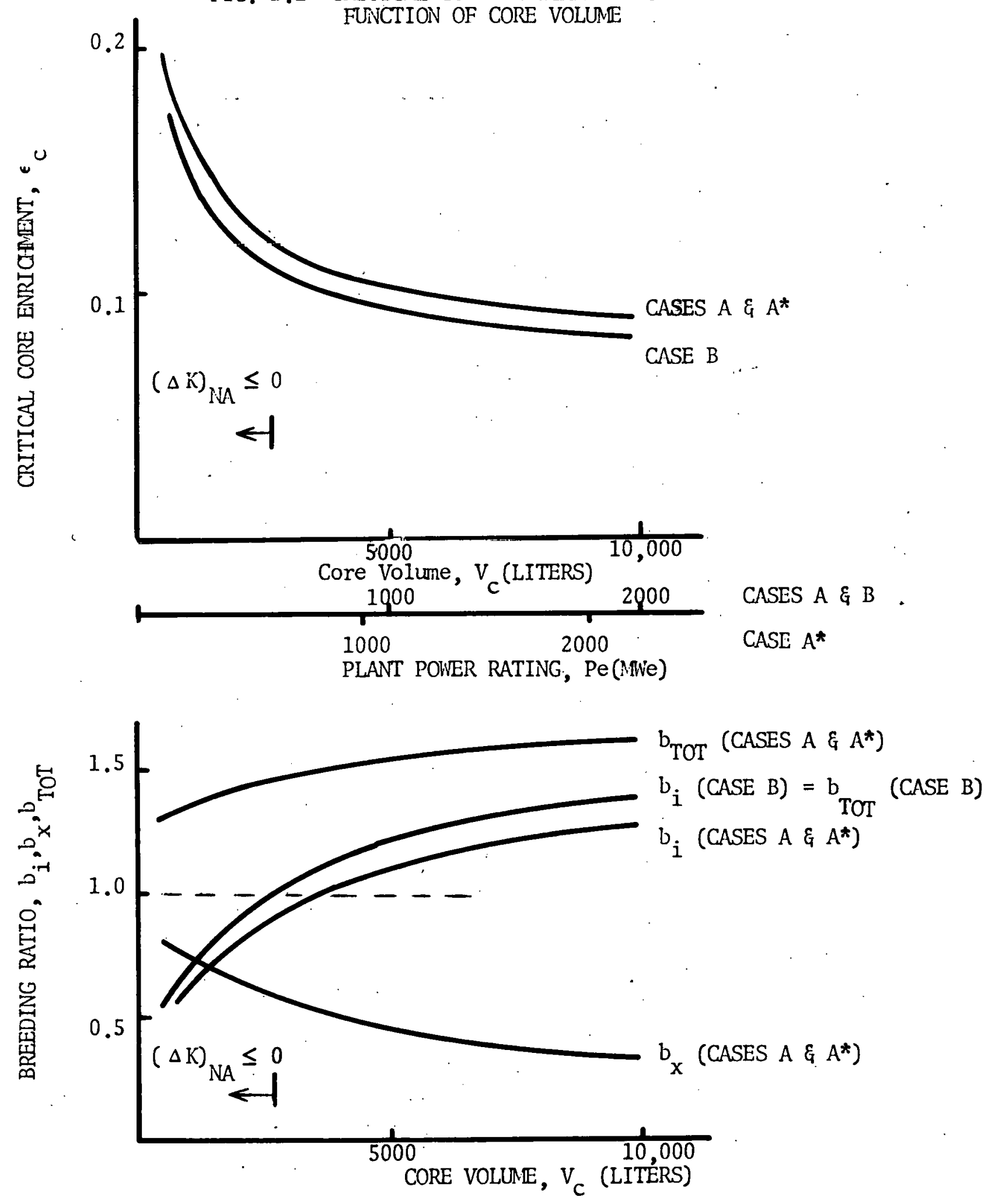

FIG. B.2 BREEDING RATIOS AS FUNCTION OF CORE VOLME 
Case A versus Case $A^{*}$ :

Effect of Blanket Pu239 Burnup Assumption

The "no blanket power" (rio blanket burnup) assumption affects energy costs (mills/KWHe) in several ways. For the same core power rating,

(a) the core fuel cost components (burnup, inventory and processing) are overestinated since the total energy delivered, in the denominators of the cost equations, is underestimated;

(b) the blanket processing component is similarly overestimated;

(c) the blanket material component, a revenue, is overestimated because the discharge Pu239 inventory is overestimated and the total energy delivered is underestimated.

Figures B. 3 and B.4 show the effects (on energy costs) of the "no blanket power" assumption. In Figure B.3, the assumption is seen to lead to an overprediction, $\overline{\mathrm{e}}>\overline{\mathrm{e}}_{\mathrm{TO}}^{*}$, of order $0.05 \mathrm{mills} / \mathrm{KWH}$. This is not insignificant compared to the effects of the radial design and management changes demonstrated in Chapter 5. Figure B.4 compares the blanket costs (net revenues), with and without the "no blanket power" assumption. The assumption is seen to favor blanket revenue significantly, $\bar{e}_{b}<\bar{e}_{b}^{*}$. This bias is, however, offset by the overestimation of core fuel costs.

Cases $A, A^{*}$ versus Case $B$ :

\section{A Breeding Blanket versus A Sodium Reflector}

Figure B. 5 shows the total reactor fuel energy costs as functions of plant power rating, for cases $A, A^{*}$ and $B$. The breeding blanket is seen to be advantageous to about $1350 \mathrm{MWe}$ (Case A), or to about $1600 \mathrm{MWe}$ (Case $\left.A^{*}\right)$. The indifference points are not sharp and definitive, owing to the similarity of the slopes of the curves; a slight change in the economic environment could have a large effect on the indifference point. Beyond 


\section{FIG. B.3 EFFECT OF BLANKET BURNUP (POWER FRACTION) ASSUMPTION ON REACTOR FUEL ENERGY COSTS}

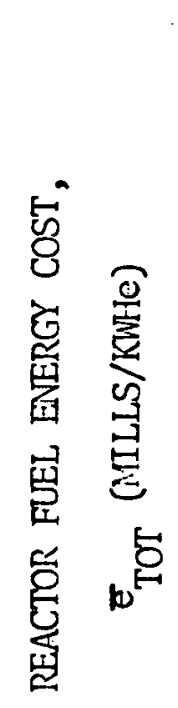

CASE A: No burnup of Pu239 in blanket (No blanket powcr)

CASE $A^{*}$ : Blanket Power Fraction $=0.10$

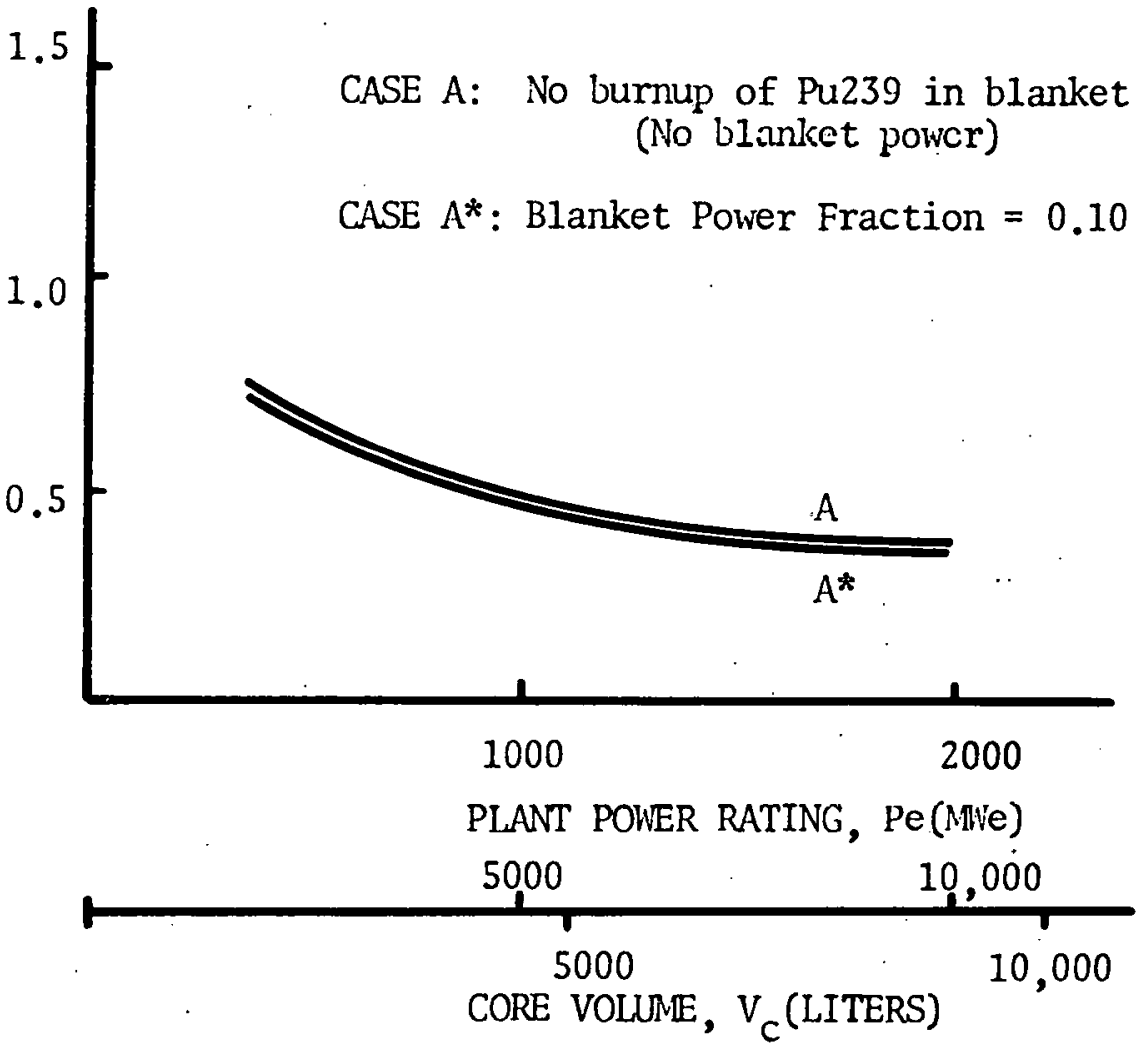

CASE A CASE $A^{*}$

PLANT POWER RATING, Pe(MNe)

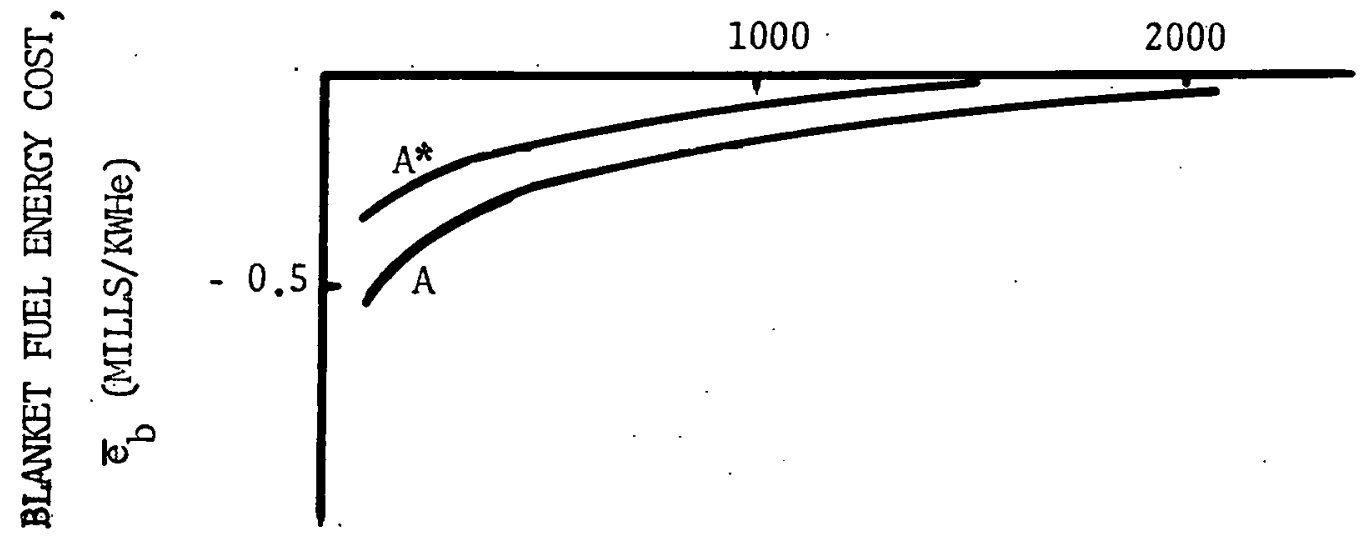

FIG. B.4 EFFECT OF BLANKET BURNUP (POWER FRACTION) ASSUMPTION ON BLANKET FUEL ENERGY COSTS 


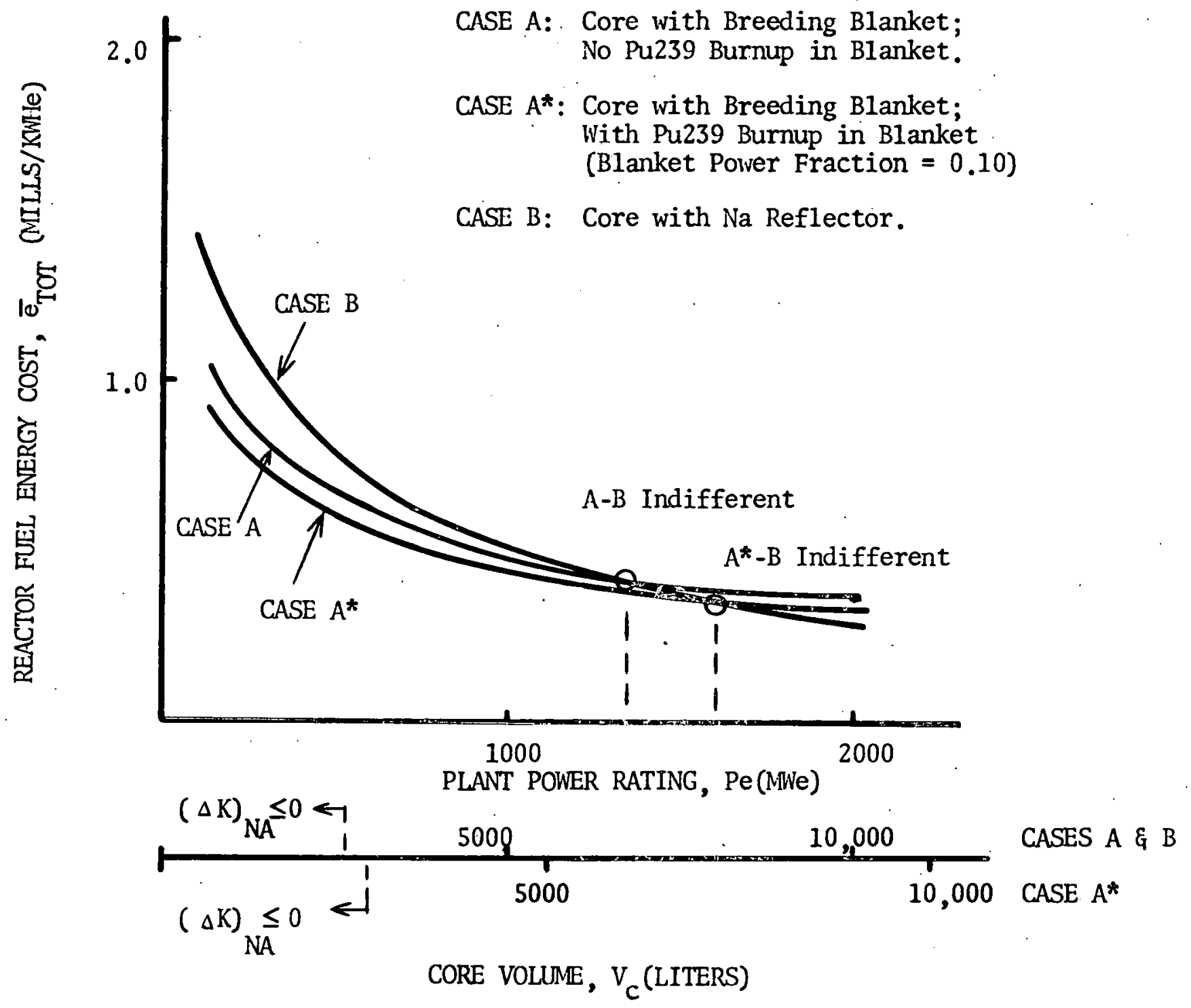

FIG. B.5 REACTOR FUEL ENERGY COSTS WITH AND WITHOUT A BREEDING BLANKET 
tine indifference points, the advantage of the reflector-only configuration is very sligint.

The fuel-econonic advantages and disadvantages of substituting a nonbreeding reflector for a breeding blasket, in large LFBRs, are summarized qualitatively in Table B.7, and are shown quantitatively, component-by-conponent, in Figures B.6 and B.7.

Figure B.6 shows the total core fuel energy costs for Cases A and B. The difference $\Delta \bar{e}_{c}$ is the savings in core fuel energy cost occasioned by the substitution of a sodium reflector for the breeding blanket. The savings is seen to increase with core size. Figure B.7 disaggregates the core fuel savings, $\Delta \overline{\mathrm{e}}_{\mathrm{c}}$, into its components $\Delta \overline{\mathrm{e}}_{\mathrm{c}}$,inv and $\Delta \overline{\mathrm{e}}_{\mathrm{c}, \mathrm{BU}} \cdot$ The improvement is seen to result largely from the burnup component savings, $\Delta \bar{e}_{c, B U}$ (ligher internal breeding ratio), the inventory savings $\Delta \bar{e}_{C, \text { Inv. }}$ being practically negligible.

Offsetting the core savings $\Delta \overline{\mathrm{e}}_{\mathrm{c}}$ is the loss of net blanket revenue, $\Delta \overline{\mathrm{e}}_{\mathrm{b}}$, as shown in Figure B.7.

Core Size and the Sodiun Void Coefficient

Terasawa et.al. (55) have perforned parametric studies similar to the study described above. As in the present study, spherical geometry was adopted. The Terasawa study was confined to LMFBR neutronics and involved sodium void and Doppler coefficients, in addition to the variables of the present study, e.g. core volume, critical enriciment, breeding ratios, etc.

of particular interest are their results concerning enriciment (core size), sodium void coefficient, and internal breeding ratio. The studies reveal that for a sodium volume fraction above about $10 \%$ (structure $\simeq 15 \%$, fuel $\leq 75 \%$ ), it is inqossible to have both (a) an intemal breeding ratio above unity and (b) a negative sodiun void coefficient ( $50 \%$ sodium $105 s$ ). For a fuel volumile fraction of $30 \%$ (assumed in present studies), 
TABLE B.7 - NDVANTAGES AID DISADVANTAGES OF SUBSTITUTING A SODIUM REFLECTOR FOR A BREEDING BLANRET:

Advantages

Disadvantages

\section{CORE}

1. Lower core inventory cost due to lower critical enriciment;

$$
\Delta \overline{\mathrm{e}}_{\mathrm{C}} \text {, inv }
$$

2. liigher internal breeding perfomlance (1ower burnup cost) due to lower critical enricisment; $\Delta \overline{\mathrm{e}}_{\mathrm{C}, \mathrm{Bu}}$

3. ivo processing costs $\longleftrightarrow \Delta \bar{e}_{\mathrm{b}} \longrightarrow 4$. No external breeding 
FIG. B. 6 CORE FUEL ENERGY COSTS FOR REACTORS

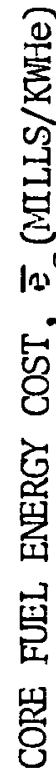
WITH AND WITHOUT BREEDING BLANKETS

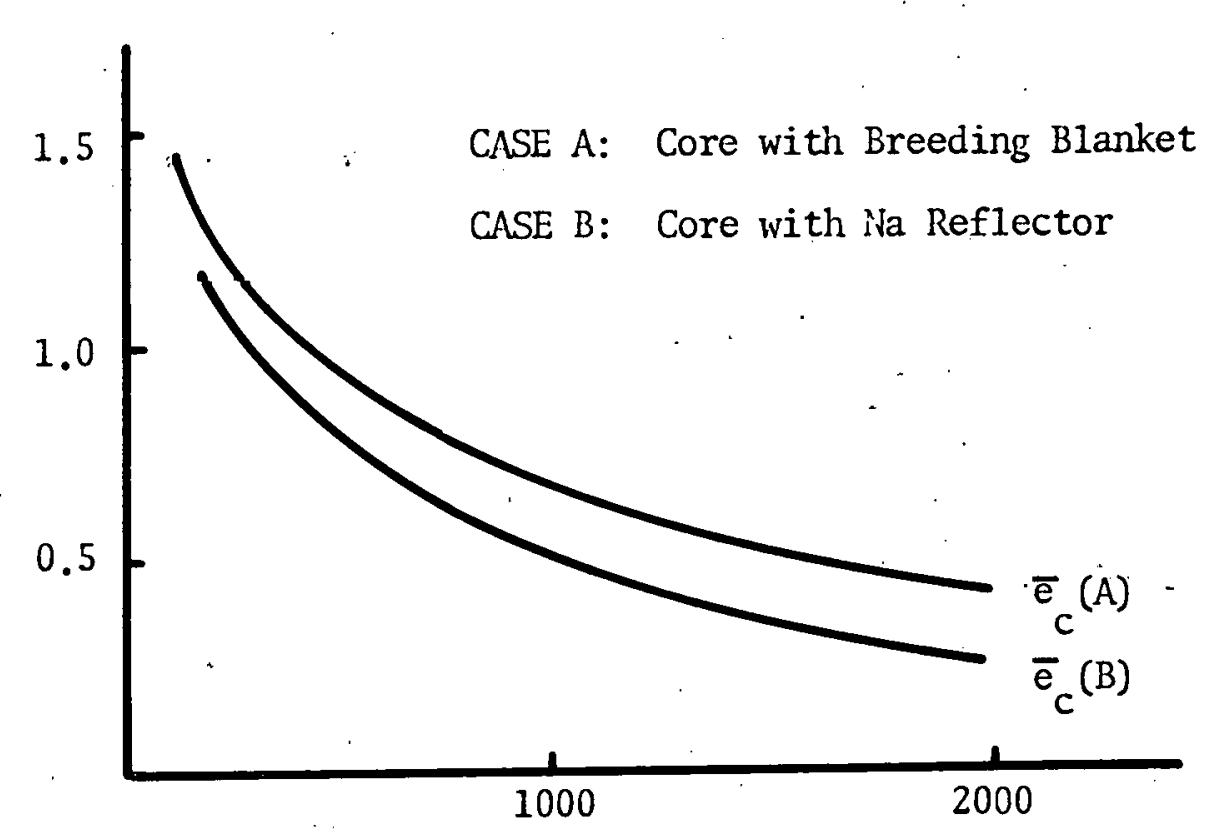

PLANT POWER RATING, Pe (MWe)

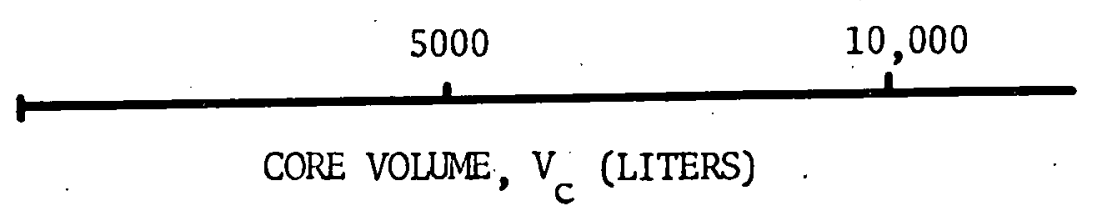

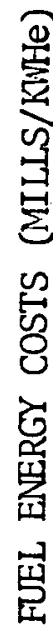

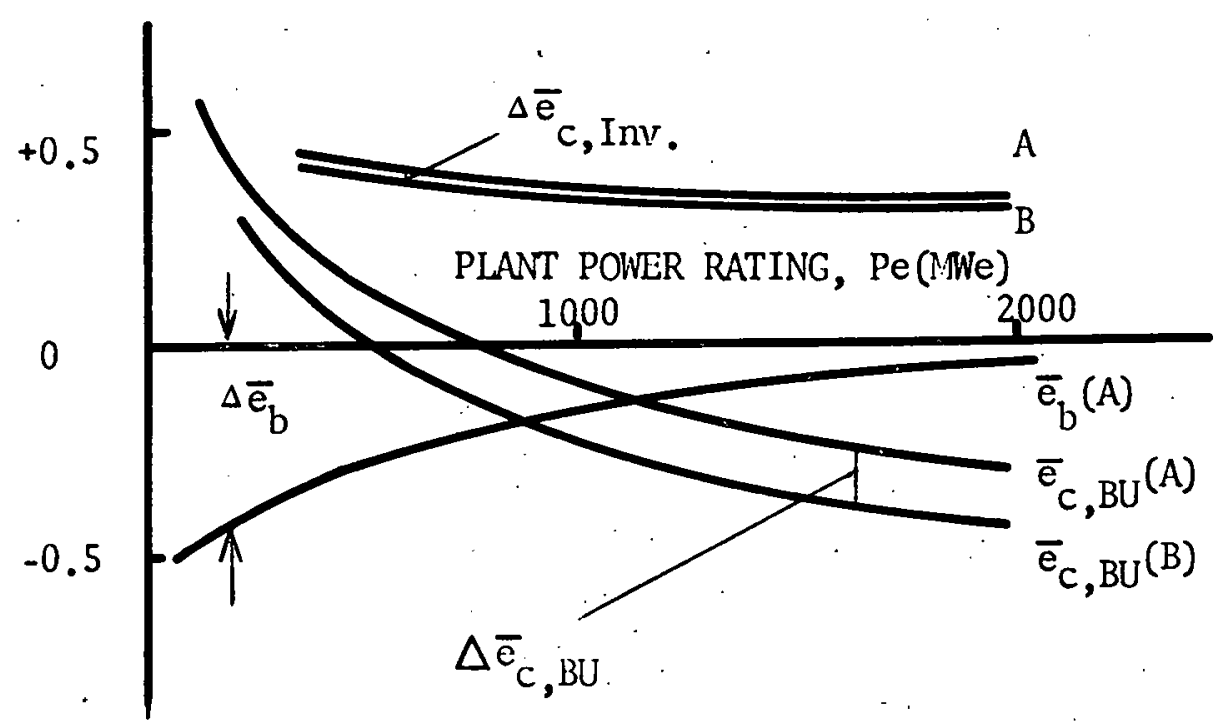

FIG. B.7 FUEL ENERGY COST COMPONENTS FOR REACTORS WITH AND WITHOUT BREEDING BLANKETS 


$$
\begin{aligned}
& \text { (a) } b_{i} \geq 1 \text { for } \epsilon_{c} \leq 0.107 \\
& \text { (b) }(\Delta k)_{\mathrm{Na}} \leq 0 \text { for } \epsilon_{\mathrm{c}} \geq 0.12
\end{aligned}
$$

where Terawawa's atoin ratio, $\mathrm{I}_{\mathrm{C}}^{1}$ (= Pü239/U238), has been converted to enrichment $\epsilon_{c}\left(=\right.$ Pu239/Pu239+U238). The threshold (a) for $b_{i}=1$ is confirmed by the present study, Figures B.1 and B.2.

From Figure B.1, the enrichment (b) of $12 \%$ occurs at a core volume of 2700 liters, or reactor poiver rating of $540 \mathrm{MWe}$ (case A) or $600 \mathrm{l}$ We (Case $\left.A^{*}\right)$. Thus, from Figure B.5, the breeding blanket cases are preferable to the sodiun reflector case, for conservatively permissible values of sodium void coefficient $(\leq 0)$. For core volumes greater than 2700 liters, core geometry may be altered to increase leakage, to maintain a negative sodium void coefficient. This would favor external breeding.

\section{Discussion}

Several major assumptions were adopted in this study - not only to simplify the analysis, but also to provide a net bias against the blanket concept:

(1) Minimum leakage geometry (spherical) was assumed throughout the range of core volumes considered. In actual design, the core geometry may have to be "spoiled" to enhance the negative component of the sodium void coefficient in large FiRs .

(2) It was assumed that blanket volume was three times core volume. Thus while the leakage decreases as core size increases, the blanket continues to be charged with constant processing charge per unit energy delivered. In actual design practice, the blanket size would be optimized, and one would expect the blanket-to-core volume ratio to decrease with core size. 
(3) In Case A, blanket power (blanket Pu239 burnup) was neglected. This assumption was seen to disfavor the blanket concept.

(4) Blanket cross sections were assumed to be the same as for the core. In reality, blanket spectra will be softer, favoring external breeding.

(5) A one zone core was assumed. An optimal material loading pattern would call for some multi-zone enrichment scheme, with outer core zones having higher load enriclunents, $(\underline{52}, \underline{53})$, tending to increase blanket flux.

(6) The study did not account for increasedcontrol costs and control absurption neutronic penalties associated with increasing internal breeding ratio substantially above unity.

In spite of these penalties, the blanket concept is seen to be economically desireable (over the no-blanket configuration) to an "indifference point" somewhat over 1000 Me. Beyond this "indifference point", thie advantage of the sodiun reflector (no blanket) configuration is very slight. 


\section{APPENDIX C}

\section{SPP1A, A DEPLETION-ECOHONICS. PROGRAM FOR FAST BREEDER REACTORS}

\section{C.1 DESCRIPTION OF PROGRAM}

The program SPP1A performs depletion-economics calculations for fast breeder reactors under fixed-element fuel rianagement schemes, i.e. batch or scatter management. Input includes fuel cycle cost information and the neutronics data (local fluxes and spectrum-weighted cross sections) from a single physics compution. The program uses the "Semi-Analytic pepletion. Method (SAP)" described in Chapter 3 to obtain local nuclide concentrations as functions of irradiation time. The cash flow equations developed in Chapter 2 are used to compute local and aggregate fuel costs in mills/Khle, $\$ / \mathrm{yr} / \mathrm{kgl} \mathrm{M}$, and $\$ / \mathrm{kgLM}$ as functions of irradiation tine. Chapter 4 gives a step-by-step procedure for using the FBR fuel depletion-economics model embodied in SPP1^.

Local fluxes and cross sections nay be taken from a multigroup physics program run for the reactor configuration assumed. Using these local ' 's and $\sigma$ 's, SPPIA solves for tine-dependent concentrations in Equations (3-9). The cost equations $(2-30),(2-33)$, and $(2-34)$ are then used to obtain local (by depletion zone), annular-regional, and major regional (i.e. core, axial blarkket, radial blanket) fuel costs as functions of irradiation tin:e. 


\section{2 INPUT INSTRUCTIONS}

Table C.1 describes the input data for SPP1A. Control constants and economic data for a single computer run are given on cards 1 through 9. Neutronic data for each depletion zone are provided by cards 10 througin 14, each zone having an individual set 10-14. 


\section{TABLE C.1}

SPP1A INPUT

$\begin{array}{lccc}\text { Variable } & \text { Colums } & \text { Fornat } & \text { Description } \\ \frac{\text { CARD 1 }}{I D(11)} & 1-66 & \text { 11AG } & \text { Identification card. }\end{array}$

CARD 2

NCASE

$1-6$

I6

The number of depletion zones.

INR

$7-12$

I6

The number of contiguous depletion zones per region,e.g. annular region. Although each zone is depleted individually, discharge compositions and economics are computed by regions which may consist of more than one zone.

INPINT

$13-18$

I6

If iNPRINT $=0$, print out of zone depletion and economics results is omitted. only region results are printed. If INPRIVT $=1$, both zone and region results are printed.

CARD 3

iNTS

$1-6$

I6

The number of tine steps. Depletion and economics results are printed out after eacin time step.

CARD 4

DT

F12.8

Duration of a time step, full power days.

CARD 5

EFF

$1-12$

F12.8

Net thermal efficiency.

CARD 6

F\$KGIN

$1-10$

F10.2

Unit fabrication cost, $\$ / K G \mathbb{M}$

$\mathrm{R}$ KGH

$11-20$

F10.2

Unit reprocessing cost, $\$ / K G$ M

S\$KG49

$21-30$.

F10.2

Price of Pu239, $\$ / K C$ Pu239 


\begin{tabular}{|c|c|c|c|}
\hline Variable & Colurins & Format & Description \\
\hline \multicolumn{4}{|c|}{ CARD 6 (continued) } \\
\hline S\$KG28 & $31-40$ & $\mathrm{~F} 10.2$ & Price of U238, \$/KG U238 \\
\hline$S \$ K G 40$ & $41-50$ & F10.2 & Price of Pu240, $\$ / K G$ Pu240 \\
\hline S\$KG4I & $51-60$ & F10.2 & Price of Pu241, \$/KG Pu241 \\
\hline S\$KG42 & $61-70$ & F10.2 & Price of Pu242, $\$ /$ KG Pu242 \\
\hline \multicolumn{4}{|l|}{ CARD 7} \\
\hline TAX & $1-12$ & $\mathrm{~F} 12.8$ & Income tax rate \\
\hline BDRTE & $13-24$ & $\mathrm{~F} 12.3$ & Bondholders' rate of return \\
\hline BDFRN & $25-36$ & F12.8 & Bond Fraction \\
\hline SIRTE & $37-48$ & F12.8 & Stockholders' rate of return \\
\hline SKFRN & $49-60$ & F12.8 & Stock fraction \\
\hline \multicolumn{4}{|l|}{ CARD 8} \\
\hline SLF & $1-12$ & F12.8 & Plant load factor \\
\hline CAPMNE & $13-24$ & F12.8 & Plant rated capacity, Mie \\
\hline \multicolumn{4}{|l|}{ CARD 9} \\
\hline TFPRE & $1-12$ & F12.8 & $\begin{array}{l}\text { Time prior to beginning of irradiation } \\
\text { that fabrication cash flow occurs, years. }\end{array}$ \\
\hline TMPPRE & $13-24$ & $\mathrm{~F} 12.8$ & $\begin{array}{l}\text { Time prior to beginning of irradiation } \\
\text { that material purchase cash flow occurs, } \\
\text { years. }\end{array}$ \\
\hline TRPAPST & $25-36$ & $\mathrm{~F} 12.8$ & $\begin{array}{l}\text { Tine after end of irradiation that } \\
\text { reprocessing cash flow occurs, years. }\end{array}$ \\
\hline T:CPST & $37-48$ & $\mathrm{~F} 12.8$ & $\begin{array}{l}\text { Time after end of irradiation that } \\
\text { material credit occurs, years. }\end{array}$ \\
\hline Note: & $\begin{array}{l}\text { There are } \\
\text { correspor } \\
\text { neutronic }\end{array}$ & $\begin{array}{l}\text { CASE se } \\
\text { ng to a } \\
\text { ata is }\end{array}$ & $\begin{array}{l}\text { f Cards } 10-14 \text {, each set } \\
\text { gle depletion zone. Zone } \\
\text { ided on Cards } 10-14 \text {. }\end{array}$ \\
\hline
\end{tabular}

CARD 10

SIGA28 $\quad 1-12 \quad$ F12.8 U238 microscopic absorption cross section, barns. 
Variable Colums Format Description

CNRD 10 (continued)

SIGF28 13-2

SIGA49 $\quad 25-36 \quad$ F12.8

SIGF49 $\quad 37-48 \quad$ FI2.8

F12.8

U238 microscopic fission cross section, barns.

SIGA4
SIGF4
CARD 11

SIGA40

$1-12$

F12.8

Pu240 microscopic absorption cross section, barns

SIGF40

$13-24$

F12.8

Pu240 microscopic fission cross section, barns

$\begin{array}{lll}\text { SIGA41 } & 25-36 & \text { F12.8 }\end{array}$

Pu241 microscopic absorption cross section, barns

SIGF41 37-48 F12.

Pu241 microscopic fission cross section, barns

SIGA42 $\quad 49-60 \quad$ F12.

Pu242 microscupic absorption cross section, barns

SIGF42

61-72 F12.8

Pu242 microscopic fission cross section, barns

CARD 12

FLUX

$1-12$

F12.8

Neutron flux, $10^{15} \mathrm{n} / \mathrm{cm}^{2}-\mathrm{sec}$

CARD 13

U28NO

$1-12$

F12.8

Initial U238 atom density, atoms/barn-cm

P49No

13-24

F12.8

Initial Pu239 atom density, atoms/barn-cm

P4ONO

$25-36$

F12.8

Initial Pu240 atom density, atoms/barn-cm

P411:0

$37-48 \quad F 12.8$

Initial Pu241 atom density, atoms/barn-cm

P42NO

$49-60$

F12.8

Initial Pu242 atom density, atoms/barn-cm

CARD 14

VOL

F12.8

Zone volume, liters 


\section{C.3 SAMPII PROBLE!}

This section describes an SPP1A coinjuter run for the reference LWER radial blanket (Figure 4.2 ).

Tile radial blanket is divided into fifteen depletion zones. Thiese depletion zones were combined to form five annular regions, three depletion zones per aurular region. Figure C.I shows the input data card deck. The reference economic enviromment, Table 4.2, is assuned. Depletion. zone neutronic data is taken from a 26 energy group multigroup computation using the prograji 2DE. Figure C.2 is SPP1A printed output giving composition and economics results for the innermost annular region $(V$ ) at an irradiation time of 3 years. The same computer run yields similar printed output for each of the INTS irradiation intervals, for each of the amnular regions. Depletion-economics of each depletion zone can be obtained as well, by setting the control constant NPRINT equal to or greater than unity. Table C.2 interprets the variable names and table headings appearing in printed output. 
.....FIG. C.1 SPP1A SA:PLE PROBLEPI INPUT DECK

SPPIA SAMPLE PROBLEM:

REFERENCE RAD ELANKET. (SPPIAHL.C3)

$\therefore$

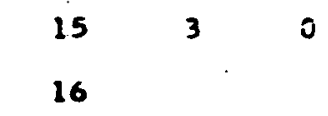


FIG. G.1 SPPAA SAPLE PROBLWI INPUT DECK - CONTINUATION

208.14

0.3991

$$
0.01531
$$

3.558

2.555

$\because$

1.431

0.2070

5.687

4.700

1.103

0.1321

1.30035

0.0109 E 00

208.14

0.4669

0.007158

4.868

3.321

2.174

c. 1512

8.381

6.891

1.662

C.07968

0.40861

0.0109 E 00

333.00

0.4251

c. 009883

$3.98 \mathrm{C}$

2.797

1.657

0.1731

.6 .530

5.375

1.271

0.1001

1.13375

0.0105 E 00

439.82

0.4339

0.009347

4.1 .59

2.903

1.762

0.1680

6.88 .4

.5 .662

1.350

0.09584

0.7874

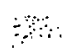

0.0109 E 00

439.82

$$
0.4954
$$

0.004854

5.429

3.651

2.510

0.1336

9.535

7.836

1.911

0.06311

0.255475

0.0109 E 00

703.72

0.4734

0.005180

4.875

3.321

2.170

0.1382

8.310

6.815

1.658

0.06721 
FIG. C.1 SPPIA SA:PLE PROBLES INPUT DECK - CONTINUATION

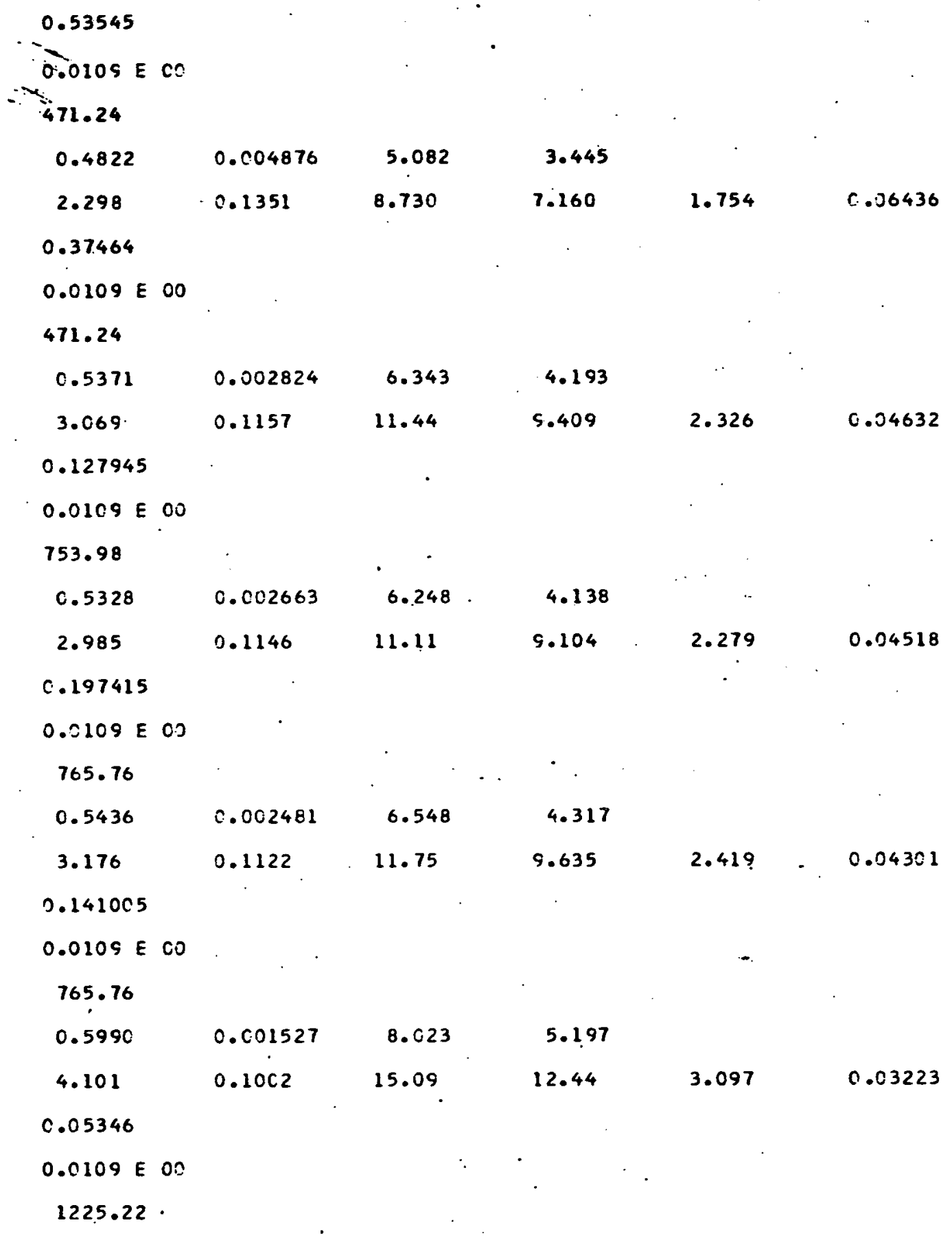




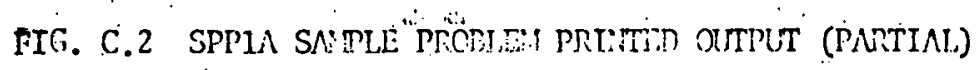

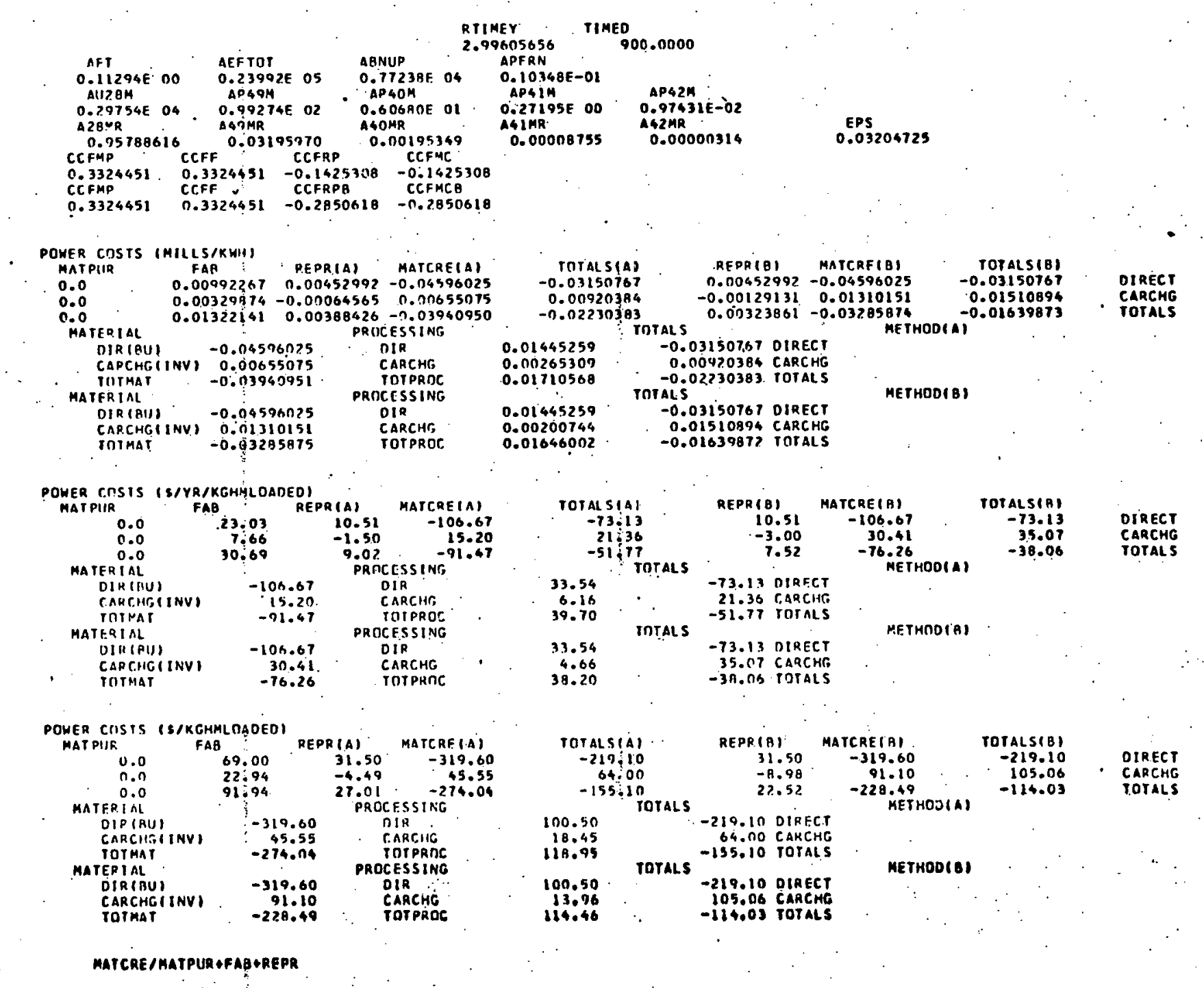


TABLE C.2

INTERPRETATION OF SPPIA PRINTED OUTPUT

\begin{tabular}{|c|c|c|}
\hline Variable & Description & Units \\
\hline RTIY:EY & Actual irradiation time & years \\
\hline TIMED & Irradiation tine in full power days & days \\
\hline ABNUP & Burnup in the annular region & $\operatorname{Min} / \mathrm{MTH}$ \\
\hline APFRN & $\begin{array}{l}\text { Fraction of total reactor power } \\
\text { supplied by the annular region }\end{array}$ & \\
\hline \multicolumn{3}{|c|}{ Nuclide lasses: } \\
\hline AU28M & $\begin{array}{l}\text { Mass of U238 in annular region } \\
\text { after irradiation }\end{array}$ & $\mathrm{kg}$ \\
\hline AP49M & $\begin{array}{l}\text { Mass of Pu239 in annular region } \\
\text { after irradiation }\end{array}$ & $\mathrm{kg}$ \\
\hline $\begin{array}{l}\text { AP40M } \\
\text { AP41M } \\
\text { AP42M }\end{array}$ & $\begin{array}{l}\text { Masses of Pu239,241,242 in annular } \\
\text { region after irradiation }\end{array}$ & $\mathrm{kg}$ \\
\hline AIMKGL & Initial mass of heavy metal $(\mathrm{U}+\mathrm{Pu})$ & $\mathrm{kg}$ \\
\hline \multicolumn{3}{|c|}{ Nuclide Fractions: } \\
\hline$A 28 \mathbb{R}$ & AU28M/AFMKGL & \\
\hline$A 49 \cdot \cdot \mathbb{R}$ & AP49M/ARMGL & \\
\hline$A 40 \cdot \mathbb{R}$ & AP49:1/AHMKGL & \\
\hline$A 41 \mathrm{R} \cdot \mathrm{R}$ & AP41:VAMKGL & \\
\hline $\mathrm{A} 42 \mathrm{NR}$ & AP42: $\mathbb{R} / A H M K G L$ & \\
\hline EPS & Fissile Mass/Initial Mass of Heavy Metal & \\
\hline $\begin{array}{l}\text { Labe1 or } \\
\text { Heading }\end{array}$ & Description & \\
\hline MATPUR & Material Purchase Component & \\
\hline FAB & Fabrication Component & \\
\hline REPR(A) & Reprocessing Component (Tax lethod A) & \\
\hline
\end{tabular}


303

Label or Heading

REPR(B)

$\operatorname{MATCRE}(\mathrm{A})$

MATCRE(B)

DIR

CACIIG

TOT: AT

TOTPROC
Description

Reprocessing Component (Tax Method B)

Material Credit Component (Tax Method A) .

Material Credit Component (Tax Method B)

Direct Component

Carrying Charge Component

Total Material Component (Burnup+Inventory)

Total Processing Component (fabrication+reprocessing, including their carrying charges) 


\section{C.4 FORTRAiV LISTIIV}

Tile SPPLA FORTRA' listing is given on the following pages. 
FAST BREEDER REACTOR FUEL DEPLET ION AND ECONOMICS CALCULATIONS FBR BLANKET TEST FACILITY, MASSACHUSETTS INSTITUTE OF TECHNJLOGY S.T. BREWER, M.J. DRISCOLL, E.A. MASON

$$
\text { * }
$$$$
\text { * }
$$$$
\text { * }
$$

GIVEN ECONJMIC PARAMETERS AND LOCAL PHYSICS DATA THIS PROGRAM COMPUTES LDCAL, ANNULAR-REGIONAL, AND REEIDNAL ICORE, AXIAL BLANKET, RADIAL BLANKETI FUEL COSTS AS FUNCTIONS OF IRRACIAT ION TIME UNCER SCATTER DR BATCH FUEL MANAGEMENT SCHEMES.

DIMENS IDN DIMENSION

1

2

DIMENSION 1

DIMENS ION

DI ME NSION $\triangle C C T B(30)$ DI MENS I ON

1 FAMCTB ( 30

DIMENS ION

1 EPS(30)

DIMENSION ABU(30), AINV( 30), AINVB(30),AMAT(30),AMATB(30),APRSD(30)

1 , APRSC (30), APRST (30), APRSCB(30),AAT(30),AATB(30),AADT(30),

$2 A \triangle C C T(30), \triangle A C C T B(30)$

CIMENSION $\triangle P R S T B(30)$

DIMENSION ID(11)

DOUBLE PREC I SION ID
CARD0002

CARD 0003

CARDO004

CARD 0005

CARD0006

CARD0007

CARD 0008

CARD0009

CARDOO10

CARDO011

CARDOO 12

CARD0013

CARDOO 14

CARDOO 15

CARD 0016

CARD0017

CARDOO18

CARO0019

CARDOO20

CAROOO21

CARDO022

CARDOO 23

CARD 0024

CARDO025

CARD 0026

CARD 0027

CARDOO28

CARD 0029

CARDOO 30

CARDOO 31

CARD 0032

CARDO0 33

CARDO034

CARD 0035

CARDO0 36 
1 FORMAT 1316$)$

CARD0037

FORMAT $(4 F 12 \cdot 8)$

22 FORMAT (SF 12.8$)$

3 FDRMAT (F12.8)

4 FORMAT (5F12,8)

5 FORMAT (F12.8)

FORMAT ( I6)

7 FORMAT (F 12.8)

21 FORMAT (2F12.8)

31 FORMAT 7 F10.2)

41 FORMAT (5F 12.8)

51 FORMAT (2F12.8)

C

61 FORMAT (4F12.8)

CARD 0038

CARD0039

CARD0040

CARD 0041

CARDO0 42

CARD 0043

CARD0044

CARDO045

CARD 0046

CARD0047

CARD 0048

CARD 0049

CARDO0 50

CARD 0051

CARD0052

PRINT 4442

4442 FORMATI//199H PROGRAM "SPPIA" * * * FBR BLANKET TEST FACILITY, M

CARD0053

CARD 0054

IIT * * * S.T.BREWER, M.J.DRISC OLL, E.A.MASONI PRINT 4443

4443 FQRMAT $/ / / 18 \times, 63 \mathrm{H}$ FAST BREEDER REACTOR FUEL DEPLETION AND ECONOMICS

1 CAL CULAT IONSI

READ 4444, ( I C (I), I = I, 11)

4444 FORMAT (1 1A6)

PRINT 4445, (ID(I), I= 1,11$)$

PR INT 400

4445 FORMAT $(/ / / / 24 \mathrm{H}$ PRDBLEM IDENTIFICATION:, 11A6)

PRINT 411

C READ AND PRINT CARD IAPUT DATA:

C CONTRDL CONSTANTS: ECONOMIC AND POWER PARAMETERS READ 1, NCASE, NVR, NPR INT

PRINT 2010

2010 FORMAT $(1 X, 6 H$ NCASE, $3 X, 4 H$ NVR, $1 X, 7 H$ NPRINT)

CARDO055

CARD 0056

CARD 0057

CARDO0 58

CARD 0059

CARDO060

CARD0061

CARD 0062

CARD0063

CARD 0064

CARD0065

CARDOO66

CARD 0067

CARD0068

CARD0069

CARD 0070

CARD0071

PRINT 2011, NCASE, NVR,NPRINT

CARD 0072 
READ 6. NTS

READ 7, DT

READ 21, EFF, DENOX

READ 31 , F\$KGHM, R\$KGHM, S\$KG49, S\$KG28, S\$KG40, S\$KG41, S\$KG42

CARD0074

CARD 0075

CARDO076

CARDO077

READ 41, TAX, BDR TE, BDFRN, SKRTE, SKFRN

READ 51 , SLF, CAPMWE

READ 61, TFPRE, TMPPRE, TRPPST, TMCPST

PR INT 406

406 FORMAT $(3 X, 4 H$ NTS $)$

PRINT 416, NTS

416 FORMAT $(1 X, I 6)$

PRINT 407

407 FORMAT $(3 X, 3 H$ DT)

PR INT 417, DT

417 FORMAT $(1 X, F 12.8)$

PRINT 500

500 FURMAT $(1 X, 19 H$ COST ANALYSIS DATA $)$ PRINT 598

598 FORMAT $(4 X, 4 H$ EFF, $4 X, 6 X, 6 H$ DENOX) PRINT 599 , EFF, OENOX

599 FORMAT $(1 \times, 2 F 12.6)$ PR INT 531

531 FORMAT $13 X, 7 H$ F\$KGHM, $2 X, 3 X, 7 H$ R\$KGHM, $2 X, 3 x, 7 H$ S\$KG 49,

$12 X, 3 X, 7 H$ S $\$ K G 28,2 X, 3 X, 7 H$ S $\$ K G 40,2 X, 3 X, 7 H$ S $\$ K G 41,2 X, 3 X, 7 H S \$ K G 421$.

CARD 0078

CARD0079

CARDO0 80

CARD 0081

CARD0082

CARD0083

CARDOOB 4

CARD0085

CARD 0086

CARD0087

CARDO088

CARD 0089

CARDOO 90

CARD 0091

CARD 0092

CARD0093

CARD 0094

CARD0095

CARD0096

CARD0097

CARD0098

CARD 0099

532 FORMAT $(1 X, 2 F 12.8,5 F 12.2)$

PRINT 541

541 FORMAT $3 X, 4 H$ TAX, $5 X, 3 X, 6 H$ BDRTE, $3 X, 3 X, 6 H$ BDFRN, $3 X, 3 X, 6 H$ SKRTE, $3 X$,

CARDO100

CARD 0101

CARDO 102

CARD0103

$13 X, 6 H$ SKFRN

PRINT 542, TAX, BDRTE, EDFRN, SKRTE, SKFRN

542 FORMAT $(1 X, 5 F 12.8)$

PRINT 551

CARD 0104

CARDO 105

CARD 0106

CARDO107

551 FORMAT $(3 X, 4 H$ SLF, $5 X, 3 X, 7 H$ CAPMWE $)$

CARDO 108 
552 FORMAT $(1 X, F 12,8, F 12,1)$ PR.INT 561

561 FORMAT $(3 X, 6 H$ TFPRE, $3 X, 2 X, 7 H$ TMPPRE, $3 X, 2 X, 7 H$ TRPPST, $3 X, 2 X$, $17 H$ TMCPSTI

PR INT 562, TFPRE, TMPPRE, TRPPST, TMCPST

562 FORMAT $(1 X, 4 F 12.8)$

C INITIALIZE

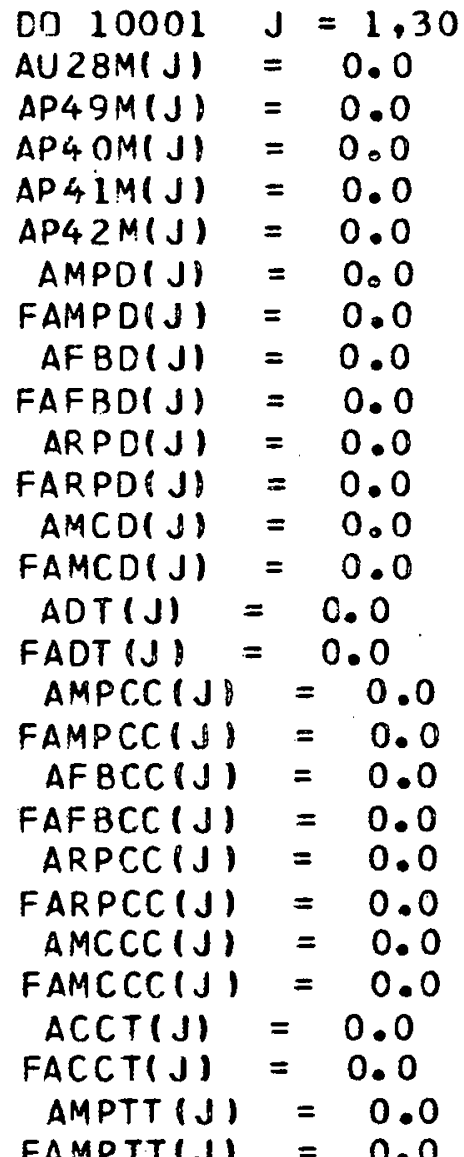

CARDOL 09

CARDO110

CARDO 111

CARD 0112

CARDO113

CARDO114

CARDO115

CARDO116

CARD 0117

CARDO1 18

CARDO119

CARDO120

CARDO1 21

CAR.DO1 22

CARDO123

CARDO124

CARDO125

CARD0126

CARDO127

CARD 0128

CARDO1 29

CARDO1 30

CARD0131

CARDO132

CARD 0133

CARDO1 34

CARDO1 35

CARD 0136

CARDO137

CAROO1 38

CARDO139

CARDO 140

CARD 0141

CARDO 142

CARD0143

CARDO1 44 


$$
\begin{aligned}
& \text { AFBTT(J) }=0.0 \\
& \text { FAFBTT }(\mathrm{J})=0.0 \\
& \triangle A R P T(J)=0.0 \\
& \text { FARPTT(J) }=0.0 \\
& \triangle M C T T(J)=0.0 \\
& \text { FAMCTT(J) }=0.0 \\
& A T(J)=0.0 \\
& F A T(J)=0.0 \\
& \triangle A R P C C B(J)=0.0 \\
& \triangle R P T T B(J)=0.0 \\
& \triangle M C C C B(J)=0.0 \\
& \triangle M C T T B(J)=0.0 \\
& A C C T B(J)=0.0 \\
& \operatorname{ATB}(\mathrm{J})=0.0 \\
& \text { FARPCB (J) }=0.0 \\
& F A M C C B(J)=0.0 \\
& \text { FACCTB }(J)=0.0 \\
& \text { FARPTB }(J)=0.0 \\
& \text { FAMC TB }(J)=0.0 \\
& \text { FATB }(J)=0.0 \\
& \triangle 28 M R(J)=0.0 \\
& \triangle 4 \text { GMR }(J)=0.0 \\
& \triangle 40 M R(J)=0.0 \\
& \triangle 41 M R(J)=0.0 \\
& A 42 M R(J)=0.0 \\
& \operatorname{EPS}(\mathrm{J})=0.0
\end{aligned}
$$

$\Delta B \cup(J)=0.0$

$\Delta I N V(J)=0.0$

$$
A I N V B(J)=0.0
$$$$
\operatorname{AMAT}(J)=0.0
$$$$
\triangle M A T B(J)=0.0
$$$$
\triangle A P R S D(J)=0.0
$$$$
\triangle P R S C(J)=0.0
$$$$
\text { APRST (J) }=0.0
$$$$
\triangle A P R S C B(J)=0.0
$$

CARDO145

CARDOI 46

CARDO147

CARDO148

CARD 0149

CARD 0150

CARDO151

CAROO152

CARDO153

CARO0154

CARD 0155

CARDO 156

CARDO157

CARDO158

CARDO159

CARD 0160

CARDO161

CARDO162

CARD 0163

CARDO164

CARDO165

CARD 0166

CARD0167

CARD 0168

CARO0169

CARD0170

CARD 0171

CARD0172

CARD 0173

CARD0174

CARDO175

CARD 0176

CARDO 177

CARDO178

CARD 0179

CARDO180 
PR INT 400

400 FORMAT (1 HI)

PR INT 401

401 FORMAT $(8 H$ CASE NO)

PRINT $101, I$

C

101 FORMAT (16///)

PRINT DUT INPUT DECK IMAGE

PRINT 411

411 FORMAT (12X, $17 H$ INPUT DECK IMAGE) PRINT 4111

4111 FORMAT $(1 X, 23 H$ PHYSICS-DEPLETION DATA PR INT 420

420 FORMAT $(3 X, 7 H$ SIGA28,2X,3X,7H SIGF $28,2 X, 3 X, 7 H$ SIGA $49,3 X, 7 H$ SIGF49) PRINT 20, SIGA28, SIGF 28 , SIGA 49 , S IGF 49

20 FORMAT $(1 X, 4 F 12,8)$ PRINT 367

367 FORMAT $(3 X, 7 H$ SIGA40,2X,3X,7H SIGF $40,2 X$,

$13 X, 7 H$ SIGA4I, $2 X, 3 X, 7 H$ SIGF $41,2 X$,

$23 X, 7 H$ SIGA42,2X,3X,7H SIGF42I

PR INT 368 , SIGA40, SI GF40, SIGA41, SIGF41, S IGA42, SIGF 42

368 FORMAT $(1 \times, 6$ F 12.8$)$

PR INT 413

413 FORMAT $(3 \times, 5 H$ FLUX)

PRINT 403, FLUX

403 FORMAT $(1 X, F 12.8)$ PRINT 404

404 FORMAT $(3 X, 6 H$ U28NO, $2 X, 3 X, 6 H$ P $9 N O, 2 X, 3 X, 6 H$ P $40 N O, 2 X, 3 X, 6 H$ P 4 NO,

1 $2 X, 3 \times, 6 \mathrm{H} P 42 \mathrm{NO})$

PRINT 414, U28NO,P49NC, P4ONO, P41NO, P42NO

414 FDRMAT $(1 \times, 5 F 12.8)$

PRINT 405

405 FIRMAT $(3 X, 4 H$ VOL)

PR INT 415, VOL$$
\text { . }
$$

CARD 0217

CARDO218

CARD 0219

CARDO2 20

CARD0221

CARD 0222

CAR.00223

CARD 0224

CAR.D 0225

CARDO226

CARD 0227

CARD0228

CARD0229

CAROO230

CARD0231

CARD 0232

CARD0233

CARDO 234

C.ARD 0235

CARDO236

CARD0237

CARD 0238

CARD0239

CARD 0240

CARD0241

CARD0242

CARD 0243

CARD0244

CARD0245

CARD 0246

CARD0247

CARD $02 \div 8$

CARD0240

CARD0250

CARD 0251

CARDO252 
CARDO255

CARD0256

CARD 0257

CARD025B

$C C 1=(S I G A \& 0-S$ IGF40 ) / (S IGA4 1-S IGA28)

$C C 2=($ SIGA4C-SIGF40)/(SIGA4 I-SIGA49)

CC3 $=($ SIGA40-SIGF40)/(SIGA4I-SIGA40)

$B E T A 2=P \& 1 N O-1$ U28NO *CONSTA*CB1*CC1-U28NO*CONSTA*CB2*CC 2

CARD 02.59

CARD 0260

CARD0261

CARO 0262

CDI = (SIGA41-SIGF4I I/ISIGA42-SIGA28)

CD2 $=($ SIGA41-SIGF41)/(SIGA42-SIGA49)

CD3 $=(S I G A 41-S I G F 41) /(S I G A 42-S I G A 40)$

CD4 = (SIGA4 I-SIGF4 I)/(SIGA42-SIGA4 I)

BETA $3=P 42 N O-1$ U2 $3 N D * C O N S T A * C B 1 * C C 1 * C D 1-U 28 N O * C O N S T A * C B 2 * C C 2 * C D 2$

1

$+P 49 N O * C B 2 * C C 2 * C D 2+B E T A 1 * C(C .3 * C D 3+B E T A 2 * C D 4)$

PR INT 600

GOO FORMAT $(1 \mathrm{HI})$

PR INT 601

601 FORMAT $(1 X, 15 H$ OUTPUT FOLLOWS $/ / / 1$

PRINT 602

602 FORMAT $(3 X, 7 H$ CONSTA

PRINT 102, CONSTA

102 FORMAT $(1 X, E 15.5)$

PRINT 1801

1801 FORMAT $(6 X, 4 H$ CB1,5X,6X,4H CB2,5X,6X,6H BETA1)

PRINT $802, C E 1, C B 2, B E T A 1$

802 FORMAT $(1 \times, 3 E 15.5)$

PRINT 803

803 FORMAT $16 \mathrm{X}, 4 \mathrm{H} \mathrm{CCl}, 5 \mathrm{X}$,

$\begin{array}{ll}1 & 6 \times, 4 H C C 2,5 X \\ 2 & 6 X, \$ H C C 3,5 X \\ 3 & 6 X, 6 H \text { BETA2 } \\ \text { PRINT } 1804, C C 1, C C 2, C C 3, B E T A 2\end{array}$

CARD0263

CARD0264

CARD 0265

CARD0266

CARD 0267

CARO0268

CARD0269

CARO 0270

CARD0271

CARD0272

CARD 0273

CARDO274

CARD 0275

CARD 0276

CARD0277

CARD 0278

CARD0279

CARD0280

CARD 0281

CARDO 282

CARO 0293

CARD0284

CARD0285

CARD 0286

CARD0287

CARD 0288 
1804 FORMAT $(1 \times, 4 E 15.5)$

CARD 0289

PR INT 805 .

805 FORMAT $(6 \mathrm{X}, 4 \mathrm{H}$ CD1, $5 \mathrm{X}, 6 \mathrm{X}, 4 \mathrm{H}$ CD2, $5 \mathrm{X}$,

1

$6 X, 4 \mathrm{H} \mathrm{CD} 3,5 X, 6 x, 4 \mathrm{H} C D 4,5 X, 6 X, 6 \mathrm{H}$ BETA3)

CARD0290

CARD 0291

CARD0292

PR INT $806, C \mathrm{C} 1, \mathrm{CD} 2, \mathrm{CD} 3, \mathrm{CD} 4, \mathrm{BETA} 3$

806 FDRMAT $(1 \times, 5$ E15.5)

CDLLAR COST PER LOT

U2 $8 M O=U 28 N D * V O L * 395.25$

$P 49 M O=P 49 N O * V O L * 396.92$

$P 40 M O=P 40 N O * V O L * 398.62$

$P 41 M O=P 41 N O * V D L * 400.28$

$P 42 M O=P 42 N O * V O L * 401.96$

HMKGLD $=U 28 M D+P 49 M O+P 4 O M D+P 41 M O+P 42 M D$

CARD0293

CARD 0294

CARDO295

CARD0296

CARD 0297

CARD0298

CARD 0299

CARD 0300

CARD0301

CARD 0302

$F A B \$ L=H M K G L D * F \$ K G H M$

REPR \$L = HMKGLD*R \$KGHM

SMP\$L $=$ P49MO*\$KG49+U28MO*S\$KG2R+P40MO*S\$KG40 +

CARD0303

CARD0304

CARD 0305

CARD0306

CARD 0307

CARD0308

PRINT 920

920 FORMAT $(4 X, 6 \mathrm{H}$ U28MD, $5 \mathrm{X}, 4 \mathrm{X}, 6 \mathrm{H}$ P49M0,5X,4X,6H P40MO, $\mathrm{X}, 4 \mathrm{X}, 6 \mathrm{H}$ P $41 \mathrm{MO}, 5 \mathrm{X}$

CARD0309

CARD 0310

CARD0311

C.ARD0312

CARD 0313

CARDO0314

CARD 0315

CARD 0316

CARD0317

CARD 0318

CARDO319

CARD0320

VFOX = HMKGLO/ (VOL *DENDX $* 0.88)$

CARD0321

PRINT 901

CARDO322

CARD0323

PR INT $902, V F O X$

CARD0324

SO2 FORMAT ( $1 X, F 12.8)$ 
CARD0330

CARD0331

CARD 0332

$\triangle A R P T=A A R P E / E F F$

PRINT 611

611 FORMAT $(/ / 3 X, 7 H$ DISRTE)

CARDO333

CARD 0334

CAP.D0335

PRINT 612, DISRTE

612 FORMAT $(1 X, F 12.8)$

PR INT 621

621 FORMAT $(/ / 3 X, 6 H$ AARPE, $E X, 3 X, 6 H$ AARPT)

PRINT 622, AARPE,AARPT

622 FORMAT $(1 X, 2 E 15.5)$

PRINT 400

C

TIME LOOP

$N=N T S$

De $100 \quad J=1, N$

$T J=J$

C EQUIVALENT FULL POWER TIME

TIMED $=T J * D T$

TIME = TIMED*86400.0

C CALCULATE U238, PU239, PU240, PU241, PU242

C ZONE ATOM DENSITIES (ATOMS/BARN-CM), MASSES (KG)

CARDO336

CARD 0337

CARD0338

CARO0339

CARD 0340

CARD0341

CARD 0342

CARD0343

CARD0344

CARD 0345

CARDO 346

CARD0347

CARD 0348

CARD0349

CARD 0350

CARD 0351

CARD0352

CARD 0353 $F T=F L U X * T I M E *(1.00 E-09)$

TMFN $1=($ EXP(-FT*SIGA28) $*(1.0-E X P(-F T *(S I G A 49-S I G A 28)))$

CARD0354

$P 49 N=($ CONSTB*TMFN 1$)+(P 49 N) * E X P(-S I G A 49 * F T))$

CARD0355

$P 49 M=P 49 N * V D L * 396.92$

$\mathrm{U} 28 \mathrm{~N}=\mathrm{U} 28 \mathrm{NO}$ \#EXP(-SIGA28*FT)

$U 28 M=U 28 N * V O L * 395.25$

P4ON $=$ U2 8NO*CONSTA*CBL*EXP(-SIG A28*FT)

CARD 0356

CARD0357

CARD 0358

CARD0359

$1-U 28 N O * C O N S T A * C B 2$ EXP(-SIGA49*FT)

CARD0360 
$2+P 49 N O * C B 2 * E X P(-S I C A 49 * F T)$

+BETA 1 *EXP(-SIGA4 O\#FT)

$P 4 O M=P 4 O N * V O L * 398.62$

$P 41 N=U 28 N O * C O N S T A * C P 1 * C C 1 * E X P(-S I G A 28 * F T)$

$-U 2$ BNO*CONSTA*CB2*CC2*EXP(-SIGA49*FT)

$+P 49 N O * C B 2 * C C 2 * E X P(-S I G A 49 * F T)$

$+B E T A 1 * C$ C 3*EXP( $-S$ I GA40*FT)

$+B E T A 2 * E X P(-S I G A 41 * F T)$

$P 41 M=P 41 N * V O L * 400.28$

$P 42 N=U 28 N O * C O N S T A * C B 1 * C C 1 * C D 1 *$ EXP $(-S I G A 28 * F T)$

$-U 28 N O * C O N S T A * C B 2 * C C 2 * C D 2 * E X P(-S I G A 49 * F T)$

$+P 49 N O * C B 2 * C C 2 * C D 2 * E X P(-S$ IGA49*FT)

$+B E T A 1 * C C 3 * C D 3 * E X P(-S I G A 40 * F T)$

$+B E T A 2 * C D 4 * E X P(-S$ I CA4 $1 * F T)$

+BETA 3*EXP(-SIGA42*FT)

$P 42 M=P 42 N * V O L * 401.96$

ACTUAL (REAL) TIME (YEARS)

RTIMEY $=$ TIMED/(3.55.C*SLF)

IF (NPRINT.LT.1) GO TC 1401

PRINT 400

PRINT 713

713 FORMAT (50X, 7H RTIMEY)

PRINT 703, RTIMEY

703 FURMAT $150 X, F 12.8)$

1401 CONTINUE

- PARAMETERS RELATED TO zONE ENERGY AND POWER

C 1. ATOMS FISSIONED IN REGIUN(LOT)

AFIS49= SIGF 49*VOL *( (EXP) -SI GA49 *FT) -1.0$) *(1($ CONSTB-P 49NO)/SIGA49)

$1-(E X P(-S I G A 28 * F T)-1.0) *(C O N S T B / S I G A 28) *(1.00 E+27)$

AFIS $28=$ SIGF 28*VOL *(U28NO/SI GA28)*(1.0-EXP(-SIGA28*FT) $) *(1.00 E+27)$ $A F I S T T=A F I S 49+A F I S 28$

C

2. FISSION ENERGY RELEASED IN REGION (LOT) (MWDT)

$E F 49=(3.715) *(1.00 E-22) * A F I S 49$

$E F 28=(3.715) *(1.00 E-22) * A F I S 28$

CARD 0361

CARDO362

C.ARD0 363

CARD 0364

CARD0365

CARD0366

CARD0367

CARD0368

CARD 0369

CARD0370

CARD0371

CARD 0372

CARD 0373

CARD0374

CAR.D 0375

CARD0376

CARD 0377

CARD0378

CARD0370

CARD 0380

CARD0381

CARD 0392

CARD0383

CARD0384

CARD 0385

CARD0386

CARD0387

CARD 0398

CARD0389

CARD 0390

CARD 0391

CARD03\%2

CARD 0393

CARD0394

CARD 0395

CARD 0396 
3. NUMBER DF PU230 ATOMS CONSUMED IN REGION (LOT)

CARD 0399

ACDN49=AFIS49* |SIGA49/SIGF49)

C 4. NUMBER UF PU239 ATOMS BRED IN REGIUN(LOT).

$\triangle B R D 49=A F$ IS 28* ( (S IGA28-S IGF28)/S IGF 28)

5. REGION(LOT) TIME INTEGRAL BREEDING RATIO...

PU239 BRED IN R.EGION/PU239 CONSUMED IN REGION

CARD 0399

CARD0400

CARD 0401

CARD 0402

CARD0 403

$B R 1=A B R D 49 / A C O N 4$ \%

CARD 0404

CARD 0405

CARD 0406

CARD 0407

CARDO408

CARD 0409

CARD 0410

CARD0 411

CARD 0412

CARD0413

CARD0414

CARD 0415

CARD0416

CARD 0417

CARD0418

CARD0419

CARD 0420

CARD0421

CARD 0422

CARD0 423

CARD0424

CARD 0425

CARDO426

CARD0427

CARO0428

CARD0 429

CARD0430

$4 X, 6 H$ TMFN $1,5 X$.

CARD0431

$5 X .5 \mathrm{H} U 28 \mathrm{M}, 5 \mathrm{X}$

CARD0432 
$5 \times, 5 \mathrm{H} \mathrm{P49M1}$

PRINT 613, TIMED,FT, TMFNI, U28N, U28M,P49N,P49M
FORMAT $(1 X, 7 E 15,5)$

613 FORMAT $11 \times$
PRINT 4.67

467 FORMAT $(5 X, 5 H$ P $40 N, 5 X, 5 X, 5 H$ P $41 N, 5 X, 5 X, 5 H$ P42N)

PRINT $468, P 40 N, P 41 N, P 42 N$

468 FORMAT $(1 \times .3$ E 15.5$)$

PR INT 469

469 FORMAT $(5 X, 5 H$ P $40 M, 5 X, E X, 5 H P 41 M, 5 X, 5 X, 5 H$ P $42 M)$

PRINT $470, P 40 M, P 41 M, P 42 M$

470 FCRMAT $(1 \times, 3 E 15.5)$

PR INT 697

697 FORMAT $(4 X, 7$ H AFIS $49,4 X, 4 X, 7 H$ AFI $28,4 X, 4 X, 7 H$ AFISTT) PRINT 698 , AFIS49, AFIS28, AFISTT

698 FORMAT $(1 \times, 3 E 15.5)$

PRINT 688

668 FORMAT $(4 X, 5 \mathrm{H}$ EF $49,6 \times, 4 \times, 5 \mathrm{H}$ EF28,6X,4X,6H EFT DT

PRINT 689, EF49,EF2B,EFTOT

689 FORMAT $11 \times, 3$ E15.5)

PR INT 677

677 FORMAT $(4 X, 7 H$ ACON49,4X,4X,7H ARRD49,4X, $11 X, 4 H$ BR 1 ) PRINT $678, A C O N 49, A B R D 49, B R I$

678 FORMAT $(1 \times .3 E 15.5)$ PRINT 671

671 FORMAT ( $4 \times, 6 H$ TERTR, $5 X, 4 X, 6 H$ PFPNL, $5 X, 4 X, 7 H$ BURNUP) PRINT 672, TERTR, PFRNL, BIJRNUP

672 FORMAT $(1 \times, 3$ E15.5) PR INT 673

673 FORMAT $(4 X, 7 H$ PDMW49, 4X,4X,7H PDMW28, 4X,4X,6H POTDT) PRINT 674, PDMW49, PDNW28,PDT OT

674 FDRMAT $(1 \times, 3 E 15.5)$ PRINT 675

675 FORMAT ( $4 X, 7 H$ PDENSD, $4 x, 4 X, 7 H$ PDENSA) PRINT 676,PDENSD,PDENSA

676 FORMAT $(1 \times, 2$ E15.5)

CARDO 433

CARDO434

CARD0 435

CARD 0436

CARDO437

CARD0 438

CARD 0439

CARD0440

CARD 0441

CARDO442

CARD0 443

CARD 0444

CARD 0445

CARD0 446

CARD 0447

CARDO 448

CARD 0449

CARDO 450

CARD0 451

CARD 0452

CARO0 453

CARD0454

CARD0455

CARD0456

CARD 0457

CARD0458

CARD0 450

CARD 0460

CARD0461

CARD0462

CARD 0463

CARO0464

CARD 0455

CARD 0466

CARD0467

CARD 0468 
C CALCULATE POWER COSTS (MILLS/KWHE)

CARD 0472

POWER COSTS, DIRECT (MILLS/KWHI

TPPE $=1000.0 /$ (AARPE *RTIIMEY)

CARD0 473

CARD 0474

CARD0 475

MATERIAL PURCHASE

$P C M P D=S M P \$ L$ *TPE

CARD 0476

CARD 0477

$F A B$
$P C F B D=F A B \$ L * T P P E$

CARD0 478

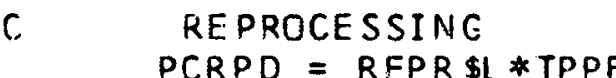

C MATERIAL CREDIT

$S M C \$ L=P 49 M * S \$ K G 49+U 28 M * S \$ K G 28+P 40 M * S \$ K G 40+P 41 M * S \$ K G 41$

CARO 0479

CARD0 480

CARD0481

1

$+P 42 M * S \$ K G 42$

IF (NPRINT.LT.1) GO TO 1403

PR INT 301

301 FORMAT $(3 \times, 6 \mathrm{H}$ SMC\$L)

PR INT 302 . SMC\$L

302 FDRMAT $(1 X, F 12.2)$

PRINT 2222

1403 CDNT INUE

$P C M C D=-S M C \$ L * T P P E$

- POWER CDSTS, CARRYING CHARGES (MILLS/KWH)

MATERIAL PURCHASE

$T M P=0.5 * R T I M E Y+T M P P R E$

DISFMP $=1.0 /(1.0+D$ ISRTE)* $(-T M P))$

CCFMP $=$ TAXF1*DISFMP - TAXF2 - 1.0

$P C M P C C=(P C M P D) *(C C F M P)$

CARD 0482

CARD0483

CARD 0484

CARD 0485

CARD0486

CARD 0487

CARD0488

CARD 0489

CARD 0490

CARD0491

CARD 0492

CARD 0493

CARD0494

CARD 0495

CARD 0496

CARD 0497

C.ARD 0498

PCMPTT $=$ PCMPD + PCMPCC

C

$$
\text { FAB }
$$

TFB $=0.5 * R T$ TMEY + TFPRE

OISFF $=1.0 /(11.0+D$ ISRTE $) *(-T F B))$

$C C F F=T A X F 1 * D I S F F-T A X F 2-1.0$

CARD0499

CARD 0500

CARD 0501

CARD0502

$P C F B C C=(P C F B D)(C C F F)$

CARD 0503

CARD0504 
PCFBTT $=P C F B D+P C F B C C$

CARDO505 REPRDCES SING

$T R P=-(0.5 * R T I M E Y+T R P P S T)$

CARD 0506

CARD0507

DISFRP $=1.0 /(1.0+0$ ISRTE)**(-TRP)

CARD 0508

CCFRP $=$ DISFRP -1.0

$P C R P C C=(P C R P D) *(C C F R P)$

PCRPTT $=$ PCRPD + PCRPCC

CCFRPB $=$ TAXF1*DISFRP - TAXF2 - 1.0

CARD 0509

CARDO5 10

CARO 0511

PCRPCB $=(P C R P D) *(C C F R P B)$

PCRPTB = PCRPD + PCRPCB

C MATERIAL CREDIT

$T M C=-(0.5 * R T$ IMEY + TMCPST $)$

DI SFMC $=1.0 /(11.0+D$ ISRTE $) *(-T M C))$

CARD0512

CARD0513

CARD 0514

CARD0513

CARDOS16

CARD 0517

$C C F M C=D I S F M C-1.0$

$P C M C C C=(P C M C D) *(C C F M C)$

PCMCTT = PCMCD + PCMCCC

CCFMCB $=$ TAXFI*DISFMC - TAXF $2-1.0$

$P C M C C B=(P C M C D) *(C C F N C B)$

$P C M C T B=P C M C D+P C M C C B$

CARDO518

CARD 0519

CARD 0520

CARD0 521

CARD 0522

CARD0523

CARD0524

CARD 0525

CARD0 26

CARO0527

CARD 0528

CARDO 529

CARD 0530

CARD0 531

CARD0532

CARD 0533

CARD0534

CARDO5 35

CARD0536

CARDO5 37

CARD 0538

CARD05 39

CARD 0540 
30310 FORMAT $13 X, 6 H$ CCFMP, $3 X, 3 X, 5 H$ CCFF, $4 X, 3 X, 7 H$ CCFRPB, $2 X, 3 X, 7 H$ CC FMCB 1 PRINT 3041 , CCFMP, CCFF,CCFRPB,CCFMCB

3041 FDRMAT $(1 \times, 4 F 12.7)$

PRINT 800

800 FORMAT (//24H POWER COSTS (MILLS/KWH))

PRINT 804

PRINT $814, P C N P D, P C F B D, P C R P D, P C M C C, P C D T, P C R P D, P C M C D, P C D T$

PRINT 815, P CMPCC, PCFBCC, PCRPCC, PCMCCC, PCCCT, PCRPCB, PCMC $B, P C C C T B$

PRINT 816 , PCMPTT,PCFETT, PCRPTT, PCMCTT, PCT, PCRPTB, PCMCTB, PCTB

\section{CONT INUE}

C

C SUM OR AVER AGE OVER ZONES TO OBTAIN ANNULAR REGION RESULTS

$A U 28 M(J)=A U 28 M(J)+U 28 M$
$A P 49 M(J)=A P 49 M(J)+P 49 M$
$A P 4 O M(J)=A P 40 M(J)+P 40 M$
$A P 41 M(J)=A P 41 M(J)+P 41 M$
$A P 42 M(J)=A P 42 M(J)+P 42 M$

AMPDIJ $=$ AMPDIJ) + PCMPD

$\triangle M P C C(J)=A M P C C(J)+P C M P C C$

$\triangle A M P T T(J)=A M P T T(J)+P C M P T T$

$\triangle F B D(J)=A F B D(J)+P C F B D$

$\triangle F B C C(J)=A F B C C(J)+P C F B C C$

$A F B T T(J)=A F B T T(J)+P C F B T T$

$\triangle R P D(J)=\triangle R P D(J)+P C R P D$

$\triangle R P C C(J)=\triangle R P C C(J)+P C R P C C$

$A R P T T(J)=A R P T T(J)+P C R P T T$

$\triangle M C D(J)=\triangle M C D(J)+P C M C D$

$A M C C C(J)=A M C C C(J)+P C M C C C$

$\triangle M C T T(J)=A M C T T(J)+P C M C T T$

$\triangle D T(J)=A D T(J)+P C D T$

$A C C T(J)=A C C T(J)+P C C C T$

$\Delta T(J)=A T(J)+P C T$

CARD 0541

CARD 0542

CARD05\&3

CARD 0544

CARD 0545

CARD0546

C.ARD 05.47

CARD0548

CARD 0549

CARD0550

CARD0551

CARD 0552

CARD0553

CARO0554

CARD 0555

CAR.00556

CARD 0557

CARD0558

CARD0559

CARD0560

CARD0561

CARD 0562

CARD 0563

CARDO564

CARD 0565

CARD0566

CARD0567

CARD 0568

CARD0569

CARD 0570

CARD 0571

CARD0572

CARD 0573

CARD0574

CARD0575

CARD 0576 
$A R P C C B(J)=A R P C C B(J)+P C R P C B$

$\triangle R P T T B(J)=A R P T T B(J)+P C R P T B$

CARD0577

$\triangle M C C C B(J)=A M C C C B(J)+P C M C C B$

$A M C T T B(J)=A M C T T B(J)+P C M C T B$

$A C C T B(J)=A C C T B(J)+P C C C T B$

$A T B(J)=A T B(J)+P C T E$

SFTV $(J)=$ SFTV(J) + FT $* V O L$

$\triangle A E F O T .(J)=A E F T O T(J)+E F T O T$ C 100 CONTINUE

$\triangle H M K G L=A H M K G L+$ HMKGLD

ATHMLD $=$ AHMKGL/ 1000.0

AVOL $=$ AVOL + VOL

CONV $1=1.0 / A H M K G L$

$A U 28 M O=A U 28 M O+U 28 N O$

$A P 49 M O=A P 49 M O+P 4 S M O$

$A P 40 M O=A P 40 M O+P 40 M O$

$A P 41 M O=A P 41 M O+P 41 M O$

$\triangle P 42 M O=A P 42 M O+P 42 M O$

$A 28 M R O=A U 28 M O * C O N V 1$

$A 49 M R O=A P 4 S M O * C O N V 1$

$\triangle 4 O M R O=A P 4 O M O * C O N V 1$

$\triangle 41 M R O=A P 41 M O * C O N V 1$

$A 42 M R O=A P \& 2 M O * C O N V 1$

EPSO $=A 49 M R C+A 41 M R O$

IF (NCOUNT .L T .NVR) GO TO 10

$I A R=I A R+1$

PR INT 400

PRINT 1001

$10 D 1$ FORMAT $(3 \times, 23 H$ ANNULAR REGION RESULTS)

CARDO578

CARD 0579

CARDO58O

CARD 0581

CARD 0582

CARDO583

CARD 0584

CARD0 585

CARD 0586

CARD 0587

CARD0 588

CARD 0589

CARD 0590

CARDO591

CARD 0592

CARD0593

CARD 0594

CARD 0595

CARD0596

CARD 0597

CARD 0598

CARD0599

CARD 0600

CARDO601

CARDO6 02

CARD 0503

CARDOS 04

CARDOSO5

CARD0606

CARD0607

CARD 0608

CARD0609

CARD0610

CARD 0611

CARD0612 
1003 FORMAT $(6 X$, I 2$)$

PRINT 2001

2001 FDRMAT $(/ / 5 X, 5 H$ AVOL $5 X, 4 X, 7 H$ AHMKGL)

CARD0615

CARD0616

CAR.D 0617

CARD06 18

CARD 0619 PRINT 2002, AVOL, AH:NKGL

2002 FORMAT $(1 X, 2 E 15.5)$

PRINT 2222

PRINT 1004

RTIMEY $=0.0$

TIMED $=0.0$

PRINT 1005, RTIMEY, TIMED

PRINT 1006

PRINT 1007, AU28MO, AP49MO, AP4OMO, AP41MO, AP42MO

PR INT 10071

PR INT 1107, A28MRO, A4 9MRO, A4OMRO, A41MPO, A 42MRO, EPSO

CARDO6 20

CARD 0621

CARD 0622

CARDO623

CARD 0624

CARD 0625

CARD06 26

CARD 0627

CARD06 28

CARD0629

CARD 0630

CAR.D06 31

CONV $=$ AARPE/ $(1000$. C*AHMKGL)

CARD0632

CARDOÓ 33

DO $10000 \quad J=1, N T S$

FAMPD(J) = AMPD (J)*CONV

FAMPCC (J) = $\triangle M P C C(J) * C O N V$

CARD0634

FAMPTT $(J)=A M P T T(J) * C O N V$

FAFBD $(\mathrm{J})=A F B D(\mathrm{~J}) * C \mathrm{CONV}$

$F A F B C C(J)=A F B C C(J) * C O N V$

FAFBTT $(J)=A F B T T(J) * C O N V$

FARPD $(J)=A R P D(J) * C O N V$

FARPCC (J) = ARPCC $(J) * C O N V$

FARPTT $(J)=A R P T T(J) * C O N V$

FAMCD (J) = $A M C D(J) * C O N V$

FAMCCC(J) = $A M C C C(J) * C O N V$

FAMCTT $(J)=A M C T T(J) * C O N V$

CARD 0635

CARDO6 36

CARD 0637

CARD 0639

CARD0639

CARD 0640

CARD0641

CARD0642

CARD 0643

CARD0644

CARD0645

FADT (J) = ADT (J)*CCAV

FACCT $(J)=A C C T(J) * C D N V$

CARD 0646

FAT $(J)=A T(J) * C O N V$

CARD0647

CARD 0648 
FARPCB $(J)=A R P C C B(J) * C O N V$

FAMCCB $(J)=A M C C C B(J) * C O N V$

$F A C C T B(J)=A C C T B(J) * C O N V$

FATB $B(J)=A T B(J) * C O N V$

FARPTB $(J)=\triangle R P T T B(J) * C O N V$

FAMCTB $(J)=A M C T T B(J) * C O N V$

CARD 0649 CARDO650

CARD 0651

CARDO6 52

CARDO653

CARD 0654

CARD0655

CARD0656

OTHER GROUPINGS OF COSTS

$A B U(J)=A M P D(J)+A M C D(J)$

$A I N V(J)=\triangle M P C C(J)+\triangle M C C C(J)$

CARD 0557

CARD0658

CARD 0659

CARO0660

$A M A T(J)=A B U(J)+A I A V(J)$

$A M A T B(J)=A B U(J)+A I N V B(J)$

$\triangle P P S D(J)=A F B D(J)+\triangle A R P D(J)$

$A P R S C(J)=A F B C C(J)+A R P C C(J)$

$A P R S T(J)=A P R S D(J)+\triangle P P R S C(J)$

$A P R S C B(J)=A F B C C(J)+\triangle A P C C B(J)$

$\triangle P P R S T B(J)=\triangle P R S D(J)+A P R S C B(J)$

$\triangle A T(J)=\triangle M A T(J)+A P R S T(J)$

$\triangle A T B(J)=A M A T B(J)+\triangle P R S T B(J)$

$\triangle A D T(J)=A B U(J)+A P R S D(J)$

$\triangle A C C T(J)=A I N V(J)+\triangle P R S C(J)$

$\triangle A C C T B(J)=A \operatorname{NVB}(J)+\triangle \operatorname{PPRSCB}(J)$

CARD 0661

CARD0662

CARD0663

CARD0664

CARD0665

CARD0666

CARD0667

CARDOE68

CARD 0669

CARD0670

CARD0671

CARO0672

$\operatorname{AFT}(J)=S F T V(J) / A V O L$

CARD0673

CARD 0674

CARD0675

CARD0676

ABNUP(J) = AEFTOT (J)/ATHMLD

CARD 0677

CARD0678

$\triangle 28 M R(J)=A U 28 M(J) * C O N V 1$

CAP.DO679

$A 4$ GMR $(J)=A P 4 Q M(J) * C C N V I$

CARDO 0680

$A$ AHOMR $(J)=A P 4 O M(J) * C O N V 1$

CARDOS81

$A 41 M R(J)=A P 41 M(J) * C O N V I$

CARD 0682

$A 42 M R(J)=A P 42 M(J) * C C N V I$

$\operatorname{EPS}(\mathrm{J})=A 49 M R(J)+A 4 I M R(J)$

CARD0683

CARD0684 
$T J=J$

TIMED $=T J * D T$

RTIMEY = TIMED/ (365.0*SLF)

CARD0686

CARDOS87

TIME $=$ TIMED*86400. C

PR INT 400

PRINT 1004

1004 FORMAT $(45 X, 7 H$ RTIMEY, EX, 6H TIMED $)$

CARD 0688

CARD0S89

CARD0690

CARD 0691

CARD0692

CARD 0693

PRINT 1005. RT IMEY, TIMED

1005 FORMAT $(44 X, F 12,8,3 X, F 12.4)$

CARDO6994

CARD0695

TERTR = AARPT*RTIMEY / $(24.0 * 1000.0)$

CARD 0696

CARD0697

APFRN = AEFTOT(J)/TERTR

PR INT 2003

2003 FORMAT $(5 X, 4 H$ AFT, $6 X, 4 X, 7 H$ AEFTOT, $4 X, 4 X, 6 H$ ABNUP, $5 X$,

CARD0698

CARD 0699

CARD0700

CARD 0701

CARD 0702

CARD0703

CARD 0704

CAR D0705

\section{PRINT 1006}

1006 FORMAT $15 X, 6 H$ AU28M, $4 \times, 5 X, 6 H$ AP49M, $4 X$,

$15 X, 6 H$ AP4OM, $4 X, 5 X, 6 H$ AP 41M, 4X,5X,6H AP42MI

CARDO706

CARD 0707

CARD0708

CARD 0709

CARD 0710

CARDO711

CARD 0712

CARD0713

CARD0714

CARD 0715

CARDO716

CARD 0717

CARD 0718

CARDO719

DISFMP $=1.0 /((1.0+D$ ISRTE $) *(-T M P))$

CCFMP $=$ TAXF1*DISFMP - TAXF2 - 1.0

$T F B=0.5 * R T$ IMEY + TFPRE

CARD 0720 


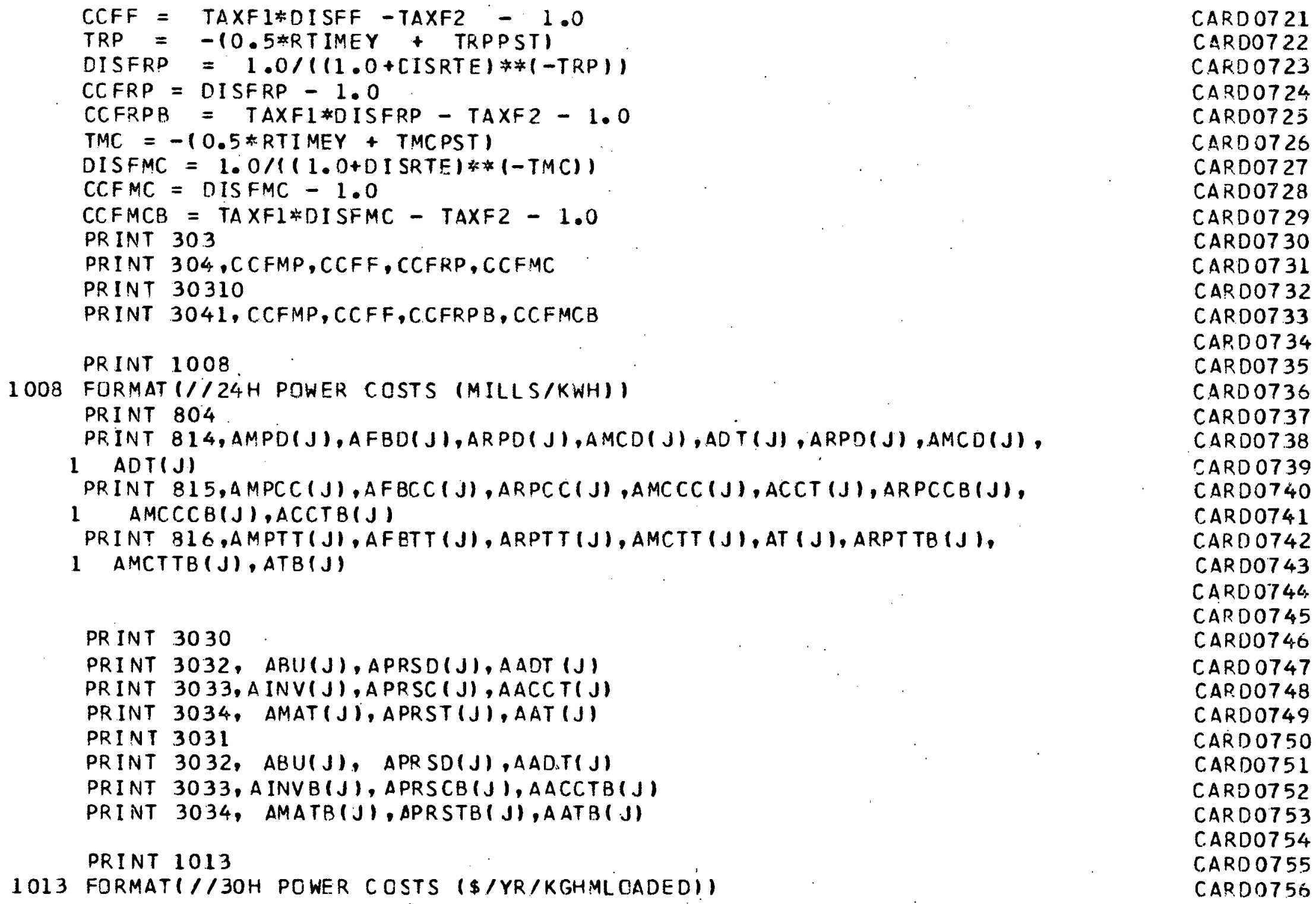

CARD0756 
PRINT 804

CARDO757

PRINT 1014, FAMPO(J), FAFBO(J), FARPD (J), FAMCD (J), FADT (J),

CARD 0758

1 FARPD (J), FAMCD (J), FADT(J)

PRINT 1015, FAMPCC (J), FAFBCC (J), FARPCC (J), FAMCCC (J), FACC $(J)$,

CARD0759

CARD0760

FARPCB $(J), F A M C C B(J), F A C C T B(J)$

, FAMPTT $(J), F A F B T T(J), F A R P T T(J), F A M C T T(J), F A T(J)$,

1 FARPTB $(J), F A M C T B(J), F A T B(J)$

CARO0761

CARDO762

CAR.00763

CARD0764

CARD 0765

CARO0766

$A B U(J)=A B U(J) * C, O N V$

$\operatorname{AINV}(J)=A \operatorname{INV}(J) * C O N V$

$A I N V B(J)=A I N V B(J) * C C N V$

$\triangle M A T(J)=\triangle M A T(J) \approx C O N V$

$\triangle M A T B(J)=A M A T B(J) * C D N V$

$\triangle P R S D(J)=A P R S D(J) * C C N V$

$\triangle P R S C(J)=A P R S C(J) \# C O N V$

$\operatorname{APRST}(J)=A P R S T(J) * C C N V$

$\triangle P R S C B(J)=A P R S C B(J) \star C O N V$

$\triangle P R S T B(J)=A P R S T B(J)$ \#CONV

$\triangle A T(J)=A A T(J) * C D N V$

$\triangle A T B(J)=\triangle A T B(J) * C O N V$

$\triangle A D T(J)=A A C T(J) \neq C O N V$

$\triangle A C C T(J)=\triangle A C C T(J) * C C N V$

$\triangle A C C T B(J)=A A C C T B(J) * C D N V$

CARD0767

CARD 0768

CARD0769

CARD 0770

CARD 0771

CARD0772

CARD 0773

CARD 0774

CARD 0775

CARD 0776

CARD0777

CARD 0778

CARD 0779

CARDO780

CARD 0781

CARD0782

PR INT 3030

PRINT 3042, $\triangle B U(J), A P R S D(J), A A D T(J)$

PR INT 3043, AINV(J), APRSC (J), AACCT(J)

PRINT 3044, AMAT (J), APRST (J), AAT (J)

PRINT 3031

PRINT 3042, $A B U(\mathrm{~J}), A P R S D(\mathrm{~J}), A A D T(\mathrm{~J})$

PRINT 3043, AINVB(J), APRSCB (J), AACCTB(J)

PRINT 3044, AMATB (J), APRSTB ( J), AATB (J)

CARD 0783

CARD 0784

CARD0785

CARD 0786

CARD0787

CARDO7B8

CAR.D 0789

CARD0790

CARD0791

CARD 0792 
2222 FORMAT $/ / / 5 X, 8 O H$ METHOD(A): (MATCRE-REPR) IS TAXED.

1 (MATCRE-REPR) IS CAP ITAL IZED.)

804 FORMATI $2 X, 7 H$ MATPUR, $3 X, 4 X, 4 H$ FAB, $4 X, 3 X, 8 H$ REPR $(A), 1 X, 2 X$,

110 M MATCRE $(A), 3 X, 4 X, 10 H$ TOTAL $S(A), 7 X, B H$ REPR $(B), 1 X, 2 X$,

$210 H$ MATCRE(B), 3X, 4X, $10 H$ TOTAL $S(B)$

814 FDRMAT $(1 X, 4 F 12.8,4 X, F 12.8,5 X, 2 F 12.8,4 X, F 12.8,5 X, 7 H$ DIRECT $)$

815 FORMAT $(1 X, 4 F 12.8,4 X, F 12.8,5 X, 2 F 12,8,4 X, F 12.8,5 X, 7 H$ CARCHG

816 FORMAT $(1 X, 4 F 12.8,4 X, F 12.8,5 X, 2 F 12.8,4 X, F 12.8,5 X, 7 H$ TOTAL $S)$

1014 FDRMAT $(1 X, 4 F 12.2,4 X, F 12.2,5 X, 2 F 12.2,4 X, F 12.2,5 X, 7 H$ DIRECT $)$

1015 FORMAT $(1 X, 4 F 12,2,4 X, F 12.2,5 X, 2 F 12.2,4 X, F 12.2,5 X, 7 H$ CARSHG)

1016 FDRMAT $(1 X, 4 F 12,2,4 X, F 12.2,5 X, 2 F 12.2,4 X, F 12.2,5 X, 7 H$ TOTALS $)$

3030 FORMAT $13 X, 9 H$ MATERIAL, 18X,3X,11H PROCESSING, 16X,3X,7H TOTALS, 20X, 1 1 OH ME THOD (A))

3031 FORMAT $(3 X, 9 H$ MATER IAL, $18 x, 3 x, 11 \mathrm{H}$ PROCESSING, 16X,3X,7H TOTALS,20X, 1 1 OH METHOD(B)

3032 FORMAT $(6 X, 8 H$ DIR $(B U), 4 X, F 12.8,6 X, 4 H$ DIR, $8 X, F 12.8,6 X, F 12.8$, 1 TH CIRECTI

3033 FORMAT (6X,12H CARCHG (INV), F12.8,6X,7H CARCHG,5X,F12.8, EX,F12.8, $17 H$ CARCHGI

3034 FORMAT $16 X, 7$ H TOTMAT, 5X,F12,8,6X,3H TOTPROC, $4 X, F 12.8,6 X, F 12.8$, 1 TH TOTALSI

3042 FURMAT $(6 x, 8 H$ DIRIBU), $4 X, F 12,2,6 X, 4 H$ DIR, 8X,F 12.2,6X, F12.2, 1 TH DIRECTI

3043 FORMAT $16 \mathrm{X}, 12 \mathrm{H}$ CARCHG (INV 1, F12.2, 6X,7H CARCHG, 5X,F12,2,6X,F12,2, 1 TH (ARCHG)

3044 FORMAT $16 X, 7 H$ TOTMAT, 5X,F 12.2,6X, 8H TOTPROC, 4 X,F12,2,6X,F 12,2, 17 H TOT ALS I

PRINT 4013

4013 FORMAT(//27H POWER COSTS (\$/KGHMLIJADED)
FAMPD $(J)=F A M P D(J)$
* RTIMEY
FAFBD $(J)=F A F B D(J)$
* RT IMEY
FARPD $(J)=$ FARPD $(J)$
* RTIMEY

CARD0793

CARD 0794

CARD 0795

CARD0796

CARD 0797

CARD0798

CARD0799

CARD0800

CARDO801

CARD0802

CARD 0803

CARDOBO4

CARD 0805

CARD0806

CAROOSO7

CARD 0808

CARD0809

CARD0810

CARD 0811

CAR.DO8 12

CARDOB 13

CARD0814

CAROOB 15

CARD0816

CARDO917

CARDO8 18

CARO0819

CARDO3 20

CARD 0821

CARD0822

CARDO8 23

CARD 0824

CARD0825

CARD 0826

CARD 0827

CARD08 28 


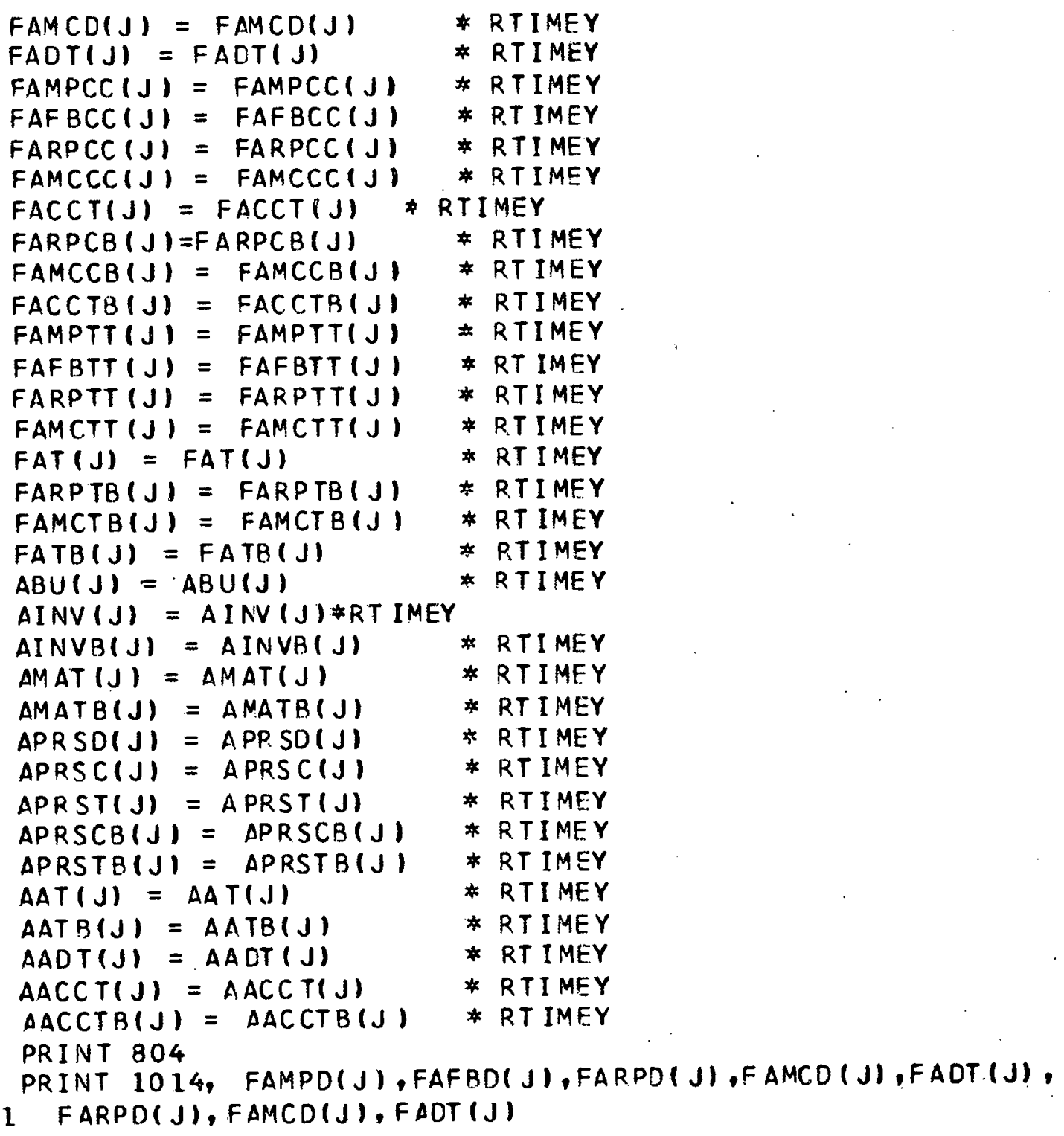

CARD 0838

CARD0839

CARD 0840

CARD 0841

CARDO8 42

CARD 0843

CARDOR 44

CARD 0845

CARD 0846

CARDO847

CARD 0848

CARD0849

CARDO 850

CARD 0851

CARD0852

CARD0853

CARD 0854

CARDOB 55

CARD 0856

CARD 0857

CARO0858

CARD 0859

CARD0860

CARD0861

CARD 0862

CARD0863

CARD 0864 
PRINT 1015, FAMPCC(J),FAFBCC (J), FARPCC (J), FAMCCC(J), FACCT(J), 1 FARPCB $(\mathrm{J})$, FAMCCB $(\mathrm{J}), F A C C T B(\mathrm{~J})$

PRINT 1016, FAMPTT $(J), F A F B T T(J), F A R P T T(J), F A M C T T(J), F A T(J)$, 1 FARPTB ( J), FAMCTB (J),FATB (J)

PR INT 3030

PRINT 3042, ABUIJ), APRSD (J), AADT (J)

PRINT 3043, AINV(J), APRSC (J), AACCT(J)

PRINT 3044, AMAT (J), APRST (J), AAT (J)

PR.INT 3031

PRINT 3042, ABU(J), APRSO(J), AADT (J)

PRINT 3043, AINVB(J), APRSCB $(J), A A C C T B(J)$

PRINT 3044, AMATB(J), APRSTB(J), AATB (J)

$R M C D=F A M C D(J) /(F A M P D(J)+F A F B D(J)+F A R P O(J))$

RMCT = FAMCTT(J)/(FAMPTT $(J)+F A F B T T(J)+F A R P T T(J))$

RMCTB $=F A M C T B(J) /(F \triangle M P T T(J)+F A F B T T(J)+F A R P T B(J))$

PRINT 9210

8210 FORMAT $(/ / 5 X, 23 H$ MATCRE/MATPUR+FAB+REPR)

PRINT 8211

8211 FORMAT $(3 x, 7 H$ DIRECT, $2 x, 3 x, 7 H$ TDT $(A), 2 x, 3 x, 7 H$ TCT $(B))$

PR INT 8212, RMCD, RMCT, RMCTB

8212 FORMAT $(1 \times, 3 F 12.6)$

$\begin{aligned} \triangle U 2 B M(J) & =0.0 \\ \triangle P 49 M(J) & =0.0 \\ \triangle P 4 O M(J) & =0.0 \\ \triangle P 41 M(J) & =0.0 \\ \triangle P 42 M(J) & =0.0 \\ \triangle M P D(J) & =0.0 \\ F A M P D(J) & =0.0 \\ \triangle A F B D(J) & =0.0 \\ F A F B D(J) & =0.0 \\ \triangle A R P D(J) & =0.0 \\ F A R P D(J) & =0.0 \\ A M C D(J) & =0.0 \\ F A M C D(J) & =0.0\end{aligned}$

CARD 0865

CARD0866

CARO0967

CARD0868

CARD036

CARD 0870

CARD0871

CARDO872

CARD0873

CARD0874

CARD 0875

CARD 0876

CARD0877

CARD 0878

CARD0879

CARD 0890

CARD0881

CARD0882

CARD 0883

CARD08 84

CARD 0885

CARD 0886

CARD0887

CARD 0888

CARD0889

CARDOB 90

CARD $0891^{\circ}$

CARDO892.

CARDOB 93

CARD 0894

CAR DO895

CARD 0396

CARD 0897

CARDO898

CARD 0899

CARDO9O0 


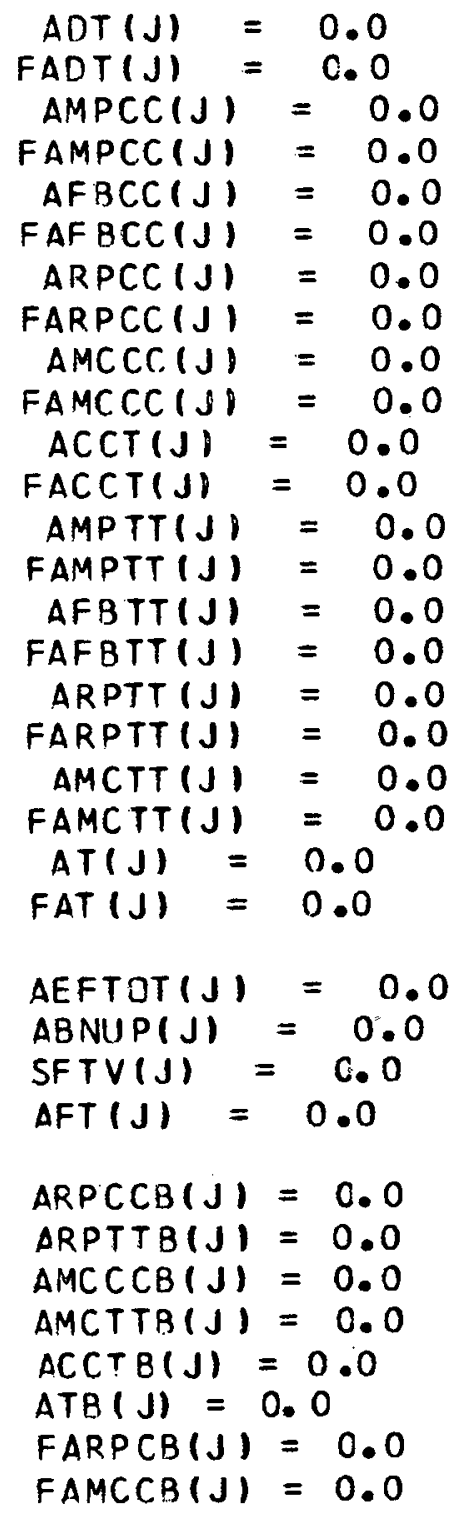

CARD0910

CARD0911

CARD 0912

CARD0913

CAP.D0914

CARD0915

CARDO916

CARD 0917

CARD 0918

CARDO910

CARD0920

CARD09 21

CARDO922

CARD 0923

CARDO924.

CARD 0925

CARD0926

CARD09 27

CARD 0928

CARD0929

CARD0930

CARD 0931

CARD09.32

CARD 0933

CARD 0934

CARD0935

CARD 09.36 


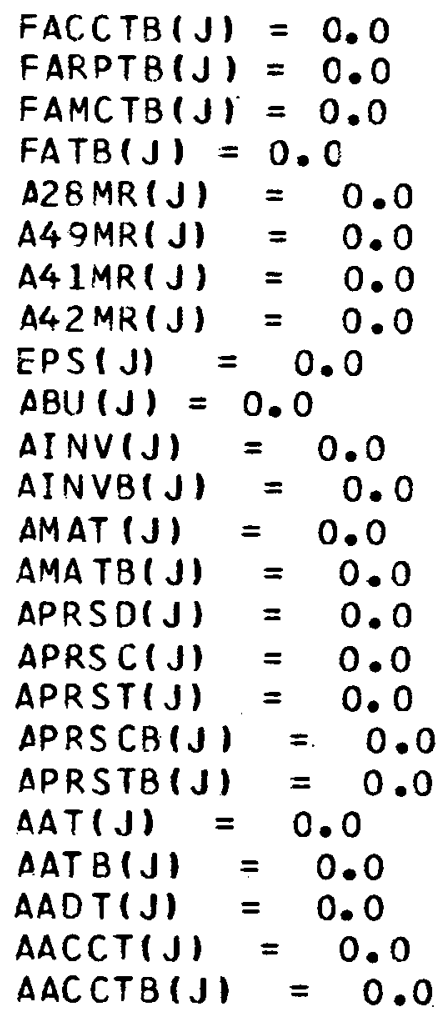

10000 CONT INUE

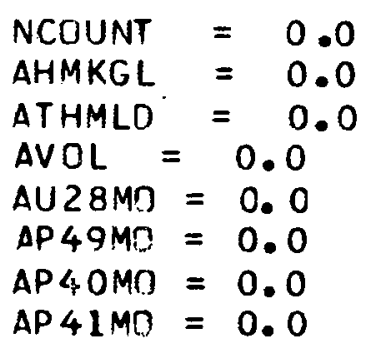

CARD0946

CARD 0947

CARD0948

CARD0949

CARD 0950

CARD0951

CARD 0952

CARD0953

CARD0954

CARD 0955

CARD0956

CARD 0957

CARD 0958

CARD0959

CARD 0960

CARD0961

CARD0962

CARD 0.963

CARD0964

CARD0965

CARD 0966

CARD0967

CARD 0968

CARD0969

CARD0970

CARD 0971

CARD0972 
$\triangle P 42 M O=0.0$

CARD0973

CARD 0974

CARD0975

CARD0976

CARD 0977

STOP

CARD0978 
APPENDIX D - REFERENCES

1. Klickman, A.E., et.al., "The Design and Economic Evaluation of Fixed Blankets for Fast Reactors", APDA-156 (Aug. 1963)

2. Klickman, A.E., et.al., "The Design and Economic Evaluation of Mobile Blankets for Fast Reactors," APD -160 (Mar. 1964)

3. Klickman, A.E., et.al., "The Design and Economic Evaluation of Blankets for Fast Reactors", Trans. ANS, Vo1. 7 (June 1964)

4. Hasnain, S.D., and D. Okrent, "On the Design and Management of Fast Reactor Blankets", NSE, 9, 314-322 (1961)

5. Perks, M.A. and R.M. Lord "Effects of Axial and Radial Blanket Design on Breeding and Economics", Proceedings of the Conference on Breeding, Economics and Safety in Large Fast Power Reactors, Argonne, II1., ANL-6792 (December 1963)

6. Golubev, V.I., M.N. Nikolaev, et.a1., "The Effect of Reflectors Made of Various Materials on the Increase in the Number of Neutron Captures in the Uranium Blanket of a Fast Reactor", Soviet Atomic Energy 15 \#4 (October 1963)

7. Gooch, D.J. and J. Ha11, "The Effect of the Core Radial Reflector on Breeding", United Kingdom Atomic Energy Authority, AEEW-M641 (Classified)

8. Smith, D.C.G, "Uncertainties in Fast Reactor Blanket Design", United Kingdom Atomic Energy Authority, AEEW-M640 (Classified)

9. Egleme, M. and A. Michel, "Technical and Economical Optimization of a Uranium Oxide Radial Blanket for a 1000 MN Sodium Cooled Fast Reactor", Kerntechnik 9, Jg. (1967) H.3/4

10. Froelich, R. "Optimal Radial Blanket Fuel Management for an LMFBR", Trans. ANS Vol. 14 (June 1971) 
11. Maeder, C., "Optimization of Gas-Cooled Fast Reactor Blankets", NSE $42,89-11$ (1970).

12. Mayer, L., "Blanketoptimienung am Beispiel eines dampfgehuhlten Schnellen Brutreaktors", Nukleonik 11, 193 (1968). Mayer, L., "Studies on the Optimum Design of the Radial Blanket on the Basis of a Steam-Cooled Fast Breeder" EURFNR 377, PSB No. 263/67 (May 18, 1967).

Mayer, L., "Studies on the Optimm Design of the Axial Blanket on the Basis of a Steam-Cooled Fast Breeder", EURFNR-378, PSB No. $271 / 67$ (July 14, 1967).

Mayer L., "Untersuchungen uber das optimale Blanketmanagement am Beispiel eines dampfgekughlten schellen Brutreaktors", PSB Bericht 241/66.

13. Brown, G., Department of Nuclear Engineering, Massachusetts Institute of Technology, Ph.n. Thesis (in progress).

14. Nunn, S.E. and D.E. Deonigi "Fue1 Cycle Parameters of Sodium Cooled Fast Reactors", BNWL-965 (July 1969).

15. Benndorf, K., et.al. "Variations in Certain Major Reactor Parameters of Sodium-Cooled 1000 MWe Fast Reactor, For Investigation into Fuel Costs and Needs", Karlsruhe, KFK568 (July 1967), EURFNR-384.

16. Buttrey, K., et.al. "Liquid Metal Fast Breeder Reactor Task Force Fuel Cycle Study", NAA-SR-1MEMO-12604 (Jan. 1968).

17. Elias, D. and F.J. Munno "Reactor Fuel Management Optimization in a Dynamic Environment", Nuclear Technology 12 (September 1971).

18. "Reactor Fuel Cycle Costs for Nuclear Power Evaluation", USAEC;WASH-1099. 19. Vondy, D.R., "Appendix F: Basis and Certain Features of the Discount Technique", Appendix F of "A Comparative Evaluation of Advanced Converters", ORNL-3686 (January 1965). 
20. Benedict, M., Course notes for MIT course 22.27 'Economics of Nuclear Power", Massachusetts Institute of Technology, Spring, 1967, 1968.

21. "Guide for Economic Evaluation of Nuclear Reactor Plant Designs", NUS Corporation, NUS-531 (January 1969).

22. "Guide to Nuclear Power Cost Evaluation", USAEC, TID-7025 (March 1962)

23. "A Uniform Procedure for Use in the Evaluation of Nuclear Power "Reactors", Atomic Industrial Forum (September 1959).

24. Dragoumis, P. et.al., "Estimating Nuclear Fuel-Cycle Costs", Nucleonics (January 1966)

25. Geller, L, et.al. "Analyzing Power Costs for Nuclear Plants", Nucleonics 22, 7 (July 1964).

26. Little, W.W. and R.W. Hardie, "2DB User's Manual - Revision \#1", BNWL-831 (August 1969) Battelie Northwest Laboratory.

27. Little, W.W. and R.W. Hardie, "1DX, A One-Dimensional Diffusion Code for Generating Effective Nuclear Cross Sections", BNWL-954 (March 1969), Battelle Northwest Laboratory.

28: Little, W.W., R.W. Hardie, L.D. O'Dell and R.B. Kidman, "Fuel management Mode1s and Analysis for the Fast Test Reactor", BNWL-SA-2758 (December 1969), Battelle Northwest Laboratory.

29. Hirons, T.J. and R.D. O'Dell, "Calculational Modeling Effects on Fast Breeder Fuel Cycle Analysis", LA-4187 (September 26, 1969), Los Alamos Scientific Laboratory.

30. Hirons, T.J. and R.E. Alcouffe 'Heterogeneity Effects on Large Fast Breeder Fue1 Cycle Calculations" Trans ANS 13, 1 (June 1970).

31. Hirons, T.J. and R.D. O'De11, 'PHENIX: A Two-Dimensional DiffusionBurnup-Refueling Code", NSE (March 1970). 
32. Hoover, J. and D.A. Meneley, et.al., "The Fuel Cycle Analyșis System, REBUS", NSE (July 1971).

33. Little, W.W., R.W. Hardie, et.al., 'Nunerical Comparison of Data Processing Codes for Fast Reactors", Trans ANS 12, 1 (June 1969).

34. Little, W.W. and R.W. Hardie, "PYRE - A Multigroup Burnup Code for Fast Reactors", BNWL-54 (April 1965) Battelle Northwest Laboratory.

35. Mayer, L. et.al., "Preliminary Description of the ASB Two-Dimensional Burnup Program Version of the Interatom Program for the IBM 360/65", EURFNR-729, EUR-431d, KFK 1079 (November 1969).

36. Channon, F.R., et.al. "Fast Reactor Fuel Burnup", Nuclear Applications (February 1965).

37. Hoover, L.J. and D.A. Meneley, "The Influence of Neutron Energy Group Structure on Fuel Cycle Analysis of Fast Breeder Reactors", Trans ANS 12, 2 (November 1969).

38. Brewer, S.I., M.J. Driscoll and E.A. Mason, "FBR Blanket Depletion Studies - Effect of Number of Energy Groups", Trans ANS (November 1970).

39. Toppe1, B.J., A.L. Rago and D.M. O'Shea, " $\mathrm{C}^{2}$ : A Code to Calculate Multigroup Cross Sections", ANL-7318 (1967) Argonne Nationa1 Laboratory.

40. Cowan, C.L., et.al., "TDOWN - A Code to Generate Composition and Spatially Dependent Cross Sections", GEAP 13740 (August 1971).

41. Vondy, D.R. "Calculation of Depletion in Nuclear Reactor Cores", Background information for a panel discussion on Comparison of Depletion Calculational Methods for Fuel Cycle Analysis, ANS Meeting June 1970. 
42. Hirons, T.J., "Reactor Fuel-Cycle Analysis at Los Alamos Scientific Laboratory," Backgraund information for a panel discussion on Comparison of Depletion Calculational Methods for Fuel Cycle Analysis, NNS meeting June 1970.

43. Rothleder, B.M., "Some Depletion Methods Used at WNES", Background information for a panel discussion on Comparison of Depletion Calculational Methods for Fuel Cycle Analysis, ANS meeting, June, 1970 .

44. Sheaffer, M., et.al. "A One-Group Method for Fast Reactor Calculations" MIT-4105-1, MITNE-108 (September 1970).

45. Greebler, P. and C.L. Cowan, "FUMBLE: An Approach to Fast Reactor Fue1 Management and Burnup Calculations", GEAP-13599 (February 1971).

46. Engle, W.W., "A User's Manual for ANISN", K-1693 (March 1967).

47. Fowler, T.B., and D.R. Vondy 'Nuclear Reactor Core Analysis Code: CITATION', ORNL-TM-2496 Rev. 1 (January 1970).

48. Bondarenko, I.I.,et.al: "Group Constants for Nuclear Reactor Calculations", Consultants Bureau, New York (1964).

49. Yiftah, S., D. Okrent and P.A. Moldauer, "Fast Reactor Cross Sections", Pergamon Press, New York (1960).

50. Hansen, H.E. and W.H. Roach "Six and Sixteen Group Cross Sections for Fast and Intermediate Critical Assemblies", LAMS-2543 (Dec. 1961).

51. Inoue, K., "Fast Reactor Core Design Optimization by Linear Programing", NSE (Marcli 1970).

52. Goldschmidt, P. and J. Quenon, 'Minimum Critical Mass in Fast Reactors with Bounded Power Density", NSE (March 1970).

53. Tzanos, C.P., et.al., "Optimization of Material Distributions in Fast Breeder Reactors", MIT-4105-6, MITNE-128 (August 1971). 
54. Heusener, G., "Optimization of Sodium-Cooled Fast Breeders by Nonlinear Programming Methods", Karlsruhe, KFK 1238, EURFNR-830 (July 1970).

55. Terasawa, S., et.a1., "Parametric Studies Leading to the Nuclear Characteristics of the JAERI Design Studies", ANL-7520 (November 1968).

56. Wright, J.H., "Core Design and Performance Considerations of FBR's" Westinghouse Engineer (January 1968).

57. "Electricity Too Cheap to Meter", Nuclear News (October 1968).

58. "Fast Breeder Reactor Report", Edison Electric Institute, EEI Pub. \#68-28 (April 1968).

59. "Report of the EEI Reactor Assessment Panel", Edison Electric Institute, EEI Pub \#70-30 (April 1970).

60. Forbes, I.A., 'Design, Construction, and Evaluation of a Facility for the Similation of Fast Reactor Blankets", MTT-4105-2, MITLE-110, (February 1970).

61. "LMFBR Blanket Physics Project, Progress Report \#1", Massachusetts Institute of Technology, MTT-4105-3, MINE-116 (June 30, 1970).

62. "Large Fast Reactor Design Study", Allis-Chalmers, Atomic Power Deve1opment Associates, and Babcock and Wilcox, ACNP-64503 (January 1964)

63. "Feasibility Study of a 1000 Ne Sodium-Cooled Fast Reactor", Atomics International, NAA-SR-11378 (June 1965).

64. "Liquid Metal Fast Breeder Reactor Design Study", Combustion Engineering CEND-200 (January 1964).

65. "Liquid Metal Fast Breeder Reactor Design Study", General Electric, GEAP-4418 (January 1964).

66. "Liquid Metal Fast Breeder Reactor Design Study", Westinghouse, WCAP3251-1 (January 1964). 
67. "An Evaluation of Four Design Studies of a 1000 Mve Ceramic Fuel Fast Breeder Reactor", Chicago Operations Office, USAEC, COO-279, December 1, 1964).

68. "An Evaluation of the Atomics International 1000 MNe Fast Breeder Reactor", Chicago Operations Office, USAEC, COO-285 (July 1966).

69. Babcock and Wilcox 1000 MVe LMFBR Follow-on Studies

"1000 iwe Follow-on Study Task I Report", BAN-1316

Vol. 1 Task I Report (June 1967)

Vol. 2 Task I Concept I System Description Report (April 1967)

Vol. 3 Task I Concept II System Description Report (June 1967)

Vo1. 4 Task I Concept III System Description Report (July 1967)

Vo1. 5 Task I Concept IV System Description Report (August 1967)

"1000 MWe LIMFBR Follow-on Study Task II and III FinalReport", BAW-1328

Vo1. I Sumnary Description and Cost Estimate (February 1969)

Vol. 2 Concept ual System Design Description (March 1969)

Vo1. 3 Conceptual System Design Description (February 1969)

Vol. 4 Trade-Off Studies (November 1968)

Vol. 5 Parametric Studies (January 1969)

"1000 MNe LAFBR Follow-on Study-Control Studies '(December 1968) $\mathrm{B} \Lambda \mathrm{W}-1330$

"Sodium Parameter Study Code NAPS - Topical Report "(Apri1 1968) BAW-1326

"1000 MNe LMFBR Follow-on Study - Task IV Final Report -

Research and Development Requirement" (June 1969) BAN-1331

Vols. I and II.

70. Atomics International 1000 MWe LMFBR Follow-on Studies

"ANL 1000 MWe LMFBR Follow-on Study Task I Report", Vols. 1 and 2 (May 1968), AI-AEC-12765 (rev.).

"1000 MNe LMFBR Follow-on Study Task II Report_Conceptual Systems Design Descriptions", Vo1s. I, II, III (May 1969), AI-AEC-12791. "1000 MVe LMFBR Follow-on Study Task III - Conceptual Design Report", Vols, I, II, III, IV, V (June 1969) AI-AEC-12792.

"1000 MNe LMFBR Follow-on Study Task IV Report-Research and Development Requirements", (June 1969), AI-AEC-12793. 
71. Combustion Engineering 1000 MWe LMFBR Follow-on Studies

"1000 MNe LMFBR Follow-on Study. Task I Report.Preliminary Studies for a reference Conceptual Design" (December 1967) CEND-322.

"1000 MWe LMFBR Follow-on Study. Task II and III Report. A

Conceptual Design" CEND-337

Vo1. I Conceptual System Design Descriptions (July 1968)

Vo1. II Static Design and Performance Analysis (May 1968)

Vol. III Safety and Control Analyses (September 1968)

"1000 MWe LMFBR Follow-on Study. Task IV Report. A Research and Development Program Needed for the CE Reference Concept". (February 1969) CEND-346.

72. General Electric 1000 MWe LMFBR Follow-on Studies

"Comparison of Two Sodium Cooled 1000 MWe Fast Reactor Concepts. Task I Report of 1000 Mve LMFBR Follow-on Work " (June 1968) GEAP-5618.

"Conceptual Plant Design, System Descriptions, and Costs for a 1000 Mive Sodium-Cooled Fast Reactor. Task II Report of 1000 MVe LMFBR Follow-on Work" (September 1968) GEAP-5678.

'Methods System Optimization, and Safety Studies for a 1000 MWe Sodium-Cooled Fast Reactor. Task III and V Report of 1000 MWe LMFBR Follow-on Work" (February 1969) GEAP-5710.

"Research and Development Requirements for a 1000 Mive SodiumCooled Fast Reactor. Task IV Report of 1000 MWe LMBR Follow-on Work" (April 1969), GEAP-5769.

73. Westinghouse 1000 MWeLMFBR Follow-on Studies

"1000 Mve LFFR Follow-on Study. Task I Final Report" (June 1968) WARD-2000-33.

"1000 Mve LMFBR-Follow-on Study. Task I Topical Report. Moisture Separation or Steam Reheat vs. Sodium Reheat. Plant Cycle Technical and Economic Evaluation". (April 1968) WARD-2000-20.

"1000 Mive LMFBR Follow-on Study. Task I Topical Report. Steam Generator Concept Selection" (January 1968) WARD-2000-22.

"1000 MNe LMFBR Follow-on Study. Task I Topical Report. Survey of State-of-the-Art of Intermediate Heat Exchanges" (March 1968) WARD-2000-23.

"1000 MWe LMFBR Follow-on Study. Task I Topical Report. Evaluation of Vented-to-Coolant Design for Sodium-Bonded Carbide Fuel Rods" (February 1968) WARD-2000-31.

"1000 MNe LMTBRR Follow-on Study. Task V Report. Safety Studies" (December 1968) WARD-2000-84. 
"1000 MWe LMFBR Follow-on Study. Task IV Report. Research and Development" (March 1969) WARD-2000-90.

"1000 Mve LMFBR Follow-on Study. Tasks II and III Topical Report. Comparison of the Westinghouse 1000 MWe LMFBR Reference Design Calculations Using the Westinghouse $6602-\mathrm{M}$ Data and $\mathrm{MC}^{2}$ Code with Neutron Cross-Section Data from ENDF/B File" (March 1969) WARD-2000-93.

"1000 MWe LMFBR Follow-on Study. Tasks II and III Topical Report. Cost Optimization and Parametric Studies" (March 1969)WARD-2000-96.

"1000 MWe LiFBR Follow-on Study. Tasks II and III Report. Conceptual Design" (April 1969) WARD-2000-97.

74. Aronstein, R.E., et.al., "Atomics International 1000 Mive LMFBR Followon Study Progress Report", Proceedings of the International Conference on Sodium Technology and Large Fast Reactor Design (November 1968) Argonne National Laboratory,ANL-7520 Part II.

75. Croft, M.W., et.al., "Babcockand Wilcox 1000 MNe LMFBR Follow-on Study Reference Design", Proceedings of the International Conference on Sodium Technology and Large Fast Reactor Design (November 1968), Argonne National Laboratory, ANL-7520 Part II.

76. Noyles, R.C., et.al., "Development and Evaluation of the Combustion Engineering Advanced 1000 MWe LMFBR Design", Proceedings of the International Conference on Sodium Technology and Large Fast Reactor Design. (November 1968), Argonne National Laboratory ANL-7520 Part II.

77. Hafele, W., et.al., 'The Karlsruhe Reference Design of a 1000 MVe Sodium Cooled Fast Breeder Reactor", Proceedings of the Conference on Safty, Fuels and Core Design in Large Fast Power Reactors (October 1965); Argonne National Laboratory, ANL-7120

78. Jansen, A. "The Long Time Behavior of FBR's with Pu-Recycle", Proceedings of the Symposium on Fast Reactor Physics and Related Safoty Problems, Karlsruhe (October 1967), Fast Reactor Physics, IAEA (1968). 
79. Argonne National Laboratory, 1000 MWe LMFBR Follow-on Study:

Evaluation Report, Draft (January 16, 1970).

Vo1. I - Sumnary Report

Vol. II - Plant Design

Vol. III - Research and Development

Vol. IV - Backup and Contractual Material.

80. Koncel, E.F., Commonwealth Edison Company, personal communication December 4, 1969.

81. Little, W.W. and R.W. Hardie, Battelle Northwest Laboratory, personal communications, April, May 1970.

82. Corey, Gordon, Cormonwealth Edison Company, Lectures at Massachusetts Institute of Technology:

"Certain Aspects of Current Financial and Regulatory Developments" (April 8, 1969)

"Financial Problems Related to Nuclear Power"(March 5, 1968).

83. Riley, Don, USAEC, Lecture at Massachusetts Institute of Technology

(January 1971), Short course on LMFBR Core Design,"Overall

Core Design View".

84. Driscol1, M.J., Massaciusetts Institute of Tecinology, personal conmunication January 1972 . 